\title{
ESTUDO CEFALOMÉTRICO EM NORMA LATERAL DAS ALTERAÇÕES DENTOESQUELÉTICAS PRODUZIDAS POR TRÊS TIPOS DE EXPANSORES: COLADO, TIPO HAAS E HYRAX
}

\section{Fausto Silva Bramante}

\begin{abstract}
Dissertação apresentada à Faculdade de Odontologia de Bauru, da Universidade de São Paulo, como parte dos requisitos para a obtenção do título de Mestre em Odontologia, área de Ortodontia.
\end{abstract}




\section{ESTUDO CEFALOMÉTRICO EM NORMA LATERAL DAS ALTERAÇÕES DENTOESQUELÉTICAS PRODUZIDAS POR TRÊS TIPOS DE EXPANSORES: COLADO, TIPO HAAS E HYRAX}

\section{Fausto Silva Bramante}

Dissertação apresentada à Faculdade de Odontologia de Bauru, da Universidade de São Paulo, como parte dos requisitos para a obtenção do título de Mestre em Odontologia, área de Ortodontia.

(Edição Revisada)

Orientador: Prof. Dr. Renato Rodrigues de Almeida

\section{BAURU}




\begin{tabular}{|c|}
\hline Bramante, Fausto Silva \\
Estudo cefalométrico em norma lateral das alterações \\
dentoesqueléticas produzidas por três tipos de expansores: \\
Colado, tipo Haas e Hyrax / Fausto Silva Bramante. - \\
Bauru, 2000. \\
xix, 195 p. + Apêndice: il. ; 29,7 cm \\
Dissertação. (Mestrado) - Faculdade de Odontologia \\
de Bauru. USP. \\
Orientador: Prof. Dr. Renato Rodrigues de Almeida
\end{tabular}

Autorizo, exclusivamente para fins acadêmicos e científicos, a reprodução total ou parcial desta dissertação, por processos fotocopiadores e/ou meios eletrônicos.

Assinatura do autor:

Data: 
"Senhor, concede-me serenidade para aceitar as coisas que não posso mudar, coragem para mudar as coisas que posso e sabedoria para saber a differença." 


\section{FAUSTO SILVA BRAMANTE}

18 de abril de 1970

Nascimento

Bauru, SP

1990-1993

Curso de Graduação em Odontologia, na Faculdade de Odontologia de Marília.

1994-1996

Curso de Residência Odontológica e Aperfeiçoamento em Ortodontia Preventiva e Interceptiva, no Departamento de Ortodontia do Hospital de Pesquisa e Reabilitação de Lesões Labiopalatais Universidade de São Paulo -Bauru. 


\title{
DEDICATÓRIA
}

Aos meus pais, Clóvis e Sylvanira, pelo apoio e carinho em todos os momentos de minha vida, sem jamais medirem esforços para a minha formação pessoal e profissional;

\begin{abstract}
À minha namorada Veridiana, por toda a dedicação, paciência e sinceridade nestes quatro anos ao meu lado, sempre presente, quando, necessitei.
\end{abstract}

Que DEUS continue iluminando vocês por muitos anos.... 


\section{AGRADEÇO...}

Ao Professor Doutor Renato Rodrigues de Almeida, pela orientação neste trabalho, pelo constante apoio, carinho e confiança a mim atribuídos durante o curso. 


\section{AGRADEÇO AINDA....}

À Diretoria da Faculdade de Odontologia de Bauru, da Universidade de São Paulo, na pessoa do seu diretor, Prof. Dr. Aymar Pavarini;

À comissão de Pósgraduação da Faculdade de Odontologia de Bauru, da Universidade de São Paulo, na pessoa do seu presidente, Prof. Dr. Luis Femando Pegoraro;

Ao CNPq, pelo auxílio financeiro, por meio de bolsa de estudo, para que este trabalho pudesse ser realizado;

Ao Departamento de Odontopediatria, Ortodontia e Saúde Coletiva, da Faculdade de Odontologia de Bauru, Universidade de São Paulo;

Ao Prof. Dr. Décio Rodrigues Martins, pelo exemplo de dedicação e aos seus ensinamentos muito importantes para a minha formação;

Ao Prof Dr. José Fernando Castanha Henriques, atual professor Títular da Disciplina de Ortodontia; 
Ao Prof. Dr. Marcos Roberto de Freitas, atual coordenador do curso de Pósgraduação em nível de Mestrado em Ortodontia;

Ao prof. Dr. Arnaldo Pinzan, pelos esforços e dedicação ao nosso aprendizado;

Ao Prof. Dr. Guilherme R. P. Janson, pela revisão do Abstract, ensinamentos e constante esforço para o nosso aprimoramento;

Ao Prof. Dr. José Roberto Pereira Lauris, que, com imensa boa vontade, foi tão solícito na realização da análise estatística deste trabalho;

Aos funcionários do Departamento de Ortodontia, Cristiane, “Tia" Maria, Tereza Cristina e Vera, pela amizade, auxílio e dedicação durante esse período;

Ao técnico e amigo Luis Sérgio Vieira, pelo incalculável auxílio na confecção de todos os aparelhos deste trabalho e sempre tão prestativo quando precise;

Ao Daniel Selmo, pelo imenso auxílio na digitalização dos pontos cefalométricos e preparação das figuras que ilustram este trabalho;

Às funcionárias de Pósgraduação, Ana, Cleusa, Giane, Heloísa, Neide e Aurélio; 
Às funcionárias da Biblioteca, Valéria, Cybelle e Maria Helena, pela revisão bibliográfica e auxílio quando requisitadas;

À colega Maria Helena, na preparação do programa computadorizado utilizado no trabalho;

Ao amigo Eduardo Dainesi e sua esposa Márcia Yuri, pela amizade e convivência durante esse período;

Ao colegas da XI Turma de Mestrado em Ortodontia: Ana Carla, Ana Cláudia, Daniela, Danilo, Karyna Vale, Karina Cruz, Paulo, Renata (grande amiga, que me auxiliou com muita boa vontade na conferência dos pontos radiográficos) e Roberto, com os quais aprendi muito;

Ao meu orientador, Prof. Dr. Renato Rodrigues de Almeida, pelo constante apoio, confiança e maneira carinhosa de nos tratar, que não serão tão facilmente esquecidos....;

À minha querida avó Deolinda, pela sua bondade e dedicação;

Ao meus irmãos Alexandre e Júnior e suas namoradas, pela convivência ao longo dos anos;

Ao meu futuro sogro Paulo que eu estimo muito, pelo constante apoio, compreensão durante essa fase e exemplo de Pai, para suas filhas; 
À minha mãe, Sylvanira pelo apoio, carinho e amor que sempre me dispensou, pela revisão da língua portuguesa e seu incalculável esforço para que este trabalho se realizasse no prazo esperado;

Ao meu pai Clóvis, exemplo de profissionalismo, incentivo e que jamais mediu esforços na minha formação pessoal e profissional;

À minha doce namorada Veridiana, a quem eu devo muito, pelo apoio nos momentos difíceis, pela coragem, determinação e por tudo que me ensinou na vida profissional e pessoal. A certeza de que encontrei a pessoa certa. 
LISTA DE FIGURAS

LISTA DE TABELAS

RESUMO

1 - INTRODUÇÃO

2- REVISÃO DE LITERATURA

3- PROPOSIÇÃO

4- MATERIAL E MÉTODOS

4.1 - Material

4.2 - Métodos

4.2.1 - Construção dos aparelhos expansores

4.2.2 - Instalação dos aparelhos

4.2.3 - Ativação dos aparelhos

4.2.4 - Radiografias cefalométricas

4.2.5 - Elaboração do cefalograma

4.2.5.1 - Material

4.2.5.2 - Desenho anatômico

4.2.5.3 - Delimitação das estruturas dentoesqueléticas e do perfil mole

4.2.5.4 - Demarcação dos pontos cefalométricos de referência

4.2.5.5 - Traçados das linhas e dos planos de orientação

4.2.5.6-

4.2.5.6.1 -

Obtenção das grandezas angulares e lineares

$4.25 .6 .2-$ Grand

4.2.6 - Análise estatística

4.2.6.1 - Método estatístico

4.2.6.2 - Erro do método

4.2.6.3 - Análise interexaminador

RESULTADOS

6-

DISCUSSÃO

$6.1-$

Erro do método

$6.2-$

Análise interexaminador

$6.3-$

Relação das bases ósseas

$6.4-$

Relação maxilomandibular

$6.5-$

Padrão do esqueleto cefálico

$6.6-$

Relação dos arcos dentários $\mathrm{x}$ bases apicais

$6.7-$

Perfil mole

$6.8-$

Considerações finais

$7-$

CONCLUSÕES

REFERÊNCIAS BIBLIOGRÁFICAS

ABSTRACT

APÊNDICES

$\mathbf{x}$

xiv

xviii

1

5

61

63

64

68

68

73

74

77

79

79

80

81

83

86

88

88

92

96

96

97

97

98

122

128

130

131

147

154

161

167

169

172

175

193

196 


\section{LISTA DE FIGURAS}

FIGURA 4.1 - Cobertura oclusal em resina acrílica dos dentes de ancoragem no aparelho expansor Colado.

FIGURA 4.2 - $\quad$ Aparelho de expansão maxilar Colado.

FIGURA 4.3 - $\quad$ Aparelho de expansão maxilar Colado.

FIGURA 4.4 - $\quad$ Aparelho de expansão maxilar do tipo Haas.

FIGURA 4.5 - $\quad$ Aparelho de expansão maxilar Hyrax.

FIGURA 4.6 - Aparelho de expansão maxilar Colado (préexpansão).

FIGURA 4.7 - Aparelho de expansão maxilar Colado (pósexpansão imediata).

FIGURA 4.8 - $\quad$ Desenho anatômico.

FIGURA 4.9 - $\quad$ Pontos cefalométricos.

FIGURA 4.10 - Traçados de orientação.

FIGURA 4.11 - Grandezas angulares.

FIGURA 4.12 - $\quad$ Grandezas angulares.

FIGURA 4.13 - Grandeza angular.

FIGURA 4.14 - Grandezas lineares.

FIGURA 4.15 - Grandezas lineares.

FIGURA 4.16 - Grandezas lineares. 
FIGURA 6.1 - Comportamento das médias da grandeza cefalométrica SNA, durante as fases estudadas, nos grupos I (Colado), II (tipo Haas) e III (Hyrax).

FIGURA 6.2 - Comportamento das médias da grandeza cefalométrica SN.ENA, durante as fases estudadas, nos grupos I (Colado), II (tipo Haas) e III (Hyrax).

FIGURA 6.3 - Comportamento das médias da grandeza cefalométrica Nperp-A, durante as fases estudadas, nos grupos I (Colado), II (tipo Haas) e III (Hyrax).

FIGURA 6.4 - Comportamento das médias da grandeza cefalométrica Sperp-A, durante as fases estudadas, nos grupos I (Colado), II (tipo Haas) e III (Hyrax).

FIGURA 6.5 - Comportamento das médias da grandeza cefalométrica N-ENA, durante as fases estudadas, nos grupos I (Colado), II (tipo Haas) e III (Hyrax).

FIGURA 6.6 - Comportamento das médias da grandeza cefalométrica ENA-PoOr, durante as fases estudadas, nos grupos I (Colado), II (tipo Haas) e III (Hyrax).

FIGURA 6.7 - Comportamento das médias da grandeza cefalométrica ENP-PoOr, durante as fases estudadas, nos grupos I (Colado), II (tipo Haas) e III (Hyrax).

FIGURA 6.8 - Comportamento das médias da grandeza cefalométrica SNB, durante as fases estudadas, nos grupos I (Colado), II (tipo Haas) e III (Hyrax). 
FIGURA 6.9 - Comportamento das médias da grandeza cefalométrica Nperp-Pog, durante as fases estudadas, nos grupos I (Colado), II (tipo Haas) e III (Hyrax).

143

FIGURA 6.10 - Comportamento das médias da grandeza cefalométrica ANB, durante as fases estudadas, nos grupos I (Colado), II (tipo Haas) e III (Hyrax).

FIGURA 6.11 - Comportamento das médias da grandeza cefalométrica NAP, durante as fases estudadas, nos grupos I (Colado), II (tipo Haas) e III (Hyrax).

FIGURA 6.12 - Comportamento das médias da grandeza cefalométrica Ar-A, durante as fases estudadas, nos grupos I (Colado), II (tipo Haas) e III (Hyrax).

FIGURA 6.13 - Comportamento das médias da grandeza cefalométrica Ar-Gn, durante as fases estudadas, nos grupos I (Colado), II (tipo Haas) e III (Hyrax).

FIGURA 6.14 - Comportamento das médias da grandeza cefalométrica ENA-Me, durante as fases estudadas, nos grupos I (Colado), II (tipo Haas) e III (Hyrax).

FIGURA 6.15 - Comportamento das médias da grandeza cefalométrica PoOr.PP, durante as fases estudadas, nos grupos I (Colado), II (tipo Haas) e III (Hyrax).

FIGURA 6.16 - Comportamento das médias da grandeza cefalométrica SN.GoMe, durante as fases estudadas, nos grupos I (Colado), II (tipo Haas) e III (Hyrax). 
FIGURA 6.17 - Comportamento das médias da grandeza cefalométrica FMA, durante as fases estudadas, nos grupos I (Colado), II (tipo Haas) e III (Hyrax).

FIGURA 6.18 - Comportamento das médias da grandeza cefalométrica SN.Gn, durante as fases estudadas, nos grupos I (Colado), II (tipo Haas) e III (Hyrax).

FIGURA 6.19 - Comportamento das médias da grandeza cefalométrica ÂBI, durante as fases estudadas, nos grupos I (Colado), II (tipo Haas) e III (Hyrax).

FIGURA 6.20 - Comportamento das médias da grandeza cefalométrica Rㅡ-PP, durante as fases estudadas, nos grupos I (Colado), II (tipo Haas) e III (Hyrax).

FIGURA 6.21 - Comportamento das médias da grandeza cefalométrica Cㅁ-PP, durante as fases estudadas, nos grupos I (Colado), II (tipo Haas) e III (Hyrax).

FIGURA 6.22 - Comportamento das médias da grandeza cefalométrica Sperp-Rㅡ, durante as fases estudadas, nos grupos I (Colado), II (tipo Haas) e III (Hyrax).

FIGURA 6.23 - Comportamento das médias da grandeza cefalométrica Sperp-C $\underline{6}$, durante as fases estudadas, nos grupos I (Colado), II (tipo Haas) e III (Hyrax).

FIGURA 6.24 - Comportamento das médias da grandeza cefalométrica ÂNL, durante as fases estudadas, nos grupos I (Colado), II (tipo Haas) e III (Hyrax). 


\section{LISTA DE TABELAS}

TABELA 4.1 - Distribuição do Grupo I (Disjuntor Colado), segundo a idade e o sexo.

TABELA 4.2 - Distribuição do Grupo II (Disjuntor do tipo Haas), segundo a idade e o sexo.

66

TABELA 4.3 - Distribuição do Grupo III (Disjuntor Hyrax), segundo a idade e o sexo.

TABELA 5.1 - Médias (X) e desvios padrão (d.p.) das medidas cefalométricas analisadas no grupo I (aparelhos expansores dentossuportados - Colado), nas fases 1 (pré-expansão), 2 (pós-expansão) e 3 (pós-contenção).

101

TABELA 5.2 - Médias (X) e desvios padrão (d.p.) das medidas cefalométricas analisadas no grupo II (aparelhos expansores dentomucossuportados - tipo Haas), nas fases 1 (pré-expansão), 2 (pós-expansão) e 3 (pós-contenção)

TABELA 5.3 - Médias (X) e desvios padrão (d.p.) das medidas cefalométricas analisadas no grupo III (aparelhos expansores dentossuportados - Hyrax), nas fases 1 (pré-expansão), 2 (pós-expansão) e 3 (póscontenção).

TABELA 5.4 - Médias (X), desvios padrão (d.p.), médias das diferenças, valor "t" e significância estatística das medidas cefalométricas analisadas no grupo I (aparelhos expansores dentossuportados Colado), nas fases 1 (pré-expansão), 2 (pósexpansão). 
TABELA 5.5 - Médias (X), desvios padrão (d.p.), médias das diferenças, valor "t" e significância estatística das medidas cefalométricas analisadas no grupo I (aparelhos expansores dentossuportados Colado), nas fases 2 (pós-expansão) e 3 (póscontenção).

TABELA 5.6 - Médias (X), desvios padrão (d.p.), médias das diferenças, valor " $t$ " e significância estatística das medidas cefalométricas analisadas no grupo I (aparelhos expansores dentossuportados Colado), nas fases 1 (pré-expansão) e 3 (póscontenção).

TABELA 5.7 - Médias (X), desvios padrão (d.p.), médias das diferenças, valor " $t$ " e significância estatística das medidas cefalométricas analisadas no grupo II (aparelhos expansores dentomucossuportados - tipo Haas), nas fases 1 (pré-expansão), 2 (pósexpansão).

TABELA 5.8 - Médias (X), desvios padrão (d.p.), médias das diferenças, valor "t" e significância estatística das medidas cefalométricas analisadas no grupo II (aparelhos expansores dentomucossuportados - tipo Haas), nas fases 2 (pós-expansão)e 3 (póscontenção).

108

TABELA 5.9 - Médias (X), desvios padrão (d.p.), das médias das diferenças, valor " $\mathrm{t}$ " $\mathrm{e}$ significância estatística das medidas cefalométricas analisadas no grupo II (aparelhos expansores dentomucossuportados - tipo Haas), nas fases 1 (pré-expansão) e 3 (pós-contenção).

TABELA 5.10 - Médias (X) e desvios padrão (d.p.) das médias das diferenças, valor " $t$ " e significância estatística das medidas cefalométricas analisadas no grupo III (aparelhos expansores dentossuportados - Hyrax), nas fases 1 (préexpansão), 2 (pós-expansão). 
TABELA 5.11 - Médias (X), desvios padrão (d.p.), médias das diferenças, valor "t" e significância estatística das medidas cefalométricas analisadas no grupo III (aparelhos expansores dentossuportados Hyrax), nas fases 2 (pós-expansão) e 3 (póscontenção).

111

TABELA 5.12 - Médias (X), desvios padrão (d.p.), médias das diferenças, valor "t" e significância estatística das medidas cefalométricas analisadas no grupo III (aparelhos expansores dentossuportados Hyrax), nas fases 1 (pré-expansão) e 3 (póscontenção).

112

TABELA 5.13 - Médias (X) e desvios padrão (d.p.) das diferenças das medidas cefalométricas analisadas nas fases 1 (pré-expansão) e 2 (pós-expansão), valor de "F", valor de "p" e significância estatística da análise de variância (ANOVA) aplicada na comparação entre os grupos I (Colado), II (Tipo Haas) e III (Hyrax).

113

TABELA 5.14 - Médias (X) e desvios padrão (d.p.) das diferenças das medidas cefalométricas analisadas nas fases 2 (pós-expansão) e 3 (pós-contenção), valor de "F", valor de "p" e significância estatística da análise de variância (ANOVA) aplicada na comparação entre os grupos I (Colado), II (Tipo Haas) e III (Hyrax).

114

TABELA 5.15 - Médias (X) e desvios padrão (d.p.) das diferenças das medidas cefalométricas analisadas nas fases 1 (pré-expansão) e 3 (pós-contenção), valor de "F", valor de "p" e significância estatística da análise de variância (ANOVA) aplicada na comparação entre os grupos I (Colado), II (Tipo Haas) e III (Hyrax).

115 
TABELA 5.16 - Comparação entre os três grupos, com as médias $(\mathrm{X})$, valor de "p" e significância estatística do teste de Tukey, para a variável Sperp-A na diferença entre as fases 2 (pós-expansão) e 3 (pós-contenção), que apresentou diferença estatisticamente significante na ANOVA.

116

TABELA 5.17 - Comparação entre os três grupos, com as médias $(\mathrm{X})$, valor de "p" e significância estatística do teste de Tukey, para a variável ENA-Me na diferença entre as fases 1 (pré-expansão) e 2 (pós-expansão), que apresentou diferença estatisticamente significante na ANOVA.

116

TABELA 5.18 - Comparação entre os três grupos, com as médias $(\mathrm{X})$, valor de "p" e significância estatística do teste de Tukey, para a variável ENA-Me na diferença entre as fases 2 (pós-expansão) e 3 (pós-contenção), que apresentou diferença estatisticamente significante na ANOVA.

TABELA 5.19 - Análise intra-examinador da precisão do método cefalométrico. Apresentação dos erros casuais (Dahlberg) nas fases 1 (pré-expansão), 2 (pósexpansão) e 3 (pós-contenção) do grupo I (Colado).

118

TABELA 5.20 - Análise intra-examinador da precisão do método. Valores iniciais e repetidos após um intervalo mínimo de 1 mês (médias e desvios-padrão), diferença das médias, valores de t, p e a significância estatística dos erros sistemáticos do grupo I (Colado).

119

TABELA 5.21 - Análise interexaminador da precisão do método. Valores das médias (X) e desvios padrão (d.p.) obtidos por KAWAKAMI $^{48}$ e pelo autor, diferença das médias, valor "t", de "p" e significância estatística. 


\section{RESUMO}

Este estudo cefalométrico teve como objetivo comparar, por meio de telerradiografias em norma lateral, as alterações dentoesqueléticas decorrentes da utilização de três tipos de expansores maxilares. A amostra constou de 69 telerradiografias de 23 pacientes, sendo 15 do sexo feminino e 8 do masculino, com idades entre 9 anos e 8 meses e 15 anos e 5 meses, portadores de mordida cruzada uni e bilateral, que utilizaram o expansor rápido maxilar Colado, com cobertura acrílica na oclusal dos dentes superiores. As radiografias foram realizadas em três fases distintas: no início do tratamento (pré-expansão), imediatamente após a expansão e após três meses de contenção com o próprio aparelho expansor. Os resultados obtidos foram comparados com o prévio estudo realizado com os expansores maxilares do tipo Haas e Hyrax, em 41 pacientes: 15 do sexo masculino e 26 do feminino, com idades entre 10 anos e 8 meses e 17 anos e 8 meses. O procedimento na realização das telerradiografias em norma lateral foi o mesmo do presente estudo. De acordo com os resultados, imediatamente após a fase ativa apenas o grupo do aparelho Colado apresentou um avanço significativo, da maxila para anterior, enquanto que

nos outros grupos esse avanço foi discreto. Depois do período de contenção, esse avanço retornou a valores próximos aos do início, não evidenciando diferenças significativas entre os três grupos de aparelhos e, portanto, não alterando o perfil mole. Além disso, ao final do período de contenção, a maxila deslocou-se inferiormente nos três grupos ocasionando a rotação da mandíbula no sentido horário também em todos os grupos sendo com maior significância para os grupos I e II, no entanto não houve 
diferença estatística entre eles, enquanto que a altura facial ântero-inferior sofreu um aumento significativo para os três grupos, ao final da terapia, sem diferença significante entre os grupos, após o período de contenção. Concluiu-se que o uso do aparelho expansor Colado, utilizado com o intuito de prevenir alterações esqueléticas no sentido vertical e a abertura da mordida anterior, não se justifica, pois ao final do período de contenção não foram verificadas alterações significativas entre os três tipos de aparelhos. 


\section{1 - INTRODUÇÃO}

A Ortodontia como ciência almeja, como ideal, o equilíbrio do complexo craniofacial e a conseqüente correção funcional e estética das más oclusões. A procura por tratamento ortodôntico está cada vez mais comum atualmente, principalmente em pacientes adultos, talvez devido a um mercado mais seletivo, em que a estética facial é cada vez mais valorizada.

Conforme SILVA FILHO; FREITAS; CAVASSAN ${ }^{84}$, a má oclusão na região de Bauru - SP, acomete, em média, 88,53\% da população. Desse total, $18,5 \%$ apresentam mordida cruzada posterior e 18,2\%, mordida cruzada anterior.

HAAS $^{37}$, relatou que a mordida cruzada posterior pode ser de origem dentária ou esquelética, podendo ser classificada de acordo com a deficiência maxilar real ou relativa. A deficiência real é caracterizada pela compressão da maxila e conseqüente constricção dos segmentos dentários posteriores, enquanto que a relativa se dá quando a maxila se encontra do tamanho adequado, em comparação com a face superior e a mandíbula, apresenta tamanho acentuado, restando as alternativas de expandir o arco superior ou contrair o inferior. As musculaturas bucal e lingual raramente permitem a inclinação para vestibular permanente dos dentes superiores e a língua dificilmente tolera a contração do arco dentário inferior, sendo, portanto, mais indicado, corrigir a discrepância na base óssea. Segundo HAAS $^{39}$, o simples movimento dentário, no afã de corrigir a deficiência 
esquelética na dimensão transversa, condenaria, invariavelmente, à recidiva.

O primeiro relato de expansão maxilar deu-se em 1860, pelo norteamericano ANGELL ${ }^{5}$. Com um dispositivo fixo, expandiu a maxila em uma paciente de 14 anos, conseguindo espaço para o canino permanente. Contudo, o fato criou grande polêmica e aversão entre médicos rinologistas e a terapia caiu em desuso, sendo esquecida por quase um século e retornando ao cenário científico em meados de 1950.

Enquanto nos Estados Unidos, a expansão maxilar estava relegada ao esquecimento, na Europa ganhava adeptos, com as novas pesquisas de $\mathrm{KREBS}^{51}$, que instalou, expandiu e avaliou implantes metálicos na maxila. KORKHAUS $^{49}$, em 1960, indicou a terapia da expansão maxilar a pacientes portadores de má oclusão de Classe II e a pacientes com estenose nasal, assim como para o correto desenvolvimento do esqueleto facial, abrindo então, novos horizontes para futuras pesquisas sobre disjunção maxilar.

Entusiasmado com os bons resultados obtidos por esses pesquisadores, $\operatorname{HAAS}^{36}$ em 1961, realizou um estudo com animais e humanos, usando aparelhos expansores. Relatou que em humanos houve aumento da distância intermolar, diastema nos incisivos centrais superiores, vestibuloversão nos molares inferiores, aumento das dimensões internas da cavidade nasal e deslocamento da maxila para anterior.

A partir de então, uma ampla gama de trabalhos ${ }^{1,5,8,11,17,18,24,30,32,}$ $36,38,39,49,55,61,83,88,91,93,99,100$ foi surgindo e confirmando as vantagens e as alterações dentárias e esqueléticas, nos sentidos vertical e sagital. 
A expansão rápida maxilar, além dos ganhos clínicos na dimensão transversa $^{36,51,59,61,74,86,91}$ e na eficiência da correção da mordida cruzada ${ }^{10,}$ 14, 98 , induz alterações indesejáveis, como o deslocamento maxilar para baixo $^{3,16,17,18,30,35,36,38,87,88,93,97,98}$, com conseqüente extrusão dos molares

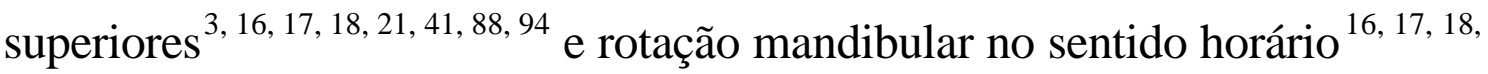
$30,38,41,48,88,90,94,98,99$, com conseqüente abertura da mordida anterior ${ }^{30,38,58}$. Com a presença de sobremordida anterior, esse acontecimento torna-se favorável, mas nos pacientes que apresentam a síndrome da face longa, mordida aberta anterior, ou excesso de crescimento vertical, esses efeitos poderão se agravar ainda mais, tornando a terapia desaconselhável.

A presente pesquisa tem como objetivo estudar os aparelhos expansores fixos com cobertura oclusal em acrílico, nos dentes superiores e suas alterações dentárias e esqueléticas decorrentes da utilização dos mesmos, assim como compará-las com as alterações ocorridas em um estudo prévio, com os aparelhos expansores tipo Haas e Hyrax. 
2

REVSÃO DE LITERATURA 


\section{2 - REMSÃO DE UTERATURA}

Em 1860, ANGELL $^{5}$ fez o primeiro relato sobre expansão maxilar. No afã de conseguir espaço suficiente para os caninos permanentes, a maxila de um paciente de 14 anos, do sexo feminino, foi expandida com um aparelho feito em ouro com um parafuso, disposto transversalmente à abóbada palatina. As ativações não excederam a duas semanas, obtendo a abertura da sutura e assim incluindo o canino no arco que não continha espaço, de maneira que, após a segunda semana, a maxila estava notavelmente mais larga e com diastema entre os incisivos centrais superiores. O autor relatou, ainda, que a perda de dentes decíduos poderia levar à constricção maxilar e conseqüente perda de espaço para os dentes sucessores.

Após esse primeiro relato da expansão da maxila, o advento gerou grande polêmica entre os ortodontistas americanos que, sob a influência de Angle, acreditavam no conceito funcional de crescimento, em que a expansão dentária causada pelo aparelho convencional estimularia o crescimento ósseo intersticial, não necessitando da terapia expansionista considerada agressiva. Como surgiram polêmicas também entre os médicos rinologistas, a terapia da expansão maxilar caiu em desuso e permaneceu por quase um século esquecida nos Estados Unidos, mas ganhou força, outra vez, com novas correntes de estudos na Europa, tornando a renascer na América do Norte.

Em 1956, preocupado com as discrepâncias esqueléticas transversais, BARNES $^{8}$ sugeriu as correções precoces das mordidas cruzadas na dentadura 
decídua, por acreditar que o reposicionamento dos dentes decíduos auxiliaria os permanentes a irromperem na posição correta e que a expansão precoce diminuiria as chances de ocorrência de apinhamentos anteriores na dentadura permanente. $\mathrm{O}$ autor relatou casos clínicos tratados com expansores fixos do tipo “arco em W".

Com o objetivo de avaliar os efeitos da expansão rápida da maxila, assim como as alterações transversas, $\mathrm{KREBS}^{51}$, em 1959, instalou implantes metálicos em humanos, na região dos ossos basal e alveolar, nos dois lados da maxila. Radiografias foram tomadas em norma frontal, lateral e oclusal, antes e após a expansão e oito meses mais tarde. A apresentação do caso clínico de um paciente do sexo feminino, com 11 anos de idade, portador de mordida cruzada posterior bilateral possibilitou uma melhor verificação dos resultados, que mostraram aumento na largura do arco dentário, durante a fase ativa, duas vezes maior do que no segmento basal maxilar. Durante a fase de contenção, a largura transversa do arco alveolar, assim como os segmentos basais maxilares, tenderam a diminuir. Os cefalogramas mostraram grande definição na determinação do aumento da distância entre os implantes, contudo, torna-se difícil ainda determinar exatamente a quantidade de rotação dos segmentos maxilares.

Em 1960, KORKHAUS ${ }^{49}$ acreditava que a má oclusão de Classe II sempre vinha acompanhada de algum grau de atresia maxilar. Relatou alguns casos clínicos tratados com aparelho de expansão e constatou que a expansão maxilar seria altamente favorável nos casos de pacientes portadores de obstrução nasal, facilitando a passagem do ar. Também 
sugeriu que a expansão maxilar seria benéfica para a oclusão e articulações, favorecendo o desenvolvimento do esqueleto facial.

$\mathrm{HAAS}^{36}$, em 1961, realizou dois estudos sobre a terapia da expansão maxilar: um experimental e outro clínico. No experimental, utilizou oito animais suínos, Duroc-Poland China, sendo seis experimentais e dois controles. Neste estudo foram analisados modelos de gesso e radiografias cefalométricas realizadas antes, durante e ao final da expansão. Injeções de alizarina, como corante vital dos ossos, foram aplicadas após as ativações dos parafusos, em intervalos de 4, 14 e 30 dias. Os animais foram então sacrificados e a maxila, após prévio preparo em resina poliéster, foi seccionada e avaliada microscopicamente. Como resultados, foi observado: a) que a abertura da sutura mediana pode ser detectada por meio do exame da palpação; b) aumento na largura do arco superior, seguido de alargamento no arco inferior, evidenciado pelos modelos de gesso e c) aumento da capacidade intranasal. Devido aos resultados favoráveis, o mesmo estudo foi realizado em humanos e para tanto foram selecionados 10 pacientes com idades entre 9 e 18 anos, que apresentavam deficiência maxilar ou nasal. Os resultados indicaram que: a) os pacientes não reclamaram de desconforto durante as ativações, apenas uma pressão nas áreas dos processos alveolares, abóbada palatina, sutura dos ossos frontal e nasal com os maxilares e suturas zigomaticomaxilar e zigomaticotemporal; b) as telerradiografias em norma frontal demonstraram alterações nas dimensões internas da cavidade nasal, nas distâncias intermolares e interincisivos, com o surgimento de diastema entre os incisivos centrais superiores, durante a ativação do aparelho; c) os dentes inferiores posteriores tiveram uma movimentação para vestibular, na tentativa de acompanhar os superiores e também devido às novas forças oclusais e à alteração no equilíbrio muscular; d) houve um deslocamento em 
todos os pacientes, do ponto A para anterior e em metade deles, para baixo, ocasionando aumento nos ângulos de convexidade facial e no SNA.

Para verificar as alterações inerentes à expansão maxilar, $\mathrm{KREBS}^{52}$, em 1964, inseriu implantes metálicos em 24 pacientes, que foram examinados até o final do crescimento. Em um período de cinco anos, a expansão maxilar foi realizada em pacientes com idades entre 8 e 19 anos, que apresentavam, como fator determinante, a mordida cruzada posterior bilateral. Os implantes foram instalados em ambos os lados do processo zigomático e no palato duro, na região de caninos e primeiros molares. Modelos de gesso e telerradiografias em normas lateral e frontal foram analisados até o final do crescimento. Os resultados demonstraram que: 1) houve grande quantidade de expansão no arco dentário e na base maxilar; 2) existe uma tendência do efeito da expansão maxilar na base óssea de diminuir com a idade; 3) o efeito da terapia no arco dentário foi menos dependente da idade do que na base maxilar; 4) os efeitos mais marcantes da expansão ocorreram antes do surto de crescimento, enquanto que após, os efeitos na sutura foram aparentemente menores; 5) ao final do período de uso da contenção houve recidiva parcial da largura do arco dentário; 6) a distância entre os implantes nos processos zigomáticos, após o final do período da contenção, apresentou discreta diminuição, aumentando posteriormente com o crescimento do paciente e 7) os aumentos alcançados nos arcos dentários não são estáveis, podendo muitas vezes serem decrescidos ao longo dos anos.

CLEALL et al. ${ }^{25}$, em 1965, estudaram a resposta da expansão em regiões como a sutura maxilar, processos alveolares, suturas adjacentes e 
estruturas da face. O trabalho analisou 12 macacos, Macacas rhesus, de acordo com a idade e foram feitas telerradiografias frontais, laterais, modelos de gesso, no início e final da expansão e exames histológicos após o sacrifício dos animais. Quatro deles tiveram os aparelhos instalados e ativados e o restante foi utilizado como controle. Os resultados mostraram um aumento na largura maxilar e abóbada palatina, que foi diretamente relacionado com a abertura da sutura palatina. Como não foram verificadas alterações desfavoráveis na região da sutura maxilar após a expansão, os autores sugerem que depois da reparação óssea, a mesma permanece estável.

HAAS $^{37}$, no mesmo ano, defendeu a abordagem da terapia da expansão maxilar em pacientes portadores de má oclusão de Classe III, atresia maxilar, mordida cruzada posterior uni ou bilateral, estenose nasal e conseqüente respiração bucal. A expansão rápida da maxila favorece o reposicionamento das bases dentárias superiores sobre as inferiores e a abertura da sutura palatina ocorre de forma triangular, com o ápice voltado para a cavidade nasal e a base, para o próstio. $\mathrm{O}$ diastema interincisivo superior também foi característico durante as expansões. O autor relatou três casos clínicos tratados com a terapia e alterações ocorridas na cavidade nasal, pela movimentação lateral das paredes externas e pelo assoalho da fossa nasal, que deslocava-se para baixo, conforme os processos alveolares se inclinavam lateralmente, resultando em um aumento da capacidade nasal. Relatou também o caso de um paciente portador de má oclusão de Classe III, em que houve um avanço real da maxila e um deslocamento para baixo após a terapia. Notou ainda a abertura da mordida anterior e a rotação do plano mandibular. 
Com o objetivo de avaliar quantitativamente as forças presentes durante a fase de ativação e contenção dos aparelhos expansores, ZIMRING; ISAACSON ${ }^{100}$, em 1965, realizaram uma pesquisa em quatro pacientes com idades de 11 a 15 anos. Todos apresentavam mordida cruzada bilateral, com algum grau de atresia maxilar. Os pacientes foram tratados com aparelhos expansores fixos convencionais, com bandas, acrílico e parafuso. Após as ativações terem sidos realizadas duas vezes ao dia e as forças, mensuradas por um dinamômetro, concluíram que:

I-) na fase ativa da expansão: a) ocorria maior pressão da ativação imediatamente após as ativações, que se dissipavam em seguida; b) no início do tratamento, as forças eram dissipadas normalmente nas 12 horas subseqüentes, o que deixou de ocorrer após alguns dias e a força residual acumulada gerou uma pressão elevada, devido à deficiência de dissipação no período entre as ativações; c) foram verificadas diferenças evidentes com relação à idade do paciente e ao tempo necessário para as forças produzidas serem dissipadas pelas ativações do aparelho, uma vez que nos pacientes mais idosos, o tempo requerido para a liberação dessas forças é maior;

II-) na fase de contenção, as forças residuais estavam presentes nos quatro pacientes, ao término das ativações. Essas forças se dissipavam em seis semanas, sendo a maioria na primeira semana de contenção, passando a diminuir gradativamente;

III-) na fase pós-contenção, as comparações das medidas feitas antes e imediatamente após a remoção do aparelho não revelaram redução nas medidas interpré-molares e intermolares superiores.

Sugerindo modificações nos expansores convencionais, BIEDERMAN $^{11}$, em 1968, citou o expansor rápido maxilar sem a presença 
do acrílico, que apresentava o parafuso no centro da sutura palatina, unido às bandas por meio de fios mais calibrosos. O autor relatou a indesejável inflamação inerente aos aparelhos portadores de acrílico, devido à impacção alimentar embaixo dos mesmos. Suas ativações se procederam de maneira semelhante às dos outros aparelhos, ou seja, dois quartos ao dia, permanecendo por três meses, para a ossificação da sutura palatina. $O$ aparelho, segundo o autor, é altamente viável para pacientes portadores de atresia maxilar, abóbada palatina com altura acentuada e para pacientes que não atingiram a maturidade esquelética. Outra vantagem é que em muitos casos não existe necessidade de extrações dentárias.

Em 1968, $\operatorname{MOSS}^{65}$ indicou a expansão rápida maxilar para pacientes portadores de fissura labiopalatal e má oclusão de Classe III com deficiência maxilar. No primeiro caso clínico, o portador de fissura labiopalatal, mordida cruzada posterior bilateral e atresia maxilar utilizou o expansor, que projetou sua maxila para anterior, melhorando o perfil e posteriormente foi realizado um enxerto na região da fissura. No segundo, portador de má oclusão Classe III, atresia no arco dentário superior e mordida cruzada utilizou o expansor, que avançou a maxila no sentido anterior, melhorando seu perfil e os arcos dentários.

Analisando os resultados que ocorrem em decorrência da separação da sutura mediana, DAVIS; KRONMAN ${ }^{30}$, em 1969, verificaram se os resultados são previsíveis e se as alterações são benéficas e podem ser controladas pelo ortodontista. Foram analisados modelos de gesso e radiografias em norma lateral e frontal de 26 pacientes norte-americanos, que fizeram o uso do expansor rápido maxilar. Os dados foram avaliados pré e 
pós-tratamento e como resultados, observou-se: a) um avanço do ponto A nos pacientes que tiveram abertas suas suturas intermaxilares; b) um aumento do ângulo do plano mandibular, abrindo a mordida anterior, embora em alguns pacientes, tenha havido diminuição desse ângulo; c) um aumento do ângulo SN.PP em metade dos pacientes, com conseqüente abaixamento do ponto $\mathrm{A}$; d) que na radiografia póstero-anterior não houve alterações significantes nas áreas estudadas; e) um aumento maior na largura intermolar do que na largura intercanino; f) que os molares inferiores tenderam a acompanhar os molares superiores e g) que a altura da abóbada palatina manteve-se estável.

Com o intuito de verificar os efeitos da expansão rápida da maxila sobre os ossos da face, $\mathrm{HEFLIN}^{41}$, em 1970, estudou radiografias cefalométricas de 54 pacientes, antes, imediatamente depois da expansão e um ano após o início do tratamento. Os pacientes foram agrupados conforme a idade cronológica, esquelética, sexo, má oclusão, padrão facial e raça. Os resultados demonstraram que: a) a base craniana não foi alterada com a terapia; b) não ocorreram alterações significantes anteroposteriores da maxila; c) houve movimentos transitórios nos segmentos maxilares, em direção oposta à linha média com o centro de rotação acima da base do crânio; d) na mandíbula existiu uma rotação para baixo e para trás; e) houve uma extrusão temporária dos molares superiores, contudo, sem alteração no sentido anteroposterior e f) ocorreu um significante aumento na dimensão vertical da face.

Nesse ano, abordando as vantagens da expansão rápida maxilar, HAAS $^{38}$ relacionou os efeitos e alterações produzidos, como: abertura da 
sutura palatina em forma triangular, com o ápice voltado para a cavidade nasal; diastema interincisivos superiores, no qual as coroas convergem primeiramente e as raízes posteriormente, até encontrarem suas posições originais; os processos alveolares inclinam-se e movem-se lateralmente com os maxilares, enquanto os processos palatinos deslocam-se inferiormente, no momento em que a sutura palatina mediana se abre e a maxila se desloca para a frente e para baixo, ocorrendo uma rotação mandibular para baixo e para trás. $\mathrm{O}$ autor ainda cita, como indicação da expansão maxilar, o tratamento da má oclusão de Classe III, pacientes com capacidade nasal insuficiente e portadores de fissura labiopalatal e apinhamentos dentários superiores. Como fatores desfavoráveis, relata o agravamento da mordida aberta anterior pré-existente, que pode piorar com a terapia. O objetivo primário da expansão palatina é coordenar as bases dentárias superiores e inferiores, devendo o aparelho ser projetado para acentuar os efeitos ortopédicos e eliminar os efeitos ortodônticos. $\mathrm{Na}$ utilização do aparelho expansor sem o botão de acrílico, os efeitos serão diretamente sobre a tábua óssea vestibular dos dentes de ancoragem, o que poderá acarretar maiores efeitos ortodônticos.

Notando carência de informações sobre o efeito da expansão maxilar na prática clínica, WERTZ ${ }^{98}$, em 1970, estudou as alterações ocorridas pela abertura da sutura palatina durante a prática ortodôntica, em especial em relação à direção e magnitude das metades maxilares, assim como os efeitos do desajuste oclusal sobre o posicionamento mandibular. $\mathrm{O}$ estudo envolveu 60 pacientes, sendo 37 do sexo feminino, com idades de 7 a 29 anos e 23 do sexo masculino, com idades de 8 a 14 anos, que apresentavam atresia maxilar e que foram tratados favoravelmente com a expansão maxilar. Os resultados foram obtidos de modelos de gesso, telerradiografias em normas lateral e 
frontal, realizadas antes, imediatamente pós-expansão e na remoção do aparelho. Os aparelhos expansores utilizados foram os do tipo convencional, com bandas e apoio em acrílico e as ativações foram efetuadas 1/4 de manhã e 1/4 à noite. Os resultados permitiram concluir que todos os pacientes tiveram suas mordidas cruzadas corrigidas, contudo, com o avançar da idade, as alterações ortopédicas foram limitadas e a maxila sofreu um movimento para baixo e para anterior, em um número limitado de casos, sendo que essas alterações se mantiveram em apenas 50\% dos pacientes, ao final do tratamento. A mandíbula sofreu alteração temporária, retornando à posição original posteriormente, os incisivos superiores moveram-se mesialmente e verticalizaram-se, diminuindo o ganho do arco e a sutura palatina manifestouse de forma radiolúcida, pela radiografia oclusal, com a maior abertura para a espinha nasal anterior e a menor, para a região posterior. A movimentação em adultos foi limitada em relação a pacientes com idades mais precoces, a colocação do botão de acrílico no palato justificou-se por auxiliar na retenção dos ossos alveolares no período da estabilização e a proposta de se corrigir a mordida cruzada com o expansor rápido é segura e traz vantagens ao tratamento ortodôntico.

Alegando existência de dois tipos de mordidas cruzadas, DIPAOLO $^{32}$, nesse mesmo ano, sugeriu que nem todas devem ser tratadas com o aparelho de expansão maxilar. O primeiro tipo é devido à real deficiência esqueletal da base maxilar e deve ser tratado com a disjunção maxilar, enquanto que o segundo e mais comum, em que a base óssea maxilar se apresenta regular e os dentes superiores, com excesso de inclinação para palatino, em relação aos dentes inferiores, deve ser tratado com elásticos, arcos de nivelamento abertos, torques e aparelhos removíveis, sem a necessidade da disjunção maxilar. $O$ autor ainda faz algumas 
considerações à expansão rápida maxilar, relatando alguns dos sintomas relacionados à terapia, durante as ativações, como visão confusa, tonturas, dores de cabeça, sangramentos nasais e dores nas regiões dos zigomáticos, devendo-se então diminuir o número de ativações diárias. Também relata que não foram encontrados indícios de deslocamento para anterior da maxila durante a expansão maxilar e concluiu que nos pacientes com excesso de desenvolvimento vertical é necessário cautela ao se indicar a expansão rápida maxilar, pois poderá se acentuar a altura facial ântero-inferior, prejudicando o perfil.

Em 1971, ALPINER; BEAVER ${ }^{4}$ comentaram os efeitos e as indicações do tratamento com a expansão rápida maxilar. A atresia pode levar à instabilidade na intercuspidação com os dentes inferiores, causando distúrbios na articulação temporomandibular e assimetria do arco maxilar ou mandibular. Entre as indicações de tratamento com a expansão rápida maxilar, o autor cita o tratamento da má oclusão de Classe III não cirúrgica, deficiência maxilar, deficiência relativa de maxila com a mandíbula ligeiramente maior, pacientes respiradores bucais, mordidas cruzadas com desvios funcionais, discrepância dente-osso negativa e pacientes portadores de fissura labiopalatal. Como contra-indicações, são citados o prognatismo maxilar, protrusão bimaxilar, dentes cruzados isolados e desarmonias esqueléticas. A expansão maxilar imita um padrão de crescimento imediato na sutura maxilar e quando indicada precocemente a terapia, poderá corrigir completamente os casos de deficiência maxilar, favorecendo a erupção dos dentes permanentes. 
Com a proposta de investigar as alterações que ocorrem no crânio, quando da abertura da sutura palatina mediana, GARDNER; KRONMAN ${ }^{35}$, em 1971, avaliaram seis fêmeas Macaca rhesus, das quais três eram controles e instalaram os expansores fixos, ativados a cada três dias. Ao final, foram aplicadas injeções intramusculares do corante oxitetraciclina nos animais, que, após sete dias, foram sacrificados, decapitados e tiveram seus crânios dissecados e analisados em luz natural e ultravioleta, observando o padrão de tetraciclina fluorescente no osso neoformado. Os resultados mostraram que a tetraciclina foi absorvida no ossos recém-formados, tornando-se fluorescente à luz ultravioleta. As suturas do palato, pré-maxila e maxila revelaram áreas sem absorção de tetraciclina e aparentemente sofreram alterações durante o procedimento da expansão maxilar. As suturas lambdóidea, parietal e sagital mediana apresentaram grandes desorganizações e se abriram acima de 1,5 mm em algumas regiões. A sincondrose esfenooccipital foi aberta pela expansão em todos os animais experimentais, podendo ser feita a correlação entre as alterações e o fato da maxila deslocar-se para a frente e para baixo, durante a expansão. A fluorescência da tetraciclina demonstrou o estímulo do crescimento ou da remodelação em muitos ossos próximos da sutura palatina mediana, pois a região infratemporal da maxila, asa maior do esfenóide, arco zigomático, lâminas pterigóides e processo hamular demonstraram um aumento marcante na absorção do corante.

No mesmo ano, BYRUM JUNIOR ${ }^{16}$ analisou cefalometricamente as telerradiografias em norma lateral, no início do tratamento e no fim do período de contenção, de 30 pacientes tratados com a terapia da expansão rápida maxilar, portadores de má oclusão de Classe I, II e III e idades entre 8 e 14 anos. A expansão levou em média três semanas. Ao final, concluiu que: a) a maxila deslocou-se inferiormente, levando consigo os molares de 
ancoragem; b) os molares superiores exibiram ligeiro grau de extrusão; c) as alturas faciais total e superior foram aumentadas pelo deslocamento da maxila para baixo, que levou a um aumento no plano mandibular, acentuando a abertura da mordida anterior; d) a altura facial ântero-inferior também aumentou, devido ao deslocamento da maxila, à extrusão dos dentes superiores e à alteração no plano mandibular; e) o plano palatino apresentou pequena mudança, em função do deslocamento maxilar e f) a maxila sofreu um suave reposicionamento para anterior.

Acreditando nos efeitos favoráveis da expansão maxilar perante as más oclusões de Classe III, BIEDERMAN ${ }^{12}$, em 1973, relatou alguns casos tratados com essa terapia. Os aparelhos Hyrax, sem a presença do botão de acrílico, os tornaria mais higiênicos e flexíveis, facilitando a instalação quando os dentes de ancoragem não estivessem paralelos entre si, eram ativados duas vezes ao dia, em um total de $2 / 4$ de volta e permaneciam em contenção por três meses. O autor relatou casos clínicos de pacientes portadores de má oclusão de Classe III, que, após a terapia, tiveram as mordidas cruzadas posterior e anterior corrigidas, devido ao avanço da maxila em direção póstero-anterior. Concluiu que a expansão rápida da maxila, perante a má oclusão de Classe III, mesmo por protrusão mandibular, é vantajosa, contudo, nos casos de grandes discrepâncias, somente a cirurgia ortognática poderá resolver o problema. A idade também deve ser considerada, pois nos pacientes mais jovens, os resultados são mais favorecidos.

Em 1973, COHEN; SILVERMAN ${ }^{26}$, alegando desvantagens e dificuldades na instalação dos expansores convencionais com bandas, 
procedimento de moldagem, inserção correta das bandas na moldagem e fase de soldagem, mencionaram a vantagem do expansor colado diretamente à superfície oclusal dos dentes superiores, poderia extinguir algumas fases por não necessitar de bandas. Relataram também a possibilidade da intrusão dos dentes posteriores, favorecendo os pacientes com padrão excessivamente vertical.

Em 1975, HOFFER JUNIOR; WALTERS ${ }^{44}$ estudaram as alterações e os efeitos da expansão rápida maxilar em 10 macacos Maccaca mulatta, com idades entre 25 e 37 meses. Os animais encontravam-se na dentadura mista e foram divididos em três grupos, com dois animais experimentais e dois controles em cada grupo. $\mathrm{O}$ aparelho era do tipo expansor com acrílico e parafuso. Os autores concluíram que: a) a sutura foi aberta com consequiente expansão do arco superior, do espaço intranasal e abóbada palatina; b) houve ampla vestibularização dos dentes superiores posteriores, que, após o período de contenção, voltaram à sua posição normal de angulação e alinhamento; c) houve modesta recidiva da expansão maxilar quando a contenção foi suspensa; d) ocorreu uma subseqüente expansão do arco dentário inferior e e) houve a neoformação óssea na região da sutura.

MONDRO; LITT $^{64}$, em 1977, sugeriram alterações nos aparelhos expansores colados com cobertura acrílica na oclusal dos dentes superiores, descrevendo o novo aparelho em sua construção, o qual não possuía a estrutura metálica convencional ligada ao parafuso, passando pelas cervicais e vestibulares dos dentes superiores, sendo apenas provido de estrutura em acrílico e parafuso expansor no centro da sutura palatina. Alegaram, como vantagens, a facilidade de construção por não haver fios, a 
remoção fácil e a possibilidade de ser utilizado em qualquer fase do tratamento ortodôntico, mesmo nos pacientes já com as bandas ortodônticas instaladas.

Em 1977, BROGAN ${ }^{14}$ avaliou 516 pacientes tratados com a expansão rápida maxilar, devido à insuficiência da passagem aérea nasal. Observou bons resultados ortopédicos e aumento efetivo e estável da largura da arcada dentária superior, associado às estruturas faciais, permitindo uma correção permanente das mordidas cruzadas posteriores uni e bilateral e facilitando a correção da má oclusão de Classe III. O volume e a largura nasal podem ser aumentados, se desejados. Para a técnica ser realmente efetiva, o aparelho deve ser rígido e a força, suficiente para mover dentes e ossos. A contenção com o próprio aparelho deve ser utilizada em média por dois anos, mantendo assim o ganho transversal.

$\mathrm{Na}$ expectativa de um estudo mais global, envolvendo vários aparelhos de expansão maxilar, WERTZ; DRESKIN ${ }^{99}$, nesse mesmo ano, compilaram dados de vários clínicos que fizeram uso dos expansores maxilares e avaliaram seus resultados e atterações em diversas idades e fases da dentição. O estudo envolveu 56 pacientes, com idades de 8 a 29 anos, tratados com vários tipos de aparelhos expansores, na correção da atresia maxilar. Radiografias cefalométricas em normas frontal e lateral padronizadas foram realizadas antes do tratamento, após a abertura da sutura palatina, na remoção do aparelho expansor e ao término do tratamento ortodôntico. Ao final, concluíram que ocorreu a expansão esperada em todos os pacientes, contudo os que apresentavam idades mais avançadas tiveram menores alterações ortopédicas, devido aos 
componentes esqueléticos mais rígidos, com a maxila deslocando-se para baixo, às vezes suavemente para trás e algumas vezes significantemente para a frente, voltando à sua posição original durante a contenção. A largura maxilar pode ser expandida sem maiores recidivas nos pacientes mais jovens, enquanto que nos pacientes com idades mais avançadas pode haver a perda dos aumentos inerentes à expansão. Nos pacientes mais jovens, a rotação mandibular no sentido horário foi menor que um grau.

No afã de estimar quando as suturas intermaxilares e palatinas transversas iniciam sua obliteração, com relação à idade, PERSSON; THILANDER ${ }^{71}$, em 1977, avaliaram 24 pacientes pós-morte, com idades entre 15 e 35 anos, mortos acidentalmente. As dissecações realizadas nas áreas da sutura intermaxilar palatina, permitiram concluir que a sutura pode mostrar obliteração no período juvenil, apesar de que um grau mais avançado de obliteração é raramente verificado antes da terceira década de vida. Uma ampla variabilidade individual pode ser encontrada com o avanço da idade, havendo grande variação na obliteração, em diversas partes da sutura. A região posterior indicou uma calcificação mais rápida do que a região anterior. Em geral, a sutura palatina inicia sua obliteração na mesma idade, porém com graus diferentes, devido à variação individual. Além da idade, outros fatores podem influenciar o início da calcificação da sutura palatina.

Para examinar as alterações dentárias, esqueléticas e sua estabilidade cinco anos após a expansão maxilar, LINDER-ARONSON; LINDGREN $^{55}$, em 1979, analisaram 23 pacientes com idade média de 14,4 anos, que apresentavam, ao início do estudo, mordida cruzada bilateral e 
pequena sobremordida. Todos usaram o expansor rápido de maxila e as avaliações sobre os modelos de gesso e telerradiografias em norma lateral foram realizadas antes, ao final da contenção e após cinco anos da finalização da expansão. Ao final do período da expansão, as medidas encontradas para os molares e caninos foram em média 6,0 e 2,1 mm, respectivamente e após cinco anos, 3,6 e 0,8 mm, respectivamente, indicando que o ganho final foi $45 \%$ e $23 \%$ do valor inicial. Após cinco anos, os aumentos das alturas faciais puderam ser interpretados como crescimento normal, ao final desta avaliação e o trespasse vertical e horizontal manteve-se inalterado. Concluindo, não houve efeitos dentários e esqueléticos desfavoráveis, associados à expansão maxilar após esse período e o ganho real transversal foi moderado.

Em 1980, BERLOCHER; MÜELLER; TINANOFF ${ }^{10}$, preocupados $^{2}$ com a possibilidade de que a atresia maxilar, associada à mordida cruzada posterior, viesse a reduzir o espaço disponível para a irrupção dos dentes permanentes sucessores, estudaram a terapia da expansão maxilar e o aumento efetivo do perímetro do arco. O trabalho constou de 29 pacientes, com idades entre 3 e 7 anos, portadores de atresia maxilar e conseqüente mordida cruzada posterior, sendo que 10 apresentavam fissura de palato. A expansão foi executada por expansores fixos do tipo Haas, ativados $0,5 \mathrm{~mm}$ por dia e permanecendo em contenção no mínimo por 60 dias. Os modelos de gesso inicial e pós-contenção foram avaliados no comprimento do arco por fio flexível, que passava às pontas de cúspides, de distal de $2^{\circ}$ molar decíduo, à distal do correspondente oposto. Os resultados demonstraram que houve aumentos significativos tanto em largura como no perímetro do arco, sendo que a média das alterações na largura, em pacientes sem fissura, foi $3,8 \mathrm{~mm}$ na região de caninos e 4,2 mm para os molares, seguida de 3,9 mm nos 
caninos e 4,8 nos pacientes portadores de fissura. O perímetro do arco aumentou na mesma proporção, em média 4,0 mm. Todos os pacientes tiveram suas mordidas cruzadas corrigidas, com correspondente aumento, tanto no perímetro, como na largura, sendo esse ganho importante para o correto alinhamento dos dentes permanentes. Não houve uma correlação estável entre o aumento do perímetro do arco e o aumento na largura transversa.

HAAS $^{39}$, nesse ano, revisando alguns de seus artigos anteriormente publicados e seis casos clínicos tratados e controlados por cerca de 20 anos, reavaliou as terapias da expansão maxilar utilizadas e a estabilidade alcançada e apresentou mais quatro casos clínicos. Entre outros, relatou a indicação da expansão rápida maxilar nas sobremordidas profundas e mordida aberta esquelética, que, ao contrário, não contra-indica a terapia, se for adotada a mentoneira de tração vertical como auxiliar da expansão maxilar. $\mathrm{O}$ autor também demonstrou que depois da expansão rápida, ocorreram, nas larguras dos intercaninos inferiores, aumentos em média de 4 a $5 \mathrm{~mm}$, que se mantiveram estáveis. Outro ponto abordado foi a superioridade dos aparelhos expansores com a presença do botão de acrílico sobre os sem o botão. Em idades mais avançadas, as forças incidiram apenas nos dentes de ancoragem, que, por conseqüência, pressionaram a tábua vestibular, levando à fratura, caso não houvesse abertura da sutura. Concluindo, o autor relata as indicações clássicas da terapia da expansão, como: a) deficiência maxilar real e relativa; b) estenose nasal; c) má oclusão de Classe III; d) pacientes portadores de fissura labiopalatal; e) deficiência maxilar anteroposterior e f) discrepâncias negativas dente/osso. 
Em 1982, BELL ${ }^{9}$, ao revisar a literatura, encontrou variáveis que poderiam interferir no sucesso da terapia da expansão maxilar e concluiu que a quantidade de expansão ortopédica pode estar associada: a) ao avanço da idade do paciente, sendo que em fases mais precoces haverá maiores alterações ortopédicas; b) magnitude da força aplicada; c) tipo de aparelho expansor utilizado e d) contenção. A correção precoce da mordida cruzada, com consequiente abertura da sutura, trará benefícios, devolvendo o redirecionamento normal da erupção dos dentes permanentes, propiciando a correção de assimetrias do posicionamento condilar e favorecendo a oclusão normal. Também relatou que a expansão lenta maxilar é mais fisiológica para a integridade do tecido da sutura, levando a um menor tempo de contenção e maior estabilidade pós-tratamento.

Com o objetivo de verificar os efeitos das forças ortopédic as no complexo craniofacial, por intermédio de vários aparelhos expansores, CHACONAS; CAPUTO $^{23}$, no mesmo ano, acompanharam quatro aparelhos fixos, Hyrax, tipo Haas, quadri-hélice e Minne expander e um aparelho móvel à placa de acrílico com parafuso expansor. A força das ativações foi verificada em um aparelho que mensurava a pressão liberada pelos aparelhos ortodônticos. Um modelo anatômico tridimensional duplicado de um crânio humano construído com material especial foi utilizado para simular as estruturas craniofaciais. Os aparelhos eram dispostos nesse modelo, ativados, examinados e fotografados em um campo de luz polarizada de transmissão. Observou-se que tanto o tipo Haas, como o Hyrax e o aparelho móvel trouxeram as mais significantes quantidades de forças ortopédicas a cada ativação; o expansor Minne expander demonstrou menor nível de força a cada ativação; o quadri-hélice produziu forças menos ortopédicas e mais ortodônticas, com exceção 
quando utilizado em pacientes com idades mais precoces. As pressões produzidas pelos aparelhos fixos foram concentradas na região anterior do palato, progredindo posteriormente na direção dos ossos palatinos. Os aparelhos tipo Haas, Hyrax e Minne expander produziram uma pressão que irradiou-se superiormente, ao longo das lâminas perpendiculares dos ossos palatinos até as estruturas anatômicas mais profundas, como os ossos lacrimais, nasais, processos pterigóides do osso esfenóide, zigomático e paredes mediais da órbita. Pressões similares foram encontradas com os aparelhos móveis.

HOWE ${ }^{46}$, em 1982, propôs um aparelho expansor colado, o qual não possuía botão de acrílico, era confeccionado com fio de aço rígido, que contornava os dentes superiores por vestibular e palatino, ao nível cervical e tinha, ao centro da linha mediana do palato, um parafuso expansor, sendo o aparelho colado às superfícies vestibular e lingual. $\mathrm{O}$ autor avaliou um paciente do sexo feminino, de 12 anos, portador de atresia maxilar, no qual o aparelho foi fixado e ativado de maneira convencional. Como resultado, observou-se a abertura da sutura palatina, confirmada pela presença de diastema interincisivo superior e pela radiografia oclusal. Entre as vantagens da utilização desse aparelho, citou a ausência das bandagens, a utilização em qualquer fase da dentição, maior higiene e a possibilidade de minimizar a inclinação dentária durante a fase ativa da expansão. Não se verificou sinais de descalcificação dos dentes na remoção do aparelho.

Com a utilização de interferometria holográfica a laser, PAVLIN; VUKICEVIC $^{68}$, em 1984, estudaram os efeitos da expansão maxilar, com aparelhos móveis, no complexo maxilar e estruturas adjacentes de um 
crânio humano. O estudo avaliou o crânio de um paciente do sexo masculino, com 32 anos de idade, dissecado imediatamente antes da avaliação, preservando assim as propriedades mecânicas. $\mathrm{O}$ tecido mole do palato e do periodonto foi reconstruído com material artificial semielástico. O aparelho, uma placa de acrílico móvel, dotada de parafuso, foi instalada e ativada com o crânio fixado e exposto a raios laser antes e após cada ativação do aparelho. Os resultados demonstraram que as alterações mecânicas foram qualitativamente similares ao grau da carga liberada pelo aparelho e que o aumento na largura da arcada superior foi devido parcialmente ao processo de deformação alveolar e inclinação dentária. O movimento rotacional da maxila levou ao deslocamento das estruturas maxilares circundantes, como processos pterigóides, ossos zigomáticos, lacrimais e nasais e ao efeito ortopédico nos ossos basais e suturas.

SPOLYAR ${ }^{92}$, no mesmo ano, em um artigo que preconizava o aparelho expansor Colado, indicou o aparelho com parafuso expansor mais anteriorizado, favorecendo a deglutição e a fala. Preconizou a cimentação do aparelho com cimento específico, que na remoção ficaria aderido ao aparelho e não ao dente. Também utilizou um regime de expansão multifases, em que a cada fase é realizada a abertura de 4 a $5 \mathrm{~mm}$, com intervalo de 6 semanas entre as fases. Estas devem ser efetuadas até se conseguir a expansão desejada, podendo ser alteradas conforme a idade do paciente, estágio da oclusão e quantidade de expansão necessária. $\mathrm{O}$ autor relata também a possibilidade de intrusão dos dentes cobertos com a resina do aparelho, assim como uma inibição do crescimento alveolar em resposta ao crescimento facial (altura facial), contudo, devido ao curto período de tempo em que o aparelho permanece na boca, isto não é significativo. Algumas vantagens deste aparelho sobre os bandados são: a) restabelecer a 
posição da rotação mandibular, que pode favorecer uma compensação anterior, descruzando a mordida anterior e possibilitando a protração maxilar; b) com a rotação mandibular ocorre um aumento no volume intraoral para acomodar a língua, que é forçada a se posicionar mais abaixo do que o normal e c) ser útil em cirurgias de osteotomia, para testar a resistência da sutura durante o procedimento em casos que se queira, de um lado, ancoragem maior e de outro, expandir um menor número de dentes.

$\mathrm{KRAUT}^{50}$, em 1984, diante do insucesso dos procedimentos da expansão maxilar convencional por resistência na separação da sutura mediopalatina, mostrou 29 pacientes, com idades médias de 24,8 anos para o sexo feminino e 22,6 anos para o sexo masculino, tratados com a expansão cirúrgica da maxila. Após as fases cirúrgicas, com os aparelhos expansores previamente instalados e ativados $1,0 \mathrm{~mm}$ ao dia e sem a resistência óssea já obtida na cirurgia, os pacientes responderam bem à terapia, com conseqüente descruzamento da mordida.

Em 1986, SATO; VIGORITO; CARVALHO ${ }^{78}$, com a finalidade de avaliar, por meios de análises cefalométricas póstero-anteriores, as implicações no diagnóstico das mordidas cruzadas, se esqueléticas ou dentárias e suas alterações decorrentes da disjunção da sutura palatina, avaliaram um caso clínico de um paciente do sexo feminino, com 11,7 anos de idade, que apresentava má oclusão de Classe II e mordida cruzada posterior. Ao analisar, na radiografia póstero-anterior, as medidas previamente descritas, verificaram que a paciente apresentava, pelo padrão de normalidade, uma atresia maxilar, sendo instalado o aparelho expansor do tipo Haas, ativado $10 \mathrm{~mm}$. Observaram aumentos significantes nas 
larguras nasal e da maxila, assim como diminuição das medidas A6-(JRGA) e da largura maxilomandibular, aproximando-se da normalidade. Os autores citam, ainda, que, com essa técnica, pode-se saber se a mordida cruzada foi totalmente corrigida, minimizando as recidivas.

Em 1987, BISHARA; STALEY ${ }^{13}$ revisaram a literatura da expansão maxilar e indicaram a terapia a pacientes com discrepâncias transversas maxilares, que resultem em mordida cruzada posterior uni ou bilateral, atresia esquelética e dentária, ou a combinação de ambas, más oclusões de Classe II e III e a pacientes com fissura palatina e discrepância dente/osso negativa. Entre as desvantagens da terapia citaram: má colaboração do paciente, dente cruzado isoladamente, mordida aberta anterior, planos mandibulares inclinados, perfil convexo, assimetrias esqueléticas de maxila e mandíbula, severa discrepância esquelética anteroposterior e vertical em adultos e problemas esqueléticos indicados para cirurgia ortognática. Entre os efeitos da expansão maxilar citaram que: a alta variabilidade da magnitude da abertura da sutura, em pacientes adultos, ocorre em menor grau; a principal resistência à abertura da sutura palatina não é devido a si própria e sim, às suturas circundantes, como o osso esfenóide e o zigomático; pode haver ou não uma melhora na passagem aérea nasal e que a idade ideal seria entre os 13 e 15 anos, porém, pacientes adultos podem ser expandidos, embora a estabilidade seja pior. Entre outros fatores a se considerar, os autores citam a magnitude da discrepância transversal, severidade da mordida cruzada e angulação inicial dos molares e pré-molares. Para a obtenção de uma maior expansão e maior segurança, o mais indicado seria o aparelho rígido, pois os aparelhos móveis não trazem grandes alterações quando precisamos de maiores expansões e, portanto, devem ser indicados em idades mais precoces. 
HARTGERINK; VIG; ABBOTT ${ }^{40}$, em 1987, realizaram um estudo com o objetivo de avaliar as alterações na resistência nasal à passagem do ar, em pacientes submetidos à expansão maxilar, um ano após a terapia. A amostra consistiu de 38 pacientes que necessitavam da expansão e de um grupo controle. Os dados com relação à passagem do ar foram coletados no início, após uma semana e novamente ao final da terapia. A idade dos pacientes variou de 7,5 a 22 anos. Alguns dos pacientes que receberam terapia de expansão maxilar apresentaram resistência nasal maior à passagem do ar antes da expansão, com relação ao grupo controle. Houve uma média significante de diminuição da resistência nasal para o grupo com expansão maxilar, resistência que se manteve estável um ano após a terapia. Segundo os autores é possível que essa expansão cause alargamento das narinas, favorecendo a redução na resistência nasal em alguns pacientes, contudo, a expansão com o objetivo único de tentar melhorar a passagem aérea não deve ser advogada.

Em uma abordagem clínica da expansão rápida maxilar, SILVA FILHO; CAPELOZZA FILHO ${ }^{83}$, em 1988, sugeriram uma volta completa no parafuso ao dia, ou seja, 2/4 de manhã e 2/4 à noite. Entre os efeitos produzidos pela expansão rápida maxilar, citaram os efeitos ortodônticos, definidos pela inclinação do processo alveolar, vestibularização e extrusão dos dentes de ancoragem e os efeitos ortopédicos, como a separação dos maxilares que giram no plano frontal e transversal, deslocando-se para baixo e para a frente. Entre as indicações da expansão maxilar está a mordida cruzada posterior esquelética, a mordida cruzada posterior dentária de grande magnitude, a atresia maxilar acompanhada de atresia do arco dentário inferior e a má oclusão de Classe III, com posterior tração reversa da maxila com Sky hook. 
Acreditando em possíveis recidivas nas larguras intercaninos e intermolares inferiores, após a expansão rápida maxilar, SANDSTROM; KLAPPER; PAPACONSTANTINOU ${ }^{75}$, no mesmo ano, estudaram o efeito da terapia sobre as larguras intermolares e intercaninos inferiores e sua estabilidade depois de dois anos de contenção. Foram analisados 28 pacientes, submetidos à expansão maxilar e avaliados os modelos de gesso e pelo cefalograma lateral. Após usarem a contenção fixa por 5,6 anos, os pacientes foram reestudados e, como resultado, obteve-se um aumento significante nas mensurações estudadas durante o tratamento. A resultante final de ganho foi significativa na distância intermolares e intercaninos. A média de ganho intercanino inferior pós-contenção foi de $1,1 \mathrm{~mm}$, considerada maior que a expansão por tratamento convencional e a média de ganho intermolar inferior pós-contenção foi de $2,8 \mathrm{~mm}$, não havendo correlação entre o ganho final de expansão nos caninos e molares com o tipo facial ou idade do paciente.

Em 1989, MOUSSA-JOËLSON; MOSSAZ ${ }^{66}$ realizaram um estudo comparando os expansores colado e bandado, com o objetivo de verificar a expansão lenta e as alterações dentoesqueléticas. Neste trabalho, os autores estudaram dois grupos de pacientes com idades que variavam de 8 a 12 anos e que possuíam mordidas cruzadas uni e bilateral. No grupo I foi instalado o expansor Colado com cobertura acrílica e no grupo II, o expansor convencional com bandas nos pré-molares e molares. Ambos os aparelhos eram dotados de mola fixa, com capacidade de força de 900 gramas, ao invés do parafuso expansor, na região da sutura mediana. A expansão se deu em um período de 7 a 15 semanas e os resultados avaliados nos modelos de gesso, radiografias oclusais, telerradiografias em normas lateral e frontal. Indicaram maior facilidade na instalação do aparelho Colado, suprindo a fase 
das bandagens, apesar da higienização e remoção desse aparelho serem mais difíceis. Nenhum dos dois grupos mostrou abertura do diastema interincisivos superior. $\mathrm{Na}$ avaliação dos modelos de gesso houve aumento na largura do arco, em ambos os grupos, contudo, a largura intercanino obteve maior aumento no grupo I e a largura intermolar, no grupo II. Na avaliação radiográfica póstero-anterior observou-se expansão esquelética ligeiramente maior no grupo Colado e alterações, nos ângulos SNA e ANB, em torno de 0,5 a 1 grau para ambos os grupos, retornando aos seus valores originais no período de contenção.

SARVER; JOHNSTON ${ }^{77}$, nesse ano, verificaram o deslocamento anterior e inferior da maxila, ocorrido com o expansor maxilar bandado, diferente do expansor Colado. Foram avaliados 20 pacientes com aparelho Colado, que apresentavam, em média, 10,8 anos e necessitavam da expansão maxilar transversa. Esses dados foram comparados a uma outra amostra de Wertz's, que compreendia 37 pacientes do sexo feminino, com idades entre 7 e 29 anos e 23 do sexo masculino, com idades entre 8 e 14 anos, que utilizaram aparelhos bandados. Avaliadas as radiografias cefalométricas laterais, antes e após a expansão, os resultados indicaram que todos os pacientes tiveram suas mordidas cruzadas corrigidas. Entretanto, no grupo do aparelho Colado, o movimento para anterior da maxila, o deslocamento da espinha nasal posterior para baixo e o reposicionamento inferior da maxila foram menores que no grupo do bandado, em que o movimento dos incisivos superiores para palatino foi maior. Ainda no grupo do Colado, ocorreram deslocamentos para posterior da maxila e da espinha nasal anterior, para baixo e para trás, devido ao movimento posterior da maxila. 
Em 1989, SILVA FILHO; VALADARES NETO; $\operatorname{ALMEIDA}^{87}$, preocupados com a ausência de uma possível autocorreção no decorrer do desenvolvimento da oclusão, sugeriram a correção precoce da mordida cruzada posterior. Relataram que entre as vantagens do tratamento precoce estão: a) a grande bioplasticidade óssea do paciente jovem; b) redirecionamento dos dentes permanentes ainda não irrompidos; c) melhor relacionamento esquelético das bases ósseas; d) eliminação de posições incorretas da articulação temporomandibular, devolvendo a relação simétrica condilo/fossa; e) correta trajetória do fechamento mandibular, eliminando desvios em relação cêntrica e f) estética facial. Entre os aparelhos citados na correção da mordida cruzada posterior, podemos encontrar os seguintes aparelhos móveis: mola coffin, placas com parafusos e Splint-coffin e os aparelhos fixos: quadri-hélice e bi-hélice e o arco em "W", que se caracterizam por apresentarem expansão lenta e efeitos principalmente ortodônticos, enquanto que o aparelho fixo tipo Haas caracteriza-se por apresentar expansão rápida e grandes efeitos ortopédicos.

HEROLD $^{42}$, em 1989, realizou um estudo retrospectivo, avaliando as alterações transversas e as inclinações dos molares e caninos superiores, tanto na expansão rápida maxilar, como na lenta com aparelhos fixos e também com aparelhos removíveis. Verificou ainda a estabilidade das expansões no arco dentário superior, após cinco anos da remoção dos aparelhos. A avaliação foi baseada em registros de modelos de gesso de 50 pacientes, submetidos ao tratamento de mordidas cruzadas, dos quais 19 receberam o expansor Hyrax, 20, o quadri-hélice e 11, o aparelho móvel. As avaliações se deram no início do tratamento, após o período de contenção e cinco anos mais tarde. Passados alguns anos, o autor constatou que houve ganhos reais, com a expansão, em todos os grupos, porém não 
houve diferença estatisticamente significante entre eles. O aparelho removível obteve maior índice de sucesso após esse período, talvez devido às forças lentas e mais fisiológicas. Independente do aparelho usado, as recidivas foram similares. $\mathrm{Na}$ expansão, os caninos inclinaram mais para vestibular, com o uso de aparelhos removíveis, sendo que no período póscontenção, houve a inclinação lingual desses dentes. Nos aparelhos quadrihélice e removível, os molares inclinaram para vestibular e no Hyrax, para lingual, indicativo da movimentação de corpo. No período pós-contenção, os três grupos mostraram inclinação lingual nos molares. A expansão residual verificada após alguns anos, na região de canino, foi igual para os três grupos, embora um grande número de pacientes que usou o aparelho quadri-hélice tenha apresentado novamente a mordida cruzada, provavelmente devido à expansão insuficiente durante a fase ativa.

Com o propósito de facilitar a instalação do aparelho expansor nas dentaduras decíduas e mistas, sem prejuízo do efeito ortopédico, SILVA FILHO et al. ${ }^{89}$, ainda em 1989, sugeriram modificações na estrutura do aparelho, que se resumiam na eliminação da barra de conexão vestibular e na substituição das bandas dos caninos decíduos pela extensão da barra de conexão palatina ao redor desses dentes. Notaram que a expansão ortopédica induz alterações suturais na maxila, não somente ao nível da sutura palatina mediana, mas de todas as suturas maxilares que unem o complexo craniofacial, resultando no reposicionamento da maxila para a frente e para baixo. Os autores citam a construção do aparelho e seu emprego clínico, em um paciente com 5 anos de idade, portador de má oclusão de Classe III, com mordida aberta anterior e atresia maxilar. Após o término da expansão, foi instalado, no paciente, um aparelho Sky hook, que tracionou a maxila anteriormente e também uma grade palatina, para o fechamento da mordida 
aberta anterior. Ao final, o paciente teve restabelecida sua oclusão normal e seu perfil facial foi satisfatório.

ADKINS; NANDA; CURRIER ${ }^{1}$, em 1990, com o objetivo de verificar uma das maiores e mais significantes alterações ortopédicas, identificada pela separação da sutura palatina, constataram um aumento no perímetro do arco dentário, após a expansão maxilar, assim como alterações dentárias superiores e inferiores. Avaliaram 21 pacientes, com idades entre 11 e 17 anos, que se submeteram à expansão maxilar e apresentaram algum grau de mordida cruzada. Foram tratados com o aparelho Hyrax e, posteriormente, tiveram checadas as alterações nos modelos de gesso pré e pós-tratamento. Os incisivos superiores sofreram inclinação para lingual, o que causou diminuição no comprimento do arco dentário, porém o perímetro do arco aumentou e os dentes superiores de ancoragem vestibularizaram-se suavemente. Uma pequena compensação, no sentido vestibular, foi observada nos dentes inferiores e não se notou correlação da idade do paciente com a inclinação dos dentes de ancoragem.

Em 1990, SANTOS-PINTO; HENRIQUES ${ }^{76}$ realizaram uma avaliação dos preceitos clínicos e radiográficos, pertinente à expansão rápida maxilar. Sugeriram avaliações radiográficas periódicas, com o intuito de averiguar as alterações esqueléticas maxilares e a disjunção na sutura palatina, ocorridas durante a terapia. Concluíram que a expansão rápida maxilar é um ótimo artifício coadjuvante para as terapias de correção das discrepâncias transversas, atresias maxilares, mordidas cruzadas posteriores e discrepâncias no sentido anteroposterior. Advertiram ainda sobre uma possível presença de sintomatologia dolorosa, devido à pressão exercida nas 
regiões das suturas nasomaxilar, frontonasal e zigomaticomaxilar, que desapareceu após alguns minutos de ativação.

SCHNEIDMAN; WILSON; ERKIS ${ }^{81}$, nesse ano, relatando fatores negativos associados ao aparelho expansor com a presença do botão de acrílico na região do palato, como dores e ulceração da mucosa palatina, em pacientes com número reduzido de dentes de ancoragem na dentadura mista, dentes pilares mal posicionados e até mesmo quando se deseja efeitos nas regiões posterior e anterior da maxila, sugeriram o uso do expansor fixo, com apoio em apenas dois dentes de ancoragem, sem o botão de acrílico. Nesse caso, o aparelho seria cimentado apenas nos primeiros molares superiores, com parafuso expansor na região da sutura palatina. O estudo envolveu 50 pacientes, com idades entre 7 e 15 anos, em que 25 utilizaram o aparelho com dois apoios e os outros 25, o aparelho convencional Hyrax, com apoio em quatro dentes permanentes. Os pacientes apresentavam, no início, má oclusão de Classe III e mordida cruzada anterior e posterior. Telerradiografias em norma lateral, modelos de gesso e fotografias foram avaliados e as ativações efetuadas em 2/4 ao dia. Os resultados demonstraram que na região posterior, o grau de expansão dos dois aparelhos foram semelhantes, assim como a abertura da sutura palatina. No aparelho com dois apoios, os molares de ancoragem sofreram maior movimento para palatino e no Hyrax, maior inclinação para vestibular e maior grau de expansão na região dos caninos superiores. Os molares inferiores no grupo do aparelho com dois apoios sofreram menor inclinação para vestibular do que no Hyrax.

\section{Em 1991, SILVA FILHO; VILLAS BOAS; CAPELOZZA} $\mathrm{FILHO}^{88}$, acreditando na ausência de autocorreção da mordida cruzada 
posterior, em fases precoces da dentição, expandiram e avaliaram cefalometricamente as alterações da expansão rápida maxilar no desenvolvimento da dentadura decídua e mista. Avaliaram 30 pacientes entre 5 e 10 anos, que apresentavam mordida cruzada posterior e foram tratados com expansor tipo Haas, ativado 2/4 ao dia. Ao final, foram avaliadas duas telerradiografias, em norma lateral, no início e fim do tratamento. Observou-se que a maxila não se deslocou no sentido anteroposterior, mas rotou para baixo, seguida do plano palatino, ocasionando uma rotação mandibular que aumentou os ângulos verticais, como SN.GoGn, SN.Gn e PP.GoGn, provocando o reposicionamento do ponto B e o consequiente aumento da altura facial total anterior. Os molares de ancoragem sofreram extrusão e inclinação para vestibular, não tendo se deslocado anteroposteriormente.

PEARSON $^{69}$, nesse mesmo ano, relatou o caso de um paciente do sexo feminino, com sete anos de idade, que apresentava atresia maxilar, má oclusão de Classe II, mordida aberta anterior por hábito deletério e crescimento predominantemente vertical, com presença de altura facial acentuada. Após a terapia com o aparelho expansor, foi instalada uma placa de contenção com cobertura oclusal, para minimizar os efeitos extrusivos dos dentes posteriores com a associação da mentoneira vertical por 12 horas ao dia. Utilizou também um bite block por 10 meses, para ajudar a fechar a mordida anterior. A paciente finalizou em oclusão normal Classe I, com auxílio do aparelho extrabucal, com tração occipital. Além da correção da mordida cruzada posterior e mordida aberta anterior, ocorreu a redução da altura facial ântero-inferior. 
Em 1992, VIAZIS et al. ${ }^{97}$ fizeram uma abordagem clínica e a demonstração de vários aparelhos de expansão maxilar, por acreditarem que nos aparelhos de expansão rápida, uma a duas semanas de ativação proporcionariam menores inclinações dentárias e maiores efeitos ortopédicos e nos expansores lentos, com dois a seis meses de ativação, haveria menor resistência dos tecidos nas estruturas maxilares e assim, melhor formação óssea na sutura intermaxilar, o que minimizaria a recidiva. Relataram vários casos clínicos de expansores maxilares que obtiveram resultados favoráveis na correção da mordida cruzada posterior.

CAVASSAN et al. $^{22}$, em 1993, avaliaram os resultados alcançados com a expansão rápida maxilar, tendo, como metodologia, modelos de gesso do arco dentário superior. Selecionou-se 16 pacientes com faixa etária entre 11 e 18 anos, que apresentavam diferentes tipos de má oclusão e tinham em comum a atresia maxilar do arco dentário superior. A expansão foi obtida com o aparelho expansor do tipo Haas e os modelos de gesso obtidos em três fases: pré-expansão, após a remoção do expansor e ao final do tratamento corretivo. Após terem sido checadas as alterações, os resultados mostraram que houve aumento nas larguras transversas do arco dentário superior e acréscimo no sentido transverso da região profunda do palato, que se mantiveram estáveis ao final do tratamento. A profundidade do palato não foi alterada, ocorreu uma evidente inclinação vestibular dos dentes de ancoragem e ao final do tratamento foram confirmados os ganhos reais na distância intercaninos, interprimeiros pré-molares e intermolares superiores.

Devido aos primeiros procedimentos cirúrgicos realizados para reconstruir as funções labiais em pacientes que apresentam fissura bilateral 
completa de lábio e palato, CAPELOZZA FILHO; ALMEIDA; URSI ${ }^{19}$, em 1994, consideraram que os segmentos maxilares se tornam atrésicos, principalmente na região anterior, em função da pressão da musculatura palatina e da cicatriz cirúrgica, levando à necessidade de expansão maxilar. Citaram, ainda, um caso clínico e concluíram que a terapia, nesses pacientes, produz um reposicionamento anterior favorável, em relação à mandíbula e às estruturas craniofaciais. $\mathrm{O}$ posicionamento mais anteriorizado auxilia na compensação da altura facial deficiente, no seu terço médio, bem como na correção das discrepâncias transversas maxilomandibulares. Observaram, também, que o aumento da altura facial anterior, visto no início do tratamento, pareceu ser temporário e tendeu a se normalizar com o crescimento e o tratamento ortodôntico.

Em 1994, MCLUCKIE ${ }^{59}$ estudou o efeito da expansão maxilar lenta nas larguras intercaninos e intermolares inferiores, na dentadura mista de 27 pacientes que utilizaram aparelhos expansores removíveis, com a presença de um parafuso expansor. Foram avaliados os modelos de gesso antes e após a terapia da expansão e os resultados demonstraram aumentos significantes nas larguras intermolar superior e inferior e nas larguras intercanino inferior. $\mathrm{O}$ maior aumento aconteceu na largura intermolar superior, concluindo-se, então, que quando há expansão no arco superior, o inferior também sofre certo grau de expansão.

Verificando a existência de uma possível correlação entre a maturação óssea em adolescentes e a ossificação da sutura palatina, REVELO; FISHMAN ${ }^{73}$, em 1994, analisaram radiografias oclusais e de mão e punho, em 84 pacientes com idades entre 8 e 18 anos. Comparados 
os estágios de ossificação com o indicador de maturação esquelética de Fishman, concluíram, como resultados que: a) existe uma correlação importante entre o desenvolvimento maturacional e o início da ossificação da sutura palatina; b) não houve diferenças significativas no padrão de ossificação entre homens e mulheres; c) a sutura não se obliterou completamente ao final da adolescência; d) a terapia da expansão maxilar obtém melhores resultados quando indicada precocemente e e) durante a expansão ortopédica da maxila, os ossos maxilares estão diretamente relacionados e dependentes de outras estruturas, como o arco zigomático.

Nesse ano, CAPELOZZA FILHO et al. ${ }^{20}$ sugeriram a expansão rápida maxilar assistida cirurgicamente, em pacientes adultos, como forma de vencer a resistência sutural. Inicialmente, tentou-se a expansão convencional de cinco pacientes fora da fase de crescimento, mas diante do insucesso do tratamento, foi realizada a expansão cirúrgica. $\mathrm{O}$ aparelho utilizado, semelhante ao descrito por Haas, após o insucesso, foi desativado e os pacientes, conduzidos à cirurgia. Após 48 a 72 horas da cirurgia, o expansor passou a ser ativado 2/4 de volta por dia, até atingir o limite satisfatório. Os autores concluíram que a expansão maxilar cirurgicamente assistida tem vantagens na qualidade e na quantidade da expansão, estando indicada a pacientes fora da fase de crescimento, pacientes com necessidade de grande expansão de base óssea, ou com perdas ósseas horizontais na região posterior da maxila, pacientes que não aceitam o desconforto da tentativa convencional, pacientes que já tenham tentado a expansão convencional, ou aos que possuem idade superior a 30 anos. 
Preocupados com o grau de reabsorção radicular ocorrida nos dentes de ancoragem, submetidos à expansão maxilar, ERVERDI et al. ${ }^{33}$, em 1994, avaliaram dois tipos de aparelhos expansores: o tipo Haas e o Cast Cap Splint, de ancoragem dentária estendida dos primeiros molares até os caninos superiores. Foram analisados 19 pacientes, que utilizaram os expansores maxilares e posteriormente sofreram a exodontia dos primeiros pré-molares superiores. As ativações foram de 0,4 mm ao dia. Após a análise radiográfica e microscópica, notou-se o alargamento da lâmina dura dos pré-molares e áreas de reabsorção de cemento e dentina foram evidenciadas para ambos os grupos. Foram detectadas cavidades de reabsorção, especialmente na superfície vestibular dos pré-molares, que eram comumente rasas e largas, ao longo da superfície. Em relação à natureza e freqüência da reabsorção, não foram encontradas diferenças acentuadas entre os dois métodos, contudo, houve uma pequena diferença na localização da reabsorção, a qual, no grupo Haas, apresentou-se vestibularmente, enquanto que no grupo Cast Cap Splint, vestibularmente e coronalmente.

Indagando os resultados da expansão rápida maxilar, em idades mais tardias como na dentadura permanente, SILVA FILHO et al. ${ }^{90}$, em 1994, avaliaram os efeitos cefalométricos em norma lateral, obtidos pela expansão maxilar, correlacionando-os com o fator idade do paciente. Uma amostra de 20 pacientes, com idades entre 12 e 33 anos, portadores de deficiência maxilar transversa, foi avaliada utilizando-se o aparelho do tipo Haas. Os resultados demonstraram que não houve alteração maxilar no sentido anteroposterior do ponto A, ou da espinha nasal posterior. O plano palatino deslocou-se inferior e paralelamente. Ocorreu rotação horária da mandíbula, com consequiente aumento da altura facial total N-Me, ânterosuperior N-ENA e ântero-inferior ENA-Me. Não houve alteração 
significativa no sentido anteroposterior dos molares de ancoragem, contudo, um deslocamento vertical desses dentes foi evidenciado.

Nesse ano, MAZZIEIRO ${ }^{58}$ estudou as alterações dentoesqueléticas propiciadas por dois tipos de expansores rápidos da maxila, o expansor do tipo Haas e Hyrax. Avaliou 41 pacientes de ambos os sexos, com idades entre 10 e 16 anos, portadores de mordida cruzada posterior uni ou bilateral, por meio de telerradiografias em norma frontal, realizadas antes das expansões, imediatamente pós-expansão e depois de três meses de contenção. As ativações se procederam em um total de 2/4 pela manhã e 2/4 à noite, totalizando uma volta completa ao dia, até se obter a sobrecorreção das cúspides palatinas superiores, ao tocar à vestibular dos dentes inferiores. Ao final, os resultados foram: a) os dois aparelhos expandiram ortopedicamente a maxila; b) não existiram diferenças estatisticamente significantes entre os aparelhos, no que diz respeito às alterações esqueléticas proporcionadas pelas expansões; c) não houve recidivas esqueléticas significativas após três meses de contenção; d) aparentemente, durante a fase ativa, os aparelhos dentomucossuportados provocaram uma maior abertura da mordida anterior, embora após o período de contenção não tenham sido observadas diferenças estatisticamente significantes; e) os molares de ancoragem comportaram-se de maneira semelhante, não existindo diferenças entre os dois grupos e f) a distância intermolares inferiores aumentou em ambos os grupos, porém sem nenhuma correlação com os aparelhos.

Em 1994, aversos aos efeitos colaterais indesejáveis da expansão maxilar, como a abertura da mordida anterior e o aumento da altura facial, 
MAJOURAU; NANDA ${ }^{56}$ avaliaram a terapia associada à mentoneira vertical, para minimizar esses efeitos deletérios. $\mathrm{O}$ estudo avaliou a terapia em um paciente do sexo feminino, de 12 anos de idade, portador de mordida cruzada posterior unilateral, mordida aberta anterior e posterior, atresia maxilar, incisivos topo-a-topo e presença, ainda, de divergência do assoalho nasal e plano mandibular, excesso de altura facial ântero-inferior e tendência esquelética de Classe III. A terapia da expansão maxilar foi auxiliada pela mentoneira de tração vertical de 250 gramas, instalada antes do início da expansão e se estendeu por 10 semanas. Os resultados obtidos foram satisfatórios, demonstrando aumento da sobremordida anterior. As sobreposições cefalométricas laterais revelaram que a paciente não apresentou efeitos colaterais verticais associados à expansão maxilar e, sim, que a mordida aberta posterior foi reduzida e a sobremordida anterior aumentou cerca de dois milímetros.

Devido à grande magnitude de força liberada pela expansão rápida maxilar contra o palato e os dentes de ancoragem, SILVA FILHO; HERNANDES; OKADA ${ }^{85}$, em 1994, verificaram os efeitos induzidos pela expansão rápida maxilar sobre os pré-molares de ancoragem, em 36 pacientes que receberam esse tipo de expansão. Avaliando as radiografias periapicais desses dentes, concluíram que o processo de rizogênese incompleta não foi interrompido com a terapia, assim como não foram observadas alterações distróficas da polpa nas câmaras e canais radiculares, ou obliteração parcial ou total da cavidade pulpar. Evidências reabsortivas nas superfícies proximais ou apicais dos pré-molares não foram verificadas e alterações referentes à integridade da lâmina dura, espessamento do ligamento periodontal e nível da crista óssea alveolar não tiveram importância clínica. 
Em 1995, SILVA FILHO; MONTES; TORELLY ${ }^{86}$ realizaram um estudo no intuito de observar os efeitos da expansão rápida maxilar na dentadura decídua e mista, registrados na análise cefalométrica frontal. Avaliaram 32 pacientes, com idades entre 5 e 11 anos e com algum grau de constricção maxilar. Instalou-se o expansor maxilar do tipo Haas modificado, no qual uma barra palatina estendia-se até a região dos caninos decíduos em que era colada. As ativações foram de uma volta completa ao dia e todos os pacientes submetidos à terapia obtiveram sucesso, com considerável aumento na largura do arco dentário superior. Os efeitos obtidos pela expansão maxilar foram alcançados por meio de movimentos ortopédicos e ortodônticos, sendo que o diastema entre os incisivos centrais superiores reflete o efeito ortopédico ocorrido. Na maxila, a abertura da sutura é de forma triangular, com maior abertura para a região interpróstio. $\mathrm{O}$ máximo aumento de largura registrado para a cavidade nasal foi de $43 \%$ da largura obtida na região alveolar.

SPILLANE; MCNAMARA JUNIOR ${ }^{91}$, no mesmo ano, realizaram um estudo para avaliar a expansão maxilar na dentadura mista, verificando a quantidade de expansão e o relacionamento entre a estabilidade do arco expandido e a largura inicial do arco. Os 162 pacientes portadores de discrepância dente/osso negativa e idade média de oito anos e oito meses foram tratados com o expansor Colado, ativado 1/4 por dia, até se obter a devida sobrecorreção. Os resultados, a partir da análise de modelos de gesso e cefalogramas, permitiram avaliar as medidas pré-tratamento, até a irrupção dos pré-molares e demonstraram que a expansão resultou em um aumento significante de largura maxilar de cinco a seis milímetros e que $72 \%$ a $91 \%$ dos ganhos transversais mantiveram-se até a irrupção dos primeiros molares permanentes. O aparelho produziu maiores movimentos de corpo dos 
molares, enquanto que os arcos dentários com maiores atresias e os molares inclinados para lingual mantiveram a melhor expansão. A altura da abóbada palatina diminuiu durante o tratamento, mas retornou aos valores iniciais depois de um ano. A quantidade de expansão não pode ser correlacionada com o sexo, idade ao início do tratamento, mordida cruzada antes do tratamento, ou largura inicial do arco.

MCNAMARA JUNIOR; BRUDON ${ }^{61}$, em 1995, fizeram algumas abordagens sobre a expansão maxilar, com os expansores convencionais, como o tipo Haas e Hyrax, indicando-os na correção das mordidas cruzadas, aumento do comprimento do arco, correção da inclinação axial dos dentes posteriores, auxílio na correção da má oclusão de Classe II e III, preparo para cirurgia ortognática e redução da resistência aérea. Abordaram ainda os expansores Colados, orientando sua construção e aplicações e relataram que além de intervirem nas dimensões transversas, trazem alterações nas dimensões verticais e anteroposterior. O aparelho Colado, com cobertura acrílica, age como um aparelho bite block, inibindo a irrupção dos dentes posteriores durante o tratamento, sendo indicado a pacientes portadores de altura facial acentuada. Além disso, em posição, esse aparelho permite a abertura da mordida posterior, facilitando a correção da mordida cruzada. Alertaram que, em sua remoção, na dentadura mista, poderão ocorrer extrações de dentes decíduos, devido à grande aderência do aparelho aos dentes.

Em 1995, KAWAKAMI ${ }^{48}$ realizou um trabalho com a finalidade de comparar, por meios de telerradiografias em norma lateral, as alterações dentoesqueléticas decorrentes da utilização de dois tipos de aparelhos 
expansores rápidos da maxila, verificadas em suas distintas fases e as prováveis diferenças cefalométricas entre os dois aparelhos. A amostra constituiu-se de 41 pacientes, sendo 15 do sexo masculino e 26 do feminino, com idades entre 10 anos e 8 meses a 17 anos e 8 meses, leucodermas, que apresentavam mordida cruzada posterior uni e bilateral e que foram submetidos à expansão rápida da maxila por meio dos aparelhos tipo Haas e Hyrax. As avaliações e resultados foram obtidos das telerradiografias tomadas ao início do tratamento (pré-expansão), imediatamente depois da expansão e três meses após a contenção com o próprio aparelho expansor. As ativações se deram 2/4 de manhã e 2/4 à noite, até se obter a sobrecorreção, em que a cúspide palatina dos dentes superiores tocasse as cúspides vestibulares dos dentes inferiores. Os resultados demonstraram que imediatamente após a expansão rápida da maxila, os dois tipos de aparelhos apresentaram resultados semelhantes, sem a ocorrência do deslocamento da maxila em direção anterior e sem reflexos para o perfil mole, induzindo, porém, a uma rotação horária da mandíbula, aumentando a altura facial ântero-inferior. Durante os três meses de contenção após a expansão, os valores da maioria das medidas cefalométricas avaliadas em norma lateral tenderam a retomar os seus índices iniciais e somente as medidas Sperp-A, ANB, NAP, Sperp-R6 e Sperp-C6 apresentaram diferenças estatísticas significantes, quando foram comparados os dois tipos de expansores, principalmente durante a fase de contenção.

No intuito de avaliar a estabilidade da expansão maxilar a longo prazo, MOUSSA; O'REILLY; CLOSE ${ }^{67}$, nesse ano, avaliaram alterações em 165 modelos de gesso de pacientes, 8 a 10 anos após a remoção da contenção superior e inferior. A idade média dos pacientes, ao final do 
tratamento, era de 15,7 anos e de 30 anos para o período pós-contenção. Concluíram que a largura intercaninos superiores, intermolares inferiores e superiores, após dez anos, manteve a valores próximos aos do fím do tratamento, porém maior que os valores pré-tratamento. A largura intercanino inferior, comprimento do arco e perímetro, após 10 anos, diminuiu, aproximando-se dos valores pré-tratamento. A irregularidade dos incisivos, após esse tempo, foi mínima, tanto para o arco superior, como para o inferior.

DARENDELILER; LORENZON ${ }^{29}$, em 1996, acreditando que a expansão rápida maxilar levasse a possíveis iatrogenias, como a reabsorção radicular dos dentes de ancoragem e que a terapia pudesse ser comprometida pela ausência de cooperação nas ativações do parafuso, pelo paciente, ou, ainda, pelo risco de excesso de ativações e conseqüente sobrecorreção exagerada, sugeriram um aparelho expansor fixo, de forças leves e contínuas, liberadas por meio de uma mola superelástica, precisamente controlada por um sistema de autobloqueio, que interrompe a expansão na quantidade desejada. Os autores citaram três casos clínicos, que foram tratados com o expansor colado, com as modificações propostas acima. Os resultados verificados nas telerradiografias em norma lateral, anteroposterior, oclusal e fotografias mostraram uma expansão previamente calculada, sem necessidade de reativações ou cooperação do paciente.

TEIXEIRA; SILVEIRA; VALE ${ }^{94}$, no mesmo ano, realizando uma revisão da literatura sobre as alterações esqueléticas anteroposteriores, transversais e verticais, decorrentes da expansão rápida maxilar, concluíram que: a) a expansão rápida da maxila corrige a deficiência 
maxilar por meio da disjunção dos processos palatinos no plano horizontal;

b) não se deve esperar o deslocamento anterior da maxila com mudanças no ângulo SNA; c) a maxila desloca-se sempre para baixo, induzindo uma rotação do plano palatino para baixo e para trás; d) os molares acompanham o deslocamento da maxila para baixo; e) o aumento da altura facial é diretamente proporcional ao deslocamento vertical dos molares superiores de ancoragem; f) a mandíbula sempre rota para baixo e para trás, aumentando a dimensão vertical no terço inferior da face; g) a expansão rápida da maxila, visando unicamente a melhoria da respiração, não deve ser realizada e h) a abertura da sutura ocorre de forma triangular, tanto no sentido anteroposterior, com o ápice voltado para a espinha nasal posterior e a base, para a espinha nasal anterior, como no sentido ínfero-superior, com a base voltada para a cavidade bucal e o ápice voltado para a cavidade nasal.

Ainda em 1996, VELÁZQUEZ; BENITO; BRAVO ${ }^{96}$ realizaram um estudo em 30 pacientes, com idade média em torno de 12,1 anos, que receberam a terapia da expansão maxilar e cujo objetivo foi investigar, a longo prazo, as consequiências da mesma no padrão esqueleto facial. O aparelho utilizado foi o do tipo Haas convencional e as avaliações, obtidas a partir de radiografias, antes e após o tratamento. Os resultados demonstraram que o eixo de crescimento manteve-se constante, o plano palatino não apresentou alterações significativas após o tratamento e não foram encontrados deslocamentos maxilares no sentido anteroposterior. Após três anos do início do tratamento ortodôntico com a expansão maxilar, não se encontraram alterações faciais verticais ou anteroposteriores relacionadas à terapia. As alterações significantes, após esse período, foram as esperadas pelo crescimento normal e as alterações 
comuns, inerentes à expansão maxilar, como mordida aberta anterior e/ou rotação do plano mandibular, podem ser corrigidas no curso do tratamento.

Conhecendo os efeitos inerentes aos aparelhos expansores convencionais, como a inclinação dos dentes de ancoragem para vestibular e a extrusão, que causam uma rotação mandibular e conseqüente abertura da mordida anterior, MEMIKOGLU; ISERI ${ }^{62}$, em 1997, realizaram uma avaliação clínica com o expansor de acrílico Colado. O uso desse aparelho, segundo os autores, ocasiona um movimento mais paralelo dos dentes de ancoragem, sendo, portanto, indicado aos pacientes que necessitem de expansão maxilar e que possuam excesso no ângulo mandibular. Dessa forma, o aparelho foi instalado em um paciente com 13 anos de idade, portador de má oclusão de Classe II e excessivo ângulo mandibular. Ao final, um menor grau de inclinação vestibular nos molares e pré-molares e uma desprezível mordida aberta anterior foram encontrados. Houve também a ausência de extrusão dos molares, e assim bom resultado no controle vertical.

Um caso clínico de paciente do sexo feminino com 10 anos de idade, que apresentava má oclusão de Classe I, com mordida cruzada posterior, ausência de espaço para erupção de pré-molar inferior e com tendência de mordida aberta anterior foi relatado por $\mathrm{DHANE}^{31}$, no mesmo ano, que notou, ainda, uma propensão de crescimento vertical pelas medidas cefalométricas. A paciente foi inicialmente tratada com expansor rápido de maxila, Hyrax, ativado 2/4 de volta ao dia. Durante o uso do expansor, foi instalada, como complemento, a terapia do extra-bucal de tração occipital, que ajudou a minimizar os efeitos de extrusão dos molares 
de ancoragem, para não agravar a mordida aberta anterior. Após 29 meses de terapia, os resultados foram aceitáveis, com a devolução da função e da estética. A paciente apresentou, durante o tratamento, crescimento predominantemente vertical, que levou a uma pequena acentuação da altura facial ântero-inferior.

Comparando as alterações dentárias e esqueléticas no sentido transversal, sagital e vertical, assim como as recidivas, com três tipos de aparelhos expansores, durante a dentadura mista, SANDIKÇIOGLU; $\mathrm{HAZAR}^{74}$, em 1997, avaliaram 30 pacientes com idades entre 6 e 8 anos, portadores de mordida cruzada uni e bilateral, que foram divididos em três grupos no qual fizeram uso do aparelho removível com mola, do quadrihélice e do Hyrax. Os resultados obtidos de cefalogramas laterais, pósteroanteriores e os modelos de gesso mostraram que: a) todos os grupos obtiveram aumentos significantes na distância intermolares, interprémolares, intercaninos superiores e intermolares inferiores; b) a maioria das alterações se deu no plano transversal, poucas no sentido vertical e nenhuma no sentido sagital; c) nos aparelhos de expansão lenta, as alterações foram maiores no plano transversal do que no sagital e vertical; d) no aparelho quadri-hélice, a altura facial anterior aumentou mais do que no aparelho móvel, com conseqüente inclinação dos dentes de ancoragem; e) no aparelho Hyrax, houve maiores alterações, no sentido transversal, no arco superior e no molar inferior, assim como no vertical, verificadas pelo ângulo SN.GoGn e houve também aumento do ANB e diminuição do SNB; f) no aparelho móvel não se verificou evidência de recidivas e g) os aparelhos fixos foram melhores que o móvel, devido à não necessidade da cooperação do paciente. 
HESSE et al. ${ }^{43}$, também em 1997, checaram as correlações da correção da mordida cruzada posterior funcional por meio da expansão maxilar, com as mudanças na posição condilar e na relação oclusal, assim como o aumento na largura transversa inferior. Os modelos de gesso de 61 pacientes, com idades entre 4 e 12 anos, que utilizaram expansores quadrihélice e o do tipo Haas foram estudados. Os resultados demonstraram que: a) os pacientes que apresentavam mordida cruzada posterior unilateral apresentavam posição assimétrica de côndilo, com o lado não cruzado em posição anterior e inferior na fossa glenóide; b) a relação de molar e canino apresenta-se assimétrica, sendo maior a de Classe II, no lado cruzado e menor no lado não cruzado, com a presença de desvio da linha média para o lado cruzado; c) houve estabelecimento de simetria oclusal e facial e posição condilar após a expansão e d) ocorreu pequena expansão do molar inferior após a expansão maxilar.

Nesse ano, CAPELOZZA FILHO; SILVA FILHO ${ }^{17,} 18$ relataram a importância da correta avaliação intra-arco alveolar superior, no qual o arco superior deverá ser analisado isoladamente e apresentar uma conformação parabólica, sendo que o formato triangular pode levar à indicação de atresia maxilar. Segundo os autores, a avaliação de intercuspidação pode oferecer uma falsa leitura, quando o arco inferior estiver com inclinação incorreta dos dentes para lingual. Chamaram a atenção para os pacientes portadores de má oclusão de Classe II, que invariavelmente poderão apresentar atresias maxilares devido à compensação ocorrida no arco superior, ao se adaptar ao inferior, distalmente deslocado. Na má oclusão de Classe III deverá ser feito o diagnóstico diferencial de atresia real ou relativa. Defendem ainda a correção da mordida cruzada posterior em idades precoces, devolvendo a correta intercuspidação, assim como a correta 
posição côndilo/fossa. Em seus resultados clínicos, não encontraram, com frequiência, avanços anteriores maxilares, a separação das duas metades da maxila a impulsiona para baixo, levando consigo os molares de ancoragem e alterando a posição mandibular que rota para baixo e para trás. Existe uma remodelação na conformação interna do nariz, que conduz ao aumento da capacidade intranasal, especialmente no terço ântero-inferior. A expansão maxilar é incapaz de alterar a largura mandibular, ou a distância interprocessos zigomáticos e tampouco provoca alterações esqueléticas na altura das órbitas. Concluíram que quanto mais avançada a idade do paciente, maior o efeito ortodôntico e menor o efeito ortopédico.

STEIMAN $^{93}$, em 1997, relatou que os expansores maxilares Colados seriam comumente usados no controle do desenvolvimento vertical e como aparelhos preventivos da mordida aberta, em pacientes com a síndrome da face longa. Alegou, contudo, que a cobertura oclusal em acrílico dificulta a visualização das cúspides palatinas superiores ao atingir uma sobrecorreção ideal com as cúspides inferiores, citando a possibilidade de colocar uma fita vermelha na fase de confecção dos aparelhos Colados, na região do acrílico das cúspides palatinas superiores, a fim de facilitar a visualização da sobrecorreção atingida ao término da expansão, tornando mais difícil a expansão insuficiente.

Com o objetivo de avaliar os efeitos da expansão maxilar e sua inter-relação com a mordida aberta anterior e o real deslocamento anteroposterior da maxila, CHANG; MCNAMARA JUNIOR; HERBERGER $^{24}$, em 1997, estudaram três grupos de pacientes. No grupo I, 25 pacientes utilizaram o expansor tipo Haas; no grupo II, 25 utilizaram 
aparelho fixo, mas não foi realizada a expansão e 23 pacientes pertenciam ao grupo controle. Os resultados verificados em telerradiografia em normas lateral e frontal e em modelos de gesso, antes, imediatamente pós-expansão e ao final da contenção, não demonstraram evidências de que a expansão maxilar pudesse levar à mordida aberta anterior, ou ao aumento do ângulo mandibular e altura facial anterior, em pacientes portadores de má oclusão Classes I e II, tratados com essa terapia. Concluíram, ainda, que a terapia não altera a posição anteroposterior da maxila a longo prazo. A diferença do ângulo SNA para o grupo tratado e de controle foi de um grau, clinicamente não significante, tendo havido também diminuição do ângulo do plano mandibular em todos os grupos estudados, principalmente no grupo que não sofreu expansão.

Nesse mesmo ano, ASANZA; CISNEROS; NIEBERG ${ }^{6}$, no intuito de verificar as diferenças entre dois tipos de aparelhos expansores, o Hyrax e o Colado, estudaram 14 pacientes portadores de mordida cruzada posterior, para verificar a expansão simétrica, inclinação dentária e a dimensão vertical. Radiografias em norma lateral e frontal foram avaliadas antes, imediatamente após a expansão e ao final do período de contenção. Os resultados demonstraram que no aparelho Colado, a espinha nasal posterior e a anterior deslocaram-se, em menor valor, para baixo que no Hyrax. No aparelho Hyrax, o deslocamento anterior da maxila e o aumento nas dimensões verticais foram maiores. Ambos os aparelhos levaram à inclinação dentária dos dentes de ancoragem.

Apontando fatores negativos associados à terapia da expansão rápida maxilar, como sangramentos, microfraturas, formações císticas e 
inflamação do tecido conjuntivo na região da sutura, CORBETT $^{27}$, em 1997, sugeriu a expansão lenta, como forma de obter maior estabilidade, com menor potencial de recidiva. $\mathrm{O}$ autor descreveu um aparelho fixo préfabricado, de níquel-titânio, com capacidade de memória, térmica de transição e que liberava 350 gramas e três milímetros de expansão por ativação. Foram relatados dois casos clínicos de pacientes jovens, portadores de atresias maxilares suaves. Os aparelhos permaneceram em fase ativa, em média de três a quatro meses e em fase de contenção, por três meses. Como vantagens, foram citadas a correção da distalização e a rotação do molar de ancoragem. $\mathrm{O}$ aparelho possibilitou a liberação de forças unilaterais lentas e contínuas, expansões pré-determinadas e conseqüentemente, melhor resposta fisiológica, com menor inclinação do dente de ancoragem.

VARDIMON et al. $^{95}$, em 1998, estudando o padrão de mineralização na região da sutura palatina, após a expansão rápida maxilar, examinaram 10 gatos, que receberam o tratamento com o expansor, tendo dois animais como controle. As ativações se procederam em fase ativa por 25 dias, em fase de contenção, por 60 dias em fase de recidiva, por 60 dias. Os resultados obtidos da radiografia oclusal avaliaram linearmente a medição de área e a densidade ótica e revelaram que durante a fase ativa, a região radiolúcida aumentou e a densidade ótica na região anterior foi 50\% maior que na região posterior, o que demonstrou aumento de perda de tecido conjuntivo na região anterior. A região anterior da sutura necessita de contenção por um tempo mais longo do que a região posterior, pois a taxa de recidiva é maior na região anterior. Durante a fase de contenção, a zona radiopaca aumentou 62\%, a radiolúcida decaiu 64\% e a largura da sutura diminuiu $65 \%$, indicando a reorganização do tecido mineralizado. A 
diminuição na densidade ótica foi duas vezes e meia maior na região posterior do que na região anterior, indicativo da direção de ossificação no sentido póstero-anterior. Durante a fase de recidiva, há uma perda na região de sutura de $41 \%$. Na comparação entre a largura da sutura e a zona radiolúcida, estas atingiram o máximo após a fase ativa e depois diminuíram, na fase de contenção, até a fase de recidiva.

Também em 1998, AKKAYA; LORENZON; ÜÇEM² propuseram avaliar as diferenças nos efeitos dentários entre as expansões rápidas maxilares e lentas, produzidas por um aparelho Colado. Uma amostra de 24 pacientes, portadores de mordida cruzada posterior, causada por atresia maxilar, foi dividida em dois grupos. O primeiro grupo utilizou o aparelho expansor rápido, Hyrax, com a presença de parafuso no centro da sutura palatina e o segundo grupo, o aparelho expansor lento Minne Expander, com presença de mola no centro da sutura, ambos colados às superfícies oclusais, palatinas e vestibulares dos dentes superiores. As avaliações obtidas de modelo de gesso indicaram que no grupo com expansor rápido, as alterações foram todas significativas e ao final do período de contenção, houve diminuição nas larguras intercaninos, interincisivos e no perímetro do arco superior. As larguras intermolares e intercaninos inferiores mostraram um aumento no final da fase de contenção, em ambos os grupos. Os aumentos das distâncias intercaninos e interincisivos foram maiores no grupo com o expansor rápido, durante a expansão. $\mathrm{O}$ aumento na distância intermolar superior foi maior durante a terapia com o aparelho de expansão lenta, enquanto que em ambos os grupos, a expansão intercaninos foi menor que a intermolar superior. No grupo da expansão rápida, o aumento intercaninos foi maior que no outro grupo. Ao final do tratamento, o aumento do perímetro do arco foi maior no expansor rápido. O ganho final, 
assim como o perímetro com as expansões, foi maior na expansão rápida que na lenta.

LÉON et al. ${ }^{54}$, em 1998, sugeriram um aparelho expansor capaz de controlar os indesejáveis efeitos colaterais da expansão maxilar, como o deslocamento vertical da maxila e da mandíbula. Aplicaram o expansor Colado, com cobertura acrílica na oclusal dos dentes superiores, em um paciente do sexo feminino, com 10 anos de idade e presença de mordida cruzada unilateral direita. A paciente apresentava tendência de crescimento vertical determinado pelos ângulos FMA, SN.GoGn e SN.Gn. O aparelho, ativado 2/4 de volta ao dia, ao final do tratamento levou à abertura da sutura palatina mediana. A disjunção conduziu a uma combinação de fatores, como a inclinação dentoalveolar e a disjunção maxilar, corrigindo a mordida cruzada. Ao final do tratamento, os ângulos FMA e SN.Gn mantiveram-se na mesma medida, enquanto que o SN.GoGn diminuiu ligeiramente, devido a um provável crescimento na altura do ramo mandibular. $\mathrm{O}$ aparelho mostrou-se eficiente no controle das dimensões verticais da face, assim como na correção da mordida cruzada posterior.

Já BROSH et al. ${ }^{15}$, neste ano, realizaram um estudo em duas fases: a primeira, com animais e a segunda, com 14 humanos, no intuito de determinar um padrão de pressão acumulada e sua dissipação durante as fases de ativação e contenção do aparelho, além de comparar essa pressão às recidivas. Na primeira fase, foram instalados dois medidores de pressão na região anterior e posterior do aparelho expansor. Foi ativada uma volta completa por sessão, num total de oito sessões, em 25 dias. No estudo com humanos, foram instalados os aparelhos expansores Hyrax, que também 
receberam os medidores de pressão. Concluíram que a pressão e a expansão aumentaram progressiva e concomitantemente durante as ativações do aparelho e que na fase ativa, a pressão imediata está diretamente relacionada à pressão que o dente sofre no ligamento periodontal. A pressão mais tardia, entre uma sessão de ativação e outra, ocorre em função do arcabouço esquelético do complexo maxilar, enquanto que a pressão da recidiva, em função das tendências maxilares, tentam retornar à sua posição original.

No afã de se verificar as alterações, estabilidade e recidivas inerentes da expansão maxilar, ALMEIDA; CAPELOZZA FILHO; TRINDADE JÚNIOR ${ }^{3}$, em 1999, avaliaram as telerradiografias em norma lateral, no início, pós-expansão, após a remoção do aparelho e um ano mais tarde, de 15 pacientes que receberam os expansores do tipo Haas. Concluíram que as alterações decorrentes da expansão maxilar, ao final do estudo, não foram significantes e apresentaram tendência à recidiva. Como fator mais relevante, ocorreu um deslocamento da maxila para baixo, que, associado à extrusão dos molares superiores, trouxe um aumento médio em torno de dois milímetros na altura facial ântero-inferior.

Em 1999, PEARSON; PEARSON ${ }^{70}$ realizaram um trabalho com 20 pacientes que necessitavam de expansão maxilar e intrusão dos incisivos superiores. Além da atresia maxilar, apresentavam os ângulos mandibulares com valores excessivos, de $36,2^{\circ}$. O aparelho expansor utilizado apresentava tubos na superfície vestibular do acrílico, que recobriam a oclusal dos dentes superiores, para a instalação de um sistema vertical de tração. Os autores mostraram um caso clínico onde, ao final do fechamento do diastema 
interincisivos, foi iniciada a intrusão desses dentes. Por meio de telerradiografias e modelos de gesso, chegaram à conclusão que os molares superiores foram expandidos, o plano palatino manteve-se estável, houve intrusão dos incisivos, molares superiores e inferiores, a altura facial diminuiu discretamente e o ponto A teve ligeira retração. A terapia mostrouse eficaz, pois não alterou desfavoravelmente a altura facial e o plano mandibular não aumentou. Os resultados dos 20 pacientes tratados demonstraram que os incisivos superiores foram intruídos, os molares superiores sofreram expansão de 7,9 mm, não houve aumento nas dimensões verticais ou alteração do plano mandibular.

Nesse ano, REED; GHOSH; NANDA ${ }^{72}$ compararam as alterações dos aparelhos expansores bandados e dos aparelhos Colados. Trinta e oito pacientes, com idade média de 12,9 anos, receberam o expansor bandado Hyrax e 55, com idade média de 13,3 anos, receberam os aparelhos Colados, com cobertura acrílica na oclusal dos dentes superiores e acrílico na região de tecido mole do palato. Alguns pacientes apresentavam mordida cruzada posterior e outros, anterior. As avaliações pós-tratamento de modelos de gesso e as telerradiografias mostraram que não houve diferença entre os dois aparelhos, nos aumentos transversais, na região de pré-molar superior, contudo, na região intermolar, houve aumento na largura duas vezes maior no grupo do aparelho bandado, assim como foram maiores as alterações verticais, como o ângulo SN.GoGn, nesse grupo. O plano palatino deslocou-se para baixo, de forma igual, em ambos os grupos e as alturas faciais anterior e posterior aumentaram nos dois grupos. Embora tenham ocorrido alterações entre um aparelho e outro, estas não são clinicamente significantes. 
Segundo FALTIN JÚNIOR; MOSCATIELLO; BARROS ${ }^{34}$, em 1999, os efeitos nocivos causados pelos disjuntores bandados, como a diminuição do eixo facial, aumento do plano palatino e aumento da profundidade maxilar podem ser minimizados utilizando-se um aparelho de disjunção palatina, com um plano de mordida posterior, em forma de capas de contenção, coladas aos dentes posteriores superiores. $\mathrm{O}$ aparelho, um semifixo, apresenta um componente fixo e uma parte removível, sendo que o componente fixo é constituído por duas placas de acrílico formando um plano de mordida posterior para a desoclusão dentária, cimentado na parte oclusal dos dentes, e a parte móvel é composta por um parafuso expansor e uma porção em acrílico. No estudo, foram comparados dois grupos de pacientes, em um total de 16 pacientes, com idades de 7 a 15 anos, dos quais, a metade utilizou o aparelho com cobertura acrílica e a outra metade, o aparelho tipo Haas. Pelas telerradiografias em norma lateral, realizadas no início e no final do tratamento, não se verificou alterações significantes entre as fases pré e pós tratamento com o aparelho de FALTIN JÚNIOR, nas medidas do ângulo do eixo facial, profundidade facial e ângulo do plano mandibular e do plano palatino, por isso este aparelho vêm sendo bem indicado a pacientes com crescimento predominantemente vertical, ou com tendência de mordida aberta anterior. No grupo do aparelho tipo Haas, houve significativo aumento da profundidade maxilar, diminuição do ângulo do eixo facial denotando que a mandíbula rotou no sentido antihorário e aumento do ângulo do plano palatino. Os dois aparelhos proporcionaram o descruzamento da mordida, acréscimo na largura da arcada e aumento da capacidade respiratória.

MEMIKOGLU; ISERI ${ }^{63}$, nesse ano, verificaram os resultados da expansão rápida maxilar por meio do expansor Colado, em pacientes em 
fase de crescimento. Trabalharam com 14 pacientes, com idade média de 12 anos, que tiveram os arcos dentários expandidos. Os aparelhos foram confeccionados com resina acrílica, que cobria a superfície oclusal e vestibular dos dentes superiores e verificou-se também presença de parafuso no centro da sutura palatina. As avaliações, em modelos de gesso e telerradiografias em normas póstero-anterior e oclusal, evidenciaram um aumento que se manteve estável ao final da terapia, nas larguras basal maxilar, nasal inferior e largura e angulação intermolar superior. Concluíram que as alterações dentoesqueléticas, nas dimensões transversas, advindas da expansão maxilar por meio do aparelho expansor Colado, mantiveram-se estáveis ao final da terapia ortodôntica.

CARREIRA $^{21}$, em 1999, no intuito de inspecionar longitudinalmente a influência da utilização de expansores com bandas sobre o comportamento da face no plano sagital, estudou 25 pacientes portadores de má oclusão de Classes I e II, com mordida cruzada posterior, uni ou bilateral, tratados com a expansão rápida da maxila, previamente à terapia ortodôntica fixa. A amostra foi comparada a um grupo de 25 pacientes de Classes I e II, que receberam tratamento corretivo sem expansão prévia e a um grupo controle de 26 pacientes, pareados por sexo e idade com os pacientes dos demais grupos. Os resultados obtidos pelas telerradiografias em norma lateral, tomadas ao início, término e três anos após o tratamento corretivo completo, indicaram que, a longo prazo, a expansão rápida da maxila não apresentou influência sobre a posição ântero-posterior das bases ósseas apicais, não alterou o padrão de crescimento facial e as dimensões da face, não influiu significantemente no posicionamento vertical dos primeiros molares, na inclinação vestibulolingual dos incisivos superiores e inferiores e nos trespasses horizontal e vertical e, conseqüentemente, não acarretou alterações 
no perfil tegumentar. Concluiu-se que as alterações cefalométricas, observadas logo após a expansão rápida maxilar, constituem fenômenos temporários e, portanto, não requerem precauções quando há necessidade de utilizá-las em pacientes com crescimento predominantemente vertical. 
(3)

PROPOSIÇÃO 


\section{3 - PROPOSICÃO}

Este estudo objetivou avaliar as alterações dentoesqueléticas de 23 pacientes jovens, portadores de mordida cruzada uni e bilateral, submetidos à disjunção rápida da sutura palatina, por meio de expansores maxilares fixos, dentossuportados, colados à superfície oclusal, vestibular e palatina dos dentes superiores e comparar as alterações dessa expansão, pela análise cefalométrica em norma lateral, com os resultados dos aparelhos previamente estudados ${ }^{48}$ : Dentomucossuportado (tipo Haas) e o Dentossuportado (Hyrax).

Comparou-se as alterações dentoesqueléticas desses três tipos de aparelhos:

3.1 - ocorridas entre o início do tratamento e imediatamente após a expansão rápida da maxila;

3.2 - ocorridas logo após a expansão maxilar até o final da fase de contenção;

3.3 - efetivamente ocorridas entre o início do tratamento e o final do período de contenção;

3.4 - comparando, entre si, as alterações proporcionadas pelos três tipos de aparelhos. 
4

MATERIAL E MÉTODOS 


\section{4 - MATERIAL E MÉTODOS}

\section{1 - MATERIAL}

A amostra do estudo consistiu de 69 telerradiografias, obtidas de 23 pacientes que apresentavam idades de 9 anos e 8 meses a 15 anos e 5 meses, sendo respectivamente 15 do sexo feminino e 8 do sexo masculino. Escolhidos a partir da seleção dos pacientes encaminhados para tratamento ortodôntico nos cursos de Especialização em Ortodontia, da Faculdade de Odontologia de Bauru, da Universidade de São Paulo, os referidos pacientes apresentavam as seguintes características:

1) eram leucodermas;

2) apresentavam mordida cruzada posterior uni ou bilateral e

3) possuíam indicação para expansão rápida da maxila, como primeira etapa do plano de tratamento corretivo da má oclusão.

A partir dessas características, foram definidos os seguintes grupos:

GRUPO I: Composto por 23 pacientes, sendo 15 do sexo feminino e 8 do sexo masculino, que receberam os aparelhos expansores dentossuportados, colados à superfície oclusal. Os pacientes apresentavam idade média de 12 anos e 7 meses ( 9 anos e 8 meses a 15 anos e 5 meses), antes da instalação do aparelho. 
GRUPO II: Composto por 20 pacientes, sendo 12 do sexo feminino e 8 do masculino, nos quais foram instalados aparelhos expansores dentomucossuportados (tipo Haas, modificado). Os pacientes apresentavam idade média de 13 anos e 5 meses (10 anos e 10 meses a 17 anos e 8 meses), antes da instalação do aparelho (dados obtidos de prévio estudo ${ }^{48}$ ).

GRUPO III: Formado por 21 pacientes, sendo 14 do sexo feminino e 7 do masculino, que utilizaram aparelhos expansores dentossuportados (Hyrax). Esse grupo apresentava, ao início do tratamento, idade média de 12 anos e 10 meses (10 anos e 8 meses a 14 anos e 11 meses) (dados obtidos de prévio estudo ${ }^{48}$ ).

O material era constituído de três radiografias cefalométricas, em norma lateral, de cada paciente avaliado, realizadas no início do tratamento, previamente à instalação do aparelho, imediatamente após o término da expansão e, finalmente, após três meses do aparelho em repouso na cavidade bucal, antes de sua remoção para os grupos II e III. Devido a presença da cobertura em acrílico na oclusal dos dentes póstero-superiores, no grupo I, o que acarreta a abertura da mordida anterior, e poderia influenciar nos resultados, optou-se pela remoção do aparelho antes da realização da telerradiografia final.

As Tabelas 4.1, 4.2 e 4.3 representam a distribuição da amostra, segundo a idade e o sexo, nos grupos I, II e III. 
TABELA 4.1 - Distribuição do Grupo I (Disjuntor Colado), segundo a idade e o sexo.

\begin{tabular}{ccc}
\hline IDADE & \multicolumn{2}{c}{ FREQÜENCIA / SEXO } \\
\hline & MASCULINO & FEMININO \\
\hline $9---10$ & 0 & 1 \\
$10---11$ & 0 & 5 \\
$11---12$ & 2 & 0 \\
$12---13$ & 4 & 1 \\
$13---14$ & 1 & 4 \\
$14---15$ & 1 & 3 \\
$15---16$ & 0 & 1 \\
\hline TOTAL & 8 & 15 \\
\hline
\end{tabular}

TABELA 4.2 - Distribuição do Grupo II (Disjuntor do tipo Haas), segundo a idade e o sexo.

\begin{tabular}{ccc}
\hline IDADE & \multicolumn{2}{c}{ FREQÜENCIA / SEXO } \\
\hline & MASCULINO & FEMININO \\
\hline $10---11$ & 1 & 1 \\
$11--12$ & 1 & 1 \\
$12---13$ & 2 & 3 \\
$13--14$ & 1 & 2 \\
$14---15$ & 1 & 0 \\
$15--16$ & 0 & 1 \\
$16--17$ & 2 & 1 \\
17 --- 18 & 0 & 12 \\
\hline TOTAL & 8 &
\end{tabular}


TABELA 4.3 - Distribuição do Grupo III (Disjuntor Hyrax), segundo a idade e o sexo.

\begin{tabular}{ccc}
\hline IDADE & \multicolumn{2}{c}{ FREQÜENCIA / SEXO } \\
\hline & MASCULINO & FEMININO \\
\hline $10---11$ & 0 & 1 \\
$11---12$ & 0 & 6 \\
$12---13$ & 5 & 0 \\
$13---14$ & 2 & 2 \\
$14---15$ & 0 & 5 \\
\hline TOTAL & 7 & 14 \\
\hline
\end{tabular}




\section{2 - MÉTODOS}

\subsection{1 - CONSTRUÇÃO DOS APARELHOS EXPANSORES}

Para a construção dos aparelhos expansores do grupo I (expansor Colado), os alunos do curso de especialização procederam duas moldagens da arcada superior dos pacientes que iriam receber o aparelho. A primeira moldagem era para a construção da parte metálica (estrutura) do aparelho, que, devido à fase da soldagem dos fios, pode deformar as estruturas do gesso, tornando necessária a segunda moldagem para a realização da estrutura em acrílico.

Os aparelhos foram confeccionados pelo técnico Luis Sérgio Vieira nas dependências do laboratório de ortodontia, da disciplina de Ortodontia da FOB - USP. Na construção de sua estrutura metálica foi utilizado fio 0,9 $\mathrm{mm}$ da Dentaurum e na região próxima ao parafuso, fio de $1,2 \mathrm{~mm}$ de espessura. O parafuso expansor foi da marca DENTAURUM, (antigo 600010), com capacidade de $7 \mathrm{~mm}$ de abertura. Foi também usada solda de prata para a união dos fios e na confecção da parte em resina utilizou-se a resina acrílica autopolimerizante.

A resina acrílica foi manipulada sobre a oclusal do modelo de gesso, de modo que englobasse toda a porção oclusal, estendendo-se até as superfícies vestibulares e palatinas ao nível cervical dos últimos dentes superiores(Figura 4.1). Em pacientes na fase da dentadura mista a cobertura oclusal em resina estendia-se até os caninos.

As Figuras 4.2 e 4.3 ilustram o aparelho Colado. 


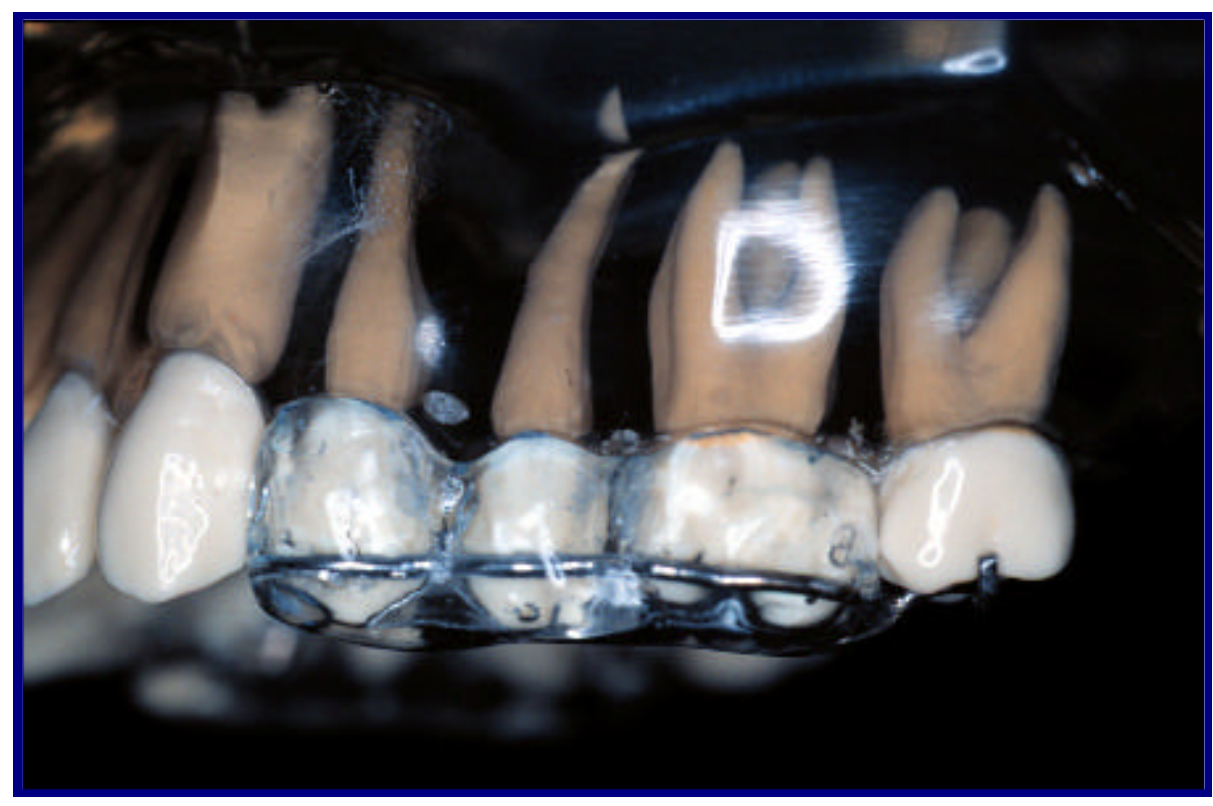

FIGURA 4.1 - Cobertura oclusal em resina acrílica dos dentes de ancoragem no aparelho expansor Colado.

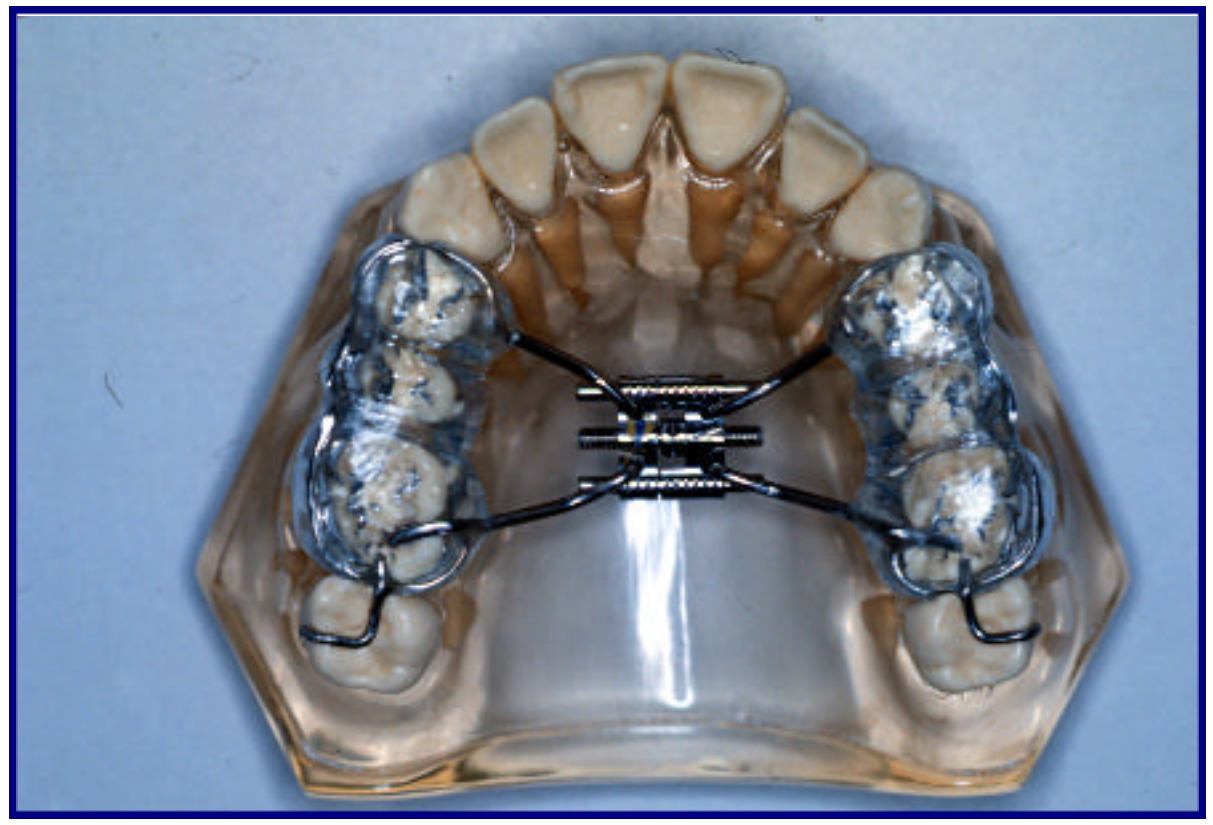

FIGURA 4.2 - Aparelho de expansão maxilar Colado. 


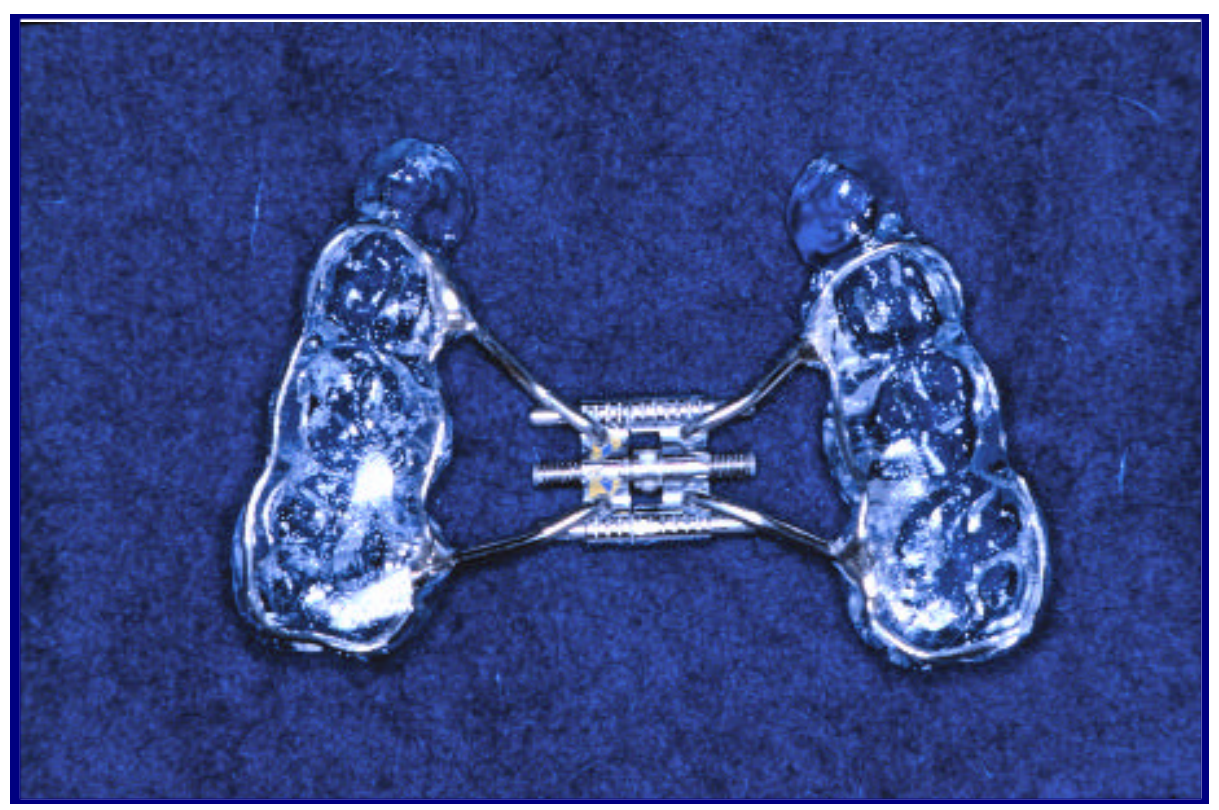

FIGURA 4.3 - Aparelho de expansão maxilar Colado. 
Para a confecção dos aparelhos dos grupos II e III, (tipo Haas e Hyrax), os alunos do curso de especialização realizaram as bandagens dos primeiros molares permanentes e dos pré-molares, devidamente adaptados, com a soldagem de acessórios ortodônticos na superfície vestibular das bandas, propiciando um melhor posicionamento na transferência das mesmas, para o molde de alginato. As bandas foram fixadas à moldagem com segmentos de fio e então vazadas com gesso comum, para não haver deslocamento.

Os aparelhos foram construídos no laboratório de prótese da disciplina de Ortodontia, da Faculdade de Odontologia de Bauru, utilizando parafusos expansores importados (DENTAURUM 600-010), com capacidade para ativação máxima de $7 \mathrm{~mm}$. A união do parafuso expansor às bandas, na superfície palatina, foi feita de duas maneiras, de acordo com os tipos de aparelhos utilizados: dentomucossuportados e dentossuportados. Utilizaram-se fios redondos, de aço inoxidável, de 1,2 $\mathrm{mm}$ de diâmetro, soldados às bandas com solda de prata, nos dois tipos de aparelhos expansores. Nos aparelhos com suporte dentomucossuportado, o parafuso expansor foi unido aos fios redondos por um corpo de resina acrílica, adaptado ao palato, proporcionando o apoio mucoso. No segundo tipo de aparelho, o parafuso foi diretamente adaptado pelo protético e soldado nos fios redondos (Figuras 4.4 e 4.5). 


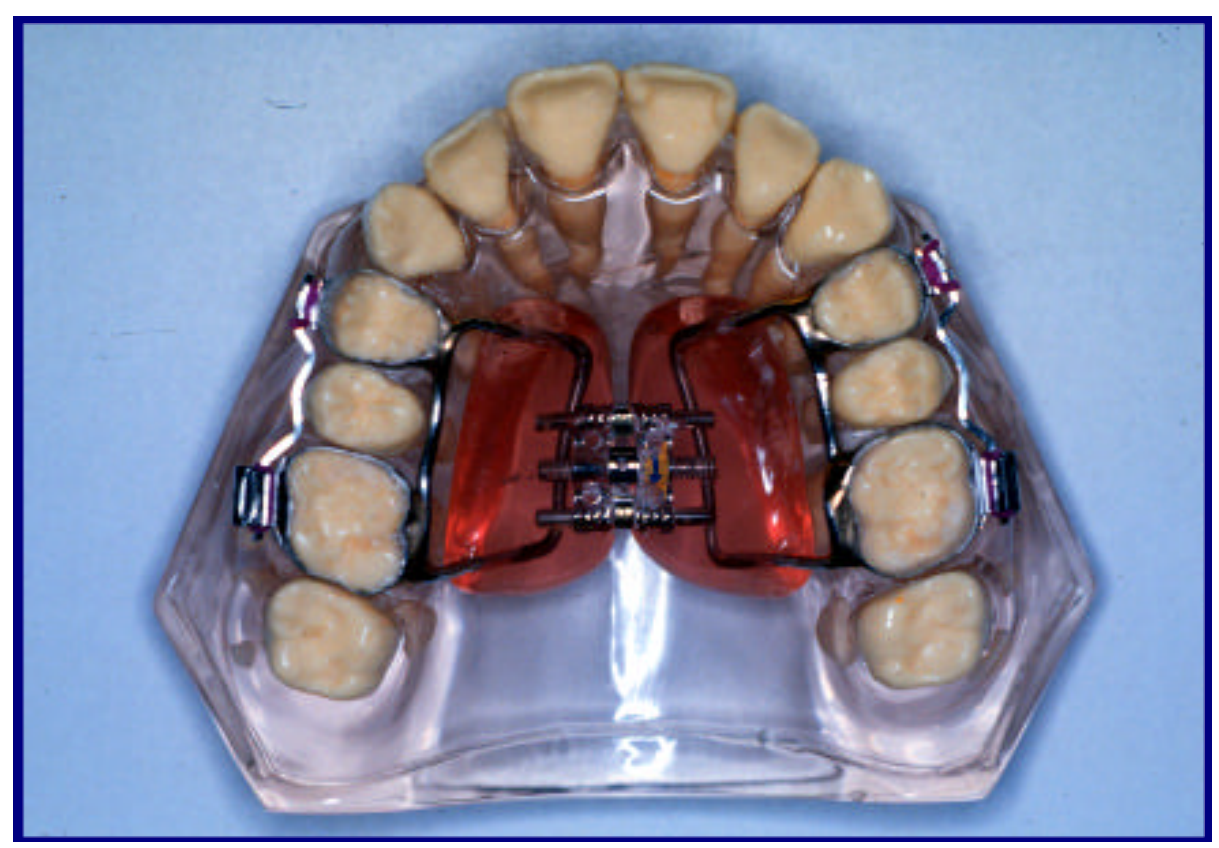

FIGURA 4.4 - Aparelho de expansão maxilar do tipo Haas.

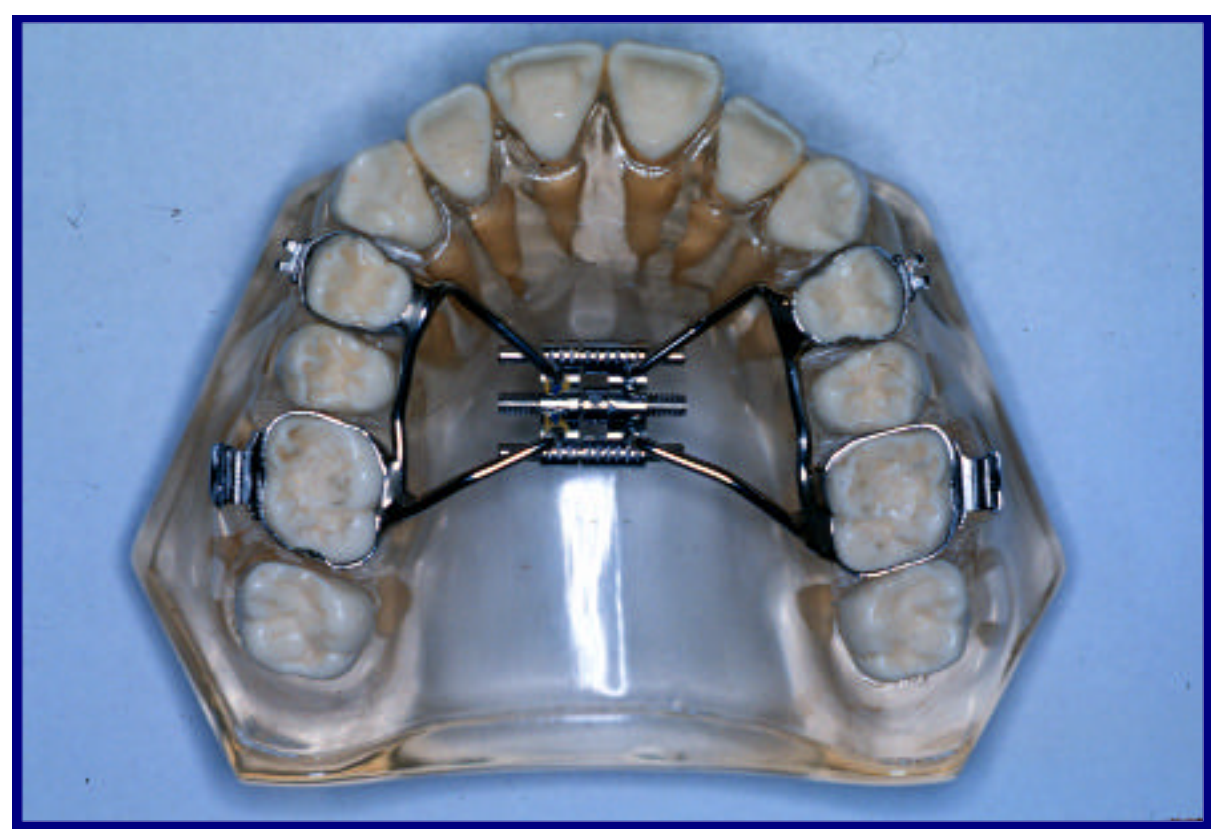

FIGURA 4.5 - Aparelho de expansão maxilar Hyrax. 


\subsection{2 - INSTALAÇÃO DOS APARELHOS}

GRUPO I - A instalação do aparelho expansor Colado foi realizado da seguinte forma: antes da cimentação definitiva, os aparelhos foram colocados em posição e com papel carbono, verificado possíveis contatos prematuros durante a oclusão e, se necessário, efetuar desgastes na porção acrílica oclusal do aparelho, com brocas de baixa rotação. Após a profilaxia com pedra pomes, água e uma taça de borracha para remover a camada gordurosa aderida à superfície de esmalte, fez-se o isolamento relativo, para manter a superfície seca. $\mathrm{O}$ cimento utilizado inicialmente foi $\mathrm{o}$ ionômero de vidro, autopolimerizável, Ketac Cem, que por apresentar baixa resistência durante as ativações, provocou a queda do aparelho em oito pacientes. A recimentação procedeu-se então com o cimento ionomérico Fuji ORTHO LC (GC Corporation, Tokio, Japan), mais resistente, manuseado e espatulado conforme as indicações do fabricante. Depois de pronto, foi passado, de maneira homogênea, no interior do aparelho e levado, à posição. Foi aplicado uma luz especial para favorecer sua polimerização, seguindo sempre as especificações do fabricante. Devese ressaltar que antes de levar o aparelho à posição, foi feito o condicionamento ácido nas superfícies vestibular e palatina dos dentes englobados pelo aparelho. O tempo do condicionamento do ácido fosfórico, a $37 \%$ foi de 60 segundos para os dentes permanentes e 120 s. para os dentes decíduos ${ }^{61}$.

GRUPOS II e III - Antes da cimentação definitiva, os aparelhos, foram levados à cavidade bucal em posição, para uma correta adaptação das bandas aos dentes de suporte e posteriormente cimentados com cimento fosfato de zinco ou ionômero de vidro. 


\subsection{3 - ATIVAÇÃO DOS APARELHOS}

GRUPO I - As ativações foram realizadas da seguinte maneira: após a instalação do aparelho, os pais e o paciente receberam orientações quanto aos cuidados e à correta higienização do mesmo. Foram dispensados e orientados a retornarem no dia seguinte para, após estarem mais adaptados ao aparelho, serem instruídos sobre as ativações. Os pais foram recomendados a ativar $4 / 4$ de volta por dia, ou seja, uma volta completa por dia, sendo $2 / 4$ pela manhã e $2 / 4$ à noite ${ }^{48}$. Os pacientes foram observados a cada três dias, para verificar a quantidade de ativações, sendo que estas só finalizaram após ter sido observada uma sobrecorreção dos dentes superiores aos inferiores.

Terminadas as ativações, os aparelhos foram estabilizados com fios de amarrilho, passando pelo parafuso e evitando, com isso, uma possível recidiva do parafuso. Os aparelhos permaneceram em posição por três meses, para, então, serem removidos (Figuras 4.6 e 4.7)

GRUPOS II e III - Nesses grupos, logo após a cimentação dos aparelhos, ativou-se o aparelho expansor em 2/4 de volta, sendo 1/4 realizada pelo profissional e 1/4 pelo acompanhante do paciente (pais ou responsáveis), supervisionado pelo aluno. Os mesmos foram orientados quanto à correta higienização, aos efeitos produzidos pelo aparelho, cuidados a serem tomados com o aparelho e a maneira correta de realizar as ativações. Padronizou-se as ativações, para todos os pacientes, em 2/4 de volta no parafuso pela manhã e $2 / 4$ à noite ${ }^{48}$, totalizando assim uma volta completa por dia, durante 8 a 9 dias, em média, para os dois grupos da amostra. 
Os pacientes desses grupos eram assistidos a cada 2 ou 3 dias, quando examinava-se a fixação do aparelho e a higienização bucal e mensurava-se a abertura do parafuso, com auxílio de um compasso de pontas secas e uma régua milimetrada. Esses controles foram realizados até o final da expansão desejada clinicamente, segundo o grau de atresia maxilar e, eventualmente, durante o período de contenção. A expansão lateral do arco superior foi considerada satisfatória somente após a obtenção dos contatos oclusais diretos, entre as pontas de cúspides palatinas nos dentes póstero-superiores, com as vestibulares dos pósteroinferiores. Após conseguida essa sobrecorreção, os próprio s aparelhos eram mantidos como contenção dos efeitos obtidos com a expansão rápida, por um período de três meses. 


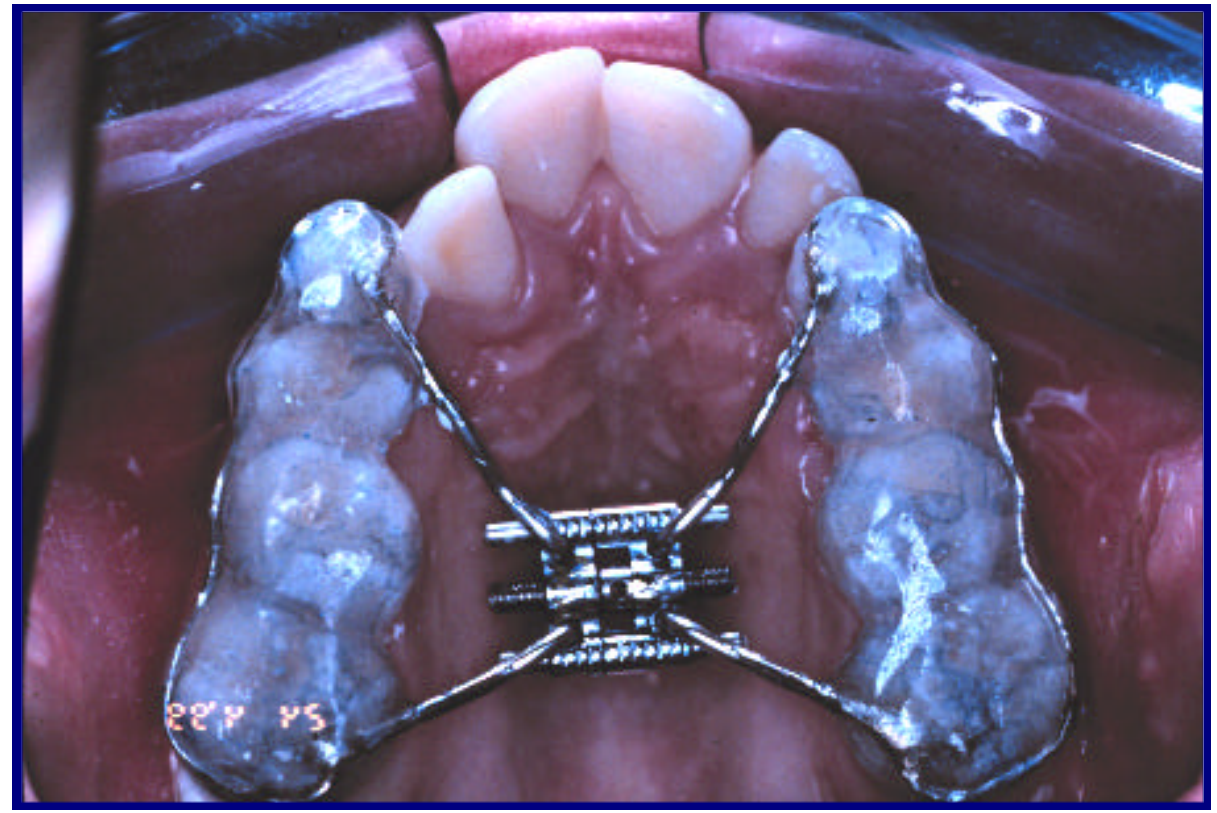

FIGURA 4.6 - Aparelho de expansão maxilar Colado (pré-expansão).

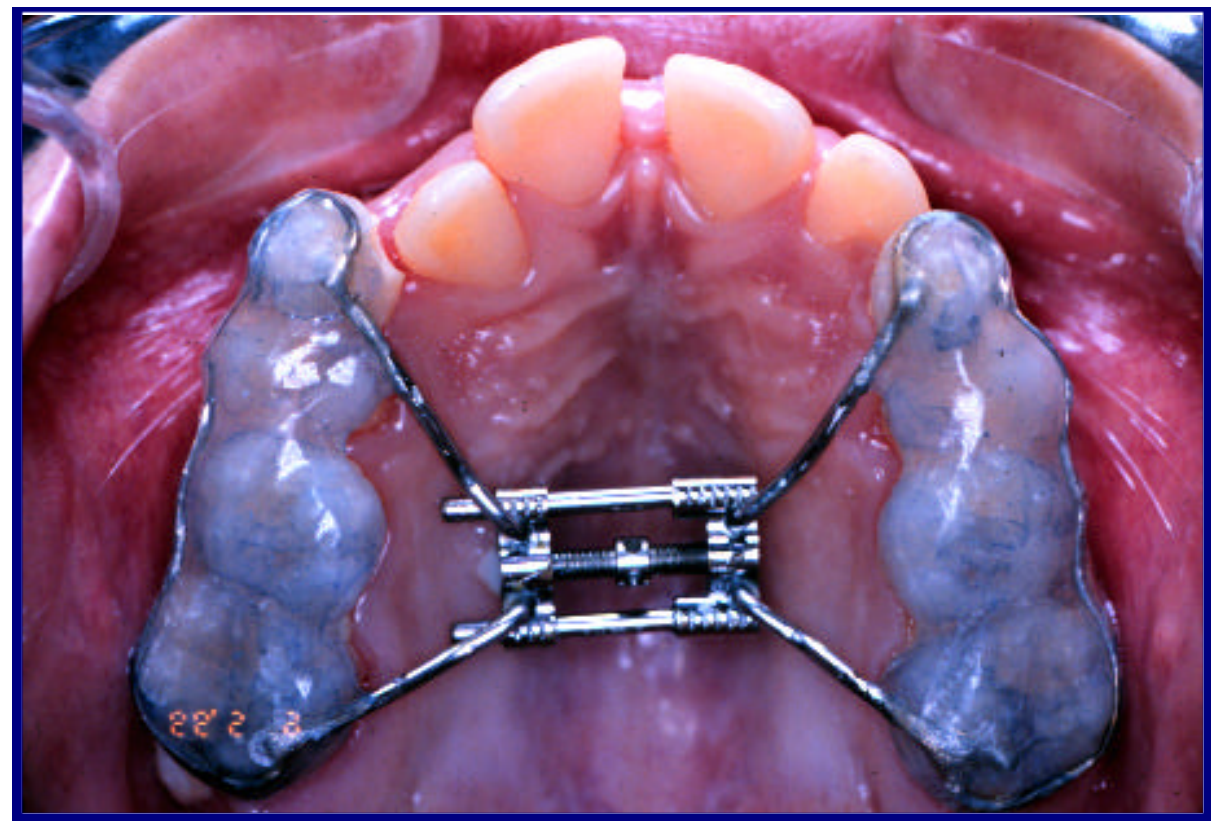

FIGURA 4.7 - Aparelho de expansão maxilar Colado (pós-expansão imediata). 


\subsection{4 - RADIOGRAFIAS CEFALOMÉTRICAS}

As telerradiografias utilizadas neste trabalho foram obtidas em norma lateral, seguindo os princípios recomendados pela Disciplina de Radiologia, da Faculdade de Odontologia de Bauru, da Universidade de São Paulo.

As tomadas radiográficas foram realizadas no Departamento de Radiologia, da Faculdade de Bauru, da Universidade de São Paulo, por um aparelho de Raios X da marca ROTOGRAPH PLUS, com fatores de exposição regulados para $80 \mathrm{KVp}$ e $10 \mathrm{~mA}$, durante 1,3 segundos, em média, a uma distância focal de 1,60m.

Para os grupos II e III, as radiografias foram realizadas em um aparelho de Raios X, da marca SIEMENS, modelo NANOBIL 2, regulado para uma exposição de $75 \mathrm{KV}$, $15 \mathrm{~mA}$, a uma distância focal de 1,56m. e duração média de 1,5 segundos.

Padronizou-se o posicionamento da cabeça, orientado pelo cefalostato, mantendo-se o plano sagital mediano do paciente perpendicular e o plano de Frankfürt, paralelo, ambos em relação ao solo.

As radiografias foram realizadas por um técnico em Radiologia, devidamente habilitado, para efeito de padronização. Os filmes utilizados para o grupo I foram da marca KODAK "T-MAT G/RA", de tamanho $20 \mathrm{~cm} \times 25 \mathrm{~cm}$, com a presença de ecrans intensificadores, da marca KODAK "LANEX REGULAR SCREENS" e para os grupos II e III utilizou-se filmes da marca KODAK 'X-OMAT XK1', sem ecrans intensificadores, de tamanho $18 \mathrm{~cm}$ x $24 \mathrm{~cm}$. 
Neste estudo é importante salientar que foi realizada correção de efeito de ampliação das imagens radiográficas obtidas para as mensurações lineares, nas medidas cefalométricas, padronizando as medidas.

Efetuou-se a correção em virtude do aparelho de Raios X utilizado no estudo apresentar um fator de ampliação de $9,2 \%{ }^{82}$, enquanto que para $\mathrm{O}$ trabalho previamente realizado, o fator de ampliação foi $6 \%^{7}$, de forma que se aplicou um índice de correção de X. 106/109,2, ou seja, o nosso resultado foi multiplicado por 106 e dividido por 109,2.

Essa correção foi empregada aos valores lineares, em milímetros, obtidos no estudo com o aparelho expansor Colado dentossuportado. 


\subsection{5 - ELABORAÇÃO DO CEFALOGRAMA}

\subsubsection{1 - MATERIAL}

O material utilizado para a realização do traçado anatômico e demarcação dos pontos cefalométricos, assim como para posterior conferência dos dados, constituiu-se de:

a) Negatoscópio, com fonte de luz constante (luz fluorescente);

b) Folha de papel acetato "ultraphan" transparente, com 0,07mm de espessura e dimensões de $17,5 \mathrm{~cm}$ x 17,5cm;

c) Lapiseira, com grafite de ponta fina $(0,5 \mathrm{~mm})$;

d) Régua milimetrada;

e) Esquadro;

f) Gabarito ("template");

g) Fita adesiva;

h) Borracha macia. 


\subsubsection{2. - DESENHO ANATÔMICO}

Sobre as telerradiografias previamente obtidas, foi fixada uma folha de papel "ultraphan" com fita adesiva e, em seguida, traçou-se o desenho anatômico, manualmente, sobre o negatoscópio, em uma sala obscurecida, para uma melhor evidenciação e exatidão das estruturas anátomoradiológicas de interesse. Após a realização do desenho anatômico, digitalizaram-se os pontos cefalométricos para a obtenção das grandezas cefalométricas lineares e angulares, medidas em décimos de milímetros e décimos de graus, respectivamente, com o auxílio de um sistema de microcomputador Pentium $166 \mathrm{MHz}$ e uma mesa digitalizadora "Numonics Accugrid ", modelo A30TL.F. O programa utilizado foi o "Dentofacial Planner 7.01 Plus”, da “Dentofacial Software Inc.”, Toronto - Canadá. 


\subsubsection{3 - DELIMITAÇÃO DAS ESTRUTURAS DENTO- ESQUELÉTICAS E DO PERFIL MOLE}

(Figura 4.8)

O desenho anatômico contou com os seguintes detalhes:

a) Perfil tegumentar, iniciando na região do osso frontal e prolongando-se até a região mandibular, completando o contorno do mento;

b) Perfil anterior dos ossos frontal e nasais;

c) Média dos limites inferiores das cavidades orbitárias;

d) Meato acústico externo;

e) Sela túrcica, nos seus limites anterior, posterior e inferior;

f) Porção póstero-inferior do clívus do osso esfenóide;

g) Maxila, compreendida desde a porção da pré-maxila até a parte cervical da crista alveolar por vestibular dos incisivos superiores (próstio), assoalho da fossa nasal, da espinha nasal anterior até a espinha nasal posterior e processos palatinos da maxila (palato ósseo);

h) Mandíbula, desde a sínfise mentoniana, em seus contornos vestibular e lingual, passando pela imagem radiográfica média das bordas inferiores do corpo e dos ramos ascendentes da mandíbula até próximo ao processo condilar (cabeça da mandíbula);

i) Dentes permanentes: primeiros molares e incisivos centrais superior e inferior. 
M aterial e M étodos 82

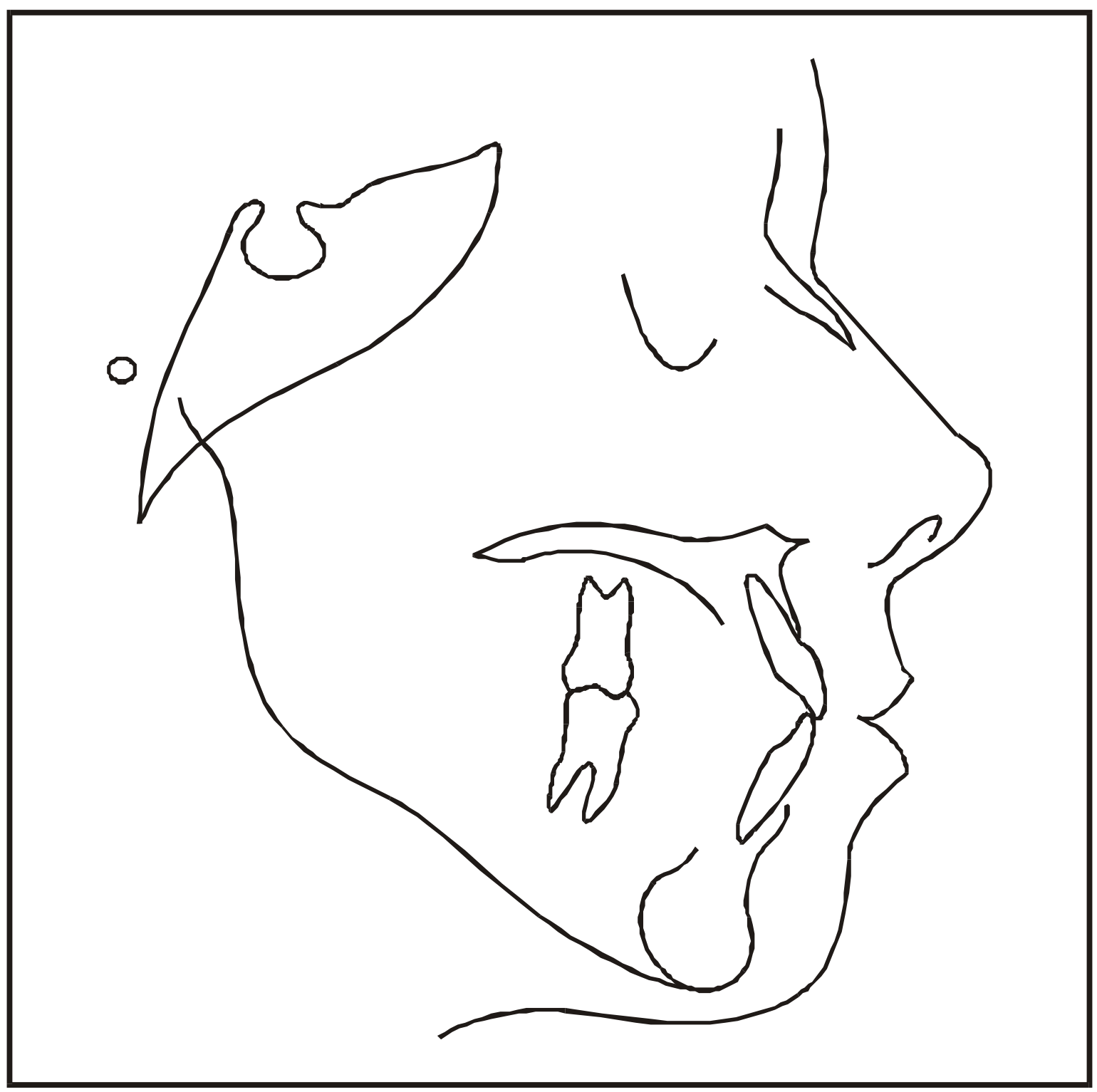

FIGURA 4.8 - Desenho anatômico. 


\subsubsection{4 - DEMARCAÇÃO DOS PONTOS CEFALOMÉTRICOS DE REFERÊNCIA}

(Figura 4.9)

Os pontos foram demarcados de acordo com KROGMAN; SASSOUNI $^{53}$, MCNAMARA JUNIOR ${ }^{60}$ e SCHEIDEMAN et al. ${ }^{80}$.

Sela (S): ponto médio, localizado no centro do contorno interno da sela túrcica (osso esfenóide);

Násio (N): ponto mais anterior da sutura frontonasal;

Pório (Po): localizado na porção mais superior do meato acústico externo;

Orbitário (Or): ponto mais inferior da margem infra-orbitária;

Articular (Ar): localizado na intersecção da superfície inferior da base do crânio e a média das superfícies posteriores do côndilo mandibular;

Espinha Nasal Posterior (ENP): ponto mais posterior, no plano sagital, dos ossos palatinos, no palato duro;

Espinha Nasal Anterior (ENA): ponto mais anterior do assoalho da fossa nasal;

Ápice do Molar Superior (Rㅡ): ponto localizado no ápice radicular mesiovestibular, do primeiro molar superior permanente;

Cúspide do Molar Superior (Cㅁ): ponto localizado na cúspide mesiovestibular, do primeiro molar superior permanente;

Subespinhal ou ponto A (A): ponto médio mais profundo, na concavidade maxilar anterior, entre a espinha nasal anterior (ENA) e o próstio;

Supramentoniano ou ponto B (B): ponto mais posterior da superfície da sínfise mentoniana, localizado entre o infradentário e o pogônio; 
Pogônio (Pog): ponto mais anterior do contorno do mento ósseo, determinado por uma tangente, passando pelo násio $(\mathrm{N})$;

Mentoniano (Me): ponto mais inferior da sínfise mentoniana;

Gônio (Go): ponto mais inferior e posterior na região goníaca, no ângulo da mandíbula, determinado pela bissetriz do ângulo formado pelas tangentes às bordas posterior (ramo ascendente) e inferior (corpo) da mandíbula;

Gnátio (Gn): ponto mais anterior e inferior do mento ósseo, determinado por uma bissetriz do ângulo formado pelo plano mandibular (GoMe) e a linha facial (Npog);

Subnasal ( $\mathrm{Sn})$ : ponto localizado na confluência entre a margem inferior da columela do nariz e o lábio superior;

Derivado do pronasal (Prn'): ponto mais proeminente, na margem inferior da columela nasal, localizado entre o pronasal e o subnasal ( $\mathrm{Sn}$ );

Labial Superior (Ls): ponto mais anterior do lábio superior, no encontro do vermelhão e a pele do lábio superior. 


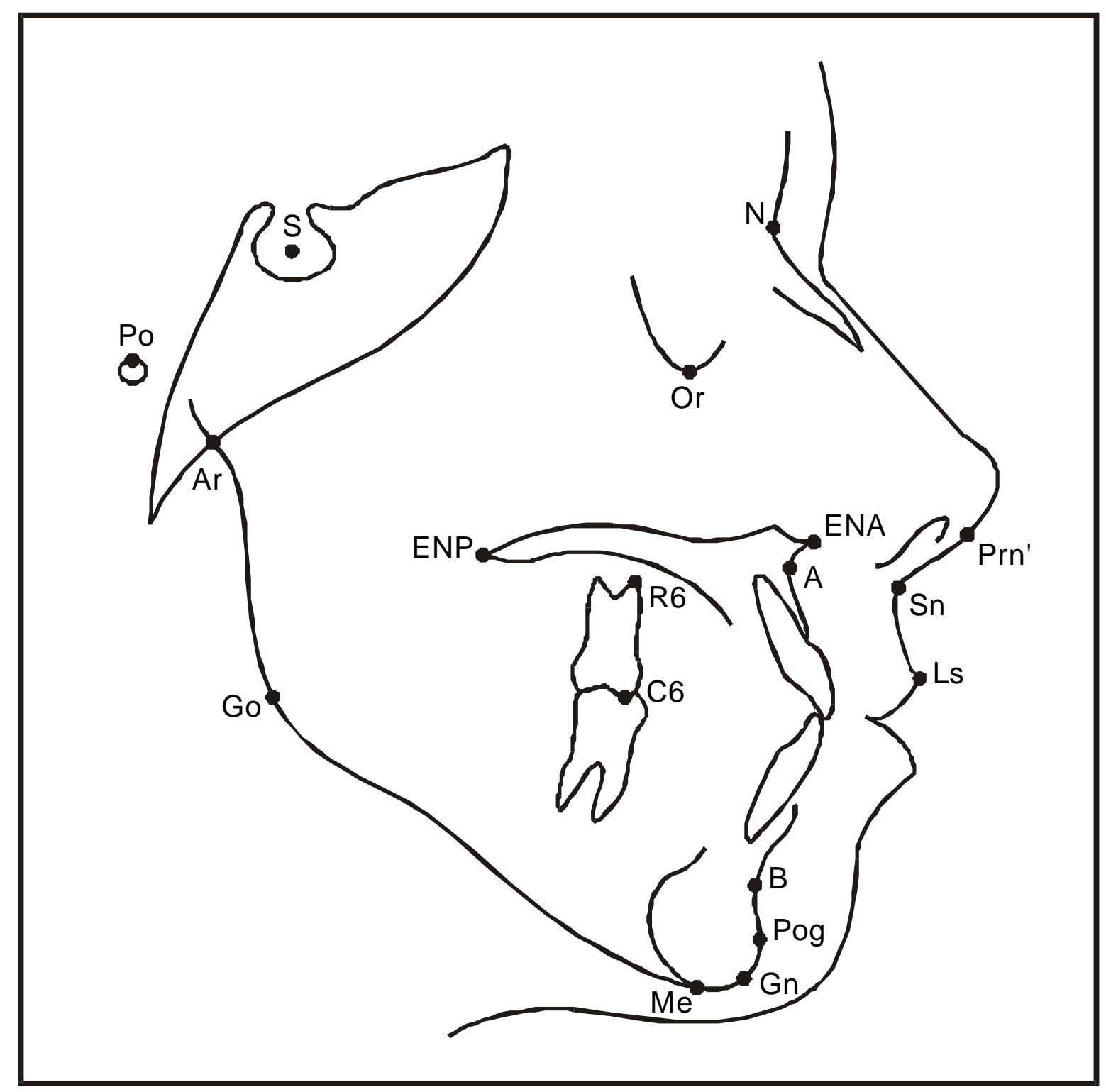

FIGURA 4.9 - Pontos cefalométricos. 


\subsubsection{5 - TRAÇADO DAS LINHAS E DOS PLANOS DE ORIENTAÇÃO}

(Figura 4.10)

(1) Linha $\mathrm{SN}$ - linha que passa pelos pontos $\mathrm{S}$ (sela) e N (násio);

(2) Linha Sperp - linha perpendicular ao plano de Frankfürt (PoOr), passando pelo ponto $\mathrm{S}$ (sela);

(3) Linha SGn - linha determinada pelos pontos S (sela) e Gn (gnátio);

(4) Linha NB - linha que passa pelos pontos $\mathrm{N}$ (násio) e $\mathrm{B}$ (supramentoniano);

(5) Linha Npog - linha que passa pelos pontos N (násio) e Pog (pogônio);

(6) Linha Nperp - linha perpendicular ao plano de Frankfürt (PoOr), passando pelo ponto $\mathrm{N}$ (násio);

(7) Linha NA - linha que passa pelos pontos $\mathrm{N}$ (násio) e $\mathrm{A}$ (subespinhal);

(8) Linha NENA - linha determinada pelos pontos N (násio) e ENA (espinha nasal anterior);

(9) Linha Apog - linha que passa pelos pontos A (subespinhal) e Pog (pogônio);

(10) Linha Prn'Sn - linha que passa pelos pontos Prn' (derivado do pronasal) e Sn (subnasal);

(11) Linha SnLs - linha que passa pelos pontos Sn (subnasal) e Ls (labial superior);

(12) Plano de Frankfürt - plano determinado pelos pontos Po (pório) e Or (orbitário);

(13) Plano palatino (PP) - plano determinado pelos pontos ENA (espinha nasal anterior) e ENP (espinha nasal posterior); 
(14) Plano mandibular - formado pelos pontos Go (gônio) e Me (mentoniano).

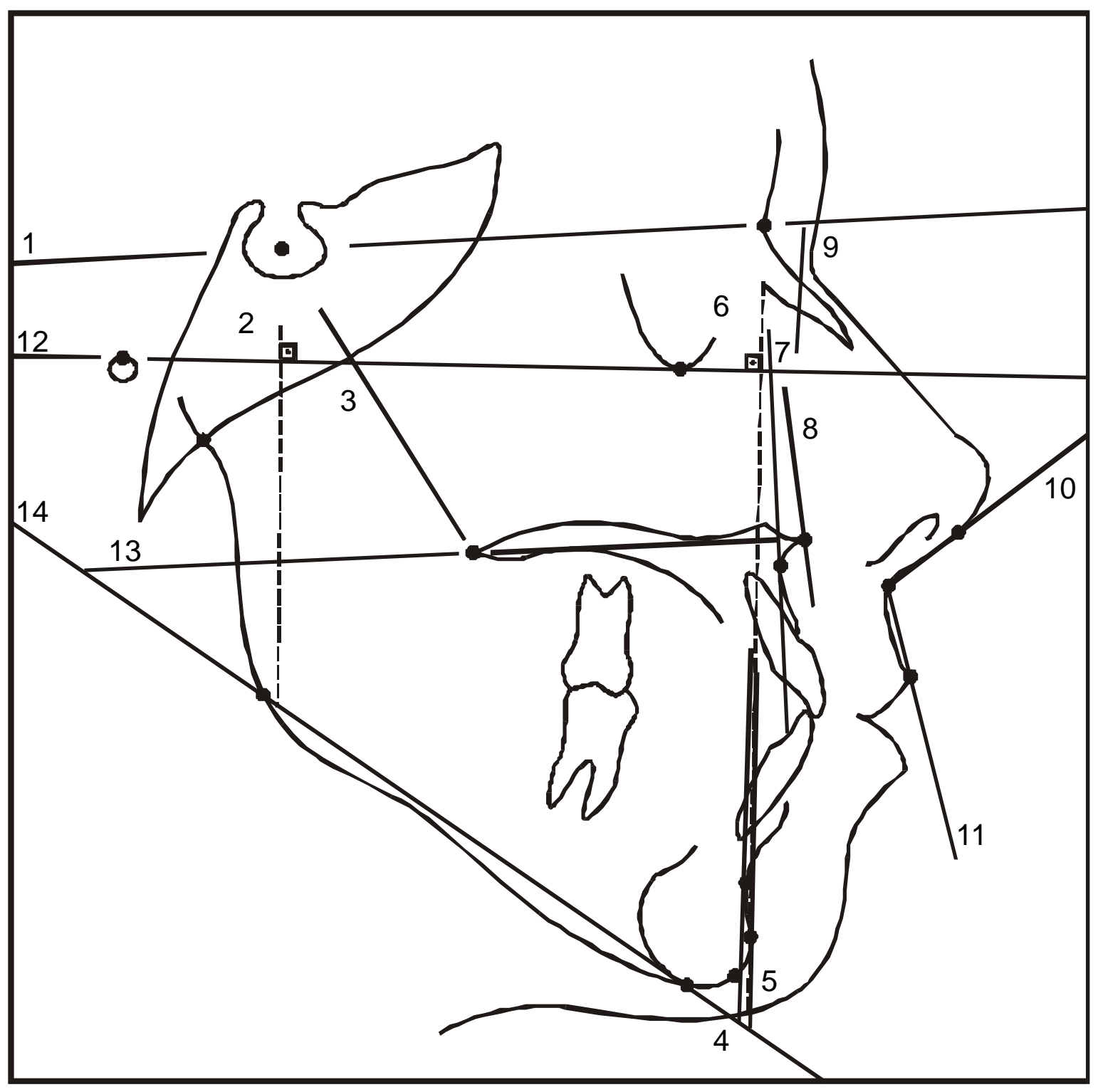

FIGURA 4.10 - Traçados de orientação.
(1) Linha SN
(2) Linha Sperp
(6) Linha Nperp
(7) Linha NA
(3) Linha SGn
(8) Linha NENA
(4) Linha NB
(9) Linha Apog
(5) Linha Npog
(10) Linha Prn'Sn

(11) Linha SnLs

(12) Plano de Frankfürt

(13) Plano Palatino

(14) Plano Mandibular 


\subsubsection{6 - OBTENÇÃO DAS GRANDEZAS ANGULARES E LINEARES}

\subsubsection{1 - GRANDEZAS ANGULARES}

\section{(FIGURAS 4.11, 4.12 e 4.13)}

(1) SNA: ângulo formado pelas linhas SN e NA;

(2) SN.ENA: ângulo formado pelas linhas SN e NENA:

(3) SNB: ângulo formado pelas linhas SN e NB;

(4) ANB: ângulo formado pelas linhas NA e NB, correspondendo à diferença entre os ângulos SNA e SNB;

(5) NAP: suplemento do ângulo formado pelas linhas NA e Apog;

(6) SN.Gn: eixo "Y" de crescimento, ângulo formado pela linha $\mathrm{SN}$ e a linha SGn;

(7) PoOr.PP: ângulo formado pelo plano de Frankfürt e o plano palatino;

(8) SN.GoMe: ângulo formado pelas linhas $\mathrm{SN}$ e o plano mandibular;

(9) FMA (PoOr.GoMe): ângulo formado pelo plano de Frankfürt e o plano mandibular;

(10) ÂBI (PP.GoMe): ângulo básio inferior, formado pelos planos palatinos e mandibular;

(11) ANL (Prn'SnLs): ângulo formado por duas semi-retas que passam pelos pontos derivados do pronasal (Prn') e labial superior (Ls), tendo como ponto comum o subnasal (Sn). 


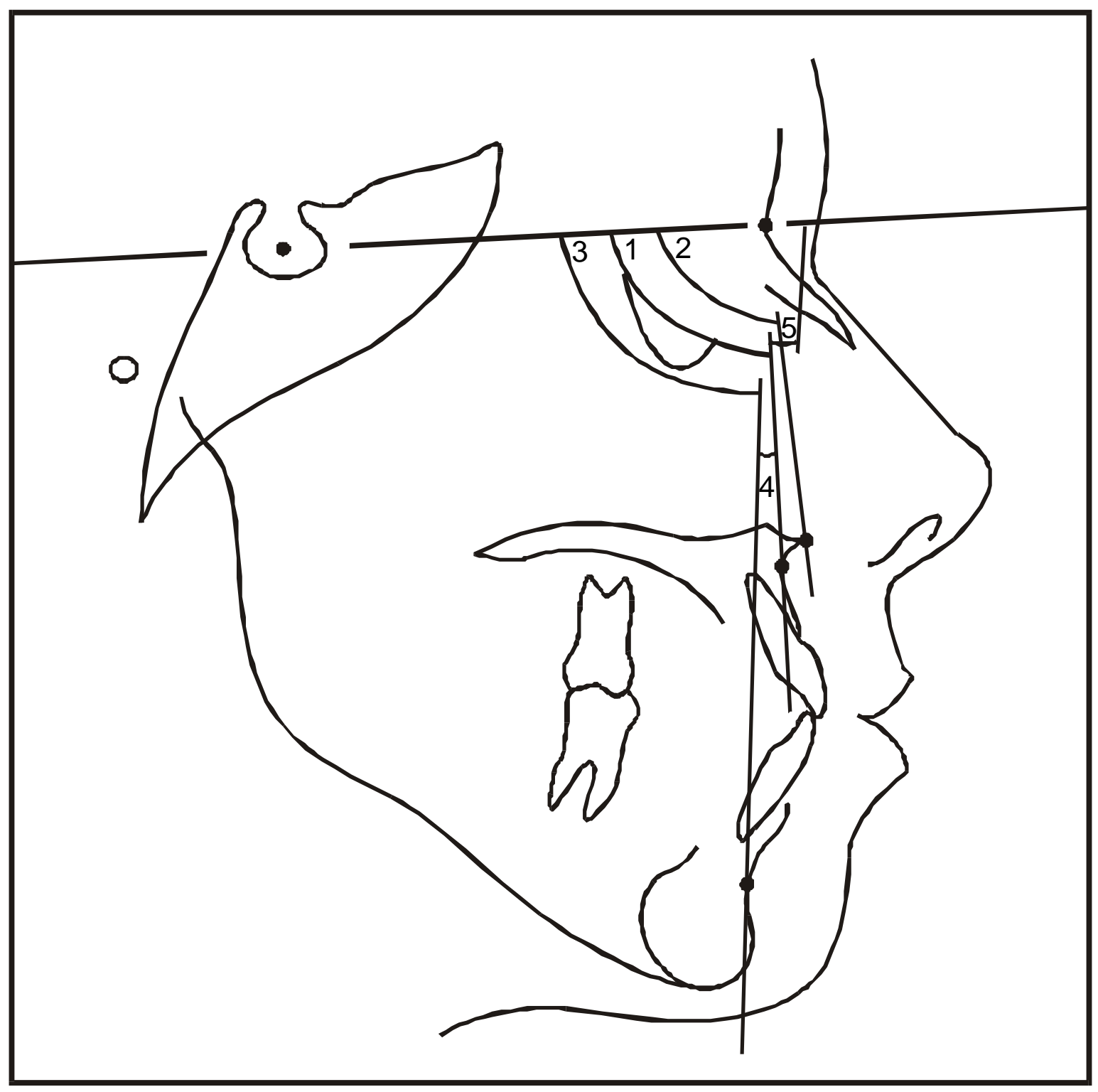

FIGURA 4.11 - Grandezas angulares.
(1) SNA
(2) SN.ENA
(3) SNB
(4) ANB
(5) NAP 


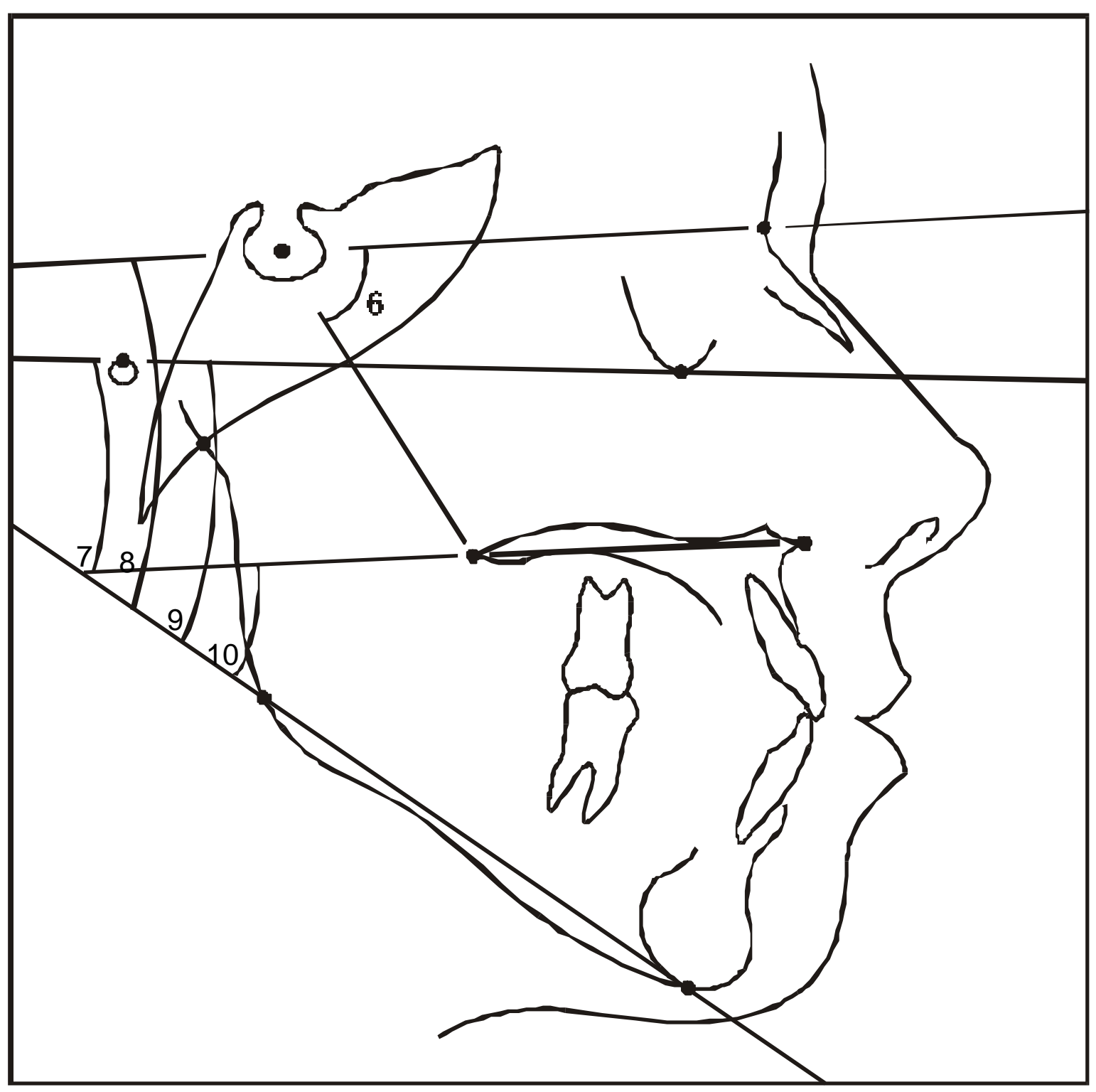

FIGURA 4.12 - Grandezas angulares.
(6) SN.Gn
(7) PoOr.PP
(8) SN.GoMe
(9) FMA (PoOr.GoMe)
(10) ÂBI (PP.GoMe) 
M aterial e M étodos 91

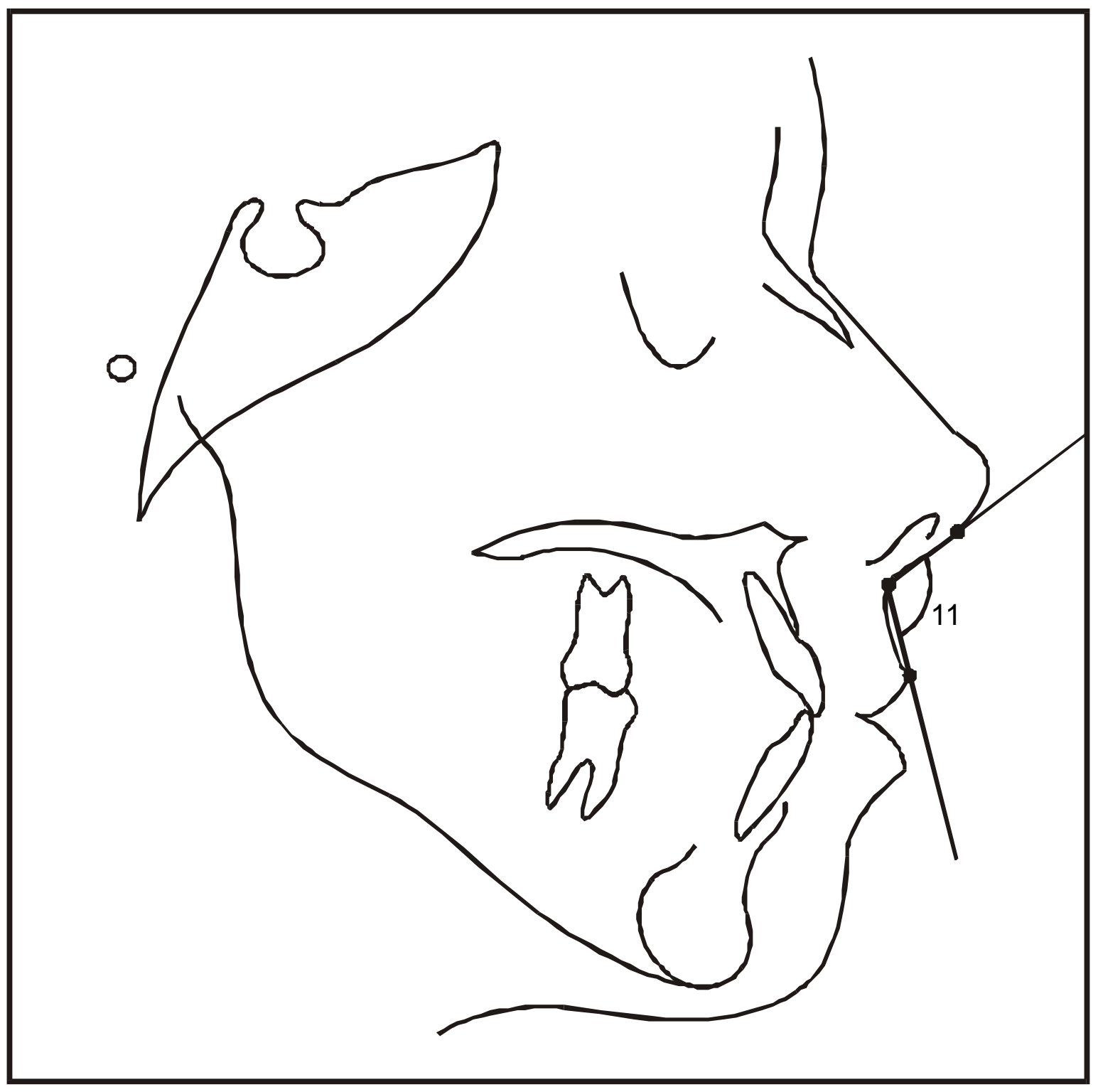

FIGURA 4.13 - Grandeza angular.

(11) ÂNL (Prn'SnLs) 


\subsubsection{2 - GRANDEZAS LINEARES}

(Figuras 4.14, 4.15 e 4.16)

(I) N-ENA: distância entre os pontos N (násio) e ENA (espinha nasal anterior);

(II) ENA-PoOr: menor distância entre o ponto ENA (espinha nasal anterior) e o plano de Frankfürt;

(III) ENP-PoOr: menor distância entre o ponto ENP (espinha nasal posterior) e o plano de Frankfürt;

(IV) Sperp-A: menor distância entre a linha Sperp e o ponto A (subespinhal);

(V) Nperp-A: menor distância entre a linha Nperp e o ponto A (subespinhal);

(VI) Nperp-Pog: menor distância entre a linha Nperp e o ponto Pog (pogônio);

(VII) Ar-A: distância entre os pontos Ar (articular) e A (subespinhal);

(VIII) Ar-Gn: distância entre os pontos Ar (articular) e Gn (gnátio);

(IX) ENA-Me: distância entre os pontos ENA (espinha nasal anterior) e Me (mentoniano), correspondente à altura facial ântero-inferior (AFAI);

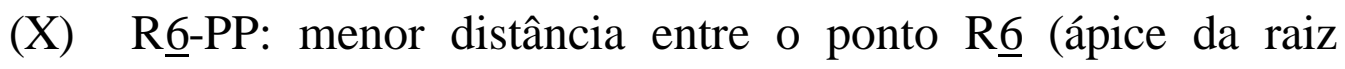
mesiovestibular do primeiro molar superior permanente) e o plano palatino;

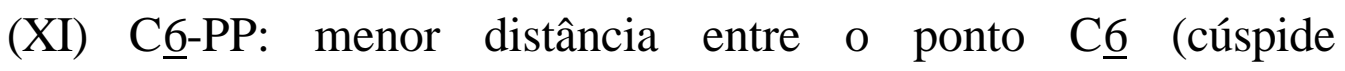
mesiovestibular) e o plano palatino;

(XII) Sperp-Rㅁ: menor distância entre a linha Sperp e o ponto R $\underline{6}$ (ápice da raiz mesiovestibular do primeiro molar superior permanente); 
(XIII) Sperp-Cㅁ: menor distância entre a linha Sperp e o ponto C $\underline{6}$ (cúspide mesiovestibular do primeiro molar superior permanente).

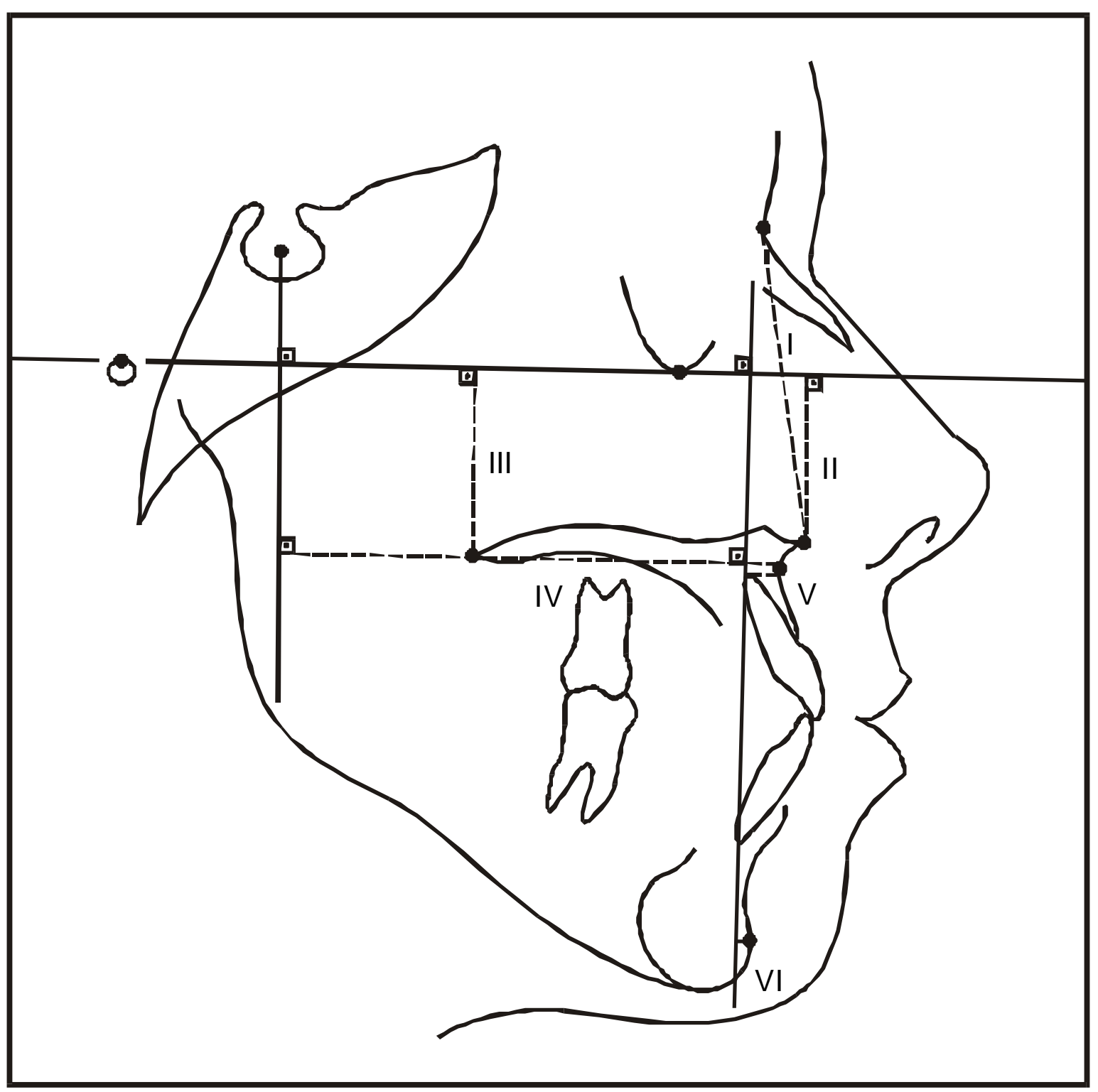

FIGURA 4.14 - Grandezas lineares.
(I) N-ENA
(II) ENA-PoOr
(IV) Sperp-A
(III) ENP-PoOr
(V) Nperp-A
(VI) Nperp-Pog 


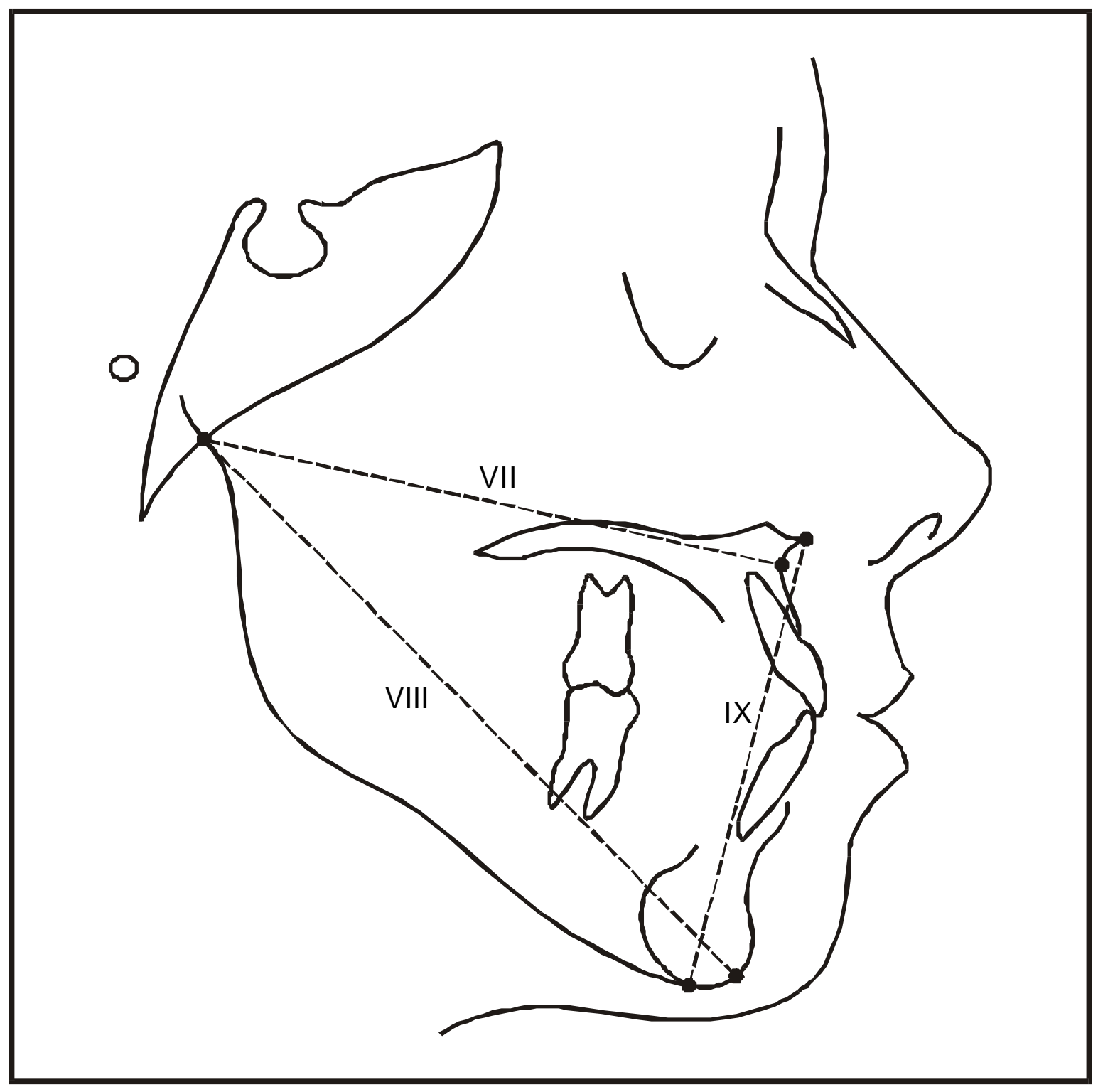

FIGURA 4.15 - Grandezas lineares.

(VII) Ar-A

(VIII) Ar-Gn

(IX) ENA-Me 
M aterial e M ćtodos

95

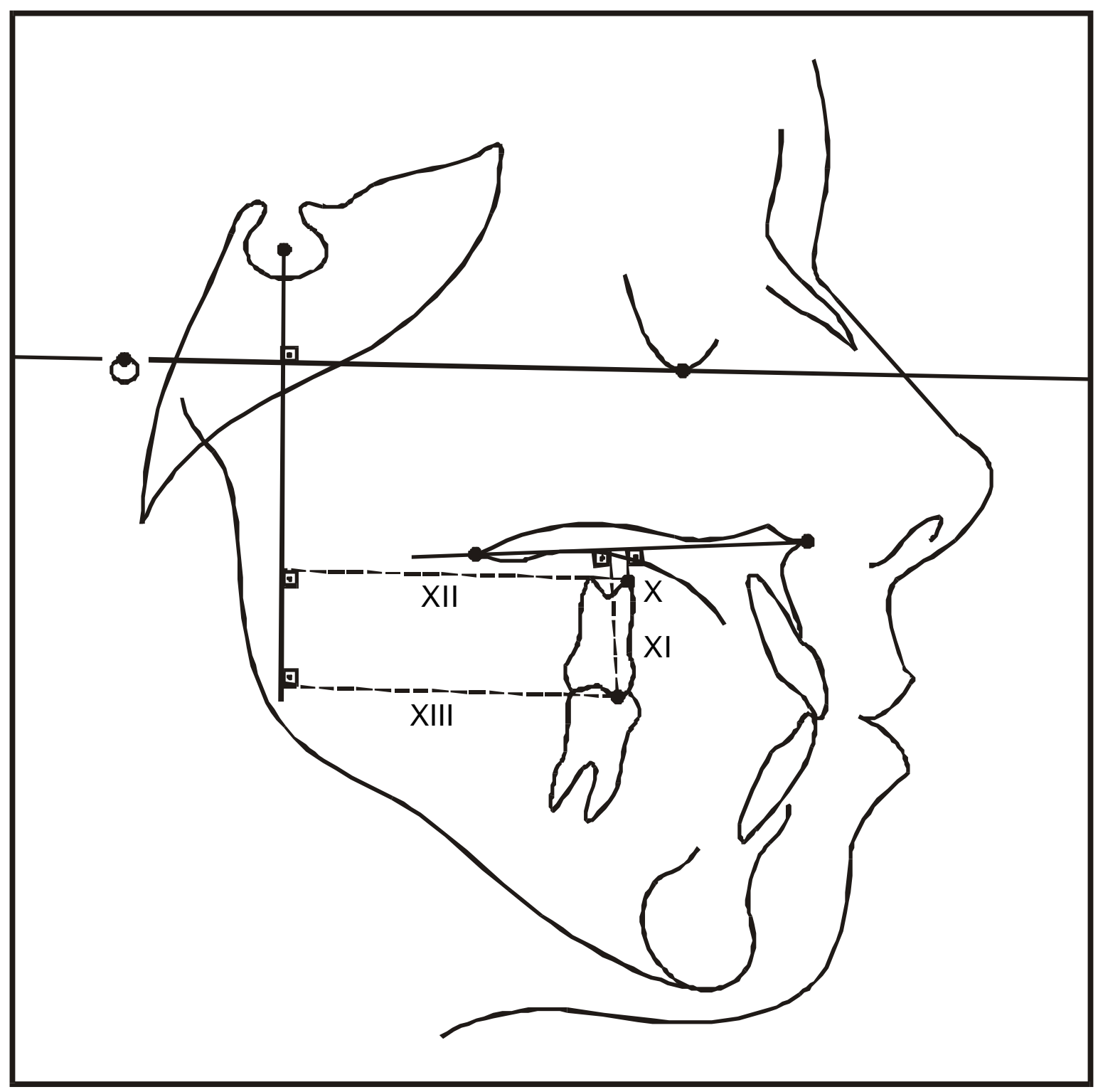

FIGURA 4.16 - Grandezas lineares.

(X) Rㅁ-PP

(XI) Cㅁ-PP

(XII) Sperp-R $\underline{6}$

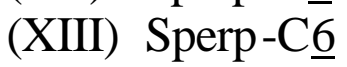




\subsection{6 - ANÁLISE ESTATÍSTICA*}

Os dados obtidos pelo Dentofacial Planner 7.01** foram transferidos para o editor de planilhas (Excel versão 97)***, onde foram organizados, preparados e, posteriormente, transferidos para o aplicativo que realizaria a análise estatística.

\subsubsection{1 - MÉTODO ESTATÍSTICO}

Utilizou-se o aplicativo Statistica for Windows, versão 5.1****, para a realização da análise, baseada nos seguintes critérios:

a) Estatística descritiva: médias, desvios padrão, valor máximo e valor mínimo para todos os grupos.

b) Teste “t”" de Student pareado (variáveis dependentes): teste utilizado na comparação entre as fases pré-expansão, pósexpansão e pós-contenção para todos os grupos.

c) Análise de variância (ANOVA): análise de variância a um critério (uma variável independente), com múltiplas variáveis dependentes e um modelo fixo. Utilizada na comparação intergrupos apresenta-se como o teste mais indicado para amostras paramétricas, independentes e tomadas em tempos distintos.

* Orientação e resultados estatísticos fornecidos pelo Prof. Dr. José Roberto Pereira Lauris, do Departamento de Odontopediatria, Ortodontia e Saúde Coletiva da Faculdade de Odontologia de Bauru - Universidade de São Paulo.

** Dentofacial Software, Inc.

*** Microsoft Co.

$* * * *$ Statsoft, Inc. 
d) Teste de Tukey: teste de comparação múltipla, utilizado para a determinação dos tempos ou grupos que demonstram as diferenças estatísticas, indicadas pela análise de variância.

\subsubsection{2 - ERRO DO MÉTODO}

Para a obtenção do erro do método, foram retraçadas e redigitalizadas novamente as radiografias de cinco pacientes do Grupo I (aparelho Colado), selecionados aleatoriamente, após um intervalo mínimo de um mês. Utilizaram-se as radiografias nos três tempos (pré-expansão, pós-expansão e pós-contenção), totalizando 15 radiografias. Aplicou-se o teste " $\mathrm{t}$ " pareado (variáveis dependentes), para a verificação do erro sistemático e a fórmula de DAHLBERG ${ }^{28}$, para estimar a ordem de grandeza dos erros casuais.

Fórmula de DAHLBERG: $\mathrm{Se}^{2}=\frac{\Sigma \mathrm{d}^{2}}{2 \mathrm{n}}$

\subsubsection{3 - ANÁLISE INTEREXAMINADOR}

Para a análise interexaminador foram retraçadas e redigitalizadas $10 \%$ das radiografias utilizadas por KAWAKAMI ${ }^{48}$. Aplicou-se o teste " $\mathrm{t}$ " pareado (variáveis dependentes) para verificar a precisão entre os examinadores. 
5

RESULTADOS 


\section{5 - RESULTADOS}

Os valores encontrados nas mensurações de cada variável cefalométrica, médias (X) e desvios padrão (d.p.), e os testes estatísticos encontram-se dispostos conforme as tabelas a seguir, para o grupos I (aparelhos expansores dentossuportados Colado), II (aparelhos expansores dentomucossuportados do tipo Haas) e III (aparelhos dentossuportados Hyrax), nas fases pré-expansão (1), pós-expansão (2) e pós-contenção (3).

As Tabelas 5.1, 5.2 e 5.3 apresentam as médias e os desvios padrão das medidas cefalométricas analisadas nos três grupos, nas fases préexpansão, pós-expansão e pós-contenção.

As Tabelas de 5.4 a 5.12 apresentam as médias, os desvios padrão e as médias das diferenças entre as fases analisadas, para os três grupos, assim como a significância estatística.

As Tabelas 5.13, 5.14 e 5.15 apresentam as médias, desvios padrão das diferenças das medidas cefalométricas entre as fases avaliadas, o valor de "F" (utilizado para o cálculo estatístico), de "p" (nível de significância) e também a significância estatística da análise de variância (ANOVA) aplicada na avaliação entre os três grupos estudados.

As Tabelas 5.16, 5.17 e 5.18 apresentam os resultados do Teste de Tukey, para as fases e grupos que demonstram diferenças estatísticas pela análise de variância (ANOVA). 
A Tabelas 5.19 demonstra a análise intra-examinador da precisão do método, através da apresentação dos erros casuais (Dahlberg), nas três fases estudadas, para o grupo I (Colado).

A Tabela 5.20 apresenta a análise intra-examinador da precisão do método, através dos valores iniciais e repetidos após um intervalo mínimo de um mês (médias e desvios padrão), diferença das médias, valor de "t", de "p" e a significância estatística dos erros sistemáticos do grupo I (Colado).

A Tabela 5.21 apresenta a análise interexaminador da precisão do método, através dos valores das médias (X) e desvios padrão (d.p.) obtidos por KAWAKAMI ${ }^{48}$ e pelo autor, diferença das médias, valor " $t$ ", de "p" e significância estatística.

No apêndice, encontram-se os valores individualizados das medidas cefalométricas de cada paciente. 
TABELA 5.1 - Médias $(\overline{\mathrm{X}})$ e desvios padrão (d.p.) das medidas cefalométricas analisadas no grupo I (aparelhos dentossuportados - Colado), nas fases 1 (pré-expansão), 2 (pós-expansão) e 3 (pós-contenção).

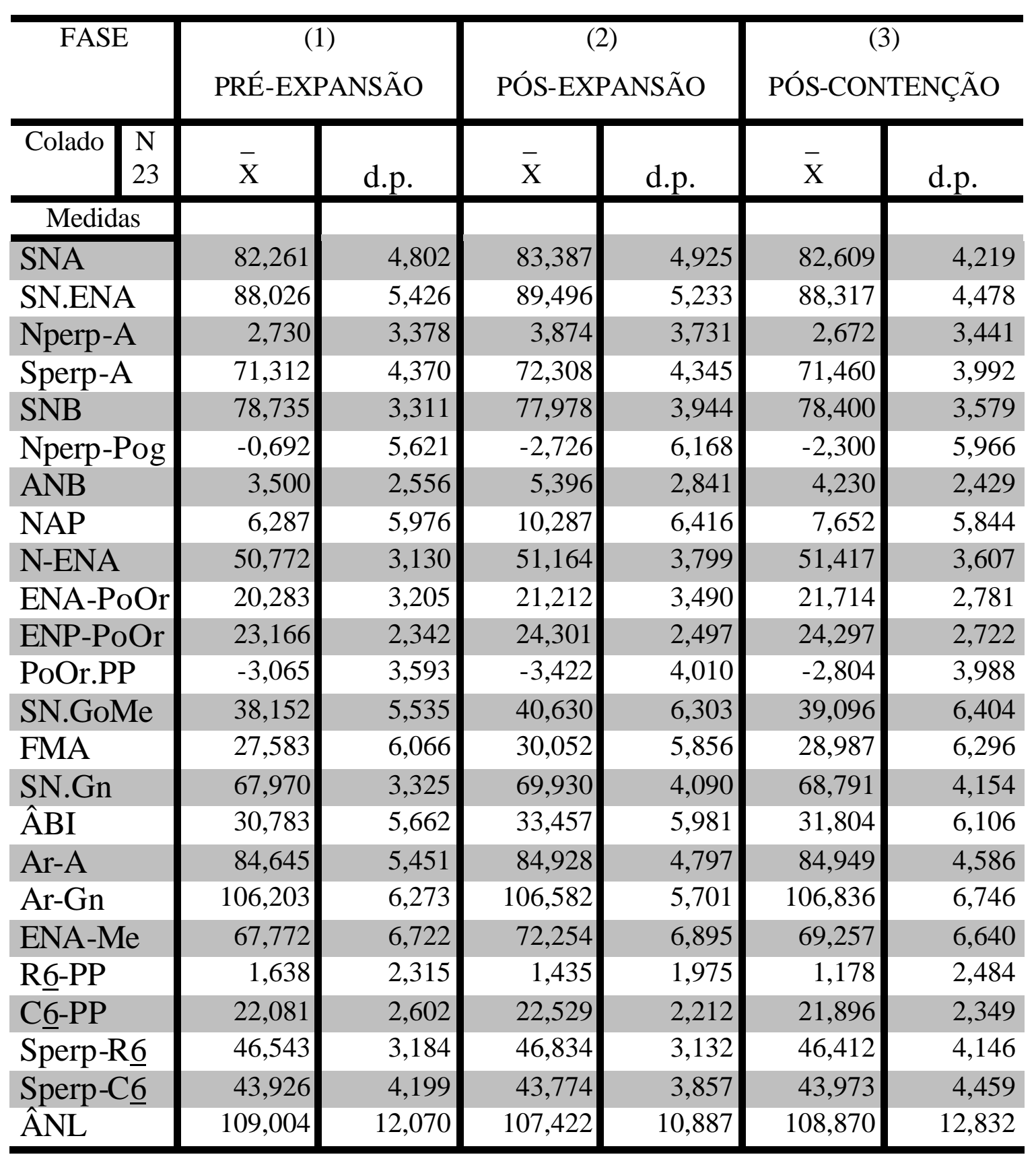


TABELA 5.2 - Médias (X) e desvios padrão (d.p.) das medidas cefalométricas analisadas no grupo II (aparelhos dentomucossuportados - tipo Haas), nas fases 1 (préexpansão), 2 (pós expansão) e 3 (pós contenção).

\begin{tabular}{|c|c|c|c|c|c|c|}
\hline FASE & \multicolumn{2}{|c|}{$\begin{array}{c}(1) \\
\text { PRÉ-EXPANSÃO }\end{array}$} & \multicolumn{2}{|c|}{$\begin{array}{c}(2) \\
\text { PÓS-EXPANSÃO }\end{array}$} & \multicolumn{2}{|c|}{$\begin{array}{c}\text { (3) } \\
\text { PÓS-CONTENÇÃO }\end{array}$} \\
\hline \begin{tabular}{c|c} 
Tipo & $\mathrm{N}$ \\
Haas & 20 \\
\end{tabular} & $\bar{X}$ & d.p. & $\bar{X}$ & d.p. & $\bar{X}$ & d.p. \\
\hline \multicolumn{7}{|l|}{ Medidas } \\
\hline SNA & 80,830 & 3,385 & 81,240 & 3,453 & 80,805 & 3,639 \\
\hline SN.ENA & 84,830 & 3,989 & 85,105 & 3,834 & 84,965 & 4,255 \\
\hline Nperp-A & $-0,910$ & 3,028 & $-0,340$ & 2,982 & $-1,355$ & 3,446 \\
\hline Sperp-A & 68,560 & 3,623 & 69,135 & 3,989 & 68,485 & 3,519 \\
\hline SNB & 77,815 & 3,170 & 76,795 & 2,777 & 77,540 & 3,176 \\
\hline Nperp-Pog & $-6,025$ & 5,991 & $-8,225$ & 5,687 & $-7,615$ & 6,393 \\
\hline $\mathrm{ANB}$ & 3,005 & 2,445 & 4,450 & 2,445 & 3,265 & 2,385 \\
\hline NAP & 4,445 & 5,615 & 7,655 & 5,559 & 5,205 & 5,628 \\
\hline N-ENA & 51,220 & 3,904 & 51,835 & 3,930 & 51,645 & 3,920 \\
\hline ENA-PoOr & 22,035 & 2,381 & 22,605 & 3,154 & 23,060 & 2,600 \\
\hline ENP-PoOr & 21,490 & 2,226 & 22,005 & 2,393 & 22,195 & 2,314 \\
\hline PoOr.PP & 0,560 & 2,651 & 0,640 & 2,696 & 0,885 & 2,104 \\
\hline SN.GoMe & 37,805 & 6,402 & 39,690 & 6,314 & 38,335 & 6,553 \\
\hline FMA & 29,565 & 5,067 & 31,295 & 5,657 & 30,470 & 5,592 \\
\hline SN.Gn & 69,015 & 3,719 & 70,655 & 3,664 & 69,555 & 3,876 \\
\hline$\hat{\mathrm{ABI}}$ & 29,000 & 5,421 & 30,655 & 5,770 & 29,565 & 5,815 \\
\hline $\mathrm{Ar}-\mathrm{A}$ & 84,705 & 3,915 & 85,525 & 4,102 & 85,270 & 3,662 \\
\hline Ar-Gn & 107,255 & 4,212 & 107,570 & 4,248 & 107,975 & 4,243 \\
\hline ENA-Me & 68,515 & 4,645 & 71,215 & 4,365 & 69,825 & 4,713 \\
\hline Rㅁ-PP & 4,050 & 2,345 & 3,705 & 1,801 & 3,870 & 2,824 \\
\hline Cㅁ-PP & 23,515 & 2,580 & 23,750 & 1,949 & 23,370 & 2,088 \\
\hline Sperp-R $\underline{6}$ & 44,035 & 3,602 & 44,380 & 3,634 & 44,080 & 3,307 \\
\hline Sperp-C $\underline{6}$ & 41,785 & 4,304 & 42,130 & 4,187 & 41,535 & 4,082 \\
\hline ÂNL & 94,740 & 12,862 & 93,935 & 8,435 & 96,890 & 11,095 \\
\hline
\end{tabular}


TABELA 5.3 - Médias (X) e desvios padrão (d.p.) das medidas cefalométricas analisadas no grupo III (aparelhos dentossuportados - Hyrax), nas fases 1 (pré-expansão), 2 (pós expansão) e 3 (pós contenção).

\begin{tabular}{|c|c|c|c|c|c|c|}
\hline FASE & \multicolumn{2}{|c|}{$\begin{array}{c}(1) \\
\text { PRÉ-EXPANSÃO }\end{array}$} & \multicolumn{2}{|c|}{$\begin{array}{c}(2) \\
\text { PÓS-EXPANSÃO }\end{array}$} & \multicolumn{2}{|c|}{$\begin{array}{c}\text { (3) } \\
\text { PÓS-CONTENÇÃO }\end{array}$} \\
\hline \begin{tabular}{l|l} 
Hyrax & N \\
& 21 \\
\end{tabular} & $\bar{X}$ & d.p. & $\overline{\mathrm{X}}$ & d.p. & $\overline{\mathrm{X}}$ & d.p. \\
\hline \multicolumn{7}{|l|}{ medidas } \\
\hline SNA & 81,257 & 2,972 & 81,919 & 3,474 & 81,591 & 3,579 \\
\hline SN.ENA & 85,800 & 3,995 & 86,233 & 4,196 & 85,948 & 4,070 \\
\hline Nperp-A & 0,233 & 2,380 & 0,267 & 3,032 & 0,219 & 2,898 \\
\hline Sperp-A & 68,105 & 4,169 & 68,205 & 4,533 & 68,514 & 4,874 \\
\hline SNB & 78,391 & 4,020 & 77,900 & 4,355 & 78,152 & 4,281 \\
\hline Nperp-Pog & $-3,338$ & 6,694 & $-5,667$ & 7,092 & $-4,705$ & 6,625 \\
\hline $\mathrm{ANB}$ & 2,862 & 3,037 & 4,024 & 2,657 & 3,467 & 2,878 \\
\hline NAP & 3,929 & 6,495 & 6,443 & 5,710 & 5,367 & 6,275 \\
\hline N-ENA & 49,981 & 3,164 & 50,267 & 3,155 & 50,657 & 2,844 \\
\hline ENA-PoOr & 21,105 & 3,520 & 21,957 & 3,698 & 22,033 & 3,411 \\
\hline ENP-PoOr & 22,257 & 2,155 & 22,962 & 2,070 & 23,114 & 2,117 \\
\hline PoOr.PP & $-1,286$ & 2,946 & $-1,138$ & 3,434 & $-1,214$ & 3,447 \\
\hline SN.GoMe & 38,424 & 4,516 & 39,471 & 4,944 & 38,695 & 4,722 \\
\hline FMA & 29,448 & 4,633 & 31,152 & 5,004 & 30,138 & 4,712 \\
\hline SN.Gn & 68,786 & 3,313 & 69,791 & 3,517 & 69,262 & 3,285 \\
\hline$\hat{A B I}$ & 30,729 & 5,157 & 32,300 & 5,640 & 31,362 & 5,044 \\
\hline $\mathrm{Ar}-\mathrm{A}$ & 82,571 & 4,975 & 83,519 & 4,998 & 83,524 & 5,220 \\
\hline Ar-Gn & 107,357 & 8,623 & 106,691 & 6,748 & 107,062 & 6,897 \\
\hline ENA-Me & 68,210 & 5,466 & 70,414 & 4,651 & 69,452 & 4,496 \\
\hline Rㅜ-PP & 3,267 & 2,665 & 3,581 & 1,923 & 2,986 & 2,347 \\
\hline Cㅁ-PP & 22,533 & 2,838 & 23,248 & 2,489 & 22,667 & 2,389 \\
\hline Sperp-R $\underline{6}$ & 43,667 & 3,498 & 43,233 & 3,251 & 43,929 & 3,875 \\
\hline Sperp-C $\underline{6}$ & 41,752 & 4,247 & 40,867 & 4,170 & 41,419 & 4,781 \\
\hline$\hat{A} N L$ & 102,610 & 13,167 & 101,729 & 11,854 & 102,371 & 11,976 \\
\hline
\end{tabular}


TABELA 5.4 - Médias ( $\overline{\mathrm{X}})$, desvios padrão (d.p.), médias das diferenças, valor " $t$ " e significância estatística das medidas cefalométricas analisadas no grupo I (aparelhos dentossuportados - Colado), nas fases 1 (pré-expansão) e 2 (pós-expansão).

\begin{tabular}{|c|c|c|c|c|c|c|c|c|c|}
\hline \multicolumn{2}{|c|}{ FASE } & \multicolumn{2}{|c|}{$\begin{array}{c}(1) \\
\text { PRÉ-EXPANSÃO }\end{array}$} & \multicolumn{2}{|c|}{$\begin{array}{c}(2) \\
\text { PÓS-EXPANSÃO }\end{array}$} & \multicolumn{2}{|c|}{$\begin{array}{c}\text { DIFERENÇA } \\
(2)-(1)\end{array}$} & \multirow{2}{*}{$\begin{array}{l}\text { valor } \\
\text { "t" }\end{array}$} & \multirow{2}{*}{$\begin{array}{l}\text { valor "p" e } \\
\text { significância }\end{array}$} \\
\hline Colado & $\begin{array}{l}\mathrm{N} \\
23\end{array}$ & $\bar{X}$ & d.p. & $\bar{X}$ & d.p. & $\bar{X}$ & d.p. & & \\
\hline \multicolumn{2}{|c|}{ medidas } & & & & & & & & \\
\hline \multicolumn{2}{|c|}{ SNA } & 82,261 & 4,802 & 83,387 & 4,925 & 1,126 & 1,287 & 4,196 & $0,000(* *)$ \\
\hline \multicolumn{2}{|c|}{ SN.ENA } & 88,026 & 5,426 & 89,496 & 5,233 & 1,470 & 1,880 & 3,749 & $0,001(* *)$ \\
\hline \multicolumn{2}{|c|}{ Nperp-A } & 2,730 & 3,378 & 3,874 & 3,731 & 1,144 & 2,100 & 2,612 & $0,016(*)$ \\
\hline \multicolumn{2}{|c|}{ Sperp-A } & 71,312 & 4,370 & 72,308 & 4,345 & 0,996 & 1,583 & 3,017 & $0,006(* *)$ \\
\hline \multicolumn{2}{|c|}{ SNB } & 78,735 & 3,311 & 77,978 & 3,944 & $-0,757$ & 1,627 & $-2,230$ & $0,036(*)$ \\
\hline \multicolumn{2}{|c|}{ Nperp-Pog } & $-0,692$ & 5,621 & $-2,726$ & 6,168 & $-2,034$ & 4,016 & $-2,429$ & $0,024(*)$ \\
\hline \multicolumn{2}{|c|}{$\mathrm{ANB}$} & 3,500 & 2,556 & 5,396 & 2,841 & 1,896 & 1,295 & 7,019 & $0,000(* *)$ \\
\hline \multicolumn{2}{|l|}{ NAP } & 6,287 & 5,976 & 10,287 & 6,416 & 4,000 & 2,268 & 8,459 & $0,000(* *)$ \\
\hline \multicolumn{2}{|c|}{ N-ENA } & 50,772 & 3,130 & 51,164 & 3,799 & 0,393 & 1,913 & 0,984 & 0,336 (ns) \\
\hline \multicolumn{2}{|c|}{ ENA-PoOr } & 20,283 & 3,205 & 21,212 & 3,490 & 0,929 & 1,750 & 2,544 & $0,019(*)$ \\
\hline \multicolumn{2}{|c|}{ ENP-PoOr } & 23,166 & 2,342 & 24,301 & 2,497 & 1,135 & 1,823 & 2,988 & 0,007 (**) \\
\hline \multicolumn{2}{|c|}{ PoOr.PP } & $-3,065$ & 3,593 & $-3,422$ & 4,010 & $-0,357$ & 2,469 & $-0,692$ & 0,496 (ns) \\
\hline \multicolumn{2}{|c|}{ SN.GoMe } & 38,152 & 5,535 & 40,630 & 6,303 & 2,478 & 2,251 & 5,281 & $0,000(* *)$ \\
\hline \multicolumn{2}{|c|}{ FMA } & 27,583 & 6,066 & 30,052 & 5,856 & 2,470 & 2,761 & 4,289 & $0,000(* *)$ \\
\hline \multicolumn{2}{|l|}{ SN.Gn } & 67,970 & 3,325 & 69,930 & 4,090 & 1,961 & 1,763 & 5,334 & $0,000(* *)$ \\
\hline \multicolumn{2}{|c|}{$\hat{\mathrm{ABI}}$} & 30,783 & 5,662 & 33,457 & 5,981 & 2,674 & 2,157 & 5,946 & $0,000(* *)$ \\
\hline \multicolumn{2}{|l|}{ Ar-A } & 84,645 & 5,451 & 84,928 & 4,797 & 0,283 & 1,573 & 0,862 & 0,398 (ns) \\
\hline \multicolumn{2}{|l|}{$\mathrm{Ar}-\mathrm{Gn}$} & 106,203 & 6,273 & 106,582 & 5,701 & 0,380 & 2,515 & 0,724 & 0,477 (ns) \\
\hline \multicolumn{2}{|c|}{ ENA-Me } & 67,772 & 6,722 & 72,254 & 6,895 & 4,482 & 1,975 & 10,881 & $0,000(* *)$ \\
\hline \multicolumn{2}{|l|}{ Rㅁ-PP } & 1,638 & 2,315 & 1,435 & 1,975 & $-0,203$ & 1,239 & $-0,784$ & 0,441 (ns) \\
\hline \multicolumn{2}{|l|}{ Cㅁ-PP } & 22,081 & 2,602 & 22,529 & 2,212 & 0,447 & 1,083 & 1,981 & 0,060 (ns) \\
\hline \multicolumn{2}{|c|}{ Sperp-R $\underline{6}$} & 46,543 & 3,184 & 46,834 & 3,132 & 0,291 & 1,526 & 0,915 & $0,370(\mathrm{~ns})$ \\
\hline \multicolumn{2}{|c|}{ Sperp-C $\underline{6}$} & 43,926 & 4,199 & 43,774 & 3,857 & $-0,152$ & 2,413 & $-0,302$ & 0,766 (ns) \\
\hline \multicolumn{2}{|c|}{$\hat{\mathrm{A} N L}$} & 109,004 & 12,070 & 107,422 & 10,887 & $-1,583$ & 5,455 & $-1,391$ & 0,178 (ns) \\
\hline
\end{tabular}

ns - não significante

$*-\mathrm{p}<0,05$ ou significante a $5 \%$

$* *-p<0,01$ ou significante a $1 \%$ 
TABELA 5.5 - Médias ( $\overline{\mathrm{X}})$, desvios padrão (d.p.), médias das diferenças, valor "t" e significância estatística das medidas cefalométricas analisadas no grupo I (aparelhos dentossuportados - Colado), nas fases 2 (pós- expansão) e 3 (pós-contenção).

\begin{tabular}{|c|c|c|c|c|c|c|c|c|}
\hline FASE & \multicolumn{2}{|c|}{$\begin{array}{c}(2) \\
\text { PÓS-EXPANSÃO }\end{array}$} & \multicolumn{2}{|c|}{$\begin{array}{c}(3) \\
\text { PÓS-CONTENÇÃO }\end{array}$} & \multicolumn{2}{|c|}{$\begin{array}{c}\text { DIFERENÇA } \\
(3)-(2)\end{array}$} & \multirow{2}{*}{$\begin{array}{l}\text { valor } \\
\text { "t" }\end{array}$} & \multirow{2}{*}{$\begin{array}{l}\text { Valor “p” e } \\
\text { significância }\end{array}$} \\
\hline Colado & $\bar{X}$ & d.p. & $\bar{X}$ & d.p. & $X$ & d.p. & & \\
\hline \multicolumn{9}{|l|}{ medidas } \\
\hline SNA & 83,387 & 4,925 & 82,609 & 4,219 & $-0,778$ & 1,559 & $-2,394$ & $0,026(*)$ \\
\hline SN.ENA & 89,496 & 5,233 & 88,317 & 4,478 & $-1,178$ & 2,065 & $-2,737$ & $0,012(*)$ \\
\hline Nperp-A & 3,874 & 3,731 & 2,672 & 3,441 & $-1,203$ & 2,227 & $-2,590$ & $0,017(*)$ \\
\hline Sperp-A & 72,308 & 4,345 & 71,460 & 3,992 & $-0,848$ & 1,726 & $-2,357$ & $0,028(*)$ \\
\hline SNB & 77,978 & 3,944 & 78,400 & 3,579 & 0,422 & 1,761 & 1,149 & 0,263 (ns) \\
\hline Nperp-Pog & $-2,726$ & 6,168 & $-2,300$ & 5,966 & 0,426 & 3,733 & 0,548 & $0,590(\mathrm{~ns})$ \\
\hline ANB & 5,396 & 2,841 & 4,230 & 2,429 & $-1,165$ & 1,378 & $-4,055$ & $0,001(* *)$ \\
\hline NAP & 10,287 & 6,416 & 7,652 & 5,844 & $-2,635$ & 2,480 & $-5,095$ & $0,000(* *)$ \\
\hline N-ENA & 51,164 & 3,799 & 51,417 & 3,607 & 0,253 & 2,155 & 0,564 & 0,579 (ns) \\
\hline ENA-PoOr & 21,212 & 3,490 & 21,714 & 2,781 & 0,502 & 1,748 & 1,378 & 0,182 (ns) \\
\hline ENP-PoOr & 24,301 & 2,497 & 24,297 & 2,722 & $-0,004$ & 1,456 & $-0,014$ & 0,989 (ns) \\
\hline PoOr.PP & $-3,422$ & 4,010 & $-2,804$ & 3,988 & 0,617 & 2,137 & 1,386 & 0,180 (ns) \\
\hline SN.GoMe & 40,630 & 6,303 & 39,096 & 6,404 & $-1,535$ & 1,916 & $-3,841$ & $0,001(* *)$ \\
\hline FMA & 30,052 & 5,856 & 28,987 & 6,296 & $-1,065$ & 2,410 & $-2,120$ & $0,046(*)$ \\
\hline SN.Gn & 69,930 & 4,090 & 68,791 & 4,154 & $-1,139$ & 1,904 & $-2,870$ & $0,009(* *)$ \\
\hline$\hat{\mathrm{ABI}}$ & 33,457 & 5,981 & 31,804 & 6,106 & $-1,652$ & 2,190 & $-3,618$ & $0,002(* *)$ \\
\hline Ar-A & 84,928 & 4,797 & 84,949 & 4,586 & 0,021 & 1,368 & 0,074 & 0,942 (ns) \\
\hline $\mathrm{Ar}-\mathrm{Gn}$ & 106,582 & 5,701 & 106,836 & 6,746 & 0,253 & 3,068 & 0,396 & 0,696 (ns) \\
\hline ENA-Me & 72,254 & 6,895 & 69,257 & 6,640 & $-2,997$ & 2,086 & $-6,888$ & $0,000(* *)$ \\
\hline Rㅁ-PP & 1,435 & 1,975 & 1,178 & 2,484 & $-0,257$ & 1,429 & $-0,864$ & $0,397(\mathrm{~ns})$ \\
\hline Cㅁ-PP & 22,529 & 2,212 & 21,896 & 2,349 & $-0,633$ & 0,844 & $-3,597$ & $0,002(* *)$ \\
\hline Sperp-R $\underline{6}$ & 46,834 & 3,132 & 46,412 & 4,146 & $-0,422$ & 2,362 & $-0,857$ & 0,401 (ns) \\
\hline Sperp-C $\underline{6}$ & 43,774 & 3,857 & 43,973 & 4,459 & 0,198 & 2,213 & 0,430 & 0,672 (ns) \\
\hline ÂNL & 107,422 & 10,887 & 108,870 & 12,832 & 1,448 & 6,207 & 1,119 & 0,275 (ns) \\
\hline
\end{tabular}

ns - não significante

$*-p<0,05$ ou significante a $5 \%$

$* *-p<0,01$ ou significante a $1 \%$ 
TABELA 5.6 - Médias ( $\overline{\mathrm{X}}$ ), desvios padrão (d.p.), médias das diferenças, valor "t" e significância estatística das medidas cefalométricas analisadas no grupo I (aparelhos dentossuportados - Colado), nas fases 1 (pré-expansão) e 3 (pós-contenção).

\begin{tabular}{|c|c|c|c|c|c|c|c|c|}
\hline FASE & \multicolumn{2}{|c|}{ PRÉ-EXPANSÃO } & \multicolumn{2}{|c|}{ PÓS-CONTENÇÃO } & \multicolumn{2}{|c|}{$\begin{array}{l}\text { DIFEREINÇA } \\
\qquad(3)-(1)\end{array}$} & \multirow{2}{*}{$\begin{array}{l}\text { valor } \\
\text { "t" }\end{array}$} & \multirow{2}{*}{$\begin{array}{l}\text { valor "p" e } \\
\text { significância }\end{array}$} \\
\hline Colado & $\bar{X}$ & d.p. & $\bar{X}$ & d.p. & $\bar{X}$ & d.p. & & \\
\hline \multicolumn{9}{|l|}{ medidas } \\
\hline SNA & 82,261 & 4,802 & 82,609 & 4,219 & 0,348 & 1,401 & 1,191 & 0,246 (ns) \\
\hline SN.ENA & 88,026 & 5,426 & 88,317 & 4,478 & 0,291 & 2,572 & 0,543 & 0,592 (ns) \\
\hline Nperp-A & 2,730 & 3,378 & 2,672 & 3,441 & $-0,059$ & 2,297 & $-0,123$ & 0,903 (ns) \\
\hline Sperp-A & 71,312 & 4,370 & 71,460 & 3,992 & 0,148 & 1,740 & 0,407 & 0,688 (ns) \\
\hline SNB & 78,735 & 3,311 & 78,400 & 3,579 & $-0,335$ & 1,505 & $-1,067$ & 0,298 (ns) \\
\hline Nperp-Pog & $-0,692$ & 5,621 & $-2,300$ & 5,966 & $-1,608$ & 3,684 & $-2,093$ & $0,048(*)$ \\
\hline ANB & 3,500 & 2,556 & 4,230 & 2,429 & 0,730 & 1,309 & 2,676 & $0,014(*)$ \\
\hline NAP & 6,287 & 5,976 & 7,652 & 5,844 & 1,365 & 2,404 & 2,724 & $0,012(*)$ \\
\hline N-ENA & 50,772 & 3,130 & 51,417 & 3,607 & 0,646 & 1,937 & 1,599 & 0,124 (ns) \\
\hline ENA-PoOr & 20,283 & 3,205 & 21,714 & 2,781 & 1,431 & 2,056 & 3,338 & $0,003(* *)$ \\
\hline ENP-PoOr & 23,166 & 2,342 & 24,297 & 2,722 & 1,131 & 1,655 & 3,277 & $0,003(* *)$ \\
\hline PoOr.PP & $-3,065$ & 3,593 & $-2,804$ & 3,988 & 0,261 & 2,483 & 0,504 & 0,619 (ns) \\
\hline SN.GoMe & 38,152 & 5,535 & 39,096 & 6,404 & 0,944 & 1,774 & 2,550 & $0,018(*)$ \\
\hline FMA & 27,583 & 6,066 & 28,987 & 6,296 & 1,404 & 2,876 & 2,342 & $0,029(*)$ \\
\hline SN.Gn & 67,970 & 3,325 & 68,791 & 4,154 & 0,822 & 1,656 & 2,379 & $0,026(*)$ \\
\hline ÂBI & 30,783 & 5,662 & 31,804 & 6,106 & 1,022 & 1,872 & 2,618 & $0,016(*)$ \\
\hline Ar-A & 84,645 & 5,451 & 84,949 & 4,586 & 0,304 & 1,571 & 0,928 & 0,364 (ns) \\
\hline Ar-Gn & 106,203 & 6,273 & 106,836 & 6,746 & 0,633 & 1,639 & 1,852 & 0,078 (ns) \\
\hline ENA-Me & 67,772 & 6,722 & 69,257 & 6,640 & 1,486 & 1,528 & 4,662 & 0,000 (**) \\
\hline R6-PP & 1,638 & 2,315 & 1,178 & 2,484 & $-0,460$ & 1,296 & $-1,703$ & 0,103 (ns) \\
\hline Cㅌ-PP & 22,081 & 2,602 & 21,896 & 2,349 & $-0,186$ & 0,851 & $-1,046$ & 0,307 (ns) \\
\hline Sperp-R $\underline{6}$ & 46,543 & 3,184 & 46,412 & 4,146 & $-0,131$ & 2,321 & $-0,270$ & 0,789 (ns) \\
\hline Sperp-C $\underline{6}$ & 43,926 & 4,199 & 43,973 & 4,459 & 0,046 & 2,351 & 0,095 & 0,925 (ns) \\
\hline$\hat{A} N L$ & 109,004 & 12,070 & 108,870 & 12,832 & $-0,135$ & 5,795 & $-0,112$ & 0,912 (ns) \\
\hline
\end{tabular}

ns - não significante

$*-p<0,05$ ou significante a $5 \%$

$* *-p<0,01$ ou significante a $1 \%$ 
TABELA 5.7 - Médias ( $\overline{\mathrm{X}})$, desvios padrão (d.p.), médias das diferenças, valor "t" e significância estatística das medidas cefalométricas analisadas no grupo II (aparelhos dentomucossuportados - tipo Haas), nas fases 1 (pré-expansão) e 2 (pós-expansão).

\begin{tabular}{|c|c|c|c|c|c|c|c|c|c|}
\hline \multicolumn{2}{|c|}{ FASE } & \multicolumn{2}{|c|}{$\begin{array}{c}(1) \\
\text { PRÉ-EXPANSÃO }\end{array}$} & \multicolumn{2}{|c|}{$\begin{array}{c}(2) \\
\text { PÓS-EXPANSÃO }\end{array}$} & \multicolumn{2}{|c|}{$\begin{array}{l}\text { DIFERENÇA } \\
\text { (2) - (1) }\end{array}$} & \multirow{2}{*}{$\begin{array}{l}\text { valor } \\
\text { "t" }\end{array}$} & \multirow{2}{*}{$\begin{array}{l}\text { valor "p" e } \\
\text { significância }\end{array}$} \\
\hline $\begin{array}{l}\text { Tipo } \\
\text { Haas }\end{array}$ & $\begin{array}{l}\mathrm{N} \\
20\end{array}$ & $\bar{X}$ & d.p. & $\bar{X}$ & d.p. & $\mathrm{X}$ & d.p. & & \\
\hline \multicolumn{2}{|c|}{ medidas } & & & & & & & & \\
\hline \multicolumn{2}{|c|}{ SNA } & 80,830 & 3,385 & 81,240 & 3,453 & 0,410 & 1,295 & 1,416 & 0,173 (ns) \\
\hline \multicolumn{2}{|c|}{ SN.ENA } & 84,830 & 3,989 & 85,105 & 3,834 & 0,275 & 1,369 & 0,898 & 0,380 (ns) \\
\hline \multicolumn{2}{|c|}{ Nperp-A } & $-0,910$ & 3,028 & $-0,340$ & 2,982 & 0,570 & 1,444 & 1,765 & 0,094 (ns) \\
\hline \multicolumn{2}{|c|}{ Sperp-A } & 68,560 & 3,623 & 69,135 & 3,989 & 0,575 & 1,338 & 1,922 & 0,070 (ns) \\
\hline \multicolumn{2}{|c|}{ SNB } & 77,815 & 3,170 & 76,795 & 2,777 & $-1,020$ & 1,227 & $-3,717$ & $0,001(* *)$ \\
\hline \multicolumn{2}{|c|}{ Nperp-Pog } & $-6,025$ & 5,991 & $-8,225$ & 5,687 & $-2,200$ & 3,064 & $-3,211$ & $0,005(* *)$ \\
\hline \multicolumn{2}{|c|}{ ANB } & 3,005 & 2,445 & 4,450 & 2,445 & 1,445 & 0,852 & 7,586 & $0,000(* *)$ \\
\hline \multicolumn{2}{|c|}{ NAP } & 4,445 & 5,615 & 7,655 & 5,559 & 3,210 & 1,656 & 8,669 & $0,000(* *)$ \\
\hline \multicolumn{2}{|c|}{ N-ENA } & 51,220 & 3,904 & 51,835 & 3,930 & 0,615 & 0,922 & 2,982 & $0,008(* *)$ \\
\hline \multicolumn{2}{|c|}{ ENA-PoOr } & 22,035 & 2,381 & 22,605 & 3,154 & 0,570 & 1,473 & 1,730 & $0,010(* *)$ \\
\hline \multicolumn{2}{|c|}{ ENP-PoOr } & 21,490 & 2,226 & 22,005 & 2,393 & 0,515 & 1,018 & 2,262 & $0,036(*)$ \\
\hline \multicolumn{2}{|c|}{ PoOr.PP } & 0,560 & 2,651 & 0,640 & 2,696 & 0,080 & 1,363 & 0,263 & 0,796 (ns) \\
\hline \multicolumn{2}{|c|}{ SN.GoMe } & 37,805 & 6,402 & 39,690 & 6,314 & 1,885 & 1,299 & 6,489 & $0,000(* *)$ \\
\hline \multicolumn{2}{|c|}{ FMA } & 29,565 & 5,067 & 31,295 & 5,657 & 1,730 & 1,814 & 4,265 & $0,000(* *)$ \\
\hline \multicolumn{2}{|c|}{ SN.Gn } & 69,015 & 3,719 & 70,655 & 3,664 & 1,640 & 1,033 & 7,098 & $0,000(* *)$ \\
\hline \multicolumn{2}{|c|}{$\hat{\mathrm{ABI}}$} & 29,000 & 5,421 & 30,655 & 5,770 & 1,655 & 1,311 & 5,646 & $0,000(* *)$ \\
\hline \multicolumn{2}{|l|}{ Ar-A } & 84,705 & 3,915 & 85,525 & 4,102 & 0,820 & 1,069 & 3,430 & $0,003(* *)$ \\
\hline \multicolumn{2}{|c|}{ Ar-Gn } & 107,255 & 4,212 & 107,570 & 4,248 & 0,315 & 1,275 & 1,105 & 0,283 (ns) \\
\hline \multicolumn{2}{|c|}{ ENA-Me } & 68,515 & 4,645 & 71,215 & 4,365 & 2,700 & 1,573 & 7,676 & $0,000(* *)$ \\
\hline \multicolumn{2}{|c|}{ Rㅁ-PP } & 4,050 & 2,345 & 3,705 & 1,801 & $-0,345$ & 1,343 & $-1,149$ & 0,265 (ns) \\
\hline \multicolumn{2}{|c|}{ Cㅁ-PP } & 23,515 & 2,580 & 23,750 & 1,949 & 0,235 & 1,197 & 0,878 & 0,391 (ns) \\
\hline \multicolumn{2}{|c|}{ Sperp-Rㅁ } & 44,035 & 3,602 & 44,380 & 3,634 & 0,345 & 1,340 & 1,151 & 0,264 (ns) \\
\hline \multicolumn{2}{|c|}{ Sperp-C $\overline{6}$} & 41,785 & 4,304 & 42,130 & 4,187 & 0,345 & 1,568 & 0,984 & 0,337 (ns) \\
\hline \multicolumn{2}{|c|}{ ÂNL } & 94,740 & 12,862 & 93,935 & 8,435 & $-0,805$ & 7,014 & $-0,513$ & 0,614 (ns) \\
\hline
\end{tabular}

ns - não significante

$*-p<0,05$ ou significante a $5 \%$

$* *-\mathrm{p}<0,01$ ou significante a $1 \%$ 
TABELA 5.8 - Médias ( $\overline{\mathrm{X}}$ ), desvios padrão (d.p.), médias das diferenças, valor "t" e significância estatística das medidas cefalométricas analisadas no grupo II (aparelhos dentomucossuportados - tipo Haas), nas fases 2 (pós- expansão) e 3 (pós-contenção).

\begin{tabular}{|c|c|c|c|c|c|c|c|c|}
\hline FASE & \multicolumn{2}{|c|}{$\begin{array}{c}(2) \\
\text { PÓS-EXPANSÃO }\end{array}$} & \multicolumn{2}{|c|}{$\begin{array}{c}(3) \\
\text { PÓS-CONTENÇÃO }\end{array}$} & \multicolumn{2}{|c|}{$\begin{array}{l}\text { DIFERENÇA } \\
(3)-(2)\end{array}$} & \multirow{2}{*}{$\begin{array}{l}\text { Valor } \\
\text { "t" }\end{array}$} & \multirow{2}{*}{$\begin{array}{l}\text { valor "p" e } \\
\text { significância }\end{array}$} \\
\hline \begin{tabular}{c|c} 
Tipo & $\mathrm{N}$ \\
Haas & 20
\end{tabular} & $\bar{X}$ & d.p. & $\bar{X}$ & d.p. & $X$ & d.p. & & \\
\hline medidas & & & & & & & & \\
\hline SNA & 81,240 & 3,453 & 80,805 & 3,639 & $-0,435$ & 1,562 & $-1,245$ & 0,228 (ns) \\
\hline SN.ENA & 85,105 & 3,834 & 84,965 & 4,255 & $-0,140$ & 1,800 & $-0,348$ & 0,732 (ns) \\
\hline Nperp-A & $-0,340$ & 2,982 & $-1,355$ & 3,446 & $-1,015$ & 1,798 & $-2,524$ & $0,021(*)$ \\
\hline Sperp-A & 69,135 & 3,989 & 68,485 & 3,519 & $-0,650$ & 1,423 & $-2,043$ & 0,055 (ns) \\
\hline SNB & 76,795 & 2,777 & 77,540 & 3,176 & 0,745 & 1,369 & 2,434 & $0,025(*)$ \\
\hline Nperp-Pog & $-8,225$ & 5,687 & $-7,615$ & 6,393 & 0,610 & 2,760 & 0,988 & 0,335 (ns) \\
\hline $\mathrm{ANB}$ & 4,450 & 2,445 & 3,265 & 2,385 & $-1,185$ & 0,854 & $-6,208$ & $0,000(* *)$ \\
\hline NAP & 7,655 & 5,559 & 5,205 & 5,628 & $-2,450$ & 1,792 & $-6,116$ & $0,000(* *)$ \\
\hline N-ENA & 51,835 & 3,930 & 51,645 & 3,920 & $-0,190$ & 1,038 & $-0,819$ & 0,423 (ns) \\
\hline ENA-PoOr & 22,605 & 3,154 & 23,060 & 2,600 & 0,455 & 1,441 & 1,413 & 0,174 (ns) \\
\hline ENP-PoOr & 22,005 & 2,393 & 22,195 & 2,314 & 0,190 & 1,217 & 0,698 & 0,494 (ns) \\
\hline PoOr.PP & 0,640 & 2,696 & 0,885 & 2,104 & 0,245 & 1,466 & 0,747 & 0,464 (ns) \\
\hline SN.GoMe & 39,690 & 6,314 & 38,335 & 6,553 & $-1,355$ & 1,584 & $-3,825$ & $0,001(* *)$ \\
\hline FMA & 31,295 & 5,657 & 30,470 & 5,592 & $-0,825$ & 1,357 & $-2,719$ & $0,014(*)$ \\
\hline SN.Gn & 70,655 & 3,664 & 69,555 & 3,876 & $-1,100$ & 1,353 & $-3,635$ & $0,002(* *)$ \\
\hline$\hat{\mathrm{ABI}}$ & 30,655 & 5,770 & 29,565 & 5,815 & $-1,090$ & 1,400 & $-3,483$ & $0,003(* *)$ \\
\hline Ar-A & 85,525 & 4,102 & 85,270 & 3,662 & $-0,255$ & 1,018 & $-1,121$ & 0,276 (ns) \\
\hline $\mathrm{Ar}-\mathrm{Gn}$ & 107,570 & 4,248 & 107,975 & 4,243 & 0,405 & 0,965 & 1,876 & 0,076 (ns) \\
\hline ENA-Me & 71,215 & 4,365 & 69,825 & 4,713 & $-1,390$ & 1,585 & $-3,923$ & $0,001(* *)$ \\
\hline Rㅁ-PP & 3,705 & 1,801 & 3,870 & 2,824 & 0,165 & 1,447 & 0,510 & 0,616 (ns) \\
\hline Cㅁ-PP & 23,750 & 1,949 & 23,370 & 2,088 & $-0,380$ & 0,828 & $-2,054$ & 0,054 (ns) \\
\hline Sperp-R $\underline{6}$ & 44,380 & 3,634 & 44,080 & 3,307 & $-0,300$ & 1,133 & $-1,184$ & 0,251 (ns) \\
\hline Sperp-C $\underline{6}$ & 42,130 & 4,187 & 41,535 & 4,082 & $-0,595$ & 1,367 & $-1,947$ & 0,067 (ns) \\
\hline ÂNL & 93,935 & 8,435 & 96,890 & 11,095 & 2,955 & 5,693 & 2,3214 & $0,032(*)$ \\
\hline
\end{tabular}

ns - não significante

$*-p<0,05$ ou significante a $5 \%$

$* *-p<0,01$ ou significante a $1 \%$ 
TABELA 5.9 - Médias ( $\overline{\mathrm{X}})$, desvios padrão (d.p.), médias das diferenças, valor "t" e significância estatística das medidas cefalométricas analisadas no grupo II (aparelhos dentomucossuportados - tipo Haas), nas fases 1 (pré-expansão) e 3 (pós-contenção).

\begin{tabular}{|c|c|c|c|c|c|c|c|c|c|}
\hline \multicolumn{2}{|c|}{ FASE } & \multicolumn{2}{|c|}{$\begin{array}{c}(1) \\
\text { PRÉ-EXPANSÃO }\end{array}$} & \multicolumn{2}{|c|}{$\begin{array}{c}(3) \\
\text { PÓS-CONTENÇÃO }\end{array}$} & \multicolumn{2}{|c|}{$\begin{array}{l}\text { DIFERENÇA } \\
\text { (3) }-(1)\end{array}$} & \multirow{2}{*}{$\begin{array}{l}\text { valor } \\
\text { "t" }\end{array}$} & \multirow{2}{*}{$\begin{array}{l}\text { valor "p" e } \\
\text { significância }\end{array}$} \\
\hline $\begin{array}{l}\text { Tipo } \\
\text { Haas }\end{array}$ & $\begin{array}{l}\mathrm{N} \\
20\end{array}$ & $\bar{X}$ & d.p. & $\mathrm{X}$ & d.p. & $\mathrm{X}$ & d.p. & & \\
\hline \multicolumn{10}{|c|}{ medidas } \\
\hline SNA & & 80,830 & 3,385 & 80,805 & 3,639 & $-0,025$ & 1,080 & $-0,104$ & 0,919 (ns) \\
\hline SN.EN & & 84,830 & 3,989 & 84,965 & 4,255 & 0,135 & 1,385 & 0,436 & 0,668 (ns) \\
\hline Nperp- & & $-0,910$ & 3,028 & $-1,355$ & 3,446 & $-0,445$ & 1,555 & $-1,280$ & 0,216 (ns) \\
\hline Sperp- & & 68,560 & 3,623 & 68,485 & 3,519 & $-0,075$ & 1,306 & $-0,257$ & 0,800 (ns) \\
\hline SNB & & 77,815 & 3,170 & 77,540 & 3,176 & $-0,275$ & 0,990 & $-1,242$ & 0,229 (ns) \\
\hline Nperp- & Pog & $-6,025$ & 5,991 & $-7,615$ & 6,393 & $-1,590$ & 2,779 & $-2,558$ & $0,019(*)$ \\
\hline ANB & & 3,005 & 2,445 & 3,265 & 2,385 & 0,260 & 0,778 & 1,494 & 0,152 (ns) \\
\hline NAP & & 4,445 & 5,615 & 5,205 & 5,628 & 0,760 & 1,656 & 2,052 & $0,054(\mathrm{~ns})$ \\
\hline N-EN/ & & 51,220 & 3,904 & 51,645 & 3,920 & 0,425 & 1,118 & 1,700 & 0,105 (ns) \\
\hline ENA-F & $\mathrm{oOr}$ & 22,035 & 2,381 & 23,060 & 2,600 & 1,025 & 1,645 & 2,787 & $0,012(*)$ \\
\hline ENP-P & $\mathrm{Or}$ & 21,490 & 2,226 & 22,195 & 2,314 & 0,705 & 1,304 & 2,419 & $0,026(*)$ \\
\hline PoOr.I & & 0,560 & 2,651 & 0,885 & 2,104 & 0,325 & 1,644 & 0,884 & 0,388 (ns) \\
\hline SN.Go & & 37,805 & 6,402 & 38,335 & 6,553 & 0,530 & 1,110 & 2,136 & $0,046(*)$ \\
\hline FMA & & 29,565 & 5,067 & 30,470 & 5,592 & 0,905 & 1,613 & 2,510 & $0,021(*)$ \\
\hline SN.Gn & & 69,015 & 3,719 & 69,555 & 3,876 & 0,540 & 0,869 & 2,779 & $0,012(*)$ \\
\hline$\hat{\mathrm{ABI}}$ & & 29,000 & 5,421 & 29,565 & 5,815 & 0,565 & 1,576 & 1,603 & 0,125 (ns) \\
\hline $\mathrm{Ar}-\mathrm{A}$ & & 84,705 & 3,915 & 85,270 & 3,662 & 0,565 & 0,896 & 2,819 & $0,011(*)$ \\
\hline $\mathrm{Ar}-\mathrm{Gn}$ & & 107,255 & 4,212 & 107,975 & 4,243 & 0,720 & 1,072 & 3,004 & $0,007(* *)$ \\
\hline ENA-I & & 68,515 & 4,645 & 69,825 & 4,713 & 1,310 & 1,259 & 4,653 & $0,000(* *)$ \\
\hline Rㅜ-PP & & 4,050 & 2,345 & 3,870 & 2,824 & $-0,180$ & 1,687 & $-0,477$ & 0,639 (ns) \\
\hline C흐-PP & & 23,515 & 2,580 & 23,370 & 2,088 & $-0,145$ & 1,295 & $-0,501$ & 0,622 (ns) \\
\hline Sperp- & & 44,035 & 3,602 & 44,080 & 3,307 & 0,045 & 1,416 & 0,142 & 0,888 (ns) \\
\hline Sperp- & & 41,785 & 4,304 & 41,535 & 4,082 & $-0,250$ & 1,456 & $-0,768$ & 0,452 (ns) \\
\hline$\hat{A N N}$ & & 94,740 & 12,862 & 96,890 & 11,095 & 2,150 & 6,621 & 1,452 & 0,163 (ns) \\
\hline
\end{tabular}

ns - não significante

* $-\mathrm{p}<0,05$ ou significante a $5 \%$

$* *$ - $p<0,01$ ou significante a $1 \%$ 
TABELA 5.10 - Médias ( $\overline{\mathrm{X}})$, desvios padrão (d.p.), médias das diferenças, valor "t" e significância estatística das medidas cefalométricas analisadas no grupo III (aparelhos dentossuportados - Hyrax), nas fases 1 (pré-expansão) e 2 (pós-expansão).

\begin{tabular}{|c|c|c|c|c|c|c|c|c|}
\hline FASE & \multicolumn{2}{|c|}{$\begin{array}{c}(1) \\
\text { PRÉ-EXPANSÃO }\end{array}$} & \multicolumn{2}{|c|}{$\begin{array}{c}(2) \\
\text { PÓS-EXPANSÃO }\end{array}$} & \multicolumn{2}{|c|}{$\begin{array}{l}\text { DIFERENÇA } \\
(2)-(1)\end{array}$} & \multirow{2}{*}{$\begin{array}{l}\text { valor } \\
\text { "t" }\end{array}$} & \multirow{2}{*}{$\begin{array}{l}\text { valor "p" e } \\
\text { significância }\end{array}$} \\
\hline Hyrax & $\bar{X}$ & d.p. & $\bar{X}$ & d.p. & $\bar{X}$ & d.p. & & \\
\hline \multicolumn{9}{|l|}{ medidas } \\
\hline SNA & 81,257 & 2,972 & 81,919 & 3,474 & 0,662 & 1,564 & 1,940 & 0,067 (ns) \\
\hline SN.ENA & 85,800 & 3,995 & 86,233 & 4,196 & 0,433 & 1,888 & 1,052 & 0,305 (ns) \\
\hline Nperp-A & 0,233 & 2,380 & 0,267 & 3,032 & 0,033 & 1,462 & 0,105 & 0,918 (ns) \\
\hline Sperp-A & 68,105 & 4,169 & 68,205 & 4,533 & 0,100 & 1,395 & 0,329 & 0,746 (ns) \\
\hline SNB & 78,391 & 4,020 & 77,900 & 4,355 & $-0,491$ & 1,251 & $-1,796$ & 0,088 (ns) \\
\hline Nperp-Pog & $-3,338$ & 6,694 & $-5,667$ & 7,092 & $-2,329$ & 2,921 & $-3,653$ & $0,001(* *)$ \\
\hline $\mathrm{ANB}$ & 2,862 & 3,037 & 4,024 & 2,657 & 1,162 & 1,438 & 3,703 & $0,001(* *)$ \\
\hline NAP & 3,929 & 6,495 & 6,443 & 5,710 & 2,514 & 2,744 & 4,199 & $0,000(* *)$ \\
\hline N-ENA & 49,981 & 3,164 & 50,267 & 3,155 & 0,286 & 0,988 & 1,326 & $0,120(\mathrm{~ns})$ \\
\hline ENA-PoOr & 21,105 & 3,520 & 21,957 & 3,698 & 0,852 & 1,853 & 2,109 & $0,048(*)$ \\
\hline ENP-PoOr & 22,257 & 2,155 & 22,962 & 2,070 & 0,705 & 1,006 & 3,211 & $0,004(* *)$ \\
\hline PoOr.PP & $-1,286$ & 2,946 & $-1,138$ & 3,434 & 0,148 & 1,821 & 0,372 & $0,714(\mathrm{~ns})$ \\
\hline SN.GoMe & 38,424 & 4,516 & 39,471 & 4,944 & 1,048 & 1,990 & 2,413 & $0,026(*)$ \\
\hline FMA & 29,448 & 4,633 & 31,152 & 5,004 & 1,705 & 1,658 & 4,711 & $0,000(* *)$ \\
\hline SN.Gn & 68,786 & 3,313 & 69,791 & 3,517 & 1,005 & 1,331 & 3,459 & $0,003(* *)$ \\
\hline$\hat{\mathrm{ABI}}$ & 30,729 & 5,157 & 32,300 & 5,640 & 1,571 & 1,966 & 3,663 & $0,002(* *)$ \\
\hline Ar-A & 82,571 & 4,975 & 83,519 & 4,998 & 0,948 & 1,320 & 3,290 & $0,004(* *)$ \\
\hline Ar-Gn & 107,357 & 8,623 & 106,691 & 6,748 & $-0,667$ & 5,804 & $-0,526$ & 0,604 (ns) \\
\hline ENA-Me & 68,210 & 5,466 & 70,414 & 4,651 & 2,205 & 1,943 & 5,199 & $0,000(* *)$ \\
\hline Rㅁ-PP & 3,267 & 2,665 & 3,581 & 1,923 & 0,314 & 1,279 & 1,126 & 0,274 (ns) \\
\hline Cㅌ-PP & 22,533 & 2,838 & 23,248 & 2,489 & 0,714 & 1,128 & 2,903 & $0,009(* *)$ \\
\hline Sperp-R $\underline{6}$ & 43,667 & 3,498 & 43,233 & 3,251 & $-0,433$ & 1,583 & $-1,255$ & 0,224 (ns) \\
\hline Sperp-C므 & 41,752 & 4,247 & 40,867 & 4,170 & $-0,886$ & 1,742 & $-2,331$ & $0,030(*)$ \\
\hline ÂNL & 102,610 & 13,167 & 101,729 & 11,854 & $-0,881$ & 5,654 & $-0,714$ & 0,484 (ns) \\
\hline
\end{tabular}

ns - não significante

* $-\mathrm{p}<0,05$ ou significante a $5 \%$

$* *$ - $p<0,01$ ou significante a $1 \%$ 
TABELA 5.11 - Médias ( $\bar{X})$, desvios padrão (d.p.), médias das diferenças, valor "t" e significância estatística das medidas cefalométricas analisadas no grupo III (aparelhos dentossuportados - Hyrax), nas fases 2 (pós- expansão) e 3 (pós-contenção).

\begin{tabular}{|c|c|c|c|c|c|c|c|c|}
\hline FASE & \multicolumn{2}{|c|}{$\begin{array}{c}(2) \\
\text { PÓS-EXPANSÃO }\end{array}$} & \multicolumn{2}{|c|}{$\begin{array}{c}\text { (3) } \\
\text { PÓS-CONTENÇÃO }\end{array}$} & \multicolumn{2}{|c|}{$\begin{array}{l}\text { DIFERENÇA } \\
(3)-(2)\end{array}$} & \multirow{2}{*}{$\begin{array}{l}\text { valor } \\
\text { "t" }\end{array}$} & \multirow{2}{*}{$\begin{array}{l}\text { valor "p" e } \\
\text { significância }\end{array}$} \\
\hline Hyrax & $\bar{X}$ & d.p. & $\bar{X}$ & d.p. & $\bar{X}$ & d.p. & & \\
\hline \multicolumn{9}{|l|}{ medidas } \\
\hline SNA & 81,919 & 3,474 & 81,591 & 3,579 & $-0,329$ & 1,586 & $-0,949$ & 0,354 (ns) \\
\hline SN.ENA & 86,233 & 4,196 & 85,948 & 4,070 & $-0,286$ & 2,087 & $-0,627$ & 0,538 (ns) \\
\hline Nperp-A & 0,267 & 3,032 & 0,219 & 2,898 & $-0,048$ & 1,460 & $-0,149$ & 0,883 (ns) \\
\hline Sperp-A & 68,205 & 4,533 & 68,514 & 4,874 & 0,310 & 1,207 & 1,175 & 0,254 (ns) \\
\hline SNB & 77,900 & 4,355 & 78,152 & 4,281 & 0,252 & 1,406 & 0,823 & 0,420 (ns) \\
\hline Nperp-Pog & $-5,667$ & 7,092 & $-4,705$ & 6,625 & 0,962 & 1,783 & 2,473 & $0,023(*)$ \\
\hline ANB & 4,024 & 2,657 & 3,467 & 2,878 & $-0,557$ & 1,073 & $-2,379$ & $0,027(*)$ \\
\hline NAP & 6,443 & 5,710 & 5,367 & 6,275 & $-1,076$ & 2,321 & $-2,125$ & $0,046(*)$ \\
\hline N-ENA & 50,267 & 3,155 & 50,657 & 2,844 & 0,391 & 1,396 & 1,282 & 0,215 (ns) \\
\hline ENA-PoOr & 21,957 & 3,698 & 22,033 & 3,411 & 0,076 & 1,416 & 0,247 & 0,808 (ns) \\
\hline ENP-PoOr & 22,962 & 2,070 & 23,114 & 2,117 & 0,152 & 1,128 & 0,619 & $0,543(\mathrm{~ns})$ \\
\hline PoOr.PP & $-1,138$ & 3,434 & $-1,214$ & 3,447 & $-0,076$ & 1,237 & $-0,282$ & 0,781 (ns) \\
\hline SN.GoMe & 39,471 & 4,944 & 38,695 & 4,722 & $-0,776$ & 1,988 & $-1,789$ & 0,089 (ns) \\
\hline FMA & 31,152 & 5,004 & 30,138 & 4,712 & $-1,014$ & 1,563 & $-2,975$ & $0,008(* *)$ \\
\hline SN.Gn & 69,791 & 3,517 & 69,262 & 3,285 & $-0,529$ & 1,374 & $-1,763$ & 0,093 (ns) \\
\hline ÂBI & 32,300 & 5,640 & 31,362 & 5,044 & $-0,938$ & 1,715 & $-2,507$ & $0,021\left(^{*}\right)$ \\
\hline Ar-A & 83,519 & 4,998 & 83,524 & 5,220 & 0,005 & 1,388 & 0,016 & 0,988 (ns) \\
\hline $\mathrm{Ar}-\mathrm{Gn}$ & 106,691 & 6,748 & 107,062 & 6,897 & 0,371 & 1,354 & 1,257 & 0,223 (ns) \\
\hline ENA-Me & 70,414 & 4,651 & 69,452 & 4,496 & $-0,962$ & 1,303 & $-3,383$ & $0,003(* *)$ \\
\hline Rㅜ-PP & 3,581 & 1,923 & 2,986 & 2,347 & $-0,595$ & 1,129 & $-2,416$ & $0,025(*)$ \\
\hline C6-PP & 23,248 & 2,489 & 22,667 & 2,389 & $-0,581$ & 0,754 & $-3,531$ & $0,002(* *)$ \\
\hline Sperp-Rㅁ & 43,233 & 3,251 & 43,929 & 3,875 & 0,695 & 1,599 & 1,993 & 0,060 (ns) \\
\hline Sperp-C므 & 40,867 & 4,170 & 41,419 & 4,781 & 0,552 & 1,891 & 1,339 & 0,196 (ns) \\
\hline ÂNL & 101,729 & 11,854 & 102,371 & 11,976 & 0,643 & 6,103 & 0,483 & 0,635 (ns) \\
\hline
\end{tabular}

ns - não significante

$*-p<0,05$ ou significante a $5 \%$

$* *-p<0,01$ ou significante a $1 \%$ 
TABELA 5.12 - Médias (X) , desvios padrão (d.p.), médias das diferenças, valor "t" e significância estatística das medidas cefalométricas analisadas no grupo III (aparelhos dentossuportados - Hyrax), nas fases 1 (pré-expansão) e 3 (pós-contenção).

\begin{tabular}{|c|c|c|c|c|c|c|c|c|}
\hline FASE & \multicolumn{2}{|c|}{$\begin{array}{c}(1) \\
\text { PRÉ-EXPANSÃO }\end{array}$} & \multicolumn{2}{|c|}{$\begin{array}{c}\text { (3) } \\
\text { PÓS-CONTENÇÃO }\end{array}$} & \multicolumn{2}{|c|}{$\begin{array}{l}\text { DIFERENÇA } \\
\text { (3) - (1) }\end{array}$} & \multirow{2}{*}{$\begin{array}{l}\text { valor } \\
\text { "t" }\end{array}$} & \multirow{2}{*}{$\begin{array}{l}\text { valor "p" e } \\
\text { significância }\end{array}$} \\
\hline Hyrax & $\overline{\mathrm{X}}$ & d.p. & $\bar{X}$ & d.p. & $\bar{X}$ & d.p. & & \\
\hline \multicolumn{9}{|l|}{ medidas } \\
\hline SNA & 81,257 & 2,972 & 81,591 & 3,579 & 0,333 & 1,363 & 1,121 & 0,276 (ns) \\
\hline SN.ENA & 85,800 & 3,995 & 85,948 & 4,070 & 0,148 & 1,588 & 0,426 & 0,675 (ns) \\
\hline Nperp-A & 0,233 & 2,380 & 0,219 & 2,898 & $-0,014$ & 1,420 & $-0,046$ & 0,964 (ns) \\
\hline Sperp-A & 68,105 & 4,169 & 68,514 & 4,874 & 0,410 & 1,436 & 1,307 & 0,206 (ns) \\
\hline SNB & 78,391 & 4,020 & 78,152 & 4,281 & $-0,238$ & 1,341 & $-0,814$ & 0,426 (ns) \\
\hline Nperp-Pog & $-3,338$ & 6,694 & $-4,705$ & 6,625 & $-1,367$ & 2,369 & $-2,644$ & $0,016(*)$ \\
\hline ANB & 2,862 & 3,037 & 3,467 & 2,878 & 0,605 & 1,122 & 2,469 & $0,023(*)$ \\
\hline NAP & 3,929 & 6,495 & 5,367 & 6,275 & 1,438 & 1,987 & 3,316 & $0,003(* *)$ \\
\hline N-ENA & 49,981 & 3,164 & 50,657 & 2,844 & 0,676 & 1,087 & 2,850 & $0,010(* *)$ \\
\hline ENA-PoOr & 21,105 & 3,520 & 22,033 & 3,411 & 0,929 & 1,954 & 2,178 & $0,042(*)$ \\
\hline ENP-PoOr & 22,257 & 2,155 & 23,114 & 2,117 & 0,857 & 1,408 & 2,790 & $0,011(*)$ \\
\hline PoOr.PP & $-1,286$ & 2,946 & $-1,214$ & 3,447 & 0,071 & 1,685 & 0,194 & 0,848 (ns) \\
\hline SN.GoMe & 38,424 & 4,516 & 38,695 & 4,722 & 0,271 & 1,988 & 0,626 & 0,539 (ns) \\
\hline FMA & 29,448 & 4,633 & 30,138 & 4,712 & 0,691 & 1,447 & 2,187 & $0,041(*)$ \\
\hline SN.Gn & 68,786 & 3,313 & 69,262 & 3,285 & 0,476 & 1,380 & 1,581 & 0,130 (ns) \\
\hline$\hat{\mathrm{ABI}}$ & 30,729 & 5,157 & 31,362 & 5,044 & 0,633 & 1,608 & 1,805 & 0,086 (ns) \\
\hline Ar-A & 82,571 & 4,975 & 83,524 & 5,220 & 0,952 & 1,288 & 3,389 & $0,003(* *)$ \\
\hline Ar-Gn & 107,357 & 8,623 & 107,062 & 6,897 & $-0,295$ & 6,230 & $-0,217$ & 0,830 (ns) \\
\hline ENA-Me & 68,210 & 5,466 & 69,452 & 4,496 & 1,243 & 1,995 & 2,855 & $0,010(* *)$ \\
\hline Rㅁ-PP & 3,267 & 2,665 & 2,986 & 2,347 & $-0,281$ & 1,454 & $-0,885$ & 0,387 (ns) \\
\hline Cㅁ-PP & 22,533 & 2,838 & 22,667 & 2,389 & 0,133 & 1,304 & 0,469 & 0,644 (ns) \\
\hline Sperp-R $\underline{6}$ & 43,667 & 3,498 & 43,929 & 3,875 & 0,262 & 1,865 & 0,644 & 0,527 (ns) \\
\hline Sperp-C $\underline{6}$ & 41,752 & 4,247 & 41,419 & 4,781 & $-0,333$ & 2,323 & $-0,657$ & 0,518 (ns) \\
\hline ÂNL & 102,610 & 13,167 & 102,371 & 11,976 & $-0,238$ & 5,086 & $-0,215$ & $0,832(\mathrm{~ns})$ \\
\hline
\end{tabular}

ns - não significante

$*-p<0,05$ ou significante a $5 \%$

$* *-\mathrm{p}<0,01$ ou significante a $1 \%$ 
TABELA 5.13 - Médias $(\overline{\mathrm{X}})$ e desvios padrão (d.p.) das diferenças das medidas cefalométricas analisadas nas fases 1 (pré-expansão) e 2 (pósexpansão), valor "F", valor "p" e significância estatística da análise de variância (ANOVA) aplicada na comparação entre os grupos I (Colado), II (tipo Haas) e III (Hyrax).

\begin{tabular}{|c|c|c|c|c|c|c|c|c|}
\hline \multirow{2}{*}{$\begin{array}{c}\text { DIFERENÇA } \\
\text { ENTRE FASES } \\
2-1\end{array}$} & \multicolumn{2}{|c|}{$\begin{array}{c}\text { COLADO } \\
\mathrm{N}=23\end{array}$} & \multicolumn{2}{|c|}{$\begin{array}{l}\text { TIPO HAAS } \\
\qquad \mathrm{N}=20\end{array}$} & \multicolumn{2}{|c|}{$\begin{array}{c}\text { HYRAX } \\
\mathrm{N}=21\end{array}$} & \multirow{2}{*}{$\begin{array}{l}\text { Valor } \\
\text { "F" }\end{array}$} & \multirow{2}{*}{$\begin{array}{l}\text { valor “p” e } \\
\text { significância }\end{array}$} \\
\hline & $\bar{X}$ & d.p. & $\bar{X}$ & d.p. & $\bar{X}$ & d.p. & & \\
\hline \multicolumn{9}{|l|}{ Medidas } \\
\hline SNA & 1,126 & 1,287 & 0,410 & 1,295 & 0,662 & 1,564 & 1,491 & 0,233 (ns) \\
\hline SN.ENA & 1,470 & 1,880 & 0,275 & 1,369 & 0,433 & 1,888 & 3,060 & 0,054 (ns) \\
\hline Nperp-A & 1,144 & 2,100 & 0,570 & 1,444 & 0,033 & 1,462 & 2,305 & 0,108 (ns) \\
\hline Sperp-A & 0,996 & 1,583 & 0,575 & 1,338 & 0,100 & 1,395 & 2,099 & $0,131(\mathrm{~ns})$ \\
\hline SNB & $-0,757$ & 1,627 & $-1,020$ & 1,227 & $-0,491$ & 1,251 & 0,742 & 0,481 (ns) \\
\hline Nperp-Pog & $-2,034$ & 4,016 & $-2,200$ & 3,064 & $-2,329$ & 2,921 & 0,042 & 0,959 (ns) \\
\hline $\mathrm{ANB}$ & 1,896 & 1,295 & 1,445 & 0,852 & 1,162 & 1,438 & 2,004 & 0,144 (ns) \\
\hline NAP & 4,000 & 2,268 & 3,210 & 1,656 & 2,514 & 2,744 & 2,350 & 0,104 (ns) \\
\hline N-ENA & 0,393 & 1,913 & 0,615 & 0,922 & 0,286 & 0,988 & 0,303 & 0,740 (ns) \\
\hline ENA-PoOr & 0,929 & 1,750 & 0,570 & 1,473 & 0,852 & 1,853 & 0,257 & 0,775 (ns) \\
\hline ENP-PoOr & 1,135 & 1,823 & 0,515 & 1,018 & 0,705 & 1,006 & 1,188 & 0,312 (ns) \\
\hline PoOr.PP & $-0,357$ & 2,469 & 0,080 & 1,363 & 0,148 & 1,821 & 0,429 & 0,653 (ns) \\
\hline SN.GoMe & 2,478 & 2,251 & 1,885 & 1,299 & 1,048 & 1,990 & 3,093 & 0,053 (ns) \\
\hline FMA & 2,470 & 2,761 & 1,730 & 1,814 & 1,705 & 1,658 & 0,893 & 0,415 (ns) \\
\hline SN.Gn & 1,961 & 1,763 & 1,640 & 1,033 & 1,005 & 1,331 & 2,528 & 0,088 (ns) \\
\hline$\hat{\mathrm{ABI}}$ & 2,674 & 2,157 & 1,655 & 1,311 & 1,571 & 1,966 & 2,397 & $0,100(\mathrm{~ns})$ \\
\hline Ar-A & 0,283 & 1,573 & 0,820 & 1,069 & 0,948 & 1,320 & 1,516 & 0,228 (ns) \\
\hline Ar-Gn & 0,380 & 2,515 & 0,315 & 1,275 & $-0,667$ & 5,804 & 0,528 & 0,592 (ns) \\
\hline ENA-Me & 4,482 & 1,975 & 2,700 & 1,573 & 2,205 & 1,943 & 9,304 & $0,000(* *)$ \\
\hline Rㅜ-PP & $-0,203$ & 1,239 & $-0,345$ & 1,343 & 0,314 & 1,279 & 1,518 & 0,227 (ns) \\
\hline C흐-PP & 0,447 & 1,083 & 0,235 & 1,197 & 0,714 & 1,128 & 0,921 & $0,404(\mathrm{~ns})$ \\
\hline Sperp-R $\underline{6}$ & 0,291 & 1,526 & 0,345 & 1,340 & $-0,433$ & 1,583 & 1,792 & 0,175 (ns) \\
\hline Sperp-C $\underline{6}$ & $-0,152$ & 2,413 & 0,345 & 1,568 & $-0,886$ & 1,742 & 2,044 & 0,138 (ns) \\
\hline ÂNL & $-1,583$ & 5,455 & $-0,805$ & 7,014 & $-0,881$ & 5,654 & 0,111 & 0,895 (ns) \\
\hline
\end{tabular}

ns - não significante

$*-\mathrm{p}<0,05$ ou significante a $5 \%$

$* *-p<0,01$ ou significante a $1 \%$ 
TABELA 5.14 - Médias $(\overline{\mathrm{X}})$ e desvios padrão (d.p.) das diferenças das medidas cefalométricas analisadas nas fases 2 (pós- expansão) e 3 (pós-contenção), valor "F”, valor “p” e significância estatística da análise de variância (ANOVA) aplicada na comparação entre os grupos I (Colado), II (tipo Haas) e III (Hyrax).

\begin{tabular}{|c|c|c|c|c|c|c|c|c|}
\hline \multirow{2}{*}{$\begin{array}{c}\text { DIFERENÇA } \\
\text { ENTRE FASES } \\
3-2\end{array}$} & \multicolumn{2}{|c|}{$\begin{array}{c}\text { COLADO } \\
\mathrm{N}=23\end{array}$} & \multicolumn{2}{|c|}{$\begin{array}{c}\text { TIPO HAAS } \\
\qquad \mathrm{N}=20\end{array}$} & \multicolumn{2}{|c|}{$\begin{array}{c}\text { HYRAX } \\
\mathrm{N}=21\end{array}$} & \multirow{2}{*}{$\begin{array}{l}\text { valor } \\
\text { "F" }\end{array}$} & \multirow{2}{*}{$\begin{array}{l}\text { valor "p" e } \\
\text { significância }\end{array}$} \\
\hline & $\bar{X}$ & d.p. & $\overline{\mathrm{X}}$ & d.p. & $\bar{X}$ & d.p. & & \\
\hline \multicolumn{9}{|l|}{ Medidas } \\
\hline SNA & $-0,778$ & 1,559 & $-0,435$ & 1,562 & $-0,329$ & 1,586 & 0,497 & $0,611(\mathrm{~ns})$ \\
\hline SN.ENA & $-1,178$ & 2,065 & $-0,140$ & 1,800 & $-0,286$ & 2,087 & 1,748 & $0,183(\mathrm{~ns})$ \\
\hline Nperp-A & $-1,203$ & 2,227 & $-1,015$ & 1,798 & $-0,048$ & 1,460 & 2,356 & 0,103 (ns) \\
\hline Sperp-A & $-0,848$ & 1,726 & $-0,650$ & 1,423 & 0,310 & 1,207 & 3,767 & $0,029(*)$ \\
\hline SNB & 0,422 & 1,761 & 0,745 & 1,369 & 0,252 & 1,406 & 0,545 & $0,583(\mathrm{~ns})$ \\
\hline Nperp-Pog & 0,426 & 3,733 & 0,610 & 2,760 & 0,962 & 1,783 & 0,191 & 0,827 (ns) \\
\hline ANB & $-1,165$ & 1,378 & $-1,185$ & 0,854 & $-0,557$ & 1,073 & 2,087 & $0,133(\mathrm{~ns})$ \\
\hline NAP & $-2,635$ & 2,480 & $-2,450$ & 1,792 & $-1,076$ & 2,321 & 3,106 & $0,052(\mathrm{~ns})$ \\
\hline N-ENA & 0,253 & 2,155 & $-0,190$ & 1,038 & 0,391 & 1,396 & 0,711 & 0,495 (ns) \\
\hline ENA-PoOr & 0,502 & 1,748 & 0,455 & 1,441 & 0,076 & 1,416 & 0,484 & 0,619 (ns) \\
\hline ENP-PoOr & $-0,004$ & 1,456 & 0,190 & 1,217 & 0,152 & 1,128 & 0,142 & $0,868(\mathrm{~ns})$ \\
\hline PoOr.PP & 0,617 & 2,137 & 0,245 & 1,466 & $-0,076$ & 1,237 & 0,941 & 0,396 (ns) \\
\hline SN.GoMe & $-1,535$ & 1,916 & $-1,355$ & 1,584 & $-0,776$ & 1,988 & 0,996 & $0,376(\mathrm{~ns})$ \\
\hline FMA & $-1,065$ & 2,410 & $-0,825$ & 1,357 & $-1,014$ & 1,563 & 0,097 & 0,908 (ns) \\
\hline SN.Gn & $-1,139$ & 1,904 & $-1,100$ & 1,353 & $-0,529$ & 1,374 & 0,995 & $0,376(\mathrm{~ns})$ \\
\hline$\hat{\mathrm{ABI}}$ & $-1,652$ & 2,190 & $-1,090$ & 1,400 & $-0,938$ & 1,715 & 0,949 & 0,393 (ns) \\
\hline Ar-A & 0,021 & 1,368 & $-0,255$ & 1,018 & 0,005 & 1,388 & 0,305 & 0,739 (ns) \\
\hline Ar-Gn & 0,253 & 3,068 & 0,405 & 0,965 & 0,371 & 1,354 & 0,033 & 0,968 (ns) \\
\hline ENA-Me & $-2,997$ & 2,086 & $-1,390$ & 1,585 & $-0,962$ & 1,303 & 8,766 & $0,001(* *)$ \\
\hline Rㅁ-PP & $-0,257$ & 1,429 & 0,165 & 1,447 & $-0,595$ & 1,129 & 1,643 & $0,202(\mathrm{~ns})$ \\
\hline C $\underline{6}-\mathrm{PP}$ & $-0,633$ & 0,844 & $-0,380$ & 0,828 & $-0,581$ & 0,754 & 0,568 & $0,570(\mathrm{~ns})$ \\
\hline Sperp-R $\underline{6}$ & $-0,422$ & 2,362 & $-0,300$ & 1,133 & 0,695 & 1,599 & 2,467 & 0,093 (ns) \\
\hline Sperp-C $\underline{6}$ & 0,198 & 2,213 & $-0,595$ & 1,367 & 0,552 & 1,891 & 2,004 & $0,144(\mathrm{~ns})$ \\
\hline ÂNL & 1,448 & 6,207 & 2,955 & 5,693 & 0,643 & 6,103 & 0,778 & $0,464(\mathrm{~ns})$ \\
\hline
\end{tabular}


TABELA 5.15 - Médias (X) e desvios padrão (d.p.) das diferenças das medidas cefalométricas analisadas nas fases 1 (pré-expansão) e 3 (póscontenção), valor "F”, valor "p" e significância estatística da análise de variância (ANOVA) aplicada na comparação entre os grupos I (Colado), II (tipo Haas) e III (Hyrax).

\begin{tabular}{|c|c|c|c|c|c|c|c|c|}
\hline \multirow{2}{*}{$\begin{array}{c}\text { DIFERENÇA } \\
\text { ENTRE FASES } \\
3-1\end{array}$} & \multicolumn{2}{|c|}{$\begin{array}{c}\text { COLADO } \\
\qquad \mathrm{N}=23\end{array}$} & \multicolumn{2}{|c|}{$\begin{array}{l}\text { TIPO HAAS } \\
\qquad \mathrm{N}=20\end{array}$} & \multicolumn{2}{|c|}{$\begin{array}{c}\text { HYRAX } \\
\mathrm{N}=21\end{array}$} & \multirow{2}{*}{$\begin{array}{l}\text { valor } \\
\text { "F" }\end{array}$} & \multirow{2}{*}{$\begin{array}{l}\text { valor "p" e } \\
\text { significância }\end{array}$} \\
\hline & $\bar{X}$ & d.p. & $\overline{\mathrm{X}}$ & d.p. & $\overline{\mathrm{X}}$ & d.p. & & \\
\hline \multicolumn{9}{|l|}{ Medidas } \\
\hline SNA & 0,348 & 1,401 & $-0,025$ & 1,080 & 0,333 & 1,363 & 0,549 & 0,581 (ns) \\
\hline SN.ENA & 0,291 & 2,572 & 0,135 & 1,385 & 0,148 & 1,588 & 0,044 & 0,957 (ns) \\
\hline Nperp-A & $-0,059$ & 2,297 & $-0,445$ & 1,555 & $-0,014$ & 1,420 & 0,347 & 0,708 (ns) \\
\hline Sperp-A & 0,148 & 1,740 & $-0,075$ & 1,306 & 0,410 & 1,436 & 0,525 & 0,594 (ns) \\
\hline SNB & $-0,335$ & 1,505 & $-0,275$ & 0,990 & $-0,238$ & 1,341 & 0,031 & 0,970 (ns) \\
\hline Nperp-Pog & $-1,608$ & 3,684 & $-1,590$ & 2,779 & $-1,367$ & 2,369 & 0,042 & 0,959 (ns) \\
\hline ANB & 0,730 & 1,309 & 0,260 & 0,778 & 0,605 & 1,122 & 1,021 & 0,366 (ns) \\
\hline NAP & 1,365 & 2,404 & 0,760 & 1,656 & 1,438 & 1,987 & 0,672 & 0,514 (ns) \\
\hline N-ENA & 0,646 & 1,937 & 0,425 & 1,118 & 0,676 & 1,087 & 0,181 & 0,835 (ns) \\
\hline ENA-PoOr & 1,431 & 2,056 & 1,025 & 1,645 & 0,929 & 1,954 & 0,435 & 0,649 (ns) \\
\hline ENP-PoOr & 1,131 & 1,655 & 0,705 & 1,304 & 0,857 & 1,408 & 0,467 & 0,629 (ns) \\
\hline PoOr.PP & 0,261 & 2,483 & 0,325 & 1,644 & 0,071 & 1,685 & 0,090 & 0,914 (ns) \\
\hline SN.GoMe & 0,944 & 1,774 & 0,530 & 1,110 & 0,271 & 1,988 & 0,902 & 0,411 (ns) \\
\hline FMA & 1,404 & 2,876 & 0,905 & 1,613 & 0,691 & 1,447 & 0,663 & 0,519 (ns) \\
\hline SN.Gn & 0,822 & 1,656 & 0,540 & 0,869 & 0,476 & 1,380 & 0,405 & 0,669 (ns) \\
\hline$\hat{\mathrm{ABI}}$ & 1,022 & 1,872 & 0,565 & 1,576 & 0,633 & 1,608 & 0,462 & 0,632 (ns) \\
\hline Ar-A & 0,304 & 1,571 & 0,565 & 0,896 & 0,952 & 1,288 & 1,380 & 0,259 (ns) \\
\hline Ar-Gn & 0,633 & 1,640 & 0,720 & 1,072 & $-0,295$ & 6,230 & 0,474 & 0,625 (ns) \\
\hline ENA-Me & 1,486 & 1,528 & 1,310 & 1,259 & 1,243 & 1,995 & 0,132 & 0,877 (ns) \\
\hline Rㅁ-PP & $-0,460$ & 1,296 & $-0,180$ & 1,687 & $-0,281$ & 1,454 & 0,200 & $0,820(\mathrm{~ns})$ \\
\hline Cㅁ-PP & $-0,186$ & 0,851 & $-0,145$ & 1,295 & 0,133 & 1,304 & 0,480 & $0,621(\mathrm{~ns})$ \\
\hline Sperp-R $\underline{6}$ & $-0,131$ & 2,321 & 0,045 & 1,416 & 0,262 & 1,865 & 0,229 & 0,796 (ns) \\
\hline Sperp-C므 & 0,046 & 2,351 & $-0,250$ & 1,456 & $-0,333$ & 2,323 & 0,200 & $0,820(\mathrm{~ns})$ \\
\hline ÂNL & $-0,135$ & 5,795 & 2,150 & 6,621 & $-0,238$ & 5,086 & 1,095 & 0,341 (ns) \\
\hline
\end{tabular}

ns - não significante

$*-p<0,05$ ou significante a $5 \%$

$* *-p<0,01$ ou significante a $1 \%$ 
TABELA 5.16 - Comparações entre os três grupos, com as médias $(\overline{\mathrm{X}})$, valor de "p" e significância estatística do teste de Tukey, para a variável Sperp-A na diferença entre as fases 2 (pósexpansão) e 3 (pós-contenção), que apresentou diferença estatisticamente significante na ANOVA.

\begin{tabular}{c|c}
\hline COMPARAÇÃO & valor “p” e significância \\
\hline $\operatorname{COLADO}(\overline{\mathrm{X}}=-0,848) \times \operatorname{TIPO} \operatorname{HAAS}(\overline{\mathrm{X}}=-0,650)$ & $0,899(\mathrm{~ns})$ \\
$\operatorname{COLADO}(\overline{\mathrm{X}}=-0,848) \times \operatorname{HYRAX}(\overline{\mathrm{X}}=0,310)$ & $0,031(*)$ \\
TIPO HAAS $(\overline{\mathrm{X}}=-0,650) \times \operatorname{HYRAX}(\overline{\mathrm{X}}=0,310)$ & 0,103 (ns) \\
\hline
\end{tabular}

ns - não significante

$*-p<0,05$ ou significante a $5 \%$

$* *-p<0,01$ ou significante a $1 \%$

TABELA 5.17 - Comparações entre os três grupos, com as médias $(\overline{\mathrm{X}})$, valor de "p" e significância estatística do teste de Tukey, para a variável ENA-Me na diferença entre as fases 1 (pré-expansão) e 2 (pósexpansão), que apresentou diferença estatisticamente significante na ANOVA.

\begin{tabular}{c|c}
\hline \multicolumn{1}{c|}{ COMPARAÇÃO } & valor “p” e significância \\
\hline $\operatorname{COLADO}(\overline{\mathrm{X}}=4,482) \times \operatorname{TIPO} \operatorname{HAAS}(\overline{\mathrm{X}}=2,700)$ & $0,007(* *)$ \\
$\operatorname{COLADO}(\overline{\mathrm{X}}=4,482) \times \operatorname{HYRAX}(\overline{\mathrm{X}}=2,205)$ & $0,001(* *)$ \\
$\operatorname{TIPO} \operatorname{HAAS}(\overline{\mathrm{X}}=2,700) \times \operatorname{HYRAX}(\overline{\mathrm{X}}=2,205)$ & $0,669(\mathrm{~ns})$ \\
\hline
\end{tabular}

ns - não significante

$*-p<0,05$ ou significante a $5 \%$

$* *-p<0,01$ ou significante a $1 \%$ 
TABELA 5.18 - Comparações entre os três grupos, com as médias $(\overline{\mathrm{X}})$, valor de "p" e significância estatística do teste de Tukey, para a variável ENA-Me na diferença entre as fases 2 (pós-expansão) e 3 (póscontenção), que apresentou diferença estatisticamente significante na ANOVA.

\begin{tabular}{cc}
\hline COMPARAÇÃO & valor “p”e significância \\
\hline $\operatorname{COLADO}(\overline{\mathrm{X}}=-2,997) \times \operatorname{TIPO} \operatorname{HAAS}(\overline{\mathrm{X}}=-1,390)$ & $0,009(* *)$ \\
$\operatorname{COLADO}(\overline{\mathrm{X}}=-2,997) \times \operatorname{HYRAX}(\overline{\mathrm{X}}=-0,962)$ & $0,001(* *)$ \\
TIPO HAAS $(\overline{\mathrm{X}}=-1,390) \times \operatorname{HYRAX}(\overline{\mathrm{X}}=-0,962)$ & $0,702(\mathrm{~ns})$ \\
\hline
\end{tabular}

ns - não significante

$*-\mathrm{p}<0,05$ ou significante a $5 \%$

$* *-p<0,01$ ou significante a $1 \%$ 
TABELA 5.19 - Análise intra-examinador da precisão do método cefalométrico. Apresentação dos erros casuais (Dahlberg), nas fases 1 (pré-expansão), 2 (pós-expansão) e 3 (póscontenção) do grupo I (Colado).

\begin{tabular}{|c|c|c|c|}
\hline VARIÁVEIS & $\begin{array}{c}\text { ERRO CASUAL } \\
\text { (PRÉ-EXPANSÃO) }\end{array}$ & $\begin{array}{c}\text { ERRO CASUAL } \\
\text { (PÓS-EXPANSÃO) }\end{array}$ & $\begin{array}{c}\text { ERRO CASUAL } \\
\text { (PÓS-CONTENÇÃO) }\end{array}$ \\
\hline SNA & 0,377 & 0,502 & 0,532 \\
\hline SN.ENA & 1,166 & 1,409 & 1,261 \\
\hline Nperp-A & 1,174 & 0,783 & 1,212 \\
\hline Sperp-A & 1,006 & 0,469 & 1,017 \\
\hline SNB & 0,230 & 0,489 & 0,381 \\
\hline Nperp-Pog & 2,458 & 1,667 & 1,954 \\
\hline ANB & 0,261 & 0,300 & 0,179 \\
\hline NAP & 0,748 & 0,500 & 0,656 \\
\hline N-ENA & 0,633 & 0,298 & 0,947 \\
\hline ENA-PoOr & 0,977 & 0,298 & 0,867 \\
\hline ENP-PoOr & 0,749 & 0,869 & 1,200 \\
\hline PoOr.PP & 0,606 & 0,589 & 0,661 \\
\hline SN.GoMe & 0,522 & 0,449 & 0,300 \\
\hline FMA & 1,489 & 0,824 & 0,777 \\
\hline SN.Gn & 0,367 & 0,346 & 0,437 \\
\hline$\hat{\mathrm{A} B I}$ & 0,521 & 0,489 & 0,786 \\
\hline $\mathrm{Ar}-\mathrm{A}$ & 0,814 & 0,367 & 0,686 \\
\hline Ar-Gn & 0,774 & 0,690 & 0,736 \\
\hline ENA-Me & 0,670 & 0,249 & 0,373 \\
\hline Rㅁ-PP & 0,979 & 1,165 & 2,085 \\
\hline C6-PP & 0,834 & 0,629 & 1,198 \\
\hline Sperp-R $\underline{6}$ & 1,721 & 1,730 & 1,069 \\
\hline Sperp-C $\underline{6}$ & 1,910 & 1,002 & 1,575 \\
\hline ÂNL & 1,408 & 2,075 & 1,892 \\
\hline
\end{tabular}


TABELA 5.20 - Análise intra-examinador da precisão do método. Valores iniciais e repetidos após o intervalo mínimo de 1 mês (médias e desvios-padrão), diferença das médias, valores de t, p e significância estatística dos erros sistemáticos do grupo I (Colado).

\begin{tabular}{|c|c|c|c|c|c|c|c|}
\hline \multirow[t]{2}{*}{ VARIÁVEIS } & \multicolumn{2}{|c|}{$\begin{array}{l}\text { VALORES } \\
\text { INICIAIS }\end{array}$} & \multicolumn{2}{|c|}{$\begin{array}{l}\text { VALORES } \\
\text { REPETIDOS }\end{array}$} & \multirow{2}{*}{$\begin{array}{c}\text { DIFERENÇA } \\
\text { DAS } \\
\text { MÉDIAS }\end{array}$} & \multirow{2}{*}{$\begin{array}{l}\text { valor } \\
\text { "t" }\end{array}$} & \multirow{2}{*}{$\begin{array}{l}\text { valor "p" e } \\
\text { significância }\end{array}$} \\
\hline & $\bar{X}$ & d.p. & $X$ & d.p. & & & \\
\hline SNA 1 & 80,400 & 1,648 & 80,720 & 2,086 & $-0,320$ & $-1,502$ & $0,208(\mathrm{~ns})$ \\
\hline SNA 2 & 81,020 & 1,838 & 81,020 & 1,972 & 0,000 & 0,000 & 1,000 (ns) \\
\hline SNA 3 & 80,740 & 1,110 & 80,840 & 1,794 & $-0,100$ & $-0,268$ & 0,802 (ns) \\
\hline SN.ENA 1 & 87,720 & 2,432 & 87,860 & 2,532 & $-0,140$ & $-0,170$ & $0,873(\mathrm{~ns})$ \\
\hline SN.ENA 2 & 87,720 & 1,248 & 87,440 & 3,122 & 0,280 & 0,284 & 0,791 (ns) \\
\hline SN.ENA 3 & 86,640 & 1,899 & 88,260 & 2,314 & $-1,620$ & $-4,339$ & $0,012(*)$ \\
\hline Nperp-A 1 & 2,000 & 1,283 & 1,242 & 1,711 & 0,757 & 1,025 & 0,363 (ns) \\
\hline Nperp-A 2 & 2,990 & 3,835 & 3,203 & 3,152 & $-0,214$ & $-0,393$ & 0,714 (ns) \\
\hline Nperp-A 3 & 1,495 & 2,142 & 1,611 & 1,888 & $-0,116$ & $-0,136$ & 0,898 (ns) \\
\hline Sperp-A 1 & 72,958 & 1,614 & 72,200 & 2,443 & 0,757 & 1,256 & 0,277 (ns) \\
\hline Sperp-A 2 & 73,831 & 2,527 & 74,006 & 2,346 & $-0,175$ & $-0,547$ & 0,614 (ns) \\
\hline Sperp-A 3 & 72,666 & 1,571 & 72,822 & 2,417 & $-0,155$ & $-0,217$ & 0,839 (ns) \\
\hline SNB 1 & 77,580 & 2,590 & 77,600 & 2,815 & $-0,020$ & $-0,123$ & 0,908 (ns) \\
\hline SNB 2 & 76,340 & 2,674 & 76,000 & 2,930 & 0,340 & 1,130 & 0,322 (ns) \\
\hline SNB 3 & 77,300 & 2,577 & 77,320 & 2,937 & $-0,020$ & $-0,074$ & 0,944 (ns) \\
\hline Nperp-Pog 1 & 0,447 & 3,749 & $-1,825$ & 1,396 & 2,271 & 1,727 & 0,159 (ns) \\
\hline Nperp-Pog 2 & $-2,077$ & 3,434 & $-2,038$ & 1,469 & $-0,039$ & $-0,033$ & 0,975 (ns) \\
\hline Nperp-Pog 3 & $-2,038$ & 1,527 & $-1,786$ & 3,232 & $-0,252$ & $-0,183$ & 0,863 (ns) \\
\hline ANB 1 & 2,820 & 1,801 & 3,140 & 1,704 & $-0,320$ & $-3,491$ & $0,025(*)$ \\
\hline ANB 2 & 4,700 & 1,995 & 4,980 & 2,029 & $-0,280$ & $-1,757$ & 0,154 (ns) \\
\hline ANB 3 & 3,480 & 1,862 & 3,480 & 1,983 & 0,000 & 0,000 & 1,000 (ns) \\
\hline NAP 1 & 3,580 & 4,661 & 4,560 & 4,581 & $-0,980$ & $-4,937$ & $0,008(* *)$ \\
\hline NAP 2 & 7,860 & 5,321 & 8,380 & 5,758 & $-0,520$ & $-2,170$ & 0,096 (ns) \\
\hline NAP 3 & 5,100 & 4,806 & 5,180 & 5,233 & $-0,080$ & $-0,173$ & 0,871 (ns) \\
\hline N-ENA 1 & 52,709 & 3,301 & 53,272 & 3,950 & $-0,563$ & $-1,619$ & 0,181 (ns) \\
\hline N-ENA 2 & 53,990 & 3,446 & 54,184 & 3,749 & $-0,194$ & $-1,040$ & 0,357 (ns) \\
\hline N-ENA 3 & 53,369 & 3,458 & 53,912 & 3,337 & $-0,544$ & $-0,888$ & 0,425 (ns) \\
\hline ENA-PoOr 1 & 20,346 & 3,611 & 21,627 & 3,143 & $-1,281$ & $-4,975$ & $0,008(* *)$ \\
\hline ENA-PoOr 2 & 22,112 & 2,564 & 21,996 & 2,607 & 0,116 & 0,576 & 0,595 (ns) \\
\hline ENA-PoOr 3 & 22,112 & 2,564 & 21,996 & 2,607 & 0,116 & 0,576 & 0,595 (ns) \\
\hline ENP-PoOr 1 & 24,520 & 2,720 & 25,083 & 3,476 & $-0,563$ & $-1,256$ & 0,278 (ns) \\
\hline ENP-PoOr 2 & 25,025 & 3,427 & 25,743 & 3,429 & $-0,718$ & $-1,441$ & 0,223 (ns) \\
\hline ENP-PoOr 3 & 25,782 & 3,286 & 26,112 & 3,893 & $-0,330$ & $-0,397$ & 0,712 (ns) \\
\hline
\end{tabular}




\begin{tabular}{|c|c|c|c|c|c|c|c|}
\hline \multirow{3}{*}{ VARIÁVEIS } & & & & & \multicolumn{3}{|c|}{ CONTINUAÇÃO } \\
\hline & \multicolumn{2}{|c|}{$\begin{array}{l}\text { VALORES } \\
\text { INICIAIS }\end{array}$} & \multicolumn{2}{|c|}{$\begin{array}{l}\text { SEGUNDA } \\
\text { MEDIÇÃO }\end{array}$} & \multirow{2}{*}{$\begin{array}{c}\text { DIFERENÇA } \\
\text { DAS } \\
\text { MÉDIAS }\end{array}$} & \multirow{2}{*}{$\begin{array}{l}\text { valor } \\
\text { "t" }\end{array}$} & \multirow{2}{*}{$\begin{array}{l}\text { valor "p" e } \\
\text { significância }\end{array}$} \\
\hline & $\bar{X}$ & d.p. & $\bar{X}$ & d.p. & & & \\
\hline PoOr.PP 1 & $-4,440$ & 3,416 & $-3,500$ & 3,323 & $-0,940$ & $-1,284$ & $0,268(\mathrm{~ns})$ \\
\hline PoOr.PP 2 & $-2,980$ & 2,937 & $-3,800$ & 3,526 & 0,820 & 1,557 & 0,194 (ns) \\
\hline PoOr.PP 3 & $-3,140$ & 3,702 & $-3,480$ & 3,336 & 0,340 & 0,354 & 0,741 (ns) \\
\hline SN.GoMe 1 & 35,380 & 5,621 & 35,160 & 5,609 & 0,220 & 0,624 & $0,567(\mathrm{~ns})$ \\
\hline SN.GoMe 2 & 38,540 & 4,899 & 38,460 & 5,142 & 0,080 & 0,254 & 0,812 (ns) \\
\hline SN.GoMe 3 & 36,780 & 5,464 & 36,500 & 5,147 & 0,280 & 1,757 & $0,154(\mathrm{~ns})$ \\
\hline FMA 1 & 23,720 & 6,218 & 24,820 & 4,527 & $-1,100$ & $-1,225$ & 0,288 (ns) \\
\hline FMA 2 & 26,800 & 2,984 & 26,460 & 3,475 & 0,340 & 0,610 & 0,575 (ns) \\
\hline FMA 3 & 26,100 & 4,259 & 25,760 & 4,815 & 0,340 & 0,651 & $0,550(\mathrm{~ns})$ \\
\hline SN.Gn 1 & 67,480 & 3,238 & 67,700 & 3,294 & $-0,220$ & $-0,935$ & 0,403 (ns) \\
\hline SN.Gn 2 & 70,100 & 2,972 & 70,180 & 3,206 & $-0,080$ & $-0,331$ & 0,757 (ns) \\
\hline SN.Gn 3 & 68,620 & 3,416 & 68,560 & 3,308 & 0,060 & 0,195 & 0,855 (ns) \\
\hline ÂBI 1 & 28,200 & 5,774 & 28,300 & 5,783 & $-0,100$ & $-0,274$ & 0,798 (ns) \\
\hline ÂBI 2 & 29,760 & 4,657 & 30,260 & 4,792 & $-0,500$ & $-2,094$ & 0,104 (ns) \\
\hline ÂBI 3 & 29,240 & 5,538 & 29,240 & 5,212 & 0,000 & 0,000 & $1,000(\mathrm{~ns})$ \\
\hline Ar-A 1 & 87,460 & 3,571 & 88,372 & 3,494 & $-0,912$ & $-2,601$ & 0,060 (ns) \\
\hline Ar-A 2 & 88,139 & 2,730 & 88,392 & 2,725 & $-0,252$ & $-1,113$ & $0,328(\mathrm{~ns})$ \\
\hline Ar-A 3 & 87,887 & 3,035 & 88,644 & 3,301 & $-0,757$ & $-2,499$ & 0,067 (ns) \\
\hline Ar-Gn 1 & 109,048 & 7,827 & 109,436 & 7,519 & $-0,388$ & $-0,759$ & 0,490 (ns) \\
\hline Ar-Gn 2 & 110,329 & 7,620 & 109,980 & 7,977 & 0,349 & 0,766 & 0,486 (ns) \\
\hline Ar-Gn 3 & 109,999 & 8,443 & 110,640 & 8,406 & $-0,641$ & $-1,562$ & 0,193 (ns) \\
\hline ENA-Me 1 & 67,832 & 8,487 & 67,619 & 8,155 & 0,214 & 0,462 & 0,668 (ns) \\
\hline ENA-Me 2 & 72,103 & 7,352 & 71,909 & 7,481 & 0,194 & 1,319 & 0,258 (ns) \\
\hline ENA-Me 3 & 69,579 & 7,987 & 69,929 & 7,940 & $-0,349$ & $-1,765$ & 0,152 (ns) \\
\hline Rㅁ-PP 1 & 2,543 & 1,953 & 1,825 & 1,974 & 0,718 & 1,214 & 0,292 (ns) \\
\hline Rㅡㅡ-PP 2 & 2,485 & 2,341 & 1,242 & 1,377 & 1,242 & 2,297 & 0,083 (ns) \\
\hline Rㅜ-PP 3 & 3,029 & 2,606 & 1,456 & 1,018 & 1,573 & 1,261 & 0,276 (ns) \\
\hline Cㅡㅡ-PP 1 & 22,151 & 3,009 & 21,666 & 2,411 & 0,485 & 0,902 & 0,418 (ns) \\
\hline C므-PP 2 & 23,297 & 2,394 & 23,336 & 1,735 & $-0,039$ & $-0,087$ & 0,935 (ns) \\
\hline C $\underline{\overline{6}}-\mathrm{PP} 3$ & 22,307 & 2,677 & 21,258 & 2,048 & 1,048 & 1,576 & 0,190 (ns) \\
\hline Sperp-R $\underline{6} 1$ & 46,593 & 0,832 & 45,467 & 2,560 & 1,126 & 1,044 & 0,355 (ns) \\
\hline Sperp-R $\overline{6} \underline{2}$ & 47,215 & 1,502 & 45,584 & 1,557 & 1,631 & 1,787 & $0,148(\mathrm{~ns})$ \\
\hline Sperp-R $\underline{6} 3$ & 46,127 & 1,049 & 46,710 & 2,307 & $-0,582$ & $-0,835$ & 0,451 (ns) \\
\hline Sperp-C $\overline{\bar{\sigma}} 1$ & 44,652 & 1,941 & 42,730 & 1,694 & 1,922 & 2,025 & 0,113 (ns) \\
\hline Sperp-C $\underline{\overline{6}} 2$ & 44,497 & 2,007 & 44,613 & 0,987 & $-0,116$ & $-0,165$ & 0,877 (ns) \\
\hline Sperp-C $\underline{6} 3$ & 43,817 & 2,201 & 43,118 & 2,431 & 0,699 & 0,661 & 0,545 (ns) \\
\hline ÂNL 1 & 120,220 & 9,792 & 120,100 & 11,497 & 0,120 & 0,121 & 0,910 (ns) \\
\hline ÂNL 2 & 113,780 & 12,154 & 114,240 & 13,468 & $-0,460$ & $-0,317$ & 0,767 (ns) \\
\hline ÂNL 3 & 120,940 & 12,201 & 120,900 & 11,825 & 0,040 & 0,030 & 0,978 (ns) \\
\hline
\end{tabular}

ns - não significante

$*-\mathrm{p}<0,05$ ou significante a $5 \%$

$* *-p<0,01$ ou significante a $1 \%$ 
TABELA 5.21 - Análise interexaminador da precisão do método. Valores das médias $(\mathrm{X})$ e desvios padrão (d.p.) obtidos por KAWAKAMI ${ }^{48}$ e pelo autor, diferença das médias, valor " $t$ ", de "p" e significância estatística.

\begin{tabular}{|c|c|c|c|c|c|c|c|}
\hline VARIÁVEIS & $\begin{array}{r}\text { VALO } \\
\text { KAWA }\end{array}$ & $\begin{array}{l}\text { ES } \\
\text { AMI }\end{array}$ & $\begin{array}{r}\text { VALC } \\
\text { AUT }\end{array}$ & & $\begin{array}{c}\text { DIFERENÇAS } \\
\text { DAS }\end{array}$ & valor & valor "p" e \\
\hline medidas & $\bar{X}$ & d.p. & $\bar{X}$ & d.p. & MÉDIAS & "t" & significância \\
\hline SNA & 79,933 & 2,543 & 79,958 & 2,442 & $-0,025$ & $-0,068$ & 0,947 (ns) \\
\hline SN.ENA & 83,633 & 3,006 & 83,575 & 3,468 & 0,058 & 0,217 & $0,832(\mathrm{~ns})$ \\
\hline Nperp-A & $-1,642$ & 2,343 & $-0,842$ & 1,860 & $-0,800$ & $-2,143$ & 0,055 (ns) \\
\hline Sperp-A & 67,300 & 3,260 & 68,117 & 2,475 & $-0,817$ & $-2,656$ & $0,022(*)$ \\
\hline SNB & 77,750 & 3,370 & 77,867 & 3,616 & $-0,117$ & $-0,415$ & 0,686 (ns) \\
\hline Nperp-Pog & $-5,617$ & 4,970 & $-5,325$ & 6,153 & $-0,292$ & $-0,568$ & 0,582 (ns) \\
\hline $\mathrm{ANB}$ & 2,192 & 3,740 & 2,092 & 3,578 & 0,100 & 0,354 & 0,730 (ns) \\
\hline NAP & 2,300 & 7,736 & 1,817 & 7,681 & 0,483 & 0,922 & 0,376 (ns) \\
\hline N-ENA & 49,800 & 3,266 & 49,600 & 3,571 & 0,200 & 0,480 & 0,641 (ns) \\
\hline ENA-PoOr & 21,300 & 2,174 & 21,483 & 2,321 & $-0,183$ & $-0,566$ & 0,583 (ns) \\
\hline ENP-PoOr & 22,975 & 2,183 & 22,167 & 3,137 & 0,808 & 1,534 & 0,153 (ns) \\
\hline PoOr.PP & $-1,925$ & 2,212 & $-1,992$ & 2,266 & 0,067 & 0,340 & 0,741 (ns) \\
\hline SN.GoMe & 38,375 & 4,398 & 37,675 & 4,406 & 0,700 & 1,315 & 0,215 (ns) \\
\hline FMA & 30,042 & 4,459 & 30,000 & 4,810 & 0,042 & 0,090 & 0,930 (ns) \\
\hline SN.Gn & 68,892 & 3,060 & 68,167 & 3,514 & 0,725 & 1,988 & 0,072 (ns) \\
\hline$\hat{\mathrm{ABI}}$ & 31,967 & 5,067 & 32,625 & 5,759 & $-0,658$ & $-1,662$ & 0,125 (ns) \\
\hline Ar-A & 82,700 & 4,159 & 83,133 & 3,670 & $-0,433$ & $-1,964$ & 0,075 (ns) \\
\hline Ar-Gn & 106,408 & 4,104 & 106,983 & 4,495 & $-0,575$ & $-1,972$ & 0,074 (ns) \\
\hline ENA-Me & 68,725 & 5,070 & 69,042 & 5,521 & $-0,317$ & $-0,987$ & 0,345 (ns) \\
\hline Rㅁ-PP & 3,167 & 2,693 & 1,108 & 2,177 & 2,058 & 4,644 & $0,001(* *)$ \\
\hline C6-PP & 22,667 & 2,693 & 22,358 & 2,214 & 0,308 & 1,001 & 0,334 (ns) \\
\hline Sperp-R $\underline{6}$ & 42,567 & 2,618 & 43,017 & 2,483 & $-0,450$ & $-1,541$ & $0,152(\mathrm{~ns})$ \\
\hline Sperp-C $\overline{6}$ & 40,458 & 2,735 & 41,258 & 2,266 & $-0,800$ & $-1,773$ & $0,104(\mathrm{~ns})$ \\
\hline ÂNL & 94,492 & 16,229 & 94,700 & 16,040 & $-0,208$ & $-0,259$ & $0,801(\mathrm{~ns})$ \\
\hline
\end{tabular}

ns - não significante

$*-\mathrm{p}<0,05$ ou significante a $5 \%$

$* *-\mathrm{p}<0,01$ ou significante a $1 \%$ 
6

DISCUSSÃO 


\section{6 - DISCUSSÃO}

A mordida cruzada posterior pode ser definida como a relação inadequada dos dentes posteriores superiores sobre os inferiores, ou seja, quando as cúspides vestibulares dos dentes superiores ocluem nas fossas centrais dos antagonistas inferiores. Apresenta-se com prevalência em torno de $18,5 \%$, na região de Bauru $-\mathrm{SP}^{84}$, tanto na dentadura decídua, como na mista e permanente e a sua ocorrência pode acarretar perdas de espaço para os dentes permanentes sucessores ${ }^{5,8}$. Essa má oclusão dificilmente se autocorrige espontaneamente, indicando-se então a correção precoce, o mais tardar até o período intertransitório da dentadura mista ${ }^{89}$. A correção precoce deve ser indicada no intuito de permitir o correto desenvolvimento do esqueleto craniofacial ${ }^{49}$, o reposicionamento das bases superiores sobre as inferiores ${ }^{37}$, o redirecionamento dos dentes permanentes para a correta posição ${ }^{9}$ a correção da assimetria na posição condilar $^{17,87}$.

BISHARA; STALEY ${ }^{13}$ relataram que os pacientes que apresentam discrepância lateral transversa, resultando em mordida cruzada posterior, uni ou bilateral, envolvendo vários dentes, são indicados à expansão maxilar. A atresia pode ser dentária, com envolvimento apenas ao nível dentário, esquelética, quando a maxila encontra-se deficiente, ou a combinação de ambas.

Segundo DIPAOLO ${ }^{32}$, a mordida cruzada pode ser classificada de duas maneiras: a) mordida cruzada por deficiência esquelética da base maxilar, que deve ser tratada com expansão maxilar e b) mordida cruzada devido ao excesso de inclinação palatina dos dentes superiores com os 
dentes inferiores, devendo ser tratada com outros mecanismos, ao invés da expansão maxilar.

O preciso diagnóstico da presença de atresia maxilar implica na correta terapia e deve ser realizado levando-se em consideração não apenas a relação de intercuspidação dos arcos dentários entre si, pois poderá induzir em erro, quando não houver o cruzamento dos dentes superiores com os inferiores, nos pacientes com inclinação acentuada dos dentes inferiores para lingual ${ }^{17,}{ }^{18}$. $\mathrm{O}$ arco alveolar superior deve apresentar formato parabólico e, na presença de atresia maxilar real, o formato deste geralmente é triangular ${ }^{17}$. $\mathrm{O}$ mais indicado seria, portanto, uma avaliação intra-arco alveolar superior.

Alguns dos fatores etiológicos associados à mordida cruzada posterior podem ser relacionados à obstrução das vias aéreas e, conseqüentemente, à respiração bucal, pressionamento lingual atípico, perdas precoces de dentes decíduos, hábitos bucais deletérios, como a sucção digital e à deficiência de desenvolvimento maxilar ${ }^{57}$.

Para a correção da atresia maxilar esquelética, torna-se clara a necessidade de uma ampla movimentação, que não envolva apenas os dentes, mas sim uma alteração ortopédica decorrente da abertura da sutura maxilar, capaz de reposicionar os alvéolos, os dentes e, conseqüentemente, os segmentos maxilares $9,13,38$.

A terapia da expansão maxilar tem como objetivo reposicionar a maxila sobre a mandíbula, favorecendo a normalização da oclusão e, em indivíduos em fase de crescimento, devolver as condições ideais de função 
e estética e possibilitar o correto desenvolvimento da oclusão, até atingir a dentadura permanente.

Como parte das indicações associadas à disjunção palatina, tão propalada na literatura e aceita por ampla gama de profissionais, estão: a mordida cruzada posterior uni e bilateral, mordida cruzada funcional, más oclusões de Classes II e III, atresias maxilares, discrepâncias dente/osso negativas, correção da inclinação axial dos dentes posteriores superiores, sobremordida profunda, redução da resistência aérea e pacientes portadores de fissura labiopalatal 4, 12, 13, 14, 37, 38, 39, 61, 65, 83 .

Após o primeiro relato de expansão maxilar com a separação ao nível da sutura palatina, por ANGELL ${ }^{5}$, em 1860, em decorrência da polêmica obtida na época, a terapia permaneceu relegada ao esquecimento até meados de 1960. A divulgação da terapia coube ao precursor norteamericano, Andrew J. Haas ${ }^{36,37,38,39}$ que, entusiasmado com os resultados obtidos por pesquisadores europeus, iniciou novas pesquisas na Universidade de Illinois, primeiramente com animais e posteriormente em humanos, onde expandiu a maxila, verificando a abertura da sutura maxilar por meio de radiografias oclusais, conseqüente aparecimento do diastema interincisivos superiores, alargamento do arco superior e deslocamento maxilar para anterior, assegurando, com isso, novos horizontes para a terapia.

A terapia da expansão maxilar, além de seus efeitos ortopédicos, como a disjunção dos maxilares superiores, por meio da separação na região da sutura palatina ${ }^{5,25,30,37,38,46,87,99}$, traz um aumento nas dimensões transversas da arcada superior $5,10,14,22,25,37,52$, com ganhos reais de massa óssea e perímetro do arco ${ }^{1,10}$ e aumentos transversos na região alta da 
abóbada palatina $^{22,25,44}$, mantendo a altura estável ${ }^{22,30}$. No entanto, alguns autores verificaram o decréscimo dessa altura ${ }^{91}$.

A evidência clínica da expansão maxilar com a separação ao nível da sutura palatina se dá com o aparecimento do diastema interincisivos ${ }^{36,}$ 37,86. A radiografia oclusal do maxilar demonstrará uma zona radiolúcida com formato triangular, com a base maior voltada para a região da espinha nasal anterior e a menor, para a espinha nasal posterior ${ }^{5,25,30,37,38,44,90,94 .}$

Além dos já relacionados efeitos ortopédicos, encontraremos os efeitos ortodônticos relacionados à inclinação dos processos alveolares ${ }^{36,38}$ e conseqüiente vestibularização dos dentes póstero-superiores ${ }^{1,22,44,54,88 .}$.

A terapia da expansão maxilar com os aparelhos expansores convencionais, como o tipo Haas e o Hyrax, está associada a outras alterações no esqueleto craniofacial, como o deslocamento maxilar para anterior $^{16,30,35,36,38,87,99}$ e para baixo $^{3,16,17,18,30,35,36,38,87,88,93,97,98}$, extrusão dos molares superiores de ancoragem ${ }^{3}, 16,17,18,21,41,88,94$ e rotação mandibular no sentido horário $16,17,18,30,38,41,48,88,90,94,98,99$. A rotação mandibular, freqüentemente associada à expansão rápida maxilar, trará alterações na altura facial, que se acentuará $^{3,} 16,19,32,48,72,85,88,94$, ocasionando uma tendência de mordida aberta anterior ${ }^{30,38,58}$, tornando-se altamente desfavorável em pacientes com altura facial já acentuada, ou mesmo em pacientes com presença de mordida aberta anterior.

O aparelho expansor Colado, com cobertura acrílica na oclusal dos dentes superiores, proposto neste estudo, destina-se, principalmente, à eliminação das alterações que possam aumentar desfavoravelmente a altura facial. 
A escassa literatura pertinente a esse tipo de aparelho tem demonstrado resultados satisfatórios na correção das discrepâncias transversais maxilares, como a mordida cruzada posterior. ${ }^{34,54,61,77}$ e o controle das dimensões verticais ${ }^{6,34,54,61,62,70,72,77 .}$.

O trabalho proposto tem como objetivo verificar as reais vantagens e alterações decorrentes dos aparelhos expansores maxilares Colado, com cobertura acrílica na oclusal dos dentes superiores, assim como comparálas às decorrentes dos aparelhos expansores do tipo Haas e Hyrax, previamente estudados.

Para avaliar os dados obtidos, discutiremos as alterações dentoesqueléticas ocorridas com a terapia da expansão maxilar e agrupadas, distintamente, de acordo com as interpretações específicas para cada grupo de medidas, divididos nos seguintes itens:

6.1 - Erro do método

6.2 - Análise interexaminador

6.3 - Relação das bases ósseas: SNA, SN.ENA, Nperp-A, Sperp-A, N-ENA, ENA-PoOr, ENP-PoOr, SNB, Nperp-Pog, NAP e ANB, (Figuras 4.11 e 4.14).

6.4 - Relação maxilomandibular: Ar-A, Ar-Gn, ENA-Me (Figura 4.15).

6.5 - Padrão do esqueleto cefálico: PoOr.PP, SN.GoMe, FMA, SN.Gn, ÂBI (Figura 4.12).

6.6 - Relação dos arcos dentários x bases apicais: Rㅁ-PP, Cㅁ-PP, Sperp-Rㅁ e Sperp-Cㅁ (Figura 4.16).

6.7 - Perfil mole: ÂNL (Figura 4.13).

6.8 - Considerações finais 


\section{1 - ERRO DO MÉTODO}

Antes de iniciar a discussão dos tópicos já citados, devemos salientar que as estruturas anatômicas e os pontos cefalométricos foram obtidos por um único pesquisador. No entanto, torna-se compreensível que na demarcação de alguns pontos, em estruturas mais difíceis de se visualizar radiograficamente, pode haver distorções dessas medidas, o que levaria a equivocadas interpretações.

HOUSTON $^{45}$ e JANSON $^{47}$ recomendam que os traçados cefalométricos e as medições sejam realizadas duas vezes, em todas as amostras porém, não sendo possível tal realização, indicam que as radiografias sejam selecionadas ao acaso, da amostra total, para verificar os erros de medição.

Para minimizar qualquer tipo de influência nesse sentido e aumentar a precisão e a confiabilidade, foram retraçadas e redigitalizadas, após um intervalo mínimo de um mês ${ }^{47,79}, 15$ telerradiografias, de cinco pacientes, nas três fases do estudo, do grupo I (aparelho Colado), número esse considerado suficiente, devido à quantidade de pacientes da amostra foi aplicado o método estatístico de DAHLBERG ${ }^{28}$, para a determinação do erro casual, apresentado em milímetros na Tabela 5.19.

A Tabela 5.19 demonstra as variações ocorridas nos três tempos das radiografias retraçadas. Observou-se que o maior erro casual para medidas lineares ocorreu para a Nperp-Pog (pré-expansão), que variou em torno de 2,4 milímetros. Para as medidas angulares, a maior variação se deu para a medida ÂNL (pós-expansão), em média de dois graus. Essas médias mais elevadas alertam para a existência de deficiência na padronização dos 
métodos, em uma ou em várias etapas, como a demarcação das estruturas anatômicas e dos pontos cefalométricos ${ }^{79}$ e sua digitalização.

Além do erro casual, avaliaram-se os erros sistemáticos mediante a aplicação do teste “t” pareado (variáveis dependentes), para a detecção de sua significância estatística.

Na Tabela 5.20, verificou-se que entre as variáveis nos três tempos da amostra, ocorreram diferenças estatisticamente significantes, para SN.ENA (pós-contenção) ANB, NAP e ENA-PoOr (pré-expansão). No entanto, devido ao grande número de variáveis analisadas, estas podem ser aceitas devido à confirmação e à existência de deficiência na padronização da demarcação dos pontos, em uma ou várias etapas, assim como a alta precisão do método de medição das variáveis por meio computadorizado. 


\section{2 - ANÁLISE INTEREXAMINADOR}

$\mathrm{Na}$ Tabela 5.21, verificou-se a precisão dos traçados entre o examinador KAWAKAMI ${ }^{48}$ e o autor. Devido às amostras terem sido obtidas em tempos diferentes e traçadas por examinadores também diferentes, uma provável distorção entre os traçados poderia interferir nos resultados. Com o objetivo de verificar a precisão entre esses traçados, foram retraçadas $10 \%$ do total das telerradiografias da amostra do prévio estudo e aplicado o método estatístico.

Observou-se que houve significância estatística para as medidas Sperp-A e Rㅁ-PP. Nesta última, justificada pela dificuldade na visualização do ápice radicular na radiografia. Apesar da medida Sperp-A demonstrar alteração em torno de um grau, esta pode ser justificada pelo nível de 5\% de significância. 


\section{3 - RELAÇÃO DAS BASES ÓSSEAS}

A relação das bases ósseas foi investigada pelas análises cefalométricas em norma lateral, avaliando o seu comportamento no sentido anteroposterior, por meio das medidas angulares (SNA, SN.ENA, SNB, NAP, ANB ), lineares (Sperp-A, Nperp-A, Nperp-Pog) e também no sentido vertical, pelas medidas lineares (N-ENA, ENA-PoOr, ENP-PoOr).

A vasta literatura pertinente ao assunto, quando se avalia a posição maxilar isoladamente, após a expansão, denota que a maxila projeta-se para anterior, como resposta imediata à terapia ${ }^{16,30,35,36,38,88,99}$. Avaliandose o posicionamento maxilar pelas medidas SNA e SN.ENA, os resultados do trabalho evidenciaram um deslocamento para anterior da maxila, nos três grupos da fase pré-expansão para a pós-expansão, ou seja, durante a fase ativa (Tabelas 5.4, 5.7 e 5.10). Entretanto, os valores foram significantes apenas para o grupo dos aparelhos Colados, decaindo posteriormente em todos os grupos, principalmente no grupo I, retornando a valores próximos do inicial, após a fase de contenção (Tabelas 5.5, 5.8, 5.11). Ao final da avaliação, no período pós-contenção, observou-se um deslocamento discreto e não significante para a anterior da maxila, nos três aparelhos. Apenas o grupo II apresentou um suave reposicionamento para posterior pela medida SNA, após o período de contenção, mas sem significância estatística. (Tabelas 5.6, 5.9 e 5.12, Figura 6.1 e 6.2).

Pela análise de variância, os três grupos não apresentaram diferenças entre as alterações cefalométricas estatisticamente significantes entre as três fases estudadas. (Tabelas de 5.13 a 5.15). 


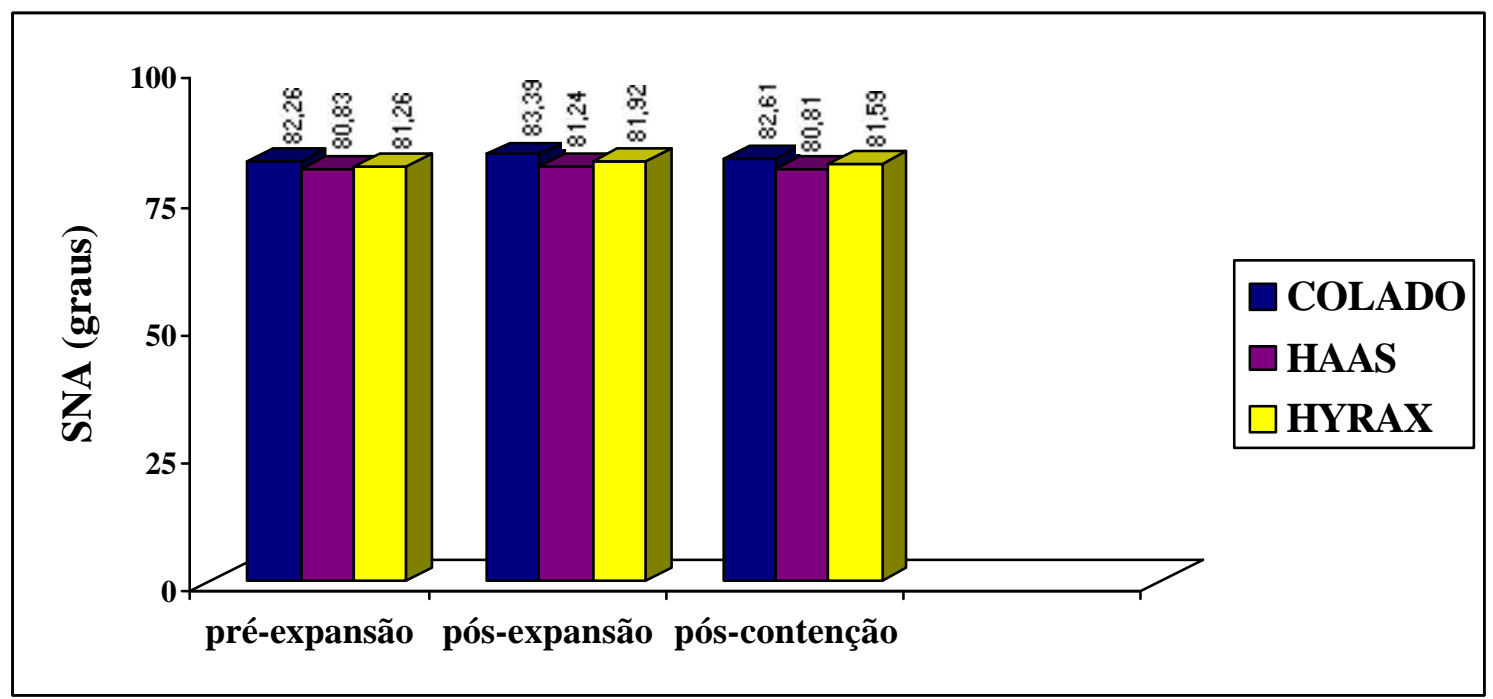

FIGURA 6.1 - Comportamento das médias da grandeza cefalométrica SNA, durante as fases estudadas, nos grupos I (Colado), II (tipo Haas) e III (Hyrax).

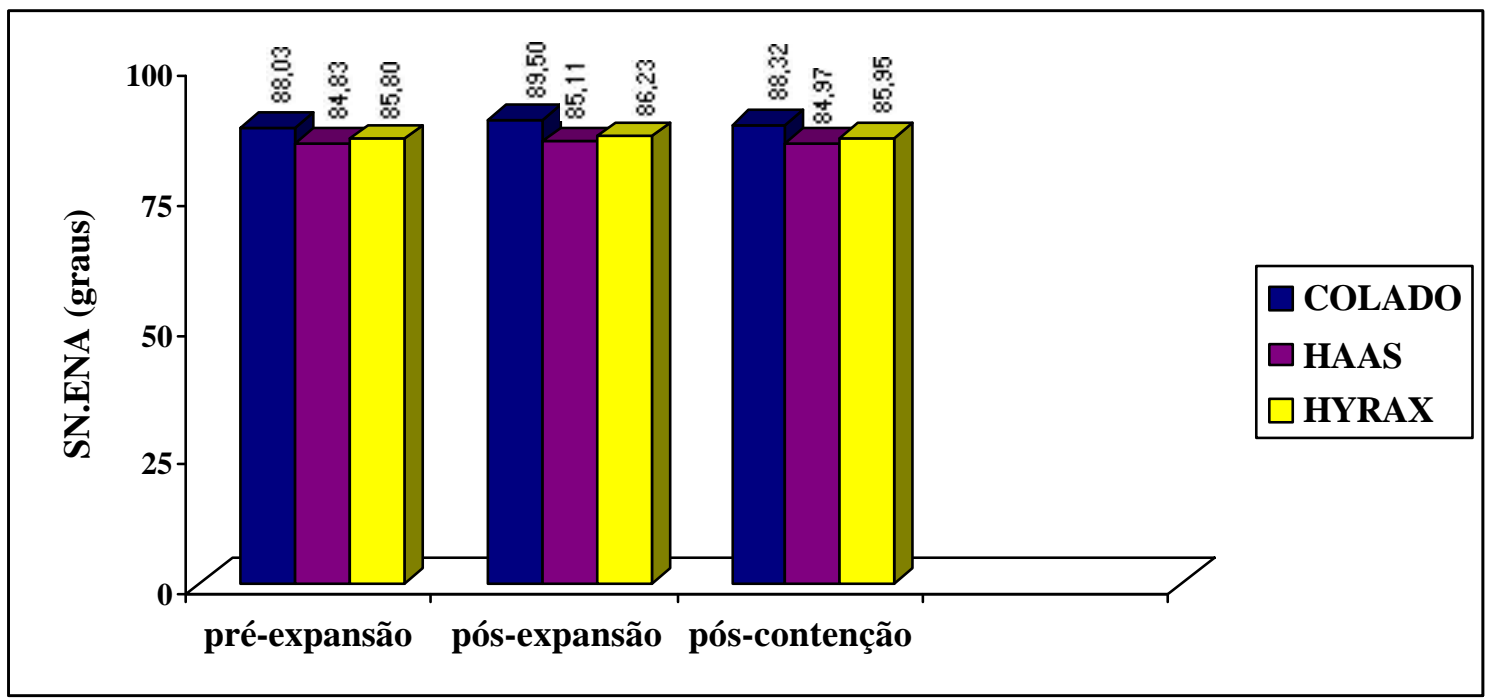

FIGURA 6.2 - Comportamento das médias da grandeza cefalométrica SN.ENA, durante as fases estudadas, nos grupos I (Colado), II (tipo Haas) e III (Hyrax). 
Além das medidas angulares, foram eleitas medidas lineares, para avaliação da alteração espacial da maxila, tanto no sentido anteroposterior, quanto no vertical. No sentido sagital, foram analisadas as grandezas Nperp-A e Sperp-A. Os resultados assemelharam-se às medidas angulares, em que durante a fase ativa da expansão houve avanços para anterior, do ponto A para todos os grupos, embora estatisticamente significante apenas para o grupo I (Tabelas 5.4, 5.7, 5.10). Da fase pós-expansão para a póscontenção, ocorreu a recidiva dos ganhos na fase pós-expansão já citados, em que a maxila se retroposicionou significantemente para os grupos I e II, para as duas medidas citadas, contudo, no grupo II sem signific ância para a Sperp-A, enquanto que no grupo III ocorreu uma ligeira retroposição do ponto A, para a medida Nperp-A, sem significância estatística (Tabelas $5.5,5.8$ e 5.11$)$.

$\mathrm{Na}$ avaliação da fase pré-expansão para a pós-contenção, nos grupos I e III, ocorreu uma ligeira diminuição da medida Nperp-A, sugerindo um retroposicionamento do ponto $\mathrm{A}$, ao final do período de contenção. No entanto, a medida Sperp-A denuncia um acréscimo suave dessa medida, onde o ponto A teria avançado ao final da contenção, sem significância estatística. No grupo II, essas duas medidas evidenciaram uma ligeira retroposição do ponto $\mathrm{A}$, ao final do tratamento, sem grande significância estatística (Tabelas 5.6, 5.9 e 5.12). Concluindo, as medidas lineares demonstraram que após a fase ativa do tratamento houve avanço da maxila para a anterior. Após o final da terapia, entretanto, esses avanços se mantiveram para os grupo I e III na medida Sperp-A muito discretamente e sem significância estatística e no grupo II, houve um reposicionamento discreto, para posterior, do ponto A. 
No entanto, não foram verificados alterações significantes da fase pré-expansão para a pós-contenção em nenhum dos três grupos que identificasse o movimento para a anterior da maxila.

Pela análise de variância, na comparação das alterações das medidas entre os três grupos, ocorreu uma diferença estatística entre a fase pós-expansão e a pós-contenção na alteração da medida Nperp-A (Tabela 5.14), que, na análise de Tukey, se constatou ser entre o grupo do aparelho Colado e o Hyrax (Tabela 5.16). Com o aparelho Colado houve um reposicionamento do ponto A para posterior, ou seja, após o período de expansão ativa, o aparelho Colado demonstrou um decréscimo dessa medida sugerindo o reposicionamento do ponto A para posterior, enquanto que o Hyrax apresentou um aumento, indicando que o ponto A avançou, com este aparelho, para anterior, após a remoção do aparelho expansor em contenção. É importante salientar que na avaliação entre os três grupos, pela análise de variância da fase inicial e final do tratamento, não se encontrou alterações significativas entre os aparelhos, denotando que apesar das diferenças significativas durante o tratamento entre os dois grupos, ao final, eles tenderam a se normalizar (Tabela 5.15, Figuras 6.3 e $6.4)$. 


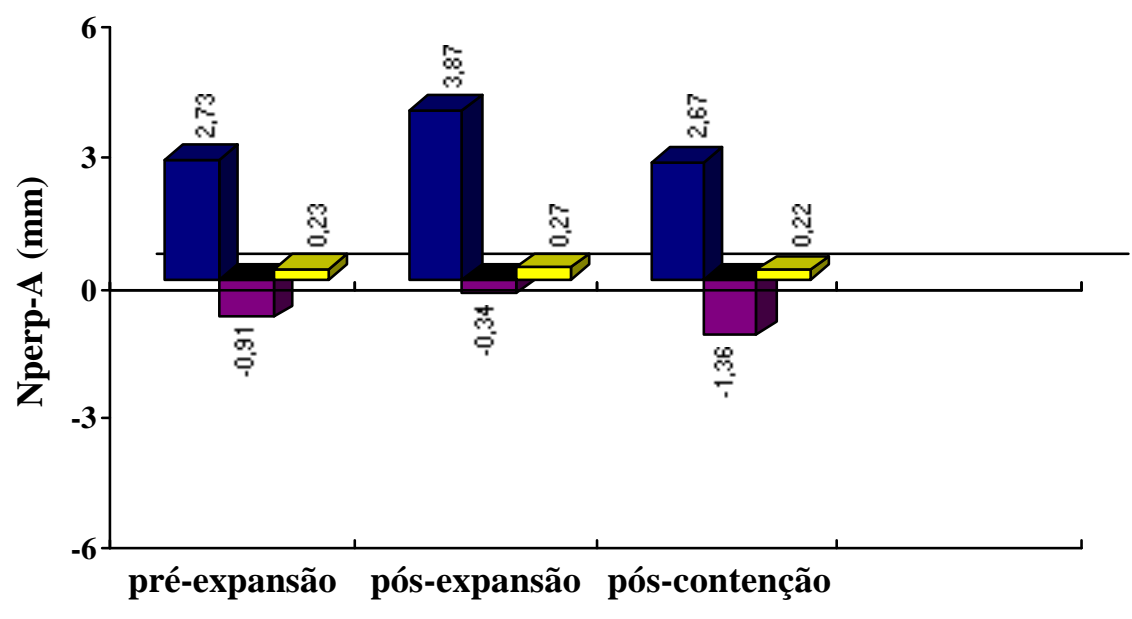

- COLADO

FIGURA 6.3 - Comportamento das médias da grandeza cefalométrica Nperp-A, durante as fases estudadas, nos grupos I (Colado), II (tipo Haas) e III (Hyrax).

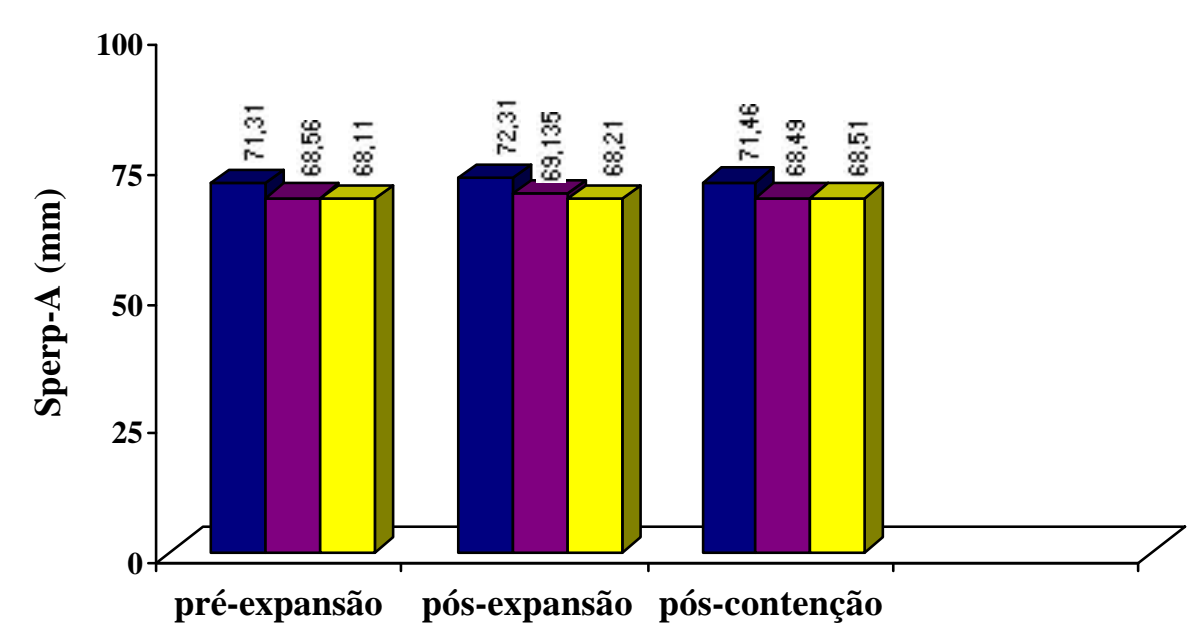

口 COLADO $\square$ HAAS $\square$ HYRAX

FIGURA 6.4 - Comportamento das médias da grandeza cefalométrica Sperp-A, durante as fases estudadas, nos grupos I (Colado), II (tipo Haas) e III (Hyrax). 
Neste trabalho não foram encontradas alterações significativas do possível avanço maxilar, ao final do tratamento, entre os grupos estudados, o que contradiz os resultados de SARVER; JOHNSTON ${ }^{77}$, que relataram o movimento maxilar para anterior menor, com os aparelhos colados, do que com os bandados. Já ASANZA;CISNEROS; NIEBERG ${ }^{6}$ relataram diferenças na movimentação para anterior, com o uso do aparelho Hyrax demonstrando maiores avanços em comparação com o aparelho Colado.

As alterações nas dimensões verticais da maxila foram verificadas pelas medidas cefalométricas NENA, ENA-PoOr e ENP-PoOr. Para os valores de N-ENA, houve aumento da fase pré-expansão para a pósexpansão, em todos os grupos, porém, significantemente apenas para o grupo do aparelho tipo Haas (Tabelas 5.4, 5.7 e 5.10). Da fase pósexpansão para a pós-contenção ocorreram aumentos para os grupos I e III e diminuição no grupo II, mas não foram estatisticamente significantes (Tabelas 5.5, 5.8 e 5.11).

$\mathrm{Na}$ avaliação entre o início e o final do tratamento ocorreu a acentuação dessa medida, para os três grupos, embora significantemente apenas no grupo do aparelho Hyrax, sugerindo um real deslocamento para baixo da espinha nasal anterior, que foi mantido, nesse grupo, ocasionando um aumento na altura facial superior da face (Tabelas 5.6, 5.9 e 5.12). Pela análise final de variância não se encontrou alterações significativas nas fases entre os três grupos e verificou-se que todos eles apresentaram um discreto aumento na altura facial superior, causado provavelmente pelo deslocamento da espinha nasal anterior para baixo (Tabelas de 5.13 a 5.15 e Figura 6.5). 


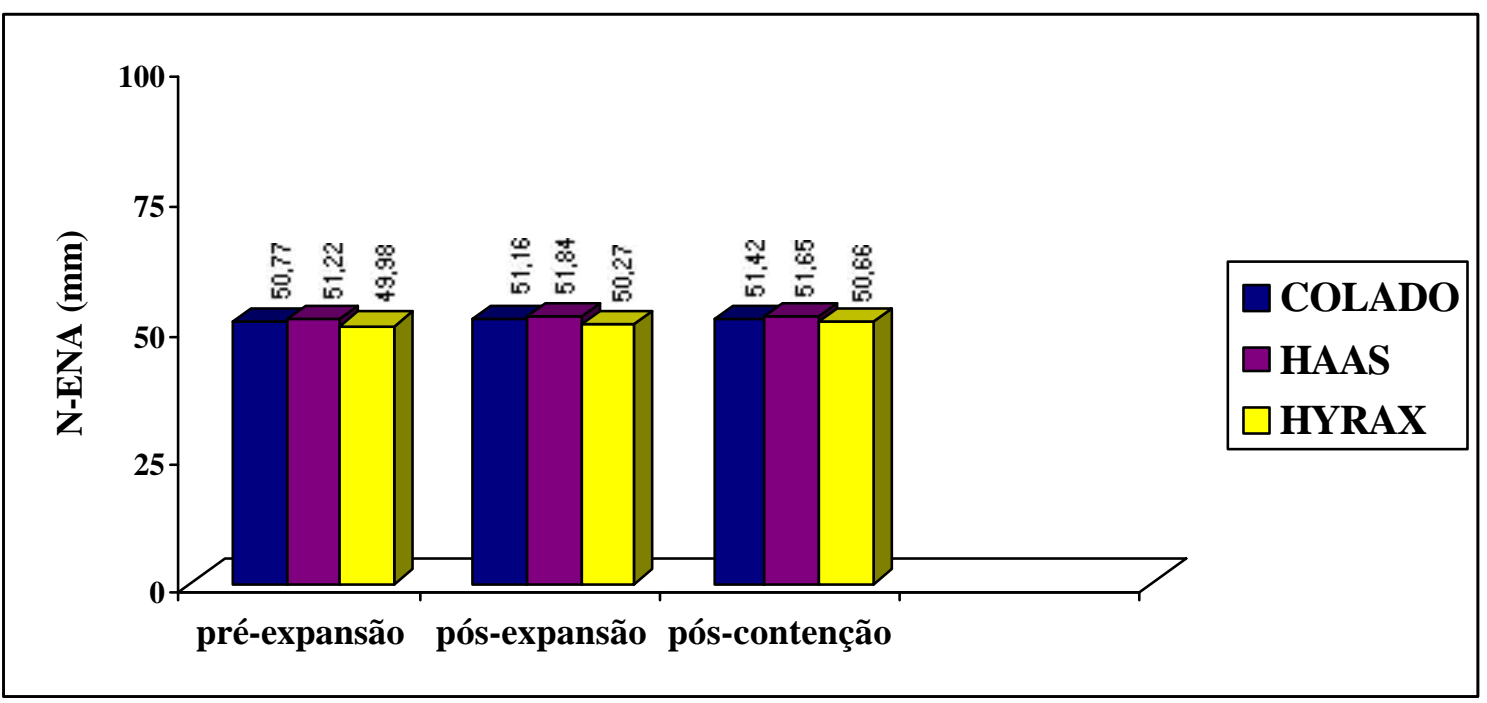

FIGURA 6.5 - Comportamento das médias da grandeza cefalométrica N-ENA, durante as fases estudadas, nos grupos I (Colado), II (tipo Haas) e III (Hyrax).

As medidas lineares ENA-PoOr e a ENP-PoOr, que verificam as possíveis alterações da espinha nasal anterior e posterior, em relação ao plano horizontal de Frankfürt, demonstraram um deslocamento para inferior da ENA e ENP, na fase ativa do tratamento, em todos os grupos, com significância para os grupos I e III, em ambas as medidas e no grupo II, para ENP-PoOr (Tabelas 5.4, 5.7 e 5.10). Na fase pós-contenção, no grupo I, ocorreu aumento da medida ENA-PoOr e diminuição da ENPPoOr, sem significância estatística, enquanto nos grupos II e III houve aumento dessas medidas, sem significância (Tabelas 5.5, 5.8 e 5.11).

$\mathrm{Na}$ avaliação entre a fase pré-tratamento e pós-contenção, notou-se aumentos significativos nas medidas dos grupos dos aparelhos Colado, tipo Haas e Hyrax, denunciando o deslocamento do plano palatino para baixo, nos três grupos (Tabelas 5.6, 5.9 e 5.12, Figuras 6.6 e 6.7). 


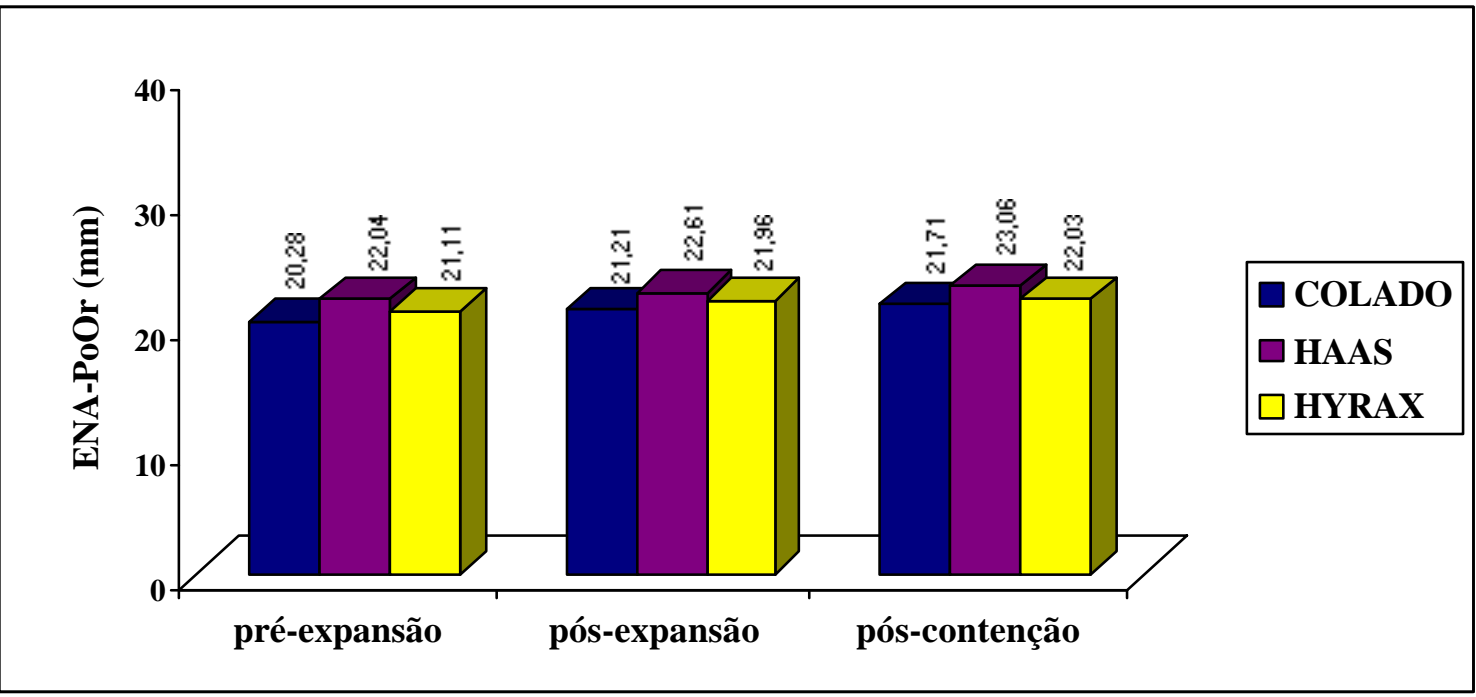

FIGURA 6.6 - Comportamento das médias da grandeza cefalométrica ENA-PoOr, durante as fases estudadas, nos grupos I (Colado), II (tipo Haas) e III (Hyrax).

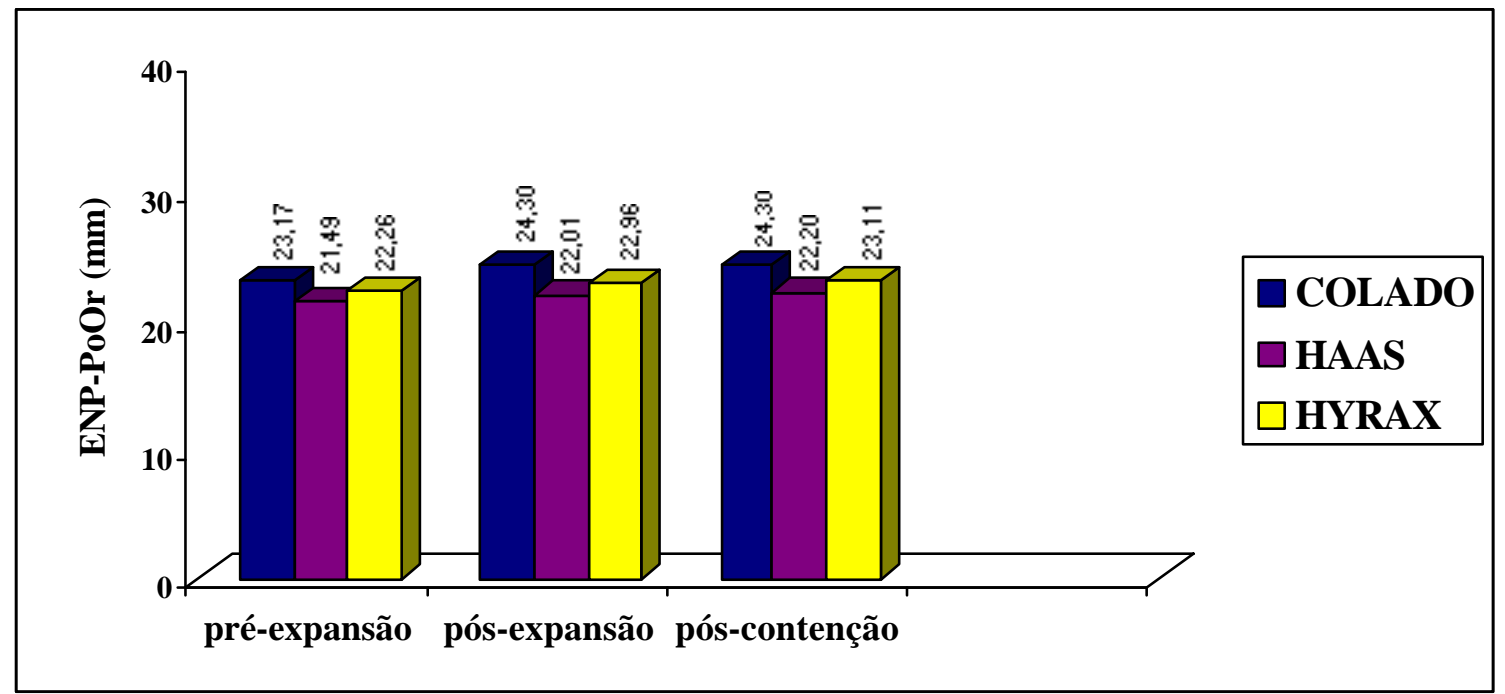

FIGURA 6.7 - Comportamento das médias da grandeza cefalométrica ENP-PoOr, durante as fases estudadas, nos grupos I (Colado), II (tipo Haas) e III (Hyrax). 
Pela análise de variância não se observou alterações significativas nesse deslocamento entre os três tipos de aparelho. (Tabelas de 5.13 a 5.15)

Desde o início dos estudos e trabalhos com a terapia da expansão maxilar, autores como DAVIS; KRONMAN ${ }^{30}$, GARDNER; KRONMAN $^{35}$, HAAS ${ }^{36}, 38$ e WERTZ; DRESKIN ${ }^{99}$ relataram um movimento para anterior da maxila, após a disjunção palatina com os aparelhos convencionais. No entanto, CARREIRA ${ }^{21}$, CHANG; MCNAMARA JUNIOR; HERBERGER ${ }^{24}$, DIPAOLO ${ }^{32}$ e HEFLIN $^{41}$ não encontraram alterações reais no sentido anteroposterior da maxila. Nos trabalhos de BYRUM JUNIOR ${ }^{16}$ e SILVA FILHO; VILLAS BOAS e CAPELOZZA FILHO ${ }^{88}$ onde se instituiu a terapia ma dentadura decídua e mista, não foi observado qualquer deslocamento, assim como nos de SILVA FILHO et al. ${ }^{90}$, onde os pacientes na dentadura permanente não evidenciaram esses deslocamentos. Para o grupo I (aparelhos Colados), ao final do período de contenção, não foram encontradas alterações significantes que indicassem o deslocamento da maxila para a anterior, o que corrobora os resultados obtidos por NIEBERG ${ }^{6}$, LÉON et al. ${ }^{54}$, MEMIKOGLU; ISERI ${ }^{62}$, REED; GHOSH; NANDA ${ }^{72}$ e SARVER; JOHNSTON $^{77}$, que também estudaram os aparelhos colados. Neste estudo, verificou-se um discreto reposicionamento do ponto A para posterior, pela medida N-perpA, sem significância estatística, confirmando os resultados de SARVER; JOHNSTON ${ }^{77}$, que também encontraram o reposicionamento do ponto A para posterior em alguns pacientes de sua amostra após o período de contenção do aparelho Colado.

Para os grupos I, II e III, as medidas angulares e lineares não confirmaram qualquer avanço estatístico significativo da maxila, ao final do período de contenção, corroborando os resultados obtidos por 
CAPELOZZA FILHO; SILVA FILHO ${ }^{18}$, SANDIKÇIOGLU; HAZAR ${ }^{74}$, SILVA FILHO et al. $^{90}$ e VELÁSQUEZ; BENITO; BRAVO ${ }^{96}$. Ao contrário, algumas medidas lineares e angulares demonstraram redução, indicando um posicionamento do ponto A mais posteriormente para os dois grupos, porém sem significância estatística, o que foi relatado também por SARVER; JOHNSTON ${ }^{77}$, WERTZ; DRESKIN ${ }^{99}$.

Apesar da maxila não ter sofrido deslocamento real para anterior, ocorreu o deslocamento para baixo, em resposta à terapia, pela avaliação das medidas N-ENA, ENA-PoOr e ENP-PoOr, para o grupo dos aparelhos Colado, tipo Haas e Hyrax, que se mantiveram estáveis ao final do período de contenção. Esses resultados foram verificados e confirmados por vários autores, como ALMEIDA; CAPELOZZA FILHO; TRINDADE JÚNIOR ${ }^{3}$, BYRUM JUNIOR ${ }^{16}$, CAPELOZZA FILHO; SILVA FILHO ${ }^{18}$, DAVIS; KRONMAN $^{30}$, GARDNER; KRONMAN ${ }^{35}$, HAAS $^{36,}{ }^{38}$, SILVA FILHO; VALLADARES NETO; ALMEIDA ${ }^{87,}{ }^{88}$, TEIXEIRA; SILVEIRA; VALE $^{94}$, WERTZ ${ }^{98}$, WERTZ; DRESKIN ${ }^{99}$. Nesse trabalho, confirmou-se que a maxila, analisada por meio do plano palatino, deslocou-se para baixo nos três grupos, sem diferenças estatísticas entre eles, sendo que o grupo do aparelho Colado apresentou maiores médias que os outros grupos para a espinha nasal anterior e posterior, o que contradiz SARVER; JOHNSTON $^{77}$, ASANZA; CISNEROS e NIEBERG ${ }^{6}$, que relataram que a espinha nasal posterior deslocou-se mais para baixo no grupo do aparelho bandado do que no grupo Colado.

Para avaliar o posicionamento espacial da mandíbula, após a terapia da expansão maxilar, avaliaram-se as medidas cefalométricas angular, SNB e linear Nperp-Pog. Pelas Tabelas 5.4, 5.7 e 5.10 e Figuras 6.8 e 6.9, pode ser verificado que o ângulo SNB, após a fase ativa do aparelho, obteve uma 
diminuição estatisticamente significante para os Grupos I e II e não significante para o grupo III, durante a fase pré-expansão para pósexpansão, denotando que a mandíbula rotou no sentido horário. Todavia, esses valores tenderam a retornar a valores próximos do inicial, após o período de contenção (Tabelas 5.5, 5.8 e 5.11). Tais alterações também foram verificadas por BYRUM JUNIOR ${ }^{16}$, CAPELOZZA FILHO; SILVA FILHO $^{18}$, CAPELOZZA FILHO; ALMEIDA; URSI ${ }^{19}$, DAVIS; KRONMAN $^{30}$, HAAS $^{38}$, HEFLIN ${ }^{41}$, KAWAKAMI ${ }^{48}$, SILVA FILHO; VILLAS BOAS; CAPELOZZA FILHO ${ }^{88}$, SILVA FILHO et al. ${ }^{90}$, TEIXEIRA $^{94}$, WERTZ $^{98}$ e WERTZ; DRESKIN ${ }^{99}$. A rotação mandibular ocorrida após a expansão maxilar, em parte pode ser relacionada ao discreto deslocamento anterior da maxila ${ }^{37,38,39,87,88,99}$ durante a fase ativa, sobrecorreção da mordida cruzada posterior ${ }^{87,89,98}$, inclinação para vestibular dos dentes póstero-superiores ${ }^{1,22,44,54,88}$, processos alveolares ${ }^{37}$, 38, 39, 68, 98 e alterações verticais, assim como ao deslocamento para inferior do plano palatino ${ }^{16,30,38,72,88,90,94}$ e à extrusão dos molares de ancoragem ${ }^{3,}$ $16,18,41,88,90,94$. Na avaliação entre os três grupos, entre as fases estudadas, pela análise de variância não foram constatadas diferenças estatísticas significantes, denotando apenas que da fase inicial para a de póstratamento, houve uma suave diminuição do ângulo SNB para os três grupos, devido à rotação mandibular no sentido horário, no final do período de contenção (Tabela 5.15 e Figura 6.8). 


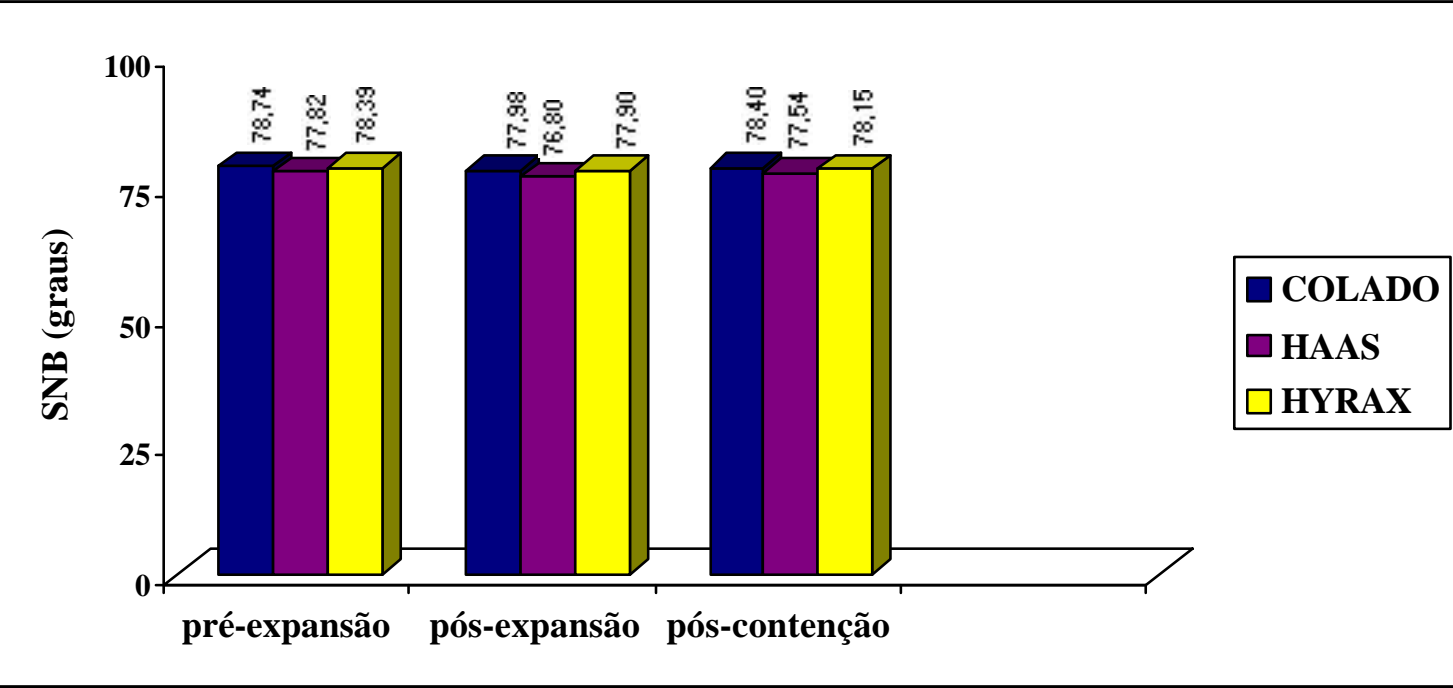

FIGURA 6.8 - Comportamento das médias da grandeza cefalométrica $\mathrm{SNB}$, durante as fases estudadas, nos grupos I (Colado), II (tipo Haas) e III (Hyrax).

$\mathrm{Na}$ avaliação da medida linear Nperp-Pog, houve diferença estatisticamente significante da fase pré-tratamento para a pós-expansão, para os três grupos, ocorrendo uma diminuição dos valores, devido à rotação mandibular acentuada nessa fase (Tabelas 5.4, 5.7 e 5.10). Já na fase pós-expansão para a pós-contenção, sem o aparelho, houve um aumento dessa medida nos três grupos, significante apenas para o grupo do Hyrax, indicando que a mandíbula rotaciona no sentido anti-horário, após a remoção do aparelho (Tabelas 5.5, 5.8 e 5.11). Ao final do tratamento, na comparação da fase pré-expansão para a pós-contenção, indica que a mandíbula, apesar de apresentar uma tendência de voltar à posição original, finaliza com alteração significante na rotação no sentido horário, que confirma a medida angular SNB, sendo que o grupo do aparelho Colado apresentou a maior rotação ao final (Tabelas 5.6, 5.9 e 5.12 e Figura 6.9). 


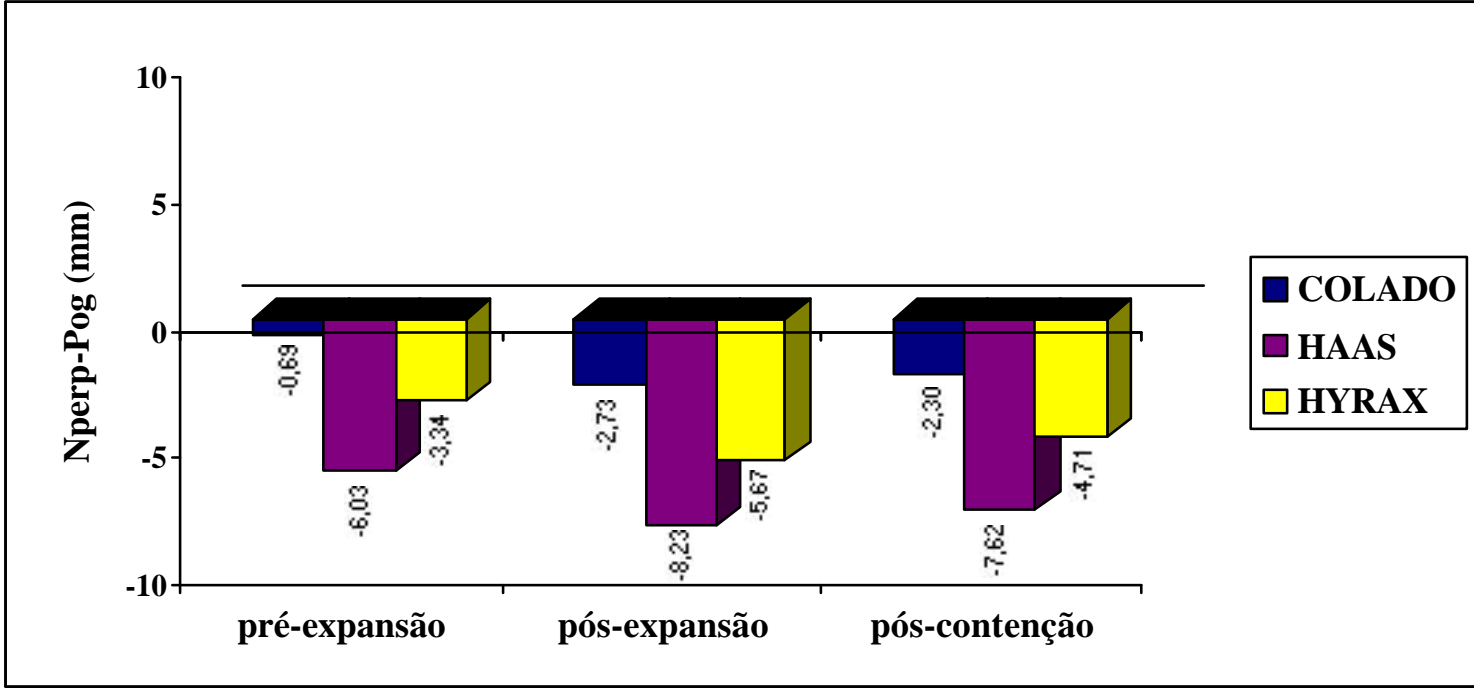

FIGURA 6.9 - Comportamento das médias da grandeza cefalométrica Nperp-Pog, durante as fases estudadas, nos grupos I (Colado), II (tipo Haas) e III (Hyrax).

$\mathrm{Na}$ avaliação entre os três grupos de aparelhos, pela análise de variância nas fases estudadas, não foram encontradas alterações significativas entre eles (Tabelas de 5.13 a 5.15).

A avaliação do comportamento sagital do perfil esquelético, estudado pelos ângulos ANB e NAP corrobora as medidas citadas anteriormente, demonstrando, para os três grupos, aumentos significantes da fase pré-expansão para a fase pós-expansão, confirmando a rotação mandibular e ligeiro avanço do ponto A, nessa fase, mas na fase póscontenção, sem o aparelho, esses valores tiveram um decréscimo significante para os três grupos de aparelhos (Tabelas 5.4, 5.7 e 5.10). As avaliações realizadas ao início da terapia e após a fase de contenção, para os grupos que utilizaram o disjuntor Colado e o Hyrax, apresentaram aumentos estatísticos, denunciando o aumento efetivo desses ângulos com 
a terapia, provavelmente devido à rotação mandibular, já que a maxila não se deslocou significantemente para anterior, após o período de contenção. Para o grupo do aparelho tipo Haas, apesar do ligeiro acréscimo nessas medidas não ter sido estatisticamente significante ao final da terapia, esse foi o aparelho que menos causou alteração nesses ângulos (Tabelas 5.6, 5.9 e 5.12). Pela avaliação entre os três grupos entre si, na análise de variância nas diversas fases, não foram encontradas alterações significantes nessas medidas (Tabelas de 5.13 a 5.15 e Figuras 6.10 e 6.11).

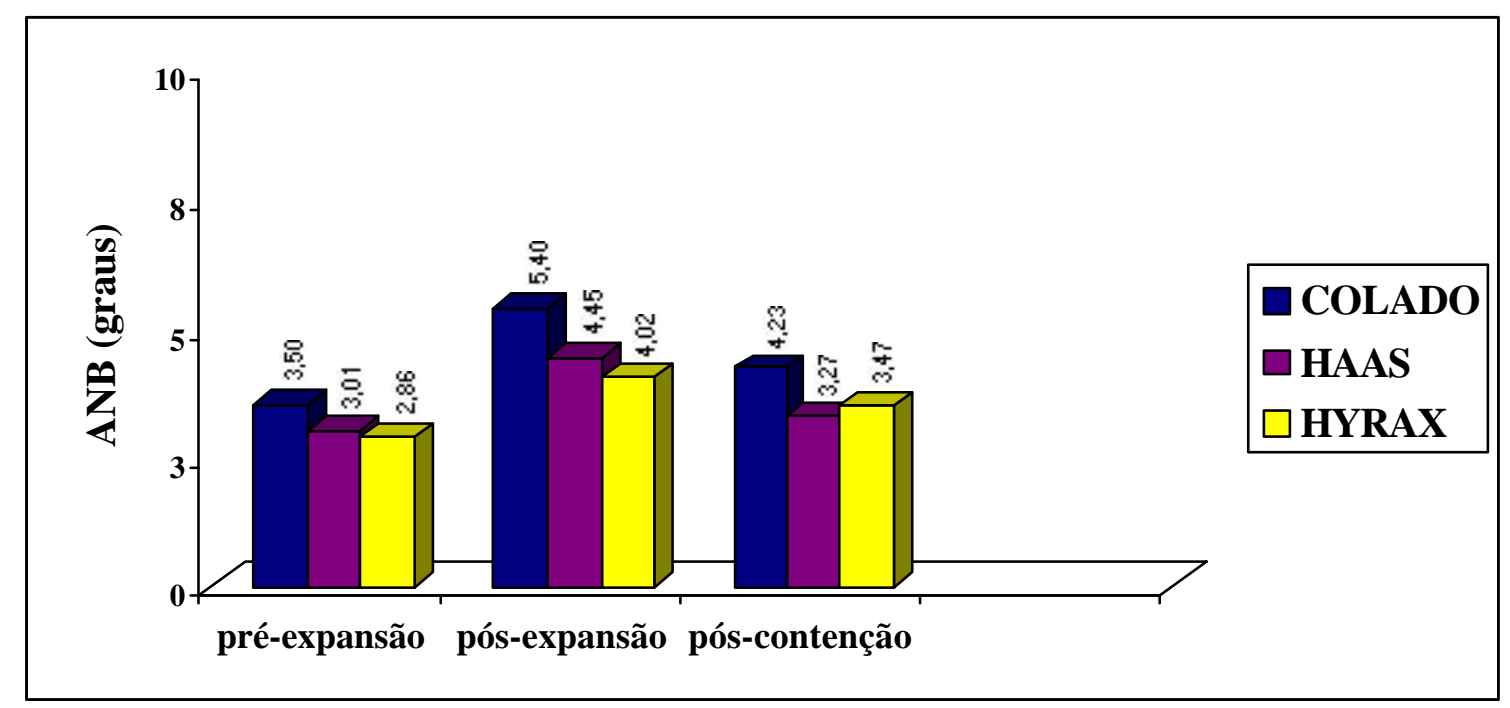

FIGURA 6.10 - Comportamento das médias da grandeza cefalométrica ANB, durante as fases estudadas, nos grupos I (Colado), II (tipo Haas) e III (Hyrax). 


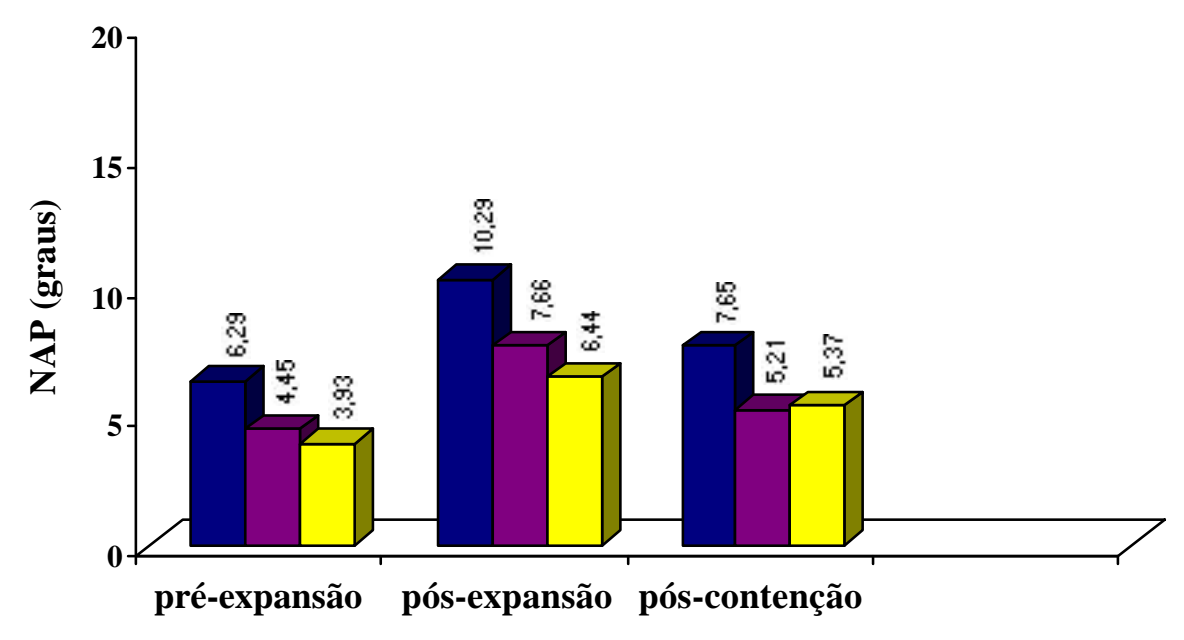

D COLADO

FIGURA 6.11 - Comportamento das médias da grandeza cefalométrica NAP, durante as fases estudadas, nos grupos I (Colado), II (tipo Haas) e III (Hyrax).

As alterações ocorridas podem ser relacionadas em parte pelo deslocamento maxilar para baixo, junto com os dentes de ancoragem e sua extrusão, levando, por conseguinte, a uma rotação mandibular no sentido horário e assim, ao reposicionamento dos pontos $\mathrm{B}$ e Pog, verificados também por BYRUM JUNIOR ${ }^{16}$, CAPELOZZA FILHO; ALMEIDA; URSI $^{19}$, CAPELOZZA FILHO; SILVA FILHO ${ }^{18}$, DAVIS; KRONMAN ${ }^{30}$, HAAS $^{38}$, HEFLIN $^{41}$, KAWAKAMI ${ }^{48}$, SILVA FILHO; VILLAS BOAS; CAPELOZZA FILHO ${ }^{88}$, SILVA FILHO et al. ${ }^{90}$, TEIXEIRA; SILVEIRA; VALE $^{94}$, WERTZ ${ }^{98}$ e WERTZ; DRESKIN ${ }^{99}$. No entanto, essa alteração mandibular apresentou tendência de se reposicionar no sentido anti-horário, após a remoção do aparelho, provavelmente devido à normalização dos dentes e à reorganização das suturas faciais. 
Apesar de não significativo, o aparelho tipo Haas foi o que causou menores alterações desses ângulos e conseqüentemente, menor rotação mandibular, em virtude, talvez, à porção de acrílico que auxilia a inclinação dos processos alveolares e a menor vestibularização dos dentes posteriores.

REED; GHOSH; NANDA ${ }^{72}$ compararam os expansores Colados e os bandados e concluíram que, nos pacientes que utilizaram os aparelhos bandados, ocorreram maiores alterações no sentido vertical, concordando com PEARSON; PEARSON ${ }^{70}$ e FALTIN JÚNIOR; MOSCATIELLO; BARROS $^{34}$, que não verificaram alterações mandibulares com o aparelho Colado. No nosso trabalho, ao contrário desses estudos, observou-se uma rotação mandibular ao final do período de contenção, nos três grupos, porém, sem diferença estatisticamente significante entre eles. Provavelmente, o aparelho Colado tenha levado à rotação mandibular devido à vestibularização dos dentes de ancoragem, corroborando os achados de ASANZA; CISNEROS; NIEBERG ${ }^{6}$, que verificaram a inclinação desses dentes, tanto no aparelho Colado, como no bandado e os de LÉON et al. ${ }^{54}$, que também relataram a vestibularização com o aparelho Colado. 


\section{4 - RELAÇÃO MAXILOMANDIBULAR}

$\mathrm{Na}$ relação maxilomandibular foram avaliadas as medidas cefalométricas lineares ENA-Me, que verificam possíveis alterações na altura facial ântero-inferior (AFAI), adotadas por MACNAMARA $\mathrm{JUNIOR}^{60}$ e as medidas Ar-A e Ar-Gn, em substituição à Co-A e Co-Gn, adotadas também por MCNAMARA JUNIOR, por causa da difícil visualização do ponto condílio. Optou-se pelo ponto articular (Ar), devido à maior facilidade de localização e visualização, facilitando a padronização da medida.

O comprimento maxilar estudado pela medida Ar-A, para o grupo I, na fase pré-tratamento para a fase pós-expansão, ou fase ativa do tratamento, demonstrou ligeiro e não significante aumento nesse grupo, sendo que nos grupos II e III foram verificados aumentos estatísticos nessa fase (Tabelas 5.4, 5.7 e 5.10). Na fase pós-expansão para a pós-contenção, nos grupos dos aparelhos Colado e Hyrax, evidenciou-se ainda um ligeiro acréscimo, não significante, enquanto no grupo do aparelho do tipo Haas, houve um pequeno decréscimo, também não significante, dessa medida (Tabelas 5.5, 5.8 e 5.11). Na comparação da fase pré-expansão para a póscontenção (Tabelas 5.6, 5.9 e 5.12), notou-se aumento dessas medidas, sem significância estatística para o grupo do aparelho Colado e aumento significativo para o tipo Haas e Hyrax (Figura 6.12). 


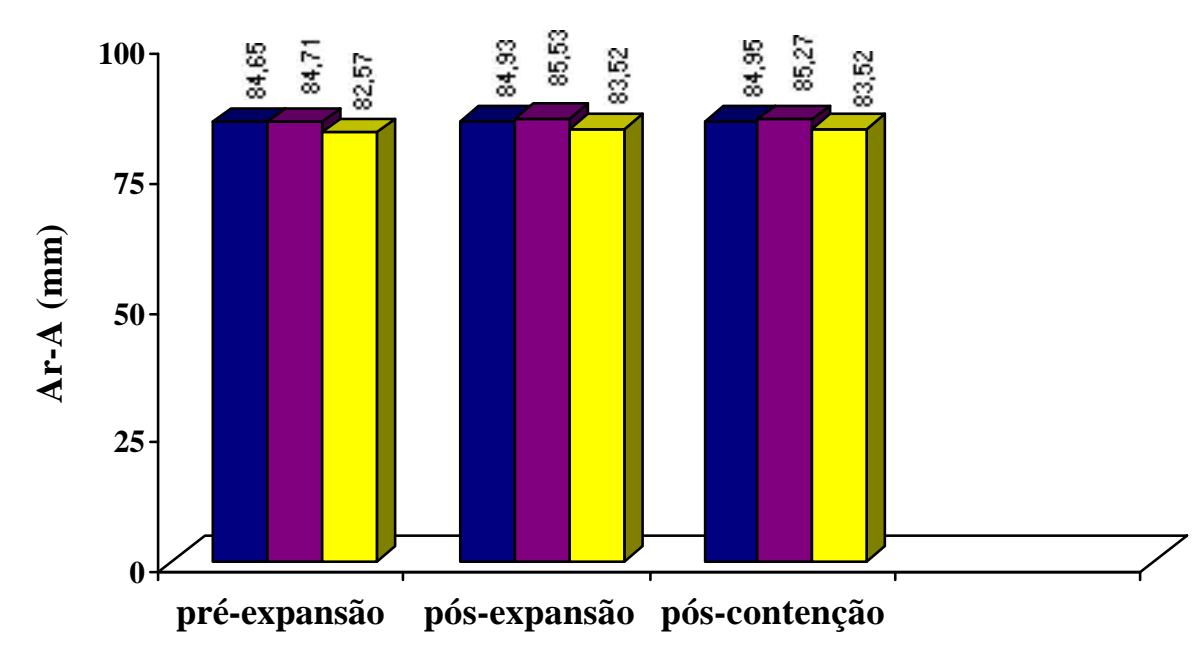

$\square$ COLADO

FIGURA 6.12 - Comportamento das médias da grandeza cefalométrica Ar-A, durante as fases estudadas, nos grupos I (Colado), II (tipo Haas) e III (Hyrax).

Concluindo, os pacientes que utilizaram o aparelho Colado apresentaram um deslocamento do ponto A discreto para anterior, em todas as fases do tratamento, mantendo esse deslocamento ao final do período de contenção. Todavia, essas alterações não foram estatisticamente significantes, ao contrário dos grupos com aparelhos Hyrax e o tipo Haas, que também apresentaram ganhos dessa medida e ao final da contenção, esse avanço do ponto A para a anterior foi significante.

Nas avaliações entre as fases, na análise de variância, com os três grupos, não se constataram alterações significativas entre eles (Tabelas de 5.13 a 5.15$)$.

Embora já tenha sido discutido o movimento para a anterior da maxila, após a expansão maxilar, esses resultados confirmam as medidas já 
verificadas como Sperp-A, SNA e SN.ENA para o Colado, que não apresentaram deslocamentos significativos da maxila para anterior, após o período de contenção enquanto que no tipo Haas e no Hyrax, a medida ArA demonstrou que haveria um deslocamento significativo para anterior do ponto A, que não foi verificado significantemente nas outras medidas e será discutido posteriormente.

O comprimento efetivo mandibular, avaliado pela medida Ar-Gn, tanto para o grupo I como para o II, apresentou aumentos gradativos na fase pré-expansão para a pós-expansão, ao contrário do grupo III, que revelou uma diminuição nessa fase, mas nenhuma com significância estatística (Tabelas 5.4, 5.7 e 5.10). Também da fase pós-expansão para a pós-contenção, ocorreram aumentos para os grupos I, II e III, sem significância estatística (Tabelas 5.5, 5.8 e 5.11). Esse aumento também se evidenciou, sem significância, na fase pós-contenção, para o grupo I, enquanto no grupo II, ao final do período de contenção, foi estatisticamente significante e no grupo III, houve uma ligeira diminuição, sem significância estatística (Tabelas 5.6, 5.9 e 5.12 e Figura 6.13). 


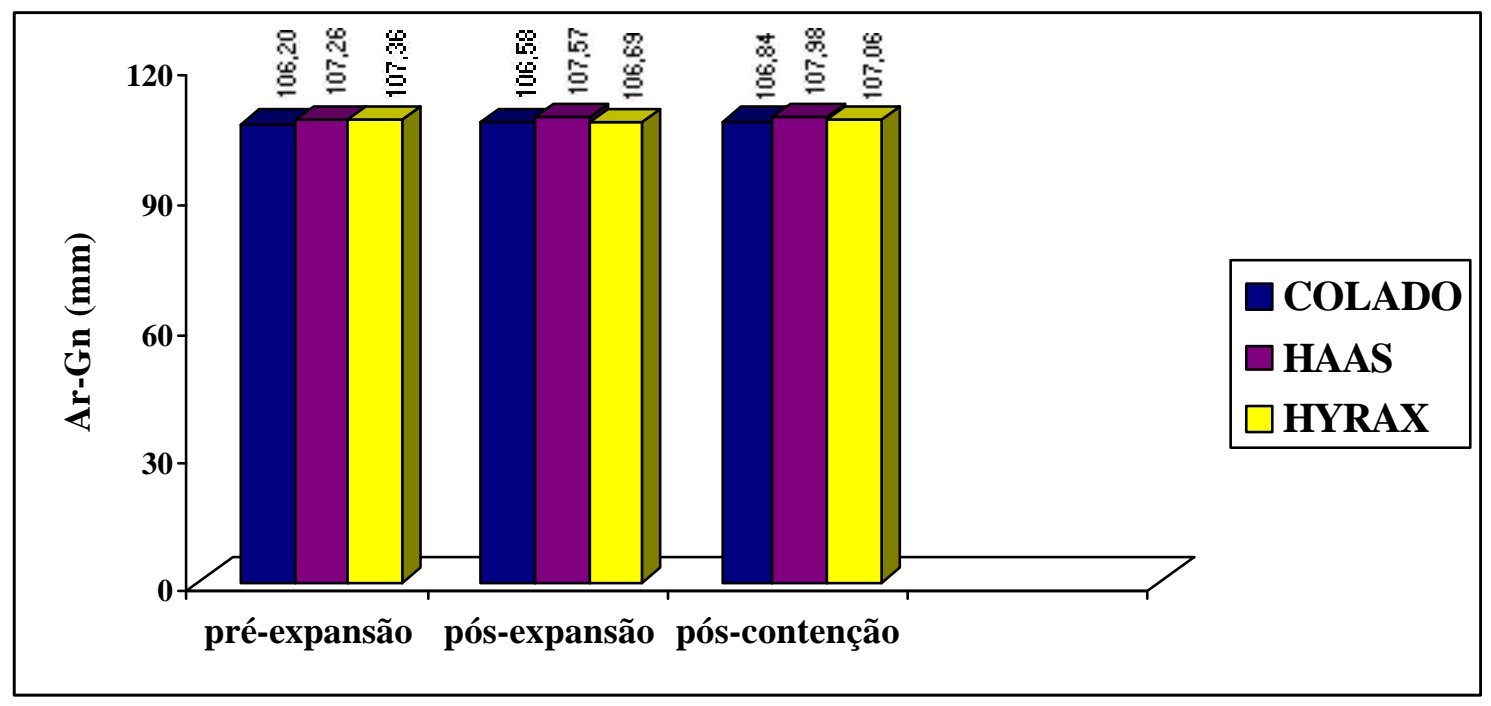

FIGURA 6.13 - Comportamento das médias da grandeza cefalométrica Ar-Gn, durante as fases estudadas, nos grupos I (Colado), II (tipo Haas) e III (Hyrax).

No entanto, na comparação entre os três grupos, pela análise de variância nas diferentes fases estudadas, não foram verificadas alterações significantes entre os três grupos (Tabelas de 5.13 a 5.15). As medidas ao início e final do tratamento basicamente se mantiveram estáveis, com pequenas alterações para a fase pós-expansão, uma vez que a expansão maxilar, além de promover alterações na largura da arcada dentária superior $^{22,36,51,59,61,72,86,91}$, causa a inclinação dos processos palatinos, a

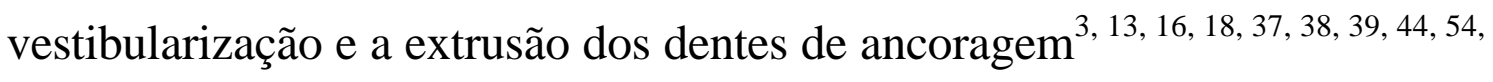
88, 94 . Esses fatores provocam um desajuste oclusal, levando à rotação mandibular no sentido horário, que poderá alterar o ponto $\mathrm{Ar}^{48}$, influenciando na medida Ar-A, que tendeu a aumentar nos três grupos, além também do já citado deslocamento discreto da maxila para a anterior nessa fase. No aparelho Colado a presença do acrílico na oclusal dos dentes favorece a rotação mandibular. O deslocamento mandibular para baixo e a 
rotação no sentido horário podem ter favorecido o aumento suave da medida Ar-Gn, observado nos grupos I e II, ao final do tratamento. Para o grupo III, houve uma discreta e não significante diminuição dessa medida, talvez devido a uma tendência de reposicionamento mandibular, no sentido anti-horário, após a fase de contenção do aparelho.

$\mathrm{Na}$ avaliação da altura facial ântero-inferior (AFAI), verificada linearmente do ponto ENA (espinha nasal anterior) ao Me (mentoniano) ENA-Me, notou-se aumentos significativos da fase pré-tratamento para a fase pós-expansão, nos três grupos estudados (Tabelas 5.4, 5.7 e 5.10), contudo esses valores decresceram significantemente após a fase de contenção, já sem o aparelho (Tabelas 5.5, 5.8 e 5.11). Da fase inicial à final do período de contenção, observaram-se aumentos significativos para os três grupos, acarretando uma acentuação da altura facial ântero-inferior (Tabelas 5.6, 5.9 e 5.12), que foi constatado também por ALMEIDA; CAPELOZZA FILHO; TRINDADE JÚNIOR ${ }^{3}$, BYRUM JUNIOR ${ }^{16}$, CARREIRA $^{21}$, CHANG; MACNAMARA JUNIOR; HERBERGER ${ }^{24}$, DIPAOLO $^{32}$, REED; GHOSH; NANDA ${ }^{72}$, SILVA FILHO; VILLAS BOAS; CAPELOZZA FILHO ${ }^{88}$, SILVA FILHO et al. ${ }^{90}$ e TEIXEIRA; SILVEIRA; VALE ${ }^{94}$ (Figura 6.14). 


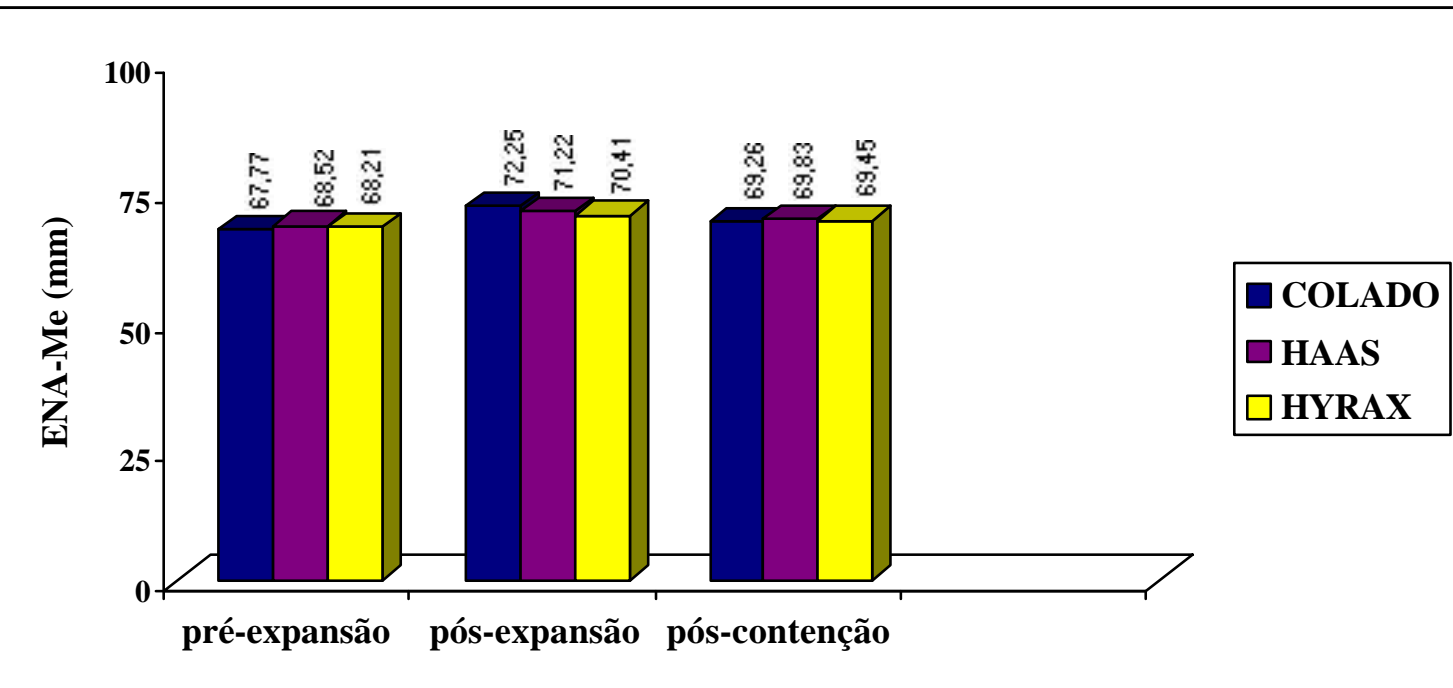

FIGURA 6.14 - Comportamento das médias da grandeza cefalométrica ENA-Me, durante as fases estudadas, nos grupos I (Colado), II (tipo Haas) e III (Hyrax).

$\mathrm{Na}$ análise de variância entre os três aparelhos, na fase préexpansão para a pós-expansão, houve uma diferença estatística significante entre eles (Tabela 5.13), identificada pelo teste de Tukey, sendo entre os grupos do aparelho Colado e tipo Haas e entre o Colado e o Hyrax, sendo que o Colado apresentou maiores médias, em relação ao tipo Haas e ao Hyrax (Tabela 5.17), acarretando aumento da medida ENA-Me, nessa fase, justificado, em parte, pela presença do acrílico na oclusal dos dentes, ocasionando a abertura da mordida e o conseqüente aumento dessa medida. Na fase pós-expansão para pós-contenção, houve decréscimo dessa medida para os três grupos, com significância entre eles (Tabela 5.14). O teste de Tukey identificou novamente as diferenças estatísticas entre o grupo do aparelho Colado e o tipo Haas e entre o grupo do Colado e o Hyrax, em que o Colado apresentou a maior redução do valor, devido provavelmente à remoção do acrílico, nessa fase (Tabela 5.18). 
No entanto, na avaliação da fase pré-expansão para a póscontenção, pela análise de variância, ao final do tratamento e remoção dos expansores, houve um ligeiro acréscimo para os três grupos, sem diferença estatística entre os grupos (Tabela 5.15). Embora discreto, o grupo do aparelho Colado apresentou as maiores médias, o que discorda dos resultados obtidos por ASANZA; CISNEROS; NIEBERG ${ }^{6}$, que demonstraram que com o aparelho Hyrax houve aumento da altura facial ântero-inferior maior que com o aparelho Colado. Já MEMIKOGLU; ISERI $^{62}$, não encontraram alterações desfavoráveis com o aparelho Colado, no sentido vertical, podendo controlá-lo. LÉON et al. ${ }^{54}$ também constataram o controle das dimensões verticais com o uso do aparelho Colado, apesar de não as terem comparado ao aparelho bandado. No trabalho de FALTIN JÚNIOR; MOSCATIELLO; BARROS ${ }^{34}$, a utilização do aparelho com cobertura acrílica, restringiu o crescimento vertical, assim como PEARSON; PEARSON $^{70}$, que, com um sistema de cobertura acrílica associado à intrusão dos incisivos superiores, verificaram uma diminuição da AFAI. REED; GHOSH; NANDA ${ }^{72}$ não encontraram alterações clínicas significantes, nem no plano palatino, nem na AFAI, entre o grupo bandado e o Colado. No nosso estudo, não ocorreu diferença estatística entre os três grupos de aparelho ao final do estudo, contudo o grupo Colado demonstrou causar maior aumento da altura facial ântero-inferior, embora bastante discreto, justificado, talvez, pela vestibularização dos dentes de ancoragem. 


\section{5 - PADRÃO DO ESQUELETO CEFÁLICO}

Para a avaliação das alterações verticais, induzidas pela terapia da expansão rápida da maxila, foram avaliadas as seguintes medidas angulares: PoOr.PP, SN.GoMe, FMA, Sn.Gn e ÂBI.

$\mathrm{Na}$ avaliação da medida angular do PoOr.PP (plano de Frankfürt com o plano palatino), para o grupo do aparelho Colado, na fase préexpansão para pós-expansão, observou-se um ligeiro decréscimo nessa angulação, sugerindo uma rotação do plano palatino, no sentido antihorário, não significante estatisticamente (Tabela 5.4). Na fase póscontenção, houve recidiva desse valor e o plano palatino rotou ligeiramente no sentido horário, aproximando-se do valor pré-expansão, também sem significância estatística (Tabela 5.5). Para o grupo II, da fase pré-expansão e pós-expansão até a pós-contenção, houve o aumento desse ângulo, sem significância, indicando que o plano palatino rotou no sentido horário e se manteve estável ao final do período de contenção (Tabela 5.9). Já para o grupo III, após a fase ativa do tratamento, ocorreu a rotação horária suave do plano palatino no sentido horário (Tabela 5.10) e no período de contenção, retornou a valores próximos dos inicias, sem significância estatística (Tabela 5.11), corroborando os trabalhos de SILVA FILHO et al. $^{90}$ e VELÁZQUEZ; BENITO; BRAVO ${ }^{96}$, nos quais não foram evidenciadas alterações significativas no plano palatino, com aparelhos bandados, ao contrário de BYRUM JUNIOR ${ }^{16}$, DAVIS; KRONMAN ${ }^{30}$, HAAS $^{38}$, SILVA FILHO; VILLAS BOAS; CAPELOZZA FILHO ${ }^{88}$ e TEIXEIRA; SILVEIRA; VALE ${ }^{94}$, que notaram um deslocamento para inferior do plano palatino, com os aparelhos bandados. Na comparação entre a fase inicial e final do tratamento, o plano palatino rotou suavemente 
no sentido horário, nos três grupos, sem significância estatística (Tabelas 5.6, 5.9 e 5.12 e Figura 6.15).

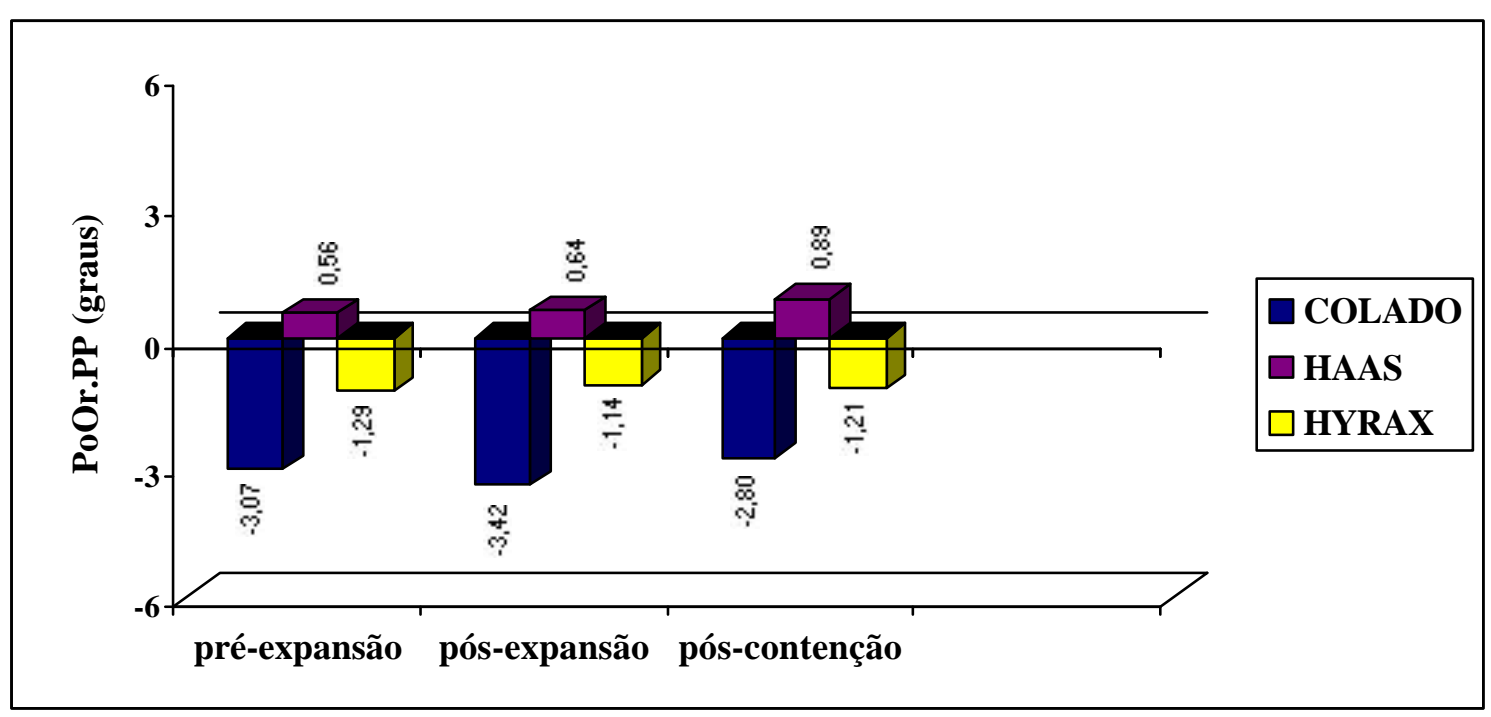

FIGURA 6.15 - Comportamento das médias da grandeza cefalométrica PoOr.PP, durante as fases estudadas, nos grupos I (Colado), II (tipo Haas) e III (Hyrax).

$\mathrm{Na}$ análise de variância entre os três grupos, nas diversas fases, não houve diferença significativa entre eles (Tabelas de 5.13 a 5.15), o que foi confirmado no estudo de REED; GHOSH; NANDA ${ }^{72}$, e diferentemente dos resultados de SARVER; JOHNSTON ${ }^{77}$ e ASANZA; CISNEROS; NIEBERG $^{6}$, que constataram um menor deslocamento da espinha nasal posterior e anterior para as medidas dos aparelhos Colados, em relação aos bandados. FALTIN JÚNIOR; MOSCATIELLO; BARROS ${ }^{34}$ também encontraram diferenças significativas do plano palatino, com o aparelho bandado, em comparação ao Colado. 
As medidas SN.GoMe, FMA, SN.Gn e ÂBI, que caracterizam a posição mandibular, demonstraram aumentos estatisticamente significantes para os três grupos da fase pré-expansão para a pós-expansão (Tabelas 5.4, 5.7 e 5.10), evidenciando que a terapia, na fase ativa, rotou a mandíbula no sentido horário. Após o período de contenção, esses valores decaíram significantemente ao se remover o aparelho expansor para os três grupos, com exceção da medida SN.Gn e SNGoMe para o grupo do aparelho Hyrax, que diminuiu, porém, sem significância estatística (Tabelas 5.5, 5.8 e 5.11). Na avaliação direta entre o início e o final do tratamento, as medidas demonstraram um acréscimo significativo em todas as medidas do grupo do aparelho Colado, evidenciando um acréscimo nas dimensões verticais. Para o grupo do aparelho tipo Haas, ocorreu também um acréscimo significante das medidas ao final da terapia, com exceção do ÂBI, que aumentou, embora não significantemente. Já no grupo do Hyrax, houve aumento dessas medidas, sendo que a única que obteve acréscimos significativos foi a FMA (Tabelas 5.6, 5.9 e 5.12 e Figuras de 6.16 a 6.19). 


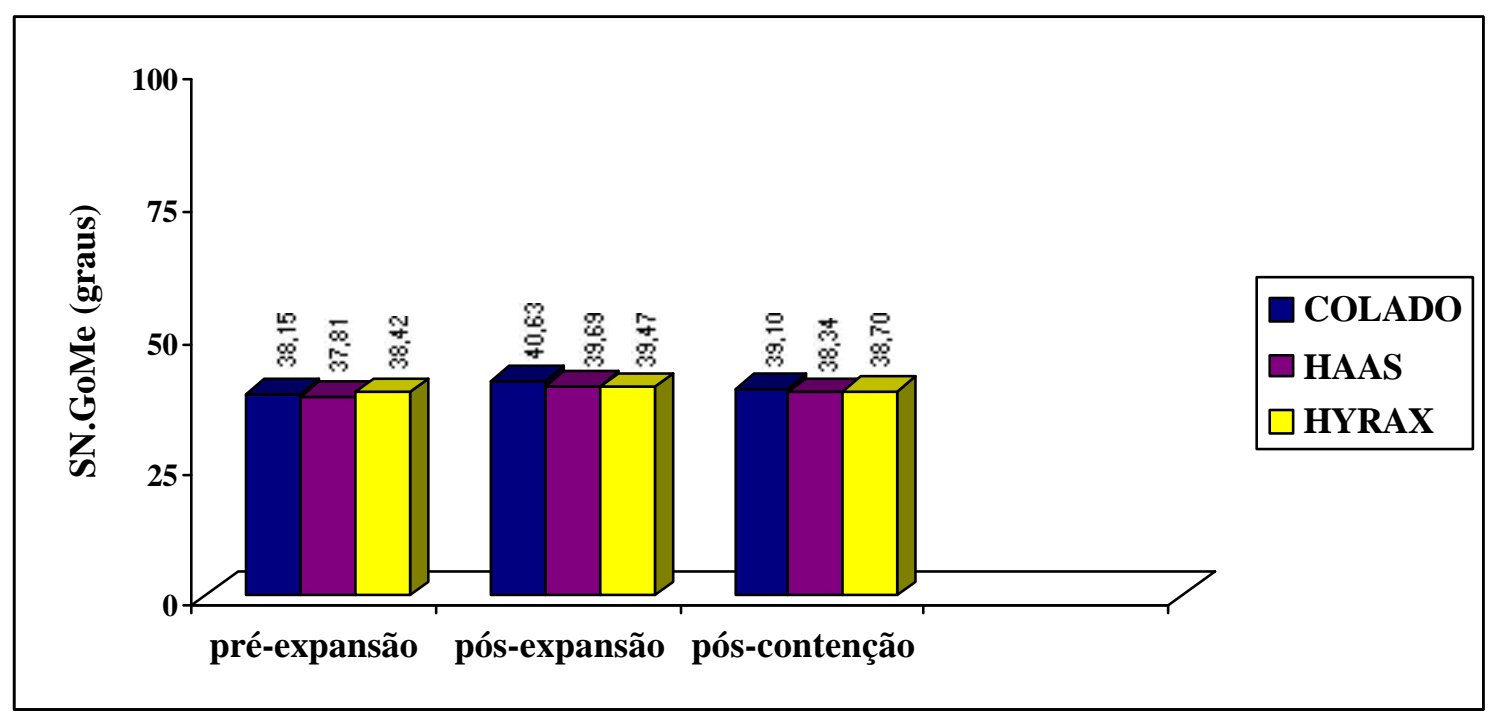

FIGURA 6.16 - Comportamento das médias da grandeza cefalométrica SN.GoMe, durante as fases estudadas, nos grupos I (Colado), II (tipo Haas) e III (Hyrax).

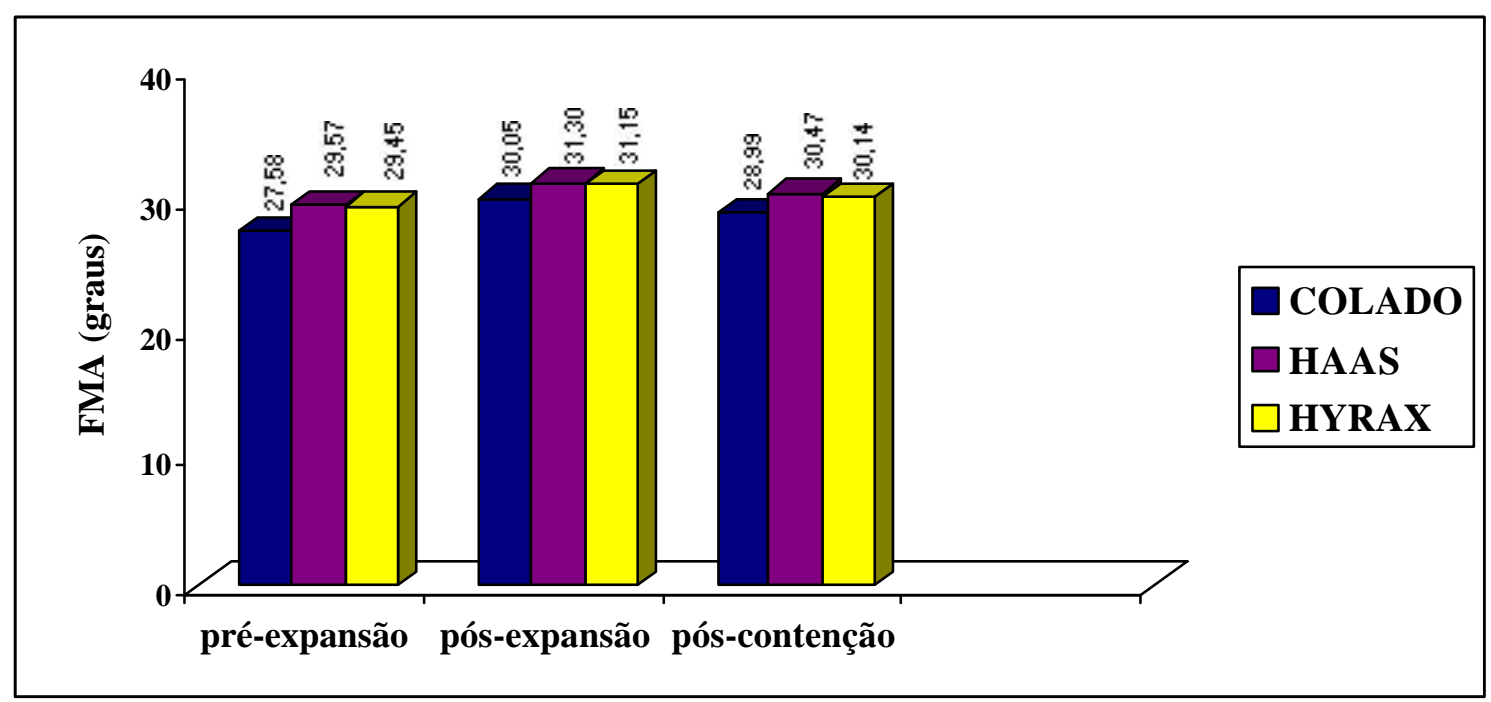

FIGURA 6.17 - Comportamento das médias da grandeza cefalométrica FMA, durante as fases estudadas, nos grupos I (Colado), II (tipo Haas) e III (Hyrax). 


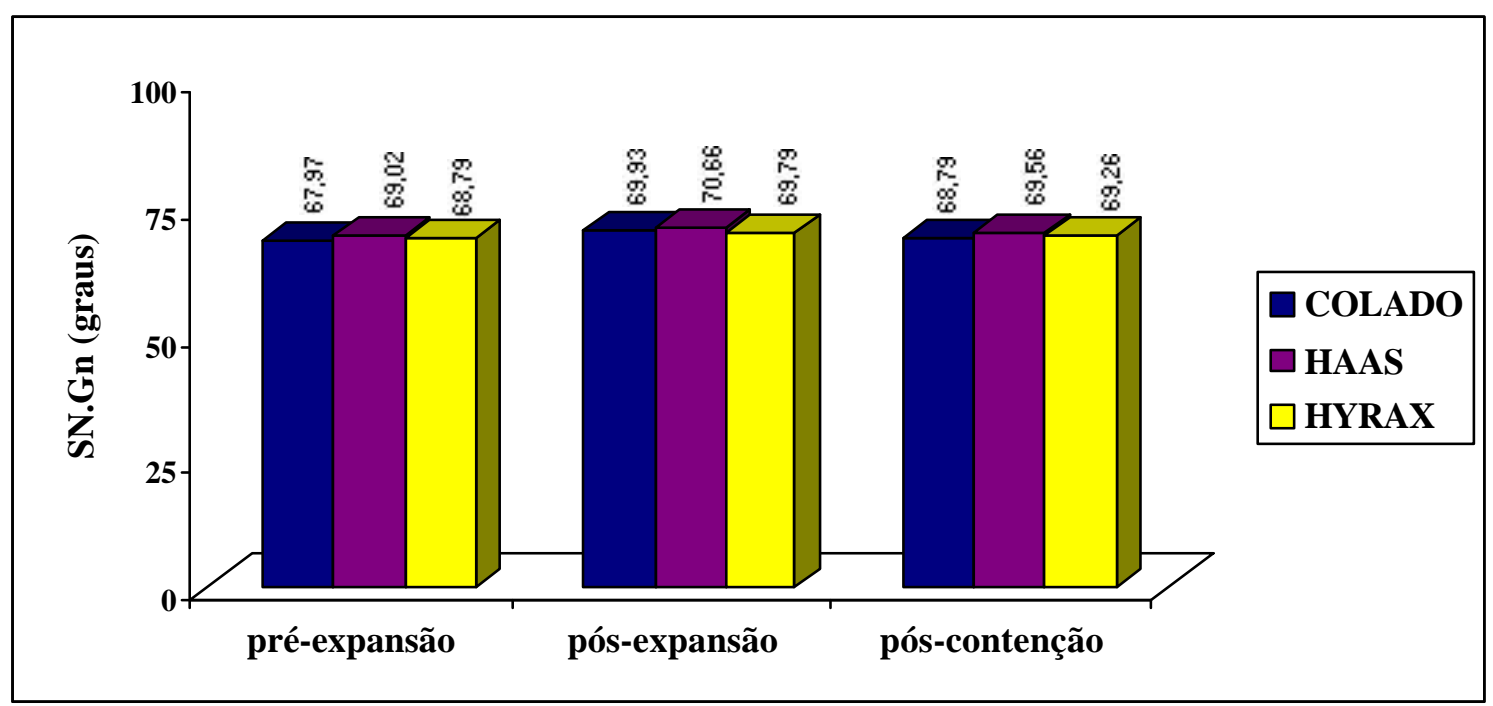

FIGURA 6.18 - Comportamento das médias da grandeza cefalométrica SN.Gn, durante as fases estudadas, nos grupos I (Colado), II (tipo Haas) e III (Hyrax).

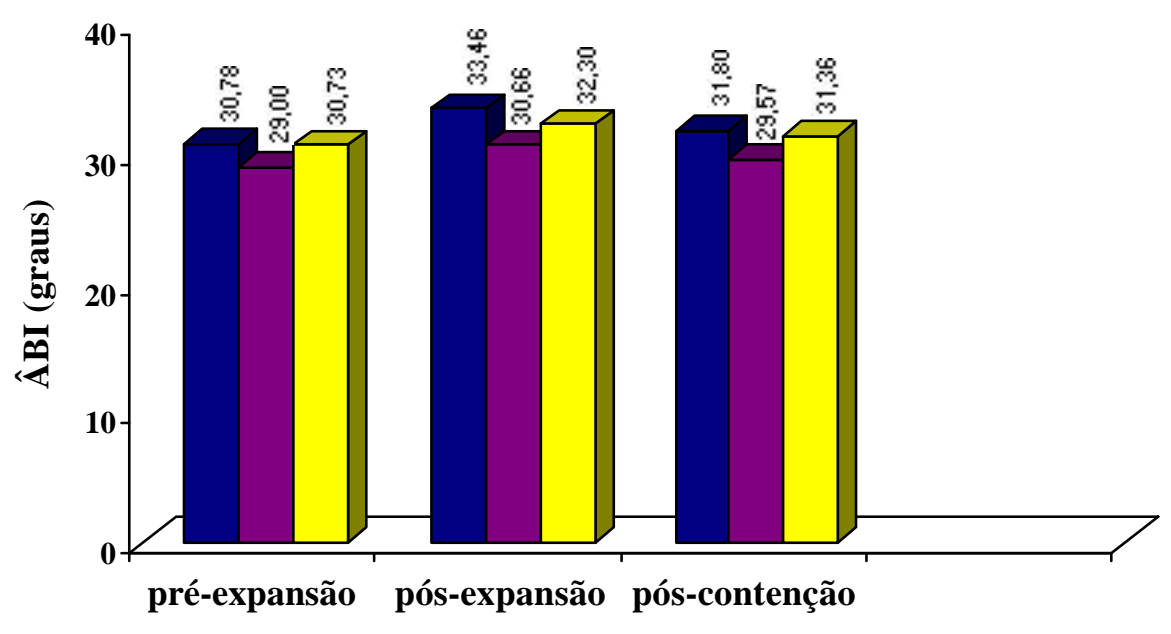

- COLADO $\square$ HAAS $\square$ HYRAX

FIGURA 6.19 - Comportamento das médias da grandeza cefalométrica ÂBI, durante as fases estudadas, nos grupos I (Colado), II (tipo Haas) e III (Hyrax). 
Pela análise de variância, entre os grupos, nas diversas fases, não se evidenciaram alterações significantes entre eles, mas é importante salientar que ao final do tratamento, o grupo do aparelho Colado, apesar de não significante, apresentou as maiores médias de aumentos nas dimensões verticais (Tabelas de 5.13 a 5.15).

As alterações encontradas nessas avaliações corroboram a literatura, no que condiz às mudanças posturais da mandíbula, diretamente relacionadas à fase ativa da expansão maxilar, aumentando as medidas

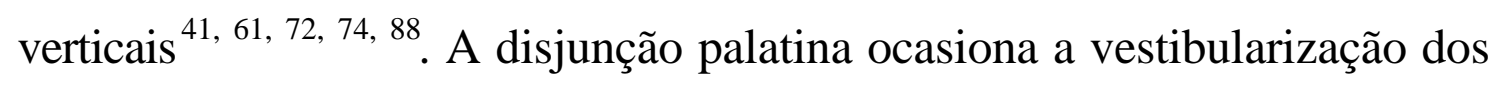
dentes póstero-superiores ${ }^{1,22,44,88,54}$, dos processos alveolares superiores ${ }^{37}$, 38, 39, 68, 98, 99 , a rotação do plano palatino para baixo ${ }^{16,30,38,72,88,90,94}$ e a extrusão dos molares de ancoragem ${ }^{3}$, 16, 18, 41, 88, 90, 94, forçando assim um novo posicionamento mandibular.

O objetivo da utilização dos aparelhos Colados seria o não agravamento das alterações verticais, verificadas com os aparelhos bandados. ASANZA; CISNEROS; NIEBERG ${ }^{6}$, FALTIN JÚNIOR; MOSCATIELLO; BARROS ${ }^{34}$, LÉON et al. ${ }^{54}$, MCNAMARA JUNIOR; BRUDON $^{61}$, MEMIKOGLU; ISERI ${ }^{62}$ e PEARSON; PEARSON ${ }^{70}$ relataram a grande vantagem do aparelho Colado, no controle das dimensões verticais, não ocasionando alterações no plano mandibular e AFAI. Os resultados desse trabalho com os aparelhos Colados revelaram que os maiores aumentos se deram no grupo I, ao final da contenção, embora na comparação com os outros dois grupos não houve diferença significativa. Provavelmente isto seja devido à excessiva inclinação para vestibular, dos dentes superiores, o que levaria à rotação mandibular. HOWE ${ }^{46}$, referindo-se ao aparelho Colado, alegou que este minimizaria a vestibularização dos dentes, assim como MEMIKOGLU; ISERI ${ }^{62}$, que 
sugeriram um movimento mais paralelo dos dentes de ancoragem com esse aparelho. Já ASANZA; CISNEROS; NIEBERG ${ }^{6}$ e LÉON et al. ${ }^{54}$ notaram movimentos para vestibular, nos dentes com o aparelho Colado. 


\section{6 - RELAÇÃO DOS ARCOS DENTÁRIOS X BASES APICAIS}

Para verificar as alterações com relação aos primeiros molares

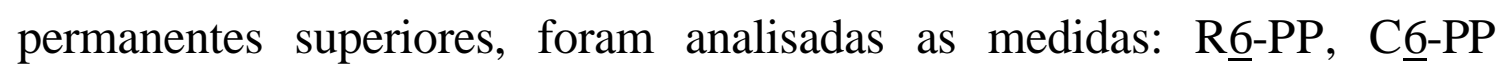

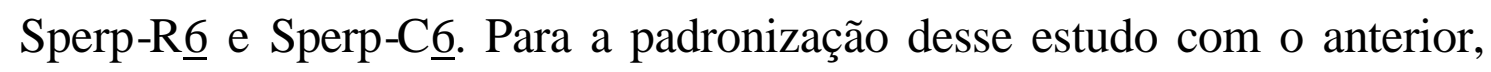
não se avaliou a posição dos molares inferiores, nem dos incisivos superior ou inferior, pois no prévio estudo, os pacientes receberam tratamento com aparelhagem fixa durante a terapia da expansão maxilar, o que poderia interferir nos resultados.

$\mathrm{Na}$ verificação das alterações verticais, induzidas aos primeiros molares superiores, ao nível radicular e coronário, foi utilizado, como referência, o plano palatino e no plano sagital, empregou-se uma linha perpendicular ao plano de Frankfürt, que passava pelo ponto sela (S).

A avaliação dos efeitos verticais dos molares de ancoragem pela medida Rㅁ-PP (medida vertical do ápice radicular mesiovestibular do primeiro molar superior ao plano palatino) demonstrou que durante a fase ativa, ou seja, da fase pré-expansão à pós-expansão, ocorreu a intrusão deste dente para os grupos I e II, sem significância estatística. Já no grupo III, houve discreta extrusão, verificada pelo aumento dessa medida, também sem significância estatística (Tabelas 5.4, 5.7 e 5.10). Na fase pósexpansão, a distância tendeu a diminuir ligeiramente no grupo Colado e significantemente no grupo do Hyrax, enquanto no tipo Haas aumentou, sem significância estatística (Tabelas 5.5, 5.8 e 5.11). Pela avaliação entre o início do tratamento e o fim do período de contenção, os três aparelhos demonstraram diminuição dessa medida (Tabelas 5.6, 5.9 e 5.12), sugerindo uma intrusão suave dos dentes, sem significância estatística. Pela 
análise de variância, não se verificaram diferenças significantes entre os três grupos, nas fases estudadas, contudo, ficou demonstrado que o aparelho Colado sofreu a maior redução dessa medida, indicando a intrusão dos molares superiores (Tabelas de 5.13 a 5.15 e Figura 6.20).

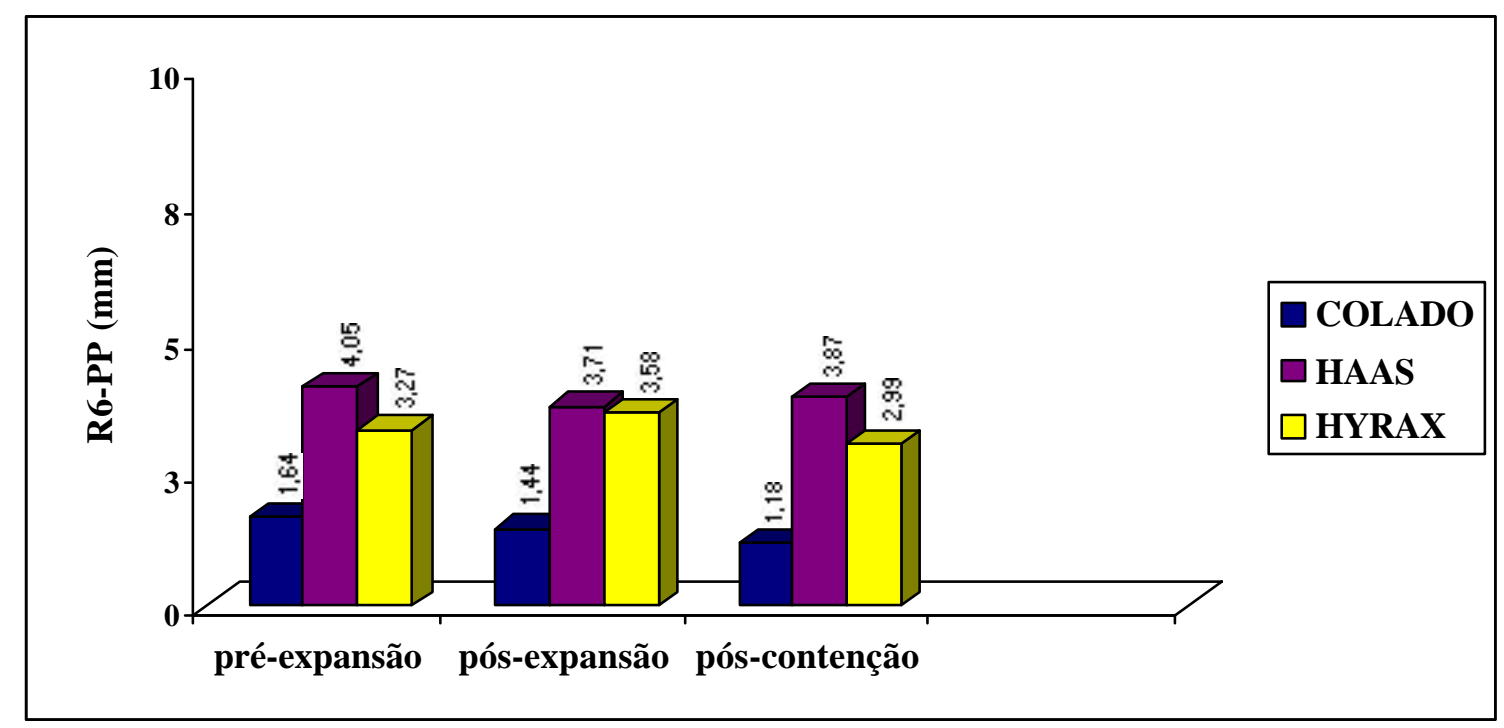

FIGURA 6.20 - Comportamento das médias da grandeza cefalométrica Rㅁ-PP, durante as fases estudadas, nos grupos I (Colado), II (tipo Haas) e III (Hyrax).

$\mathrm{Na}$ avaliação da medida Cㅁ-PP (cúspide mesiovestibular do primeiro molar superior permanente ao plano palatino), verificou-se um aumento dessa medida para os três grupos da fase inicial à fase pósexpansão, com significância estatística para o grupo do aparelho Hyrax, sugerindo a extrusão desses dentes (Tabelas 5.4, 5.7, 5.10). Na fase pósexpansão para a pós-contenção, após a remoção do aparelho, para os três grupos, houve uma diminuição significativa apenas nos grupos I e III (Tabelas 5.5, 5.8 e 5.11). Na avaliação entre o início e o fím do período de contenção, para os grupos I e II, houve uma redução e no grupo III, um 
acréscimo, sem significância dessa medida (Tabelas 5.6, 5.9 e 5.12 e Figura $6.21)$.

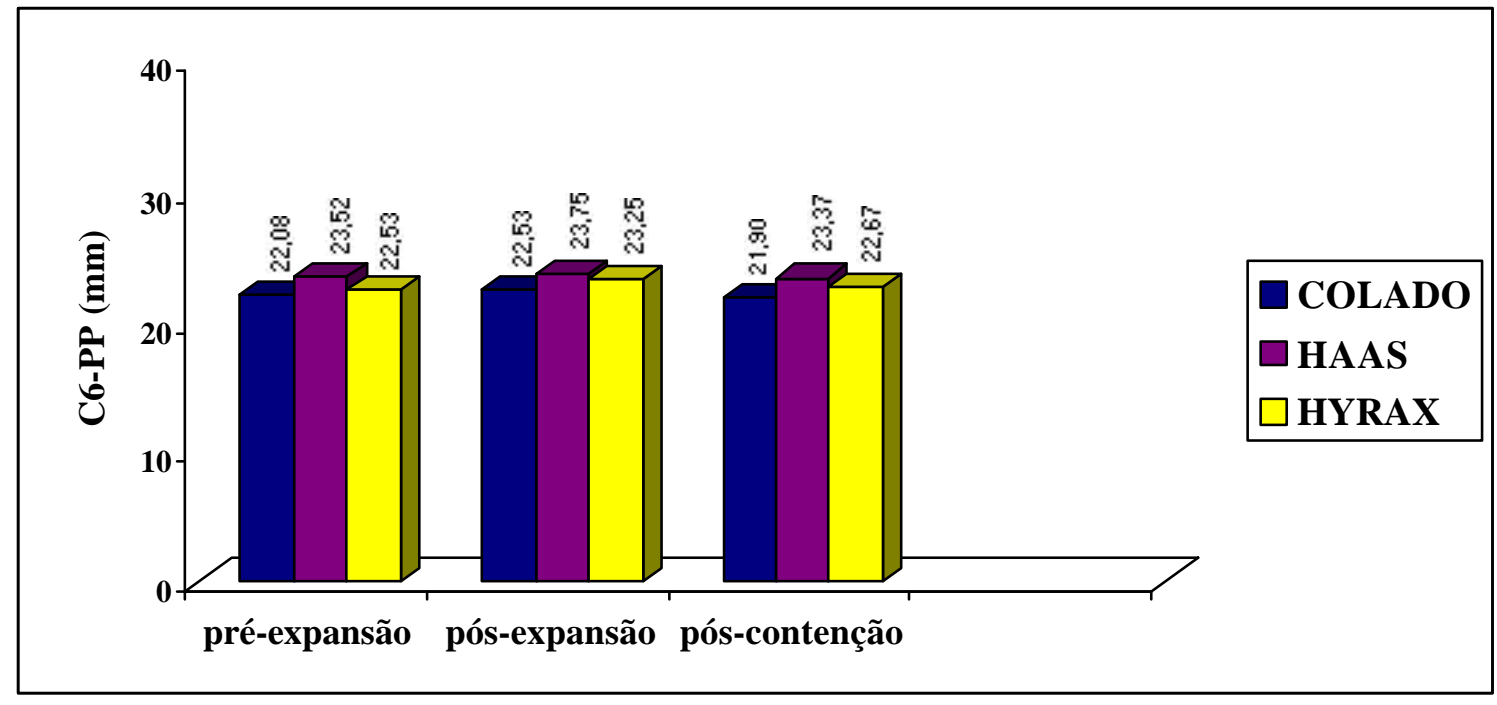

FIGURA 6.21 - Comportamento das médias da grandeza cefalométrica Cㅁ-PP, durante as fases estudadas, nos grupos I (Colado), II (tipo Haas) e III (Hyrax).

Pela análise de variância não ocorreram diferenças significantes entre os grupos estudados, concluindo-se que no grupo Colado e tipo Haas houve uma suave intrusão dos molares superiores, ao final do tratamento (Tabelas de 5.13 a 5.15).

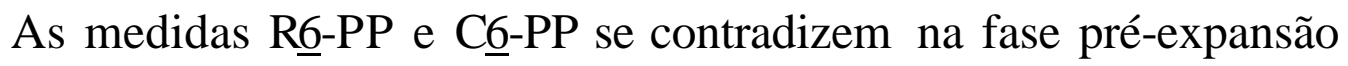
para a pós-expansão, para o aparelho Colado, indicando intrusão em uma e extrusão na outra, alteração essa que pode ser justificada pela dificuldade na visualização radiográfica dessas estruturas. Ao final do tratamento, as duas indicaram uma discreta intrusão desses dentes com o aparelho Colado, confirmada por PEARSON; PEARSON ${ }^{70}$, SPOLIAR $^{92}$, que também 
estudaram os efeitos dos aparelhos Colados nos dentes de ancoragem e por MEMIKOGLU; ISERI ${ }^{62}$, que apesar de não verificarem a intrusão, relataram que não houve a extrusão com esse tipo de aparelho. Tal ocorrido com os aparelhos Colados pode ser devido ao efeito bite block durante os meses que o aparelho permaneceu na cavidade bucal.

No grupo do aparelho tipo Haas também verificou-se uma padronização ao final do tratamento, para as duas medidas, com discreta redução das mesmas, sugerindo a intrusão dos dentes de ancoragem. No grupo do Hyrax, ao final da contenção, essas medidas também se contradizem, provavelmente devido à já citada dificuldade da visualização dessas estruturas dentárias, na telerradiografia e também devido à análise de uma imagem radiográfica bidimensional de uma estrutura tridimensional projetada, que sofreu alterações no seu eixo axial, por movimentos de inclinação para vestibular ${ }^{48}$.

A extrusão dos dentes de ancoragem, após a terapia da expansão

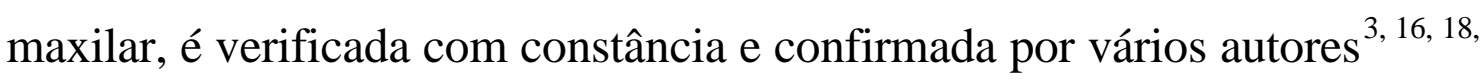
41, 88, 90, 94 , contudo, em nosso estudo com os aparelhos tipo Haas e colados, não foram verificadas essas extrusões, encontrando-se a intrusão suave, o que se assemelhou aos resultados do trabalho de PEARSON; PEARSON ${ }^{70}$, com os aparelhos colados, que não verificaram extrusões significativas. A discordância deve-se provavelmente ao fato de, na avaliação vertical, ter sido tomado, como referência, o plano palatino, que, conforme já foi citado anteriormente, sofreu um suave deslocamento no sentido horário. Nos trabalhos de ALMEIDA; CAPELOZZA FILHO; TRINDADE JÚNIOR ${ }^{3}$, SILVA FILHO et al. $^{90}$, que verificaram a extrusão dos molares de ancoragem com expansores bandados, tomou-se, como referência, a linha $\mathrm{S}-\mathrm{N}$, perpendicular à cúspide mesial dos molares superiores. 
$\mathrm{Na}$ avaliação de possíveis mudanças dos molares, no sentido mesiodistal, as medidas cefalométricas Sperp-Rㅁ (distância da raiz mesiovestibular do primeiro molar superior a linha Sperp ao Frankfürt) e a Sperp-Ć (distância da coroa mesiovestibular do primeiro molar superior à linha Sperp ao Frankfürt) demonstraram que não houve constância nessas medidas, entre as fases estudadas, justificada pela difícil visualização das estruturas dentárias. Notou-se apenas alterações significativas para o grupo do Hyrax, na fase pré-expansão para a pós-expansão, na medida Sperp-C므 (Tabela 5.10), que apresentou um decréscimo significativo, sugerindo uma inclinação da coroa para posterior. Ao final das avaliações, não houve sinais de deslocamento significativo para anterior, em nenhum dos grupos (Tabelas 5.6, 5.9 e 5.12), assim como, pela análise de variância, não se encontrou diferença significativa entre os três grupos, nas diversas fases (Tabelas de 5.13 a 5.15 e Figuras 6.22 e 6.23).

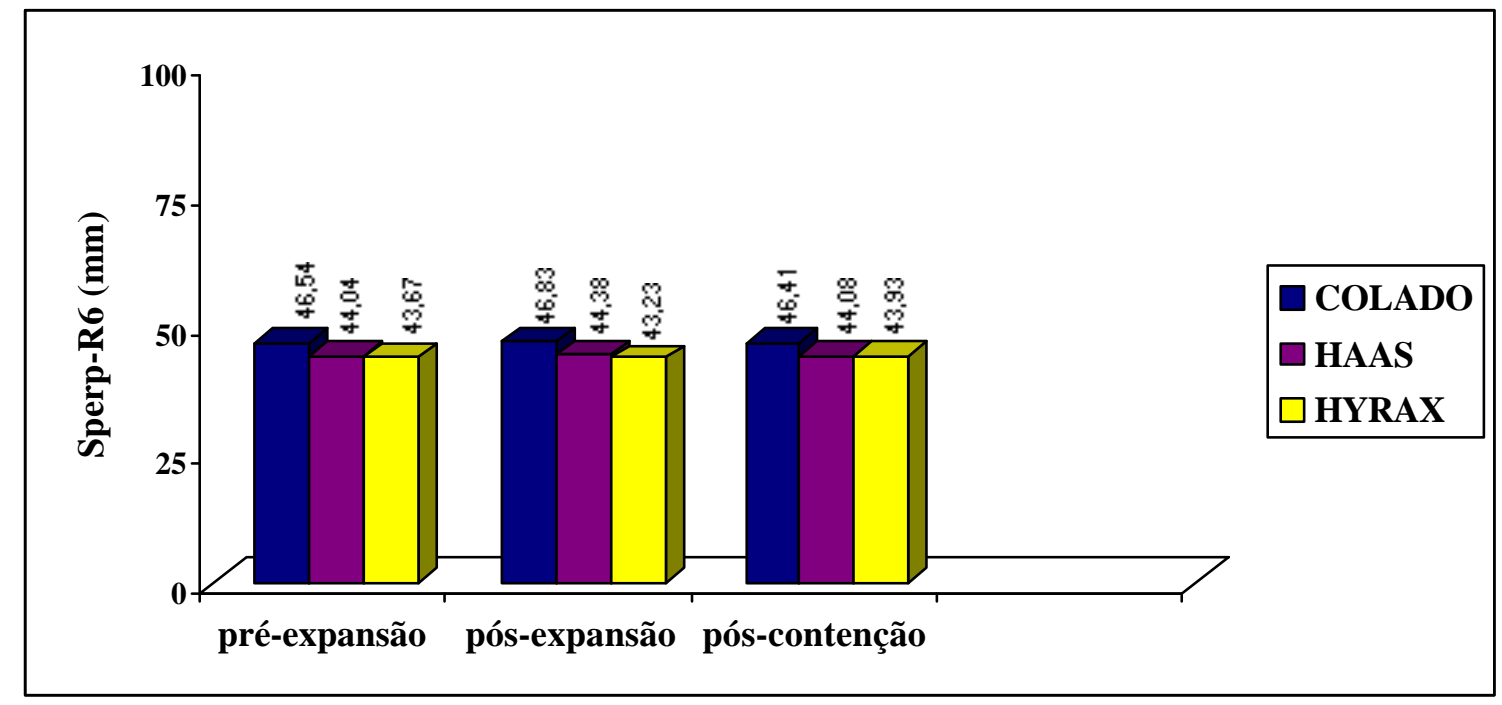

FIGURA 6.22 - Comportamento das médias da grandeza cefalométrica Sperp-Rㅁ, durante as fases estudadas, nos grupos I (Colado), II (tipo Haas) e III (Hyrax). 


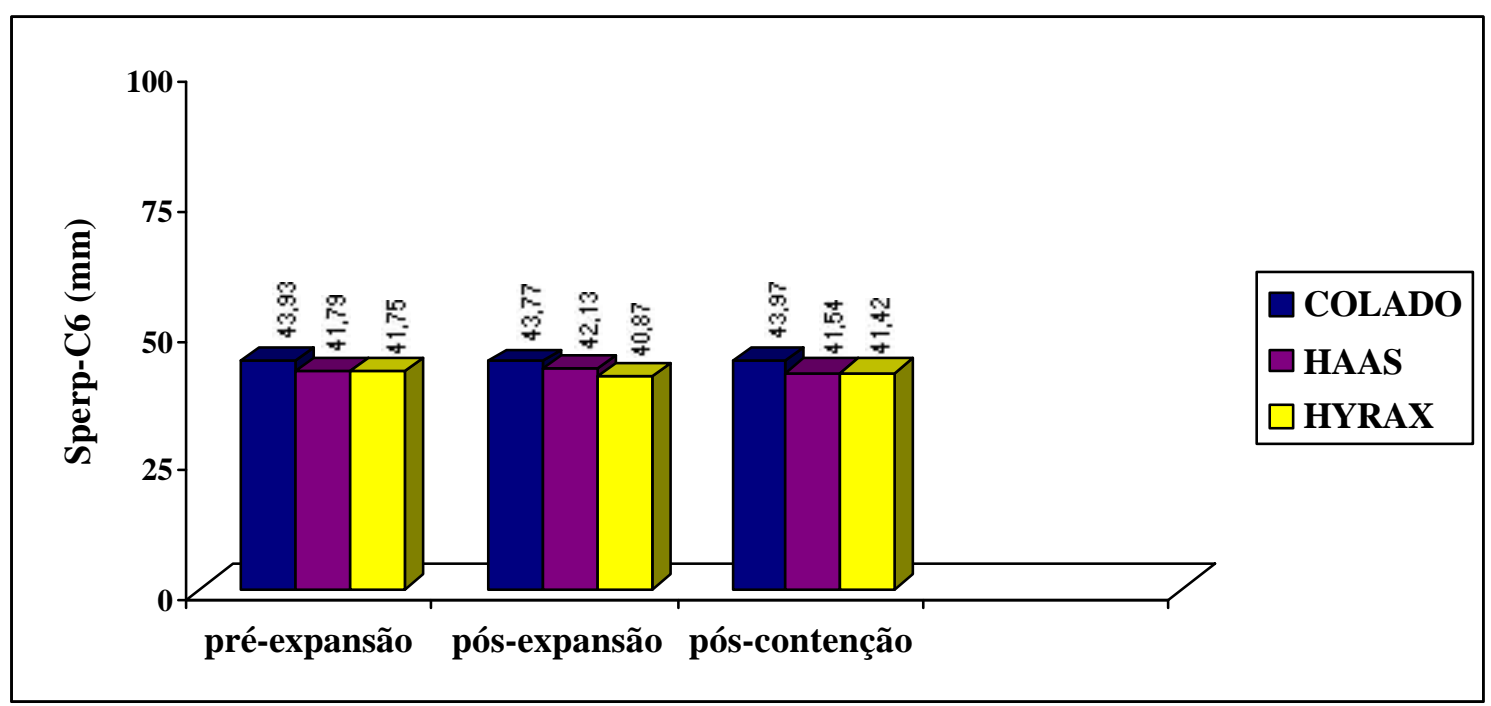

FIGURA 6.23 - Comportamento das médias da grandeza cefalométrica Sperp-Cㅁ, durante as fases estudadas, nos grupos I (Colado), II (tipo Haas) e III (Hyrax).

Os resultados dessa avaliação confirmam os verificados por HEFLIN $^{41}$ e SILVA FILHO et al. ${ }^{90}$, que não observaram alterações no sentido anteroposterior dos dentes de ancoragem. 


\section{7 - PERFIL MOLE}

O perfil mole foi avaliado pela medida cefalométrica ÂNL (ângulo nasolabial), que demonstrou uma diminuição do valor da fase prétratamento para a pós-expansão (Tabelas 5.4, 5.7 e 5.10), em todos os grupos, embora sem significância estatística, sendo que houve novamente um acréscimo na fase pós-contenção, com significância estatística para o grupo do aparelho tipo Haas (Tabela 5.8). Na avaliação entre o início e o final do período de contenção no grupo Colado e Hyrax, houve um ligeiro decréscimo com relação à medida inicial, ou seja, esse ângulo tendeu a diminuir e no grupo do aparelho tipo Haas, ocorreu um suave acréscimo, todos sem significância estatística (Tabelas 5.6, 5.9 e 5.12).

Pela análise de variância não ocorreu diferença estatística entre os três grupos, nas fases estudadas (Tabelas 5.13 a 5.15 e Figura 6.24).

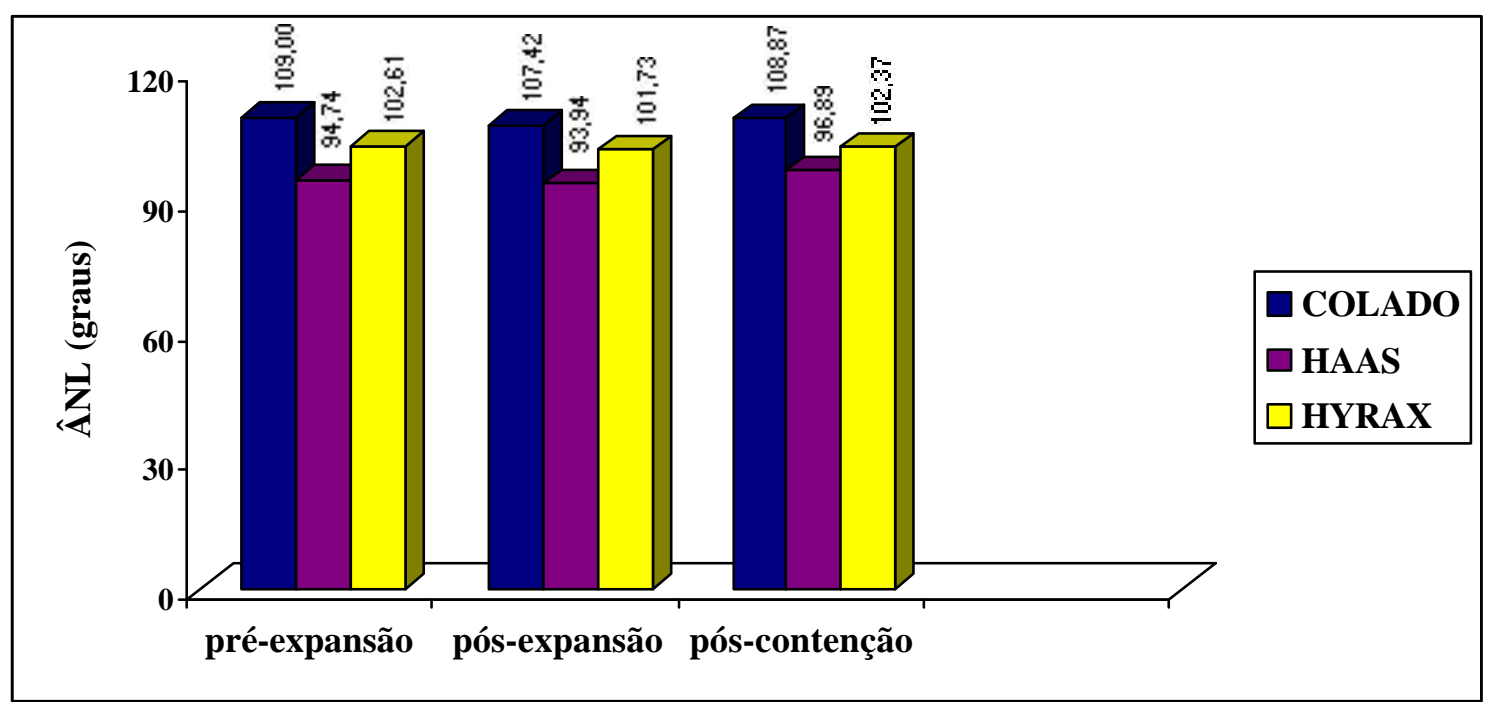

FIGURA 6.24 - Comportamento das médias da grandeza cefalométrica ÂNL, durante as fases estudadas, nos grupos I (Colado), II (tipo Haas) e III (Hyrax). 
As pequenas alterações ocorridas nesse ângulo, quando do uso da terapia da expansão maxilar, podem ser devido às pequenas alterações na maxila, vistas anteriormente, assim como uma possível verticalização dos incisivos superiores na fase de contenção ${ }^{3}$. Também é importante ressaltar, como já foi verificado na análise do erro casual apresentado ao início da discussão, que o ângulo nasolabial sofreu alterações em média de 1,8 graus, o que pode ter influenciado essa avaliação. No entanto, essas alterações são transitórias, a longo prazo, sem significância clínica ${ }^{21}$. 


\section{8 - CONSIDERAÇÕES FINAIS}

O trabalho aqui estudado leva em consideração três tipos de aparelhos expansores fixos: o dentossuportado colado à superfície oclusal dos dentes superiores, o dentomucossuportado, denominado tipo Haas, e ainda o também dentossuportado Hyrax. As conclusões entre os três tipos são semelhantes no que condiz à correção das mordidas cruzadas esqueléticas, aos possíveis movimentos anteriores da maxila, explicitamente demonstrados, que não ocorreram significantemente em nenhum grupo após o período de contenção. Houve sim, deslocamento maxilar para baixo, ocasionando rotação mandibular no sentido horário e agravamento da altura facial ântero-inferior.

Ao contrário do esperado, o aparelho com cobertura oclusal não trouxe maiores benefícios, em relação aos outros dois aparelhos avaliados, no que se refere à rotação mandibular e altura facial ântero-inferior, havendo um aumento significante dessas medidas para o aparelho Colado ao final do estudo. Tais alterações podem ser explicadas, talvez, devido à maior inclinação para vestibular dos dentes englobados por esse aparelho.

Vale ressaltar aqui, que os três aparelhos cumpriram o seu objetivo, levando à almejada separação, ao nível da sutura palatina e à conseqüente correção da mordida cruzada posterior. Os três aparelhos são considerados fixos, não dependendo de colaboração por parte do paciente, apesar de serem ativados em casa, diariamente, pelos pais ou responsáveis.

O estudo anterior, com o aparelho dentomucossuportado tipo Haas, segundo KAWAKAMI ${ }^{48}$, apresentou maior dificuldade na higienização da área palatina, tendo sido observados casos de estomatites, com lesões 
eritematosas e ulcerativas, decorrentes da compressão da mucosa palatina pelo acrílico, que poderá contra-indicar esse tipo de aparelho em alguns casos.

No entanto, em pacientes com idades mais avançadas, que necessitem de expansão maxilar, caso não haja abertura da sutura mediana durante a fase ativa, o aparelho Hyrax poderá levar à fratura da tábua óssea vestibular dos dentes de ancoragem, enquanto que no tipo Haas, a porção de acrílico pressionará a mucosa palatina e o paciente relatará uma sintomatologia dolorosa.

O aparelho expansor Colado apresenta a vantagem da ausência da fase das bandagens, poder ser utilizado em qualquer fase da dentição, independente do estágio de erupção dos dentes, em casos de dentes com coroas baixas ou expulsivas, ou ainda de dentes mal formados.

Como desvantagem, o aparelho Colado deve ser bem cimentado aos dentes de apoio, com um cimento resistente, capaz de suportar a fase ativa das expansões, devendo também ser removidos contatos prematuros, durante a oclusão, caso contrário, poderá favorecer o descolamento do aparelho.

Ao final do tratamento, notou-se uma gengivite generalizada nas papilas interproximais, recobertas pelo aparelho e regiões de tecido mole, próximas do acrílico, uma vez que a higienização nessa região torna-se prejudicada. Finalmente, foi necessário um tempo bastante grande para a remoção do aparelho, em alguns casos necessitando do seu seccionamento com brocas de alta rotação e de limpeza do cimento aderido aos dentes. Deve-se salientar que, em muitos casos de pacientes, na fase da dentadura 
mista, ocorreu a extração de dentes decíduos, junto com o aparelho, favorecendo a sensibilidade dolorosa do paciente e necessitando de anestesia local.

Como um dos pontos mais importantes, é necessário salientar que cabe ao clínico avaliar as condições e as necessidades dos pacientes e finalmente decidir sua opção pelo tipo de expansor a ser empregado na sua prática diária. 


\section{7 - CONCLUSÕES}

Examinando os resultados obtidos, segundo as condições do estudo e a metodologia, com relação às alterações dentoesqueléticas decorridas por meio da expansão rápida da maxila, pudemos chegar às seguintes conclusões:

7.1 - Imediatamente após a fase ativa de expansão, o grupo I do aparelho Colado foi o único que evidenciou um avanço estatisticamente significante da maxila para a anterior;

7.1.1 - Durante a fase ativa foi verificado que a espinha nasal anterior e a posterior (ENA e ENP) deslocaram-se inferiormente nos três grupos, induzindo a rotação mandibular no sentido horário, o que acarretou o aumento da altura facial ântero-inferior (AFAI);

7.2 - Da fase pós-expansão ao final do período de contenção, a maioria das alterações citadas anteriormente mostrou tendência a retornar aos valores iniciais, com exceção da rotação mandibular e da altura facial ântero-inferior, contudo sem significância clínica, o que provavelmente não alterou o perfil mole dos pacientes;

7.3 - Da fase pré-tratamento ao final do período de contenção, constatou-se que os três grupos apresentaram um deslocamento da maxila para baixo, estatisticamente significante $\mathrm{e}$ 
identificado pela ENA e ENP, que acarretou a rotação mandibular, com maior incidência nos grupos I e II. No entanto, a AFAI acentuou-se significantemente após esse período, para os três grupos;

7.4 - Na comparação direta entre os três grupos, os resultados estatísticos identificaram diferenças significativas na medida Sperp-A, entre os aparelhos Colado e Hyrax, na fase pósexpansão para a pós-contenção, em que o Colado demonstrou a retroposição do ponto A e o Hyrax, o avanço deste;

7.4.1 - A medida ENA-Me, na fase pré-expansão para a imediatamente pós-expansão e na fase pós-expansão para a pós-contenção, denunciou diferença estatística entre o aparelho Colado e o tipo Haas e o Colado e o Hyrax, claramente justificada pela presença da cobertura acrílica, característica do aparelho Colado, que causa a abertura da mordida anterior e, após sua remoção, o reposicionamento desta;

7.4.2 - A comparação geral de todas as medidas, entre o início e o final do período de contenção, para os três grupos, não demonstrou diferenças significativas entre eles, levando-nos a concluir que não há superioridade do aparelho Colado na prevenção de alterações desfavoráveis, no sentido vertical. 


\section{REFERÊNCIAS BIBLIOGRÁFICAS}




\section{REFERÊNCIAS BIBLIOGRÁFICAS*}

1. ADKINS, M.D.; NANDA, R.S.; CURRIER, G.F. Arch perimeter changes on rapid palatal expansion. Amer. J. Orthodont. Dentofac. Orthop., v.97, n.3, p.194-9, Mar. 1990.

2. AKKAYA, S.; LORENZON, S.; ÜÇEM, T.T. Comparison of dental arch and perimeter changes between bonded rapid and slow maxillary expansion procedures. Europ. J. Orthodont., v.20, n.3, p.255-61, June 1998.

3. ALMEIDA, G.A.; CAPELOZZA FILHO, L.; TRINDADE JÚNIOR, A.S. Expansão rápida da maxila: estudo cefalométrico prospectivo. Ortodontia, v.32, n.1, p.4556, jan./abr. 1999 .

4. ALPINER, M.L.; BEAVER, H.A. Criteria for rapid maxillary expansion. J. Mich. dent. Ass., v.53, n.2, p.39-42, Feb. 1971.

5. ANGELL, E.H. Treatment of irregularity of the permanent or adult teeth. Dent. Cosmos, v.1, p.540-4, 599-601, 1860.

\footnotetext{
* Normas recomendadas para uso no âmbito da Universidade de São Paulo, com base no documento "Referências Bibliográficas: exemplos", emanado do Conselho Supervisor do Sistema Integrado de Bibliotecas da USP, em reunião de 20 de setembro de 1990.
} 
6. ASANZA, S.; CISNEROS, G. J.; NIEBERG. L. G. Comparison of Hyrax and bonded expansion appliances. Angle Orthodont., v.67, n.1, p.15-22, 1997.

7. BARBOSA, J.A. Estudo cefalométrico longitudinal, do crescimento anterior da face, relacionado com a sobremordida, em adolescentes, brasileiros, leucodermas, com “oclusão normal”. Bauru, 1978. 63p. Dissertação (Mestrado) - Faculdade de Odontologia de Bauru, Universidade de São Paulo.

8. BARNES, R.E. The early expansion of deciduous arches and its effect on the developing permanent dentition. Amer. J. Orthodont., v.42, n.2, p.83-97, Feb. 1956.

9. BELL, R.A. A review of maxillary expansion in relation to rate of expansion and patient's age. Amer. J. Orthodont., v.81, n.1, p.32-7, Jan. 1982.

10. BERLOCHER, W.C.; MÜELLER, B.H.; TINANOFF, N. The effect of maxillary palatal expansion on the primary dental arch circumference. Pediat. Dent., v.2, n.1, p.2730, 1980.

11. BIEDERMAN, W. A hygienic appliance for rapid expansion. J. pract. Orthodont., v.2, n.2, p.67-70, Feb. 1968. 
12. BIEDERMAN, W. Rapid correction of Class III malocclusion by midpalatal expansion. Amer. J. Orthodont., v.63, n.1, p.47-55, Jan. 1973.

13. BISHARA, S.E.; STALEY, R.N. Maxillary expansion: clinical implications. Amer. J. Dentofac. Orthop., v.91, n.1, p.314, Jan. 1987.

14. BROGAN, W.F. The estability of maxillary expansion. Aust. dent. J., v.22, n. 2, p.92-9, Apr. 1977.

15. BROSH, T. et al. Rapid palatal expansion. Part 3: Strain developed during active and retention phases. Amer. J. Dentofac. Orthop., v.114, n.2, p.123-33, Aug. 1998.

16. BYRUM JUNIOR, A.G. Evaluation of anterior-posterior and vertical skeletal changes vs. dental change in rapid palatal expansion. cases as studied by lateral cephalograms. Amer. J. Orthodont., v.60, n.4, p.419, Oct. 1971.

17. CAPELOZZA FILHO, L.; SILVA FILHO, O.G. Expansão rápida da maxila: considerações gerais e aplicação clínica. Parte I. Rev. dent. Press Ortod. Ortop. Facial, v.2, n.3, p.88-102, maio/jun. 1997.

18. CAPELOZZA FILHO, L.; SILVA FILHO, O.G. Expansão rápida da maxila: considerações gerais e aplicação clínica. Parte II. Rev. dent. Press Ortod. Ortop. Facial, v.2, n.4, p.86-108, jul./ago. 1997. 
19. CAPELLOZA FILHO, L.; ALMEIDA, A.M.; URSI, W.J.S. Rapid maxillary expansion in cleft lip and palate patients. J. clin. Orthodont., v.28, n.1, p.34-9, Jan. 1994.

20. CAPELOZZA FILHO, L. et al. Expansão rápida da maxila cirúrgicamente assistida. Ortodontia, v.27, n.1, p.21-30, jan./abr. 1994.

21. CARREIRA, D.G.G. Avaliação cefalométrica longitudinal das alterações dentoesqueléticas produzidas pela expansão rápida da maxila. Bauru, 1999. 194p. Dissertação (Mestrado) - Faculdade de Odontologia de Bauru, Universidade de São Paulo.

22. CAVASSAN, A.O. et al. Expansão rápida da maxila: avaliação em modelos de gesso. Ortodontia, v.26, n.3, p.53-63, set./dez. 1993.

23. CHACONAS, S.J.; CAPUTO, A.A. Observation of orthopedic force distribution produced by maxillary orthodontic appliances. Amer. J. Orthodont., v.82, n.6, p.492-501, Dec. 1982.

24. CHANG, J.Y.; MCNAMARA JUNIOR, J.A.; HERBERGER, T.A. A longitudinal study of skeletal side effects induced by rapid maxillary expansion. Amer. J. Orthodont. Dentofac. Orthop., v.112, n.3, p.330-7, Sept. 1997. 
25. CLEALL, J.F. et al. Expansion of the midpalatal suture in the monkey. Angle Orthodont., v.35, n.1, p.23-35, Jan. 1965.

26. COHEN, M.; SILVERMAN, E. A new and simple palate splitting device. J. clin. Orthodont., v.7, n.6, p.368-9, June 1973.

27. CORBETT, M.C. Slow and continuous maxillary expansion, molar rotation, and molar distalization. J. Clin. Orthodont., v.31, n.4, p.253-63, 1997.

28. DAHLBERG, G. Statistical methods for medical and biological students. New York, Intescence, 1940 apud HOUSTON, W.J.B. ${ }^{45}$ p. 387.

29. DARENDELILER, M.A.; LORENZON, C. Maxillary expander using light, continuous force and autoblocking. J. clin. Orthodont., v.30, n.4, p.212-6, Apr. 1996.

30. DAVIS, W.M.; KRONMAN, J.H. Anatomical changes induced by splitting of the midpalatal suture. Angle Orthodont., v.39, n.2, p.126-32, Apr. 1969.

31. DHANE, J.M. An american board of orthodontics case report: Treatment of a Class I malocclusion with a significant trasverse discrepancy and high mandibular plane angle. Amer. J. Orthodont. Dentofac. Orthop., v.111, n.3, p.247-52, Mar. 1997. 
32. DIPAOLO, R.J. Thoughts on palatal expansion. J. clin. Orthodont., v.4, n.9, p.493-7, Sept. 1970.

33. ERVERDI, N. et al. A comparison of two different rapid palatal expansion techniques from the point of root resorption. Amer. J. Orthodont. Dentofac. Orthop., v.106, n.1, p.47-51, July 1994.

34. FALTIN JÚNIOR, K.; MOSCATIELLO, V.A.M.; BARROS, E.C. Disjuntor palatino Faltin Jr. Alterações dentofaciais decorrentes da disjunção da sutura palatina mediana. Rev. dent. Press Ortod. Ortop. Facial, v.4, n.4, p.5-13, jul. 1999.

35. GARDNER, G.E.; KRONMAN, J.H. Cranioskeletal displacements caused by rapid palatal expansion in the rhesus monkey. Amer. J. Orthodont., v.59, n.2, p.14655, Feb. 1971.

36. HAAS, A.J. Rapid expansion of the maxillary dental arch and nasal cavity by opening the midpalatal suture. Angle Orthodont., v.31, n.2, p.73-90, Apr. 1961.

37. HAAS, A.J. The treatment of maxillary deficiency by opening the midpalatal suture. Angle Orthodont., v.35, n.3, p.200-17, July 1965. 
38. HAAS, A.J. Palatal expansion: just beginning of dentofacial orthopedics., Amer. J. Orthodont., v.57, n.3, p.219-55, Mar. 1970.

39. HAAS, A.J. Long-term posttreatment evaluation of rapid palatal expansion. Angle Orthodont., v.50, n.3, p.189217, July 1980.

40. HARTGERINK, D.V.; VIG, P.S.; ABBOTT, D.W. The effect of rapid maxillary expansion on nasal airway resistance. Amer. J. Orthodont. Dentofac. Orthop., v.92, n.5, p.381-9, Nov. 1987.

41. HEFLIN, B.M. A three-dimensional cephalometric study of the influence of expansion of the midpalatal suture on the bones of the face. Amer. J. Orthodont., v.57, n.2, p.1945, Feb. 1970.

42. HEROLD, J.S. Maxillary expansion: a retrospective study of three methods of expansion and their long-term sequelae. Brit. J. Orthodont., v.16, n.3, p.195-200, Aug. 1989.

43. HESSE, K.L. et al. Changes in condilar position and occlusion associated with maxillary expansion for correction of functional unilateral posterior crossbite. Amer. J. Orthodont. Dentofac. Orthop., v.111, n.4, p.410-8, Apr. 1997. 
44. HOFFER JUNIOR, F.L.; WALTERS, R.D. Adaptive changes in the face of the Macaca mulatta monkey following orthopedic opening of the midpalatal suture. Angle Orthodont., v.45, n.4, p.282-90, Oct. 1975.

45. HOUSTON, W.J.B. Analysis of errors in orthodontic measurements. Amer. J. Orthodont. Dentofac. Orthop., v.83, n.5, p.382-90, May. 1983.

46. HOWE, R.P. Palatal expansion using a bonded appliance. Amer. J. Orthodont., v.82, n.6, p.464-8, Dec. 1982.

47. JANSON, G.R.P. Estudo tridimensional das assimetrias dentárias e esqueléticas na má oclusão de Classe II, subdivisão. Bauru, 1998. 271p. Tese (Livre Docência)Faculdade de Odontologia de Bauru, Universidade de São Paulo.

48. KAWAKAMI,R.Y. Comparação dos efeitos dentoesqueléticos, produzidos por dois tipos de disjuntores palatinos, por meio de análise cefalométrica em norma lateral. Bauru, 1995. 155p. Dissertação (Mestrado)- Faculdade de Odontologia de Bauru, Universidade de São Paulo.

49. KORKHAUS, G. Present orthodontic thought in Germany: jaw widening with active appliances in cases of mounth breathing. Amer. J. Orthodont., v.46, n.3, p.187-206, Mar. 1960. 
50. KRAUT, R.A. Surgically assisted rapid maxillary expansion by opening the midpalatal suture. J. Oral Maxilofac. Surg., v.42, n.10, p.651-5, Oct. 1984.

51. KREBS, A. Expansion on the midpalatal suture, studied by means of metallic implants. Acta. odont. scand., v.17, n.4, p.491-501, Dec. 1959.

52. KREBS, A. Midpalatal suture expansion studied by the implant method over a seven-year period. Europ. Orthodont. Soc., v.40, p.131-42, July 1964.

53. KROGMAN, W.M.; SASSOUNI, V. Syllabus in roentgenographic cephalometry. Philadelphia, Philadelphia Center for Reserch in Child Growth, 1957.

54. LÉON, A. P. F. et al. Aparelho expansor colado com cobertura acrílica para o controle vertical, durante a expansão rápida da maxila: apresentação de um caso clínico. Rev. dent. Press Ortod. Ortop. Facial, v.3, n.3, p.25-33, maio/jun. 1998.

55. LINDER-ARONSON, S.; LINDGREN, J. The skeletal and dental effects of rapid maxillary expansion. Brit. J. Orthodont., v.6, n.1, p.25-9, Jan. 1979. 
56. MAJOURAU, A.; NANDA, R. Biomechanical basis of vertical dimension control during rapid palatal expansion therapy. Amer. J. Orthodont. Dentofac. Orthop., v.106, n.3, p.322-8, Sept. 1994.

57. MARTINS, D.R.; ALMEIDA, R.R.; DAINESI, E.A. Mordidas cruzadas anterior e posterior. Odonto Master, v.1, n.2, p.1-19, 1994.

58. MAZZIEIRO, E.T. Estudo cefalométrico, em norma frontal, das alterações dentoesqueléticas após a expansão rápida da maxila, em pacientes na faixa etária de 10 a 16anos e 2 meses. Bauru, 1994. 128p. Dissertação (Mestrado) - Faculdade de Odontologia de Bauru, Universidade de São Paulo.

59. MCLUCKIE, W.C. Effects of slow maxillary expansion on mandibular arch width. Amer. J. Orthodont. Dentofac. Orthop., v.105, n.3, p.317-8, Mar. 1994. /Reviews and abstracts/

60. MCNAMARA JUNIOR, J.A. A method of cephalometric evaluation. Amer. J. Orthodont., v.86, n.6, p.449-69, Dec. 1984. 
61. MCNAMARA JUNIOR, J.A.; BRUDON, W.L. Bonded rapid maxillary expansion appliances. In:

Orthodontic and orthopedic treatment in the mixed dentition. 5.ed. Ann Arbor, Needham Press, 1995.Cap.7, p.145-69.

62. MEMIKOGLU, T.U.T.; ISERI, H. Nonextraction treatment with a rigid acrilic, bonded rapid maxillary expander. J. clin. Orthodont., v.31, n.2, p.113-8, Feb. 1997.

63. MEMIKOGLU, T.U.T.; ISERI, H. Effects of a bonded rapid maxillary expansion appliance during orthodontic treatment. Angle Orthodont., v.69, n.3, p.251-6, 1999.

64. MONDRO, J.F.; LITT, R.A. An improved direct-bonded palatal expansion appliance. J. clin. Orthodont., v.11, n.3, p.203-6, Mar. 1977.

65. MOSS, J.P. Rapid expansion of the maxillary arch. Part I. J. pract. Orthodont., v.2, n.4, p.165-71, Apr. 1968.

66. MOSSAZ-JOËLSON, K.; MOSSAZ, C.F. Slow maxillary expansion: a comparison between banded and bonded appliances. Europ. J. Orthodontics., v.11, n.1 , p.67-76, Feb. 1989. 
67. MOUSSA, R.; O’REILLY, M.T.; CLOSE, J.M. Long-term stability of rapid palatal expander treatment and edgewise mechanotherapy. Amer. J. Orthodont. Dentofac. Orthop., v.108, n.5, p. 478-88, Nov. 1995.

68. PAVLIN, D.; VUKICEVIC, D. Mechanical reactions of facial skeleton to maxillary expansion determined by laser holography. Amer. J. Orthodont., v.85, n.6, p.498-507, June 1984.

69. PEARSON, L.E. Treatment of a severe openbite excessive vertical pattern with an eclectic non-surgical approach. Angle Orthodontic., v.61, n.1, p.71-6, 1991.

70. PEARSON, L.E.; PEARSON, B.L. Rapid maxillary expansion with incis or intrusion: A study of vertical control. Amer. J. Orthodont. Dentofac. Orthop., v.115, n.5, p.576-82, May 1999.

71. PERSSON, M.; THILANDER, B. Palatal suture closure in man from 15 to 35 years of age. Amer. J. Orthodont., v.72, n.1, p.42-52, July 1977.

72. REED, N.; GHOSH, J.; NANDA, R.S. Comparison of treatment outcomes with banded and bonded RPE appliances. Amer. J. Orthodont. Dentofac. Orthop., v.116, n.1, p.31-40, July 1999. 
73. REVELO, B.; FISHMAN, L.S. Maturational evaluation of ossification of the midpalatal suture. Amer. J. Orthodont. Dentofac. Orthop., v.105, n.3, p.288-92, Mar. 1994.

74. SANDIKÇIOGLU, M.; HAZAR, S. Skeletal and dental changes after maxillary expansion in the mixed dentition. Amer. J. Orthodont. Dentofac. Orthop., v.111, n.3, p.321-7, Mar. 1997.

75. SANDSTROM,

R.A.;

KLAPPER,

L.;

PAPACONSTANTINOU, S. Expansion of the lower arch concurrent with rapid maxillary expansion. Amer. J. Orthodont. Dentofac. Orthop., v.94, n.4, p.296-302, Oct. 1988.

76. SANTOS-PINTO, C.C.M.; HENRIQUES, J.F.C. Expansão rápida da maxila: preceitos clínicos e radiográficos. Rev. Odont. USP, v.4, n.2, p.164-6, abr./jun. 1990.

77. SARVER, D.M.; JOHNSTON, M.W. Skeletal changes in vertical and anterior displacement of the maxilla with bonded rapid palatal expansion. Amer. J. Orthodont. Dentofac. Orthop., v.95, n.6, p.462-6, June 1989.

78. SATO, K.; VIGORITO, J.W.; CARVALHO, L.S. Avaliação cefalométrica da disjunção rápida da sutura palatina mediana, através da telerradiografia em norma frontal (P.A.). Ortodontia, v.19, n.1/2, p.44-51, 1986. 
79. SCAVONE JÚNIOR, E. O perfil facial tegumentar dos $\mathbf{1 3}$ aos 18 anos de idade. Bauru, 1996. 219p. Tese (Doutorado) - Faculdade de Odontologia de Bauru, Universidade de São Paulo.

80. SCHEIDEMAN, G.B. et al. Cephalometric analysis of dentofacial normals. Amer. J. Orthodont., v.78, n.4, p.404-20, Oct. 1980.

81. SCHNEIDMAN, E.; WILSON, S.; ERKIS, R. Two-point rapid palatal expansion: an alternate approach to traditional treatment. Pediat. Dent., v.12, n.2, p.92-7, Apr./May 1990.

82. SILVA, C.C.A. Avaliação cefalométrica dos efeitos do aparelho guia de erupção no tratamento da má oclusão de Classe II, divisão 1, após dois anos. Bauru, 1997. 173p. Dissertação (Mestrado) - Faculdade de Odontologia de Bauru, Universidade de São Paulo.

83. SILVA FILHO, O.G.; CAPELOZZA FILHO, L. Expansão rápida da maxila: preceitos clínicos. Ortodontia, v.21, n.1, p.61-81, jan./jun. 1988.

84. SILVA FILHO, O.G.; FREITAS, S.F.; CAVASSAN, A.O. Prevalência de oclusão normal e maloclusão em escolares da cidade de Bauru (São Paulo): Part. I. Relação Sagital. Rev. Odont. USP, v.4, n.2, p.130-7, abr./jun. 1990. 
85. SILVA FILHO, O.G.; HERNANDES, R.; OKADA, T. Efeitos induzidos pela expansão rápida da maxila sobre os prémolares de ancoragem: estudo radiográfico. Ortodontia, v.27, n.3, p.18-36, set./dez. 1994.

86. SILVA FILHO, O.G.; MONTES, L.A.P.; TORELLY, L.F. Rapid maxillary expansion in the deciduous and mixed dentition evaluated through posteroanterior cephalometric analysis. Amer. J. Orthodont. Dentofac. Orthop., v.107, n.3, p.268-75, Mar. 1995.

87. SILVA FILHO, O.G.; VALLADARES NETO, J.; ALMEIDA, R.R. Early correction of posterior crossbite: biomechanical characteristics of the appliances. J. Pedod., v.13, n.3, p.195-221, Spring 1989.

88. SILVA FILHO, O.G.; VILLAS BOAS, M.C.; CAPELOZZA FILHO, L. Rapid maxillary expansion in the primary and mixed dentitions: a cephalometric evaluation. Amer. J. Orthodont. Dentofac. Orthop., v.100, n.2, p.171-9, Aug. 1991.

89. SILVA FILHO, O.G. et al. Expansão ortopédica da maxila em estágios precoces do desenvolvimento oclusal confecção laboratorial e apresentação de caso clínico. Rev. bras. Odont., v.46, n.6, p.25-34, nov./dez. 1989. 
90. SILVA FILHO, O.G. et al. Expansão rápida da maxila na dentadura permanente: avaliação cefalométrica. Ortodontia, v.27, n.2, p.68-76, maio/ago. 1994.

91. SPILLANE, L.M.; MCNAMARA JUNIOR, J.A. Maxillary adaptation to expansion in mixed dentition. Seminars in orthodontics, v.1, n.3, p.176-87, Sept. 1995.

92. SPOLYAR, J.L. The design, fabrication, and use of a fullcoverage bonded rapid maxillary expansion appliance. Amer. J. Orthodont., v.86, n.2, p.136-45, Aug. 1984.

93. STEIMAN, H. Visual aid for bonded acrylic rapid palatal expander. J. clin. Orthodont., v.31, n.5, p.327, 1997.

94. TEIXEIRA, L.R.A.C.; SILVEIRA, A.C.A.; VALE, D.M.V. Avaliação das alterações esqueléticas ântero-posteriores, transversais e verticais decorrentes da expansão rápida da maxila., Rev. SOPEO, v.3, n.2, p.18-23, 1996.

95. VARDIMON, A.D. et al. Rapid palatal expansion: Part 1. Mineralization pattern of the midpalatal suture in cats. Amer. J. Orthodont. Dentofac. Orthop., v.113, n.4, p.371-8, Apr. 1998.

96. VELÁZQUEZ, P.; BENITO, E.; BRAVO, L.A. Rapid maxillary expansion. A study of the long-term effects. Amer. J. Orthodont. Dentofac. Orthop., v.109, n.4, p.361-7, Apr. 1996. 
97. VIAZIS, A.D. et al. Designs and applications of palatal expansion appliances. J. clin. Orthodont., v.26, n.4, p.239-43, Apr. 1992.

98. WERTZ, R.A. Skeletal and dental changes accompanying rapid midpalatal suture opening. Amer. J. Orthodont., v.58, n.1, p.41-66, July 1970.

99. WERTZ, R.; DRESKIN, M. Midpalatal suture opening: a normative study. Amer. J. Orthodont., v.71, n.4, p.36781, Apr. 1977.

100. ZIMRING, J.F.; ISAACSON, R.J. Forces produced by rapid maxillary expansion. III- Forces present during retention. Angle Orthodont., v.35, n.3, p.178-86, July 1965. 


\section{ABSTRACT}

\section{Cephalometric study through lateral cephalograms of dentoskeletal changes following by the use of three maxillary expansion appliances: bonded, Haas and Hyrax.}

The objective of this cephalometric study was to compare, through lateral cephalograms, the dentoskeletal changes following the use of three types of rapid maxillary expansion appliances. The sample consisted of 69 lateral cephalograms taken from 23 subjects, 15 females and 8 males, with an initial age ranging from 9 years 8 months to 15 years 5 months, presenting uni or bilateral posterior crossbite, that underwent rapid maxillary expansion with a bonded maxillary expander with a full occlusal acrylic coverage. The lateral cephalograms were taken before treatment (pre-expansion), immediately after expansion and three months after retention with the same appliance. The results were compared to a previous study of the Haas and Hyrax expanders in 41 subjects, 26 females and 15 males, with an initial age ranging from 10 years 8 months to 17 years 8 months, with uni or bilateral posterior crossbite. The lateral cephalograms were taken at the same time intervals as the first group. Results demonstrated that immediately after rapid maxillary expansion only the group with the bonded maxillary expander showed a statistically significant anterior displacement of the maxilla, while the other appliances groups showed no significant displacements. However, after the retention period, this significant displacement returned to values close to its initial and no statistically significant difference was found in the displacement among the groups. Additionally, after the retention period, an inferior displacement of the maxilla was shown in the three groups, causing a slight clockwise rotation of the mandible, which was more significant in the groups I and II, 
while the lower anterior face height underwent a statistically significant increase, similarly in the three groups, nevertheless, no statistically significant difference was found among the groups after this period. In conclusion, the use of a bonded maxillary expander to prevent unfavorable dentoskeletal changes in the vertical plane, in patients with long lower anterior face height, was not justified in this study since no significant differences were shown between the changes produced by the three appliances, in the postretention period. 
APÊNDICES 


\section{APÊNDICES}

APÊNDICE 1 - Tabela correlacionando os pacientes com a idade e o sexo, no grupo I (aparelhos dentossuportados - Colado).

\begin{tabular}{|c|c|c|c|}
\hline PACIENTE & IDADE & $\begin{array}{l}\text { IDADE } \\
\text { (meses) }\end{array}$ & SEXO \\
\hline 01-ACT & $13 \mathrm{a} 05 \mathrm{~m}$ & 161 & FEM \\
\hline $02-\mathrm{ABG}$ & 13a $05 \mathrm{~m}$ & 161 & MASC \\
\hline 03-BAC & $13 \mathrm{a} 03 \mathrm{~m}$ & 159 & FEM \\
\hline 04-BN & $14 \mathrm{a} 04 \mathrm{~m}$ & 172 & FEM \\
\hline 05-BSM & 10a $04 \mathrm{~m}$ & 124 & FEM \\
\hline 06-DTF & 10a $03 \mathrm{~m}$ & 123 & FEM \\
\hline 07-ECP & $13 \mathrm{a} 11 \mathrm{~m}$ & 167 & FEM \\
\hline 08-ESS & $14 \mathrm{a} 11 \mathrm{~m}$ & 179 & FEM \\
\hline 09-ES & $13 \mathrm{a} 05 \mathrm{~m}$ & 161 & FEM \\
\hline 10-FHN & $14 \mathrm{a} 03 \mathrm{~m}$ & 171 & MASC \\
\hline 11-FRN & $12 \mathrm{a} 01 \mathrm{~m}$ & 145 & MASC \\
\hline 12-GSM & 10a 09m & 129 & FEM \\
\hline 13-JGF & $10 \mathrm{a} 01 \mathrm{~m}$ & 121 & FEM \\
\hline 14-JPP & 09a 08m & 116 & FEM \\
\hline 15-MAC & 13a $07 m$ & 163 & MASC \\
\hline 16-MR & $10 \mathrm{a} 11 \mathrm{~m}$ & 131 & FEM \\
\hline 17-MEL & $13 \mathrm{a} 03 \mathrm{~m}$ & 159 & MASC \\
\hline 18-MMO & $14 \mathrm{a} 06 \mathrm{~m}$ & 174 & FEM \\
\hline 19-NC & $12 \mathrm{a} 03 \mathrm{~m}$ & 147 & FEM \\
\hline 20-SAF & $15 \mathrm{a} 05 \mathrm{~m}$ & 185 & FEM \\
\hline 21-VFP & $13 a$ & 156 & MASC \\
\hline 22-VHP & $11 \mathrm{a} 11 \mathrm{~m}$ & 143 & MASC \\
\hline 23-WS & 11a $04 \mathrm{~m}$ & 136 & MASC \\
\hline
\end{tabular}


APÊNDICE 2 - Tabela correlacionando os pacientes com a idade e o sexo, no grupo II (aparelhos dentomucossuportados - tipo Haas).

\begin{tabular}{|c|c|c|c|}
\hline PACIENTE & IDADE & $\begin{array}{l}\text { IDADE } \\
\text { (meses) }\end{array}$ & SEXO \\
\hline 01-ACM & $10 \mathrm{a} 11 \mathrm{~m}$ & 131 & FEM \\
\hline 02-DCA & $12 \mathrm{a} 02 \mathrm{~m}$ & 146 & FEM \\
\hline 03-AFC & $13 \mathrm{a} 05 \mathrm{~m}$ & 161 & FEM \\
\hline 04-APD & $11 \mathrm{a}$ & 132 & FEM \\
\hline 05-IMM & $13 \mathrm{a} 03 \mathrm{~m}$ & 159 & FEM \\
\hline 06-MMR & $16 a$ & 192 & FEM \\
\hline 07-KVF & $14 \mathrm{a} 11 \mathrm{~m}$ & 179 & FEM \\
\hline 08-JBN & 13a $02 \mathrm{~m}$ & 158 & FEM \\
\hline 09-РAB & $12 \mathrm{a} 02 \mathrm{~m}$ & 146 & FEM \\
\hline 10-VML & $14 \mathrm{a} 01 \mathrm{~m}$ & 169 & FEM \\
\hline 11-VAAO & $12 \mathrm{a} 03 \mathrm{~m}$ & 147 & FEM \\
\hline 12-RG & $17 \mathrm{a} 08 \mathrm{~m}$ & 212 & FEM \\
\hline 13-ASP & $14 \mathrm{a} 08 \mathrm{~m}$ & 176 & MASC \\
\hline 14-ALC & $13 \mathrm{a}$ & 156 & MASC \\
\hline $15-\mathrm{DO}$ & 10a $10 \mathrm{~m}$ & 130 & MASC \\
\hline 16-DCJ & $16 a 03 m$ & 195 & MASC \\
\hline 17-FBB & $12 \mathrm{a} 04 \mathrm{~m}$ & 148 & MASC \\
\hline 18-FMR & 11a 11m & 143 & MASC \\
\hline 19-LFC & $12 \mathrm{a}$ & 144 & MASC \\
\hline 20-RBM & $16 \mathrm{a} 02 \mathrm{~m}$ & 194 & MASC \\
\hline
\end{tabular}


APÊNDICE 3 - Tabela correlacionando os pacientes com a idade e o sexo, no grupo III (aparelhos dentossuportados - Hyrax).

\begin{tabular}{|c|c|c|c|}
\hline PACIENTE & IDADE & $\begin{array}{l}\text { IDADE } \\
\text { (meses) }\end{array}$ & SEXO \\
\hline 01-ACPS & $13 \mathrm{a} 01 \mathrm{~m}$ & 157 & FEM \\
\hline 02-JLU & $11 \mathrm{a} 10 \mathrm{~m}$ & 142 & FEM \\
\hline 03-CAD & $14 \mathrm{a} 04 \mathrm{~m}$ & 172 & FEM \\
\hline 04-ACS & $14 \mathrm{a} 09 \mathrm{~m}$ & 177 & FEM \\
\hline 05-MSCB & 11a & 132 & FEM \\
\hline 06-FMFM & 11a $07 \mathrm{~m}$ & 139 & FEM \\
\hline 07-AFC & $11 \mathrm{a} 11 \mathrm{~m}$ & 143 & FEM \\
\hline 08-NCM & $14 \mathrm{a} 03 \mathrm{~m}$ & 171 & FEM \\
\hline 09-GMM & $14 a$ & 168 & FEM \\
\hline 10-CLCS & $10 \mathrm{a} 08 \mathrm{~m}$ & 128 & FEM \\
\hline 11-PRDB & 11a $05 \mathrm{~m}$ & 137 & FEM \\
\hline 12-ТCM & $11 \mathrm{a} 01 \mathrm{~m}$ & 133 & FEM \\
\hline 13-VGS & $14 \mathrm{a} 11 \mathrm{~m}$ & 179 & FEM \\
\hline 14-ROTP & 13a $05 \mathrm{~m}$ & 161 & FEM \\
\hline $15-A G$ & $12 \mathrm{a} 11 \mathrm{~m}$ & 155 & MASC \\
\hline 16-DRS & $12 \mathrm{a} 08 \mathrm{~m}$ & 152 & MASC \\
\hline 17-MVS & $12 \mathrm{a} 04 \mathrm{~m}$ & 148 & MASC \\
\hline 18-BMAN & $12 \mathrm{a} 09 \mathrm{~m}$ & 153 & MASC \\
\hline 19-FRP & $13 \mathrm{a} 05 \mathrm{~m}$ & 161 & MASC \\
\hline 20-RCD & 12a $11 \mathrm{~m}$ & 155 & MASC \\
\hline 21-SAOJ & $13 \mathrm{a} 06 \mathrm{~m}$ & 162 & MASC \\
\hline
\end{tabular}


APÊNDICE 4 - Tabela com os valores cefalométricos das medidas analisadas (SNA e SN.ENA) nas 3 fases estudadas (pré-expansão, pós-expansão e pós-contenção), no grupo I (aparelhos dentossuportados - Colado).

\begin{tabular}{l|c|c|c|c|c|c}
\hline MEDIDA & \multicolumn{3}{|c|}{ SNA $\left(^{\circ}\right)$} & \multicolumn{3}{c}{ SN.ENA $\left(^{\circ}\right)$} \\
\hline \multicolumn{1}{c|}{ Fase } & $\begin{array}{c}\text { pré- } \\
\text { expansão }\end{array}$ & $\begin{array}{c}\text { pós- } \\
\text { expansão }\end{array}$ & $\begin{array}{c}\text { pós- } \\
\text { contenção }\end{array}$ & $\begin{array}{c}\text { pré- } \\
\text { expansão }\end{array}$ & $\begin{array}{c}\text { pós- } \\
\text { expansão }\end{array}$ & $\begin{array}{c}\text { pós- } \\
\text { contenção }\end{array}$ \\
\hline 01-ACT & 74,5 & 76,0 & 76,7 & 79,1 & 81,4 & 81,9 \\
02-AB & 82,3 & 82,6 & 82,0 & 90,3 & 89,2 & 89,5 \\
03-BA & 81,1 & 81,7 & 80,7 & 89,2 & 86,2 & 85,3 \\
04-BN & 86,8 & 86,5 & 86,6 & 93,2 & 93,2 & 93,3 \\
05-BSM & 80,6 & 79,7 & 80,7 & 85,6 & 85,8 & 87,3 \\
06-DT & 86,8 & 88,7 & 89,9 & 91,1 & 95,5 & 95,7 \\
07-ECP & 81,8 & 81,7 & 80,8 & 86,6 & 88,8 & 86,7 \\
08-ESS & 84,5 & 87,4 & 85,6 & 89,1 & 93,1 & 92,3 \\
09-ES & 79,1 & 81,9 & 81,2 & 85,0 & 87,9 & 85,9 \\
10-FH & 90,9 & 92,3 & 87,5 & 96,7 & 97,9 & 92,5 \\
11-FR & 90,8 & 92,0 & 88,8 & 96,6 & 97,6 & 93,7 \\
12-GS & 78,6 & 80,5 & 79,5 & 82,5 & 85,1 & 84,1 \\
13-JG & 82,5 & 82,1 & 83,5 & 86,4 & 89,5 & 91,0 \\
14-JPP & 78,1 & 78,7 & 77,8 & 85,8 & 86,4 & 83,8 \\
15-MC & 91,7 & 93,4 & 91,4 & 100,7 & 101,8 & 96,5 \\
16-MR & 77,8 & 78,1 & 79,0 & 84,1 & 86,7 & 84,7 \\
17-ME & 80,4 & 82,3 & 81,3 & 86,6 & 88,5 & 87,4 \\
18-MM & 80,4 & 80,4 & 80,7 & 88,4 & 88,0 & 86,3 \\
19-NC & 75,4 & 76,2 & 75,7 & 81,7 & 82,5 & 82,1 \\
20-SA & 84,9 & 85,2 & 84,6 & 89,7 & 91,1 & 91,4 \\
21-VF & 84,5 & 84,7 & 85,0 & 91,4 & 90,2 & 91,9 \\
22-VH & 76,5 & 79,6 & 78,5 & 78,9 & 81,4 & 81,8 \\
23-WS & 82,0 & 86,2 & 82,5 & 85,9 & 90,6 & 86,2 \\
\hline
\end{tabular}


APÊNDICE 5 - Tabela com os valores cefalométricos das medidas analisadas (Nperp-A e Sperp-A) nas 3 fases estudadas (pré-expansão, pós-expansão e pós-contenção), no grupo I (aparelhos dentossuportados - Colado).

\begin{tabular}{l|c|c|c|c|c|c}
\hline MEDIDA & \multicolumn{3}{|c|}{ Nperp-A (mm) } & \multicolumn{3}{c}{ Sperp-A (mm) } \\
\hline Fase & $\begin{array}{c}\text { pré- } \\
\text { expansão }\end{array}$ & $\begin{array}{c}\text { pós- } \\
\text { expansão }\end{array}$ & $\begin{array}{c}\text { pós- } \\
\text { contenção }\end{array}$ & $\begin{array}{c}\text { pré- } \\
\text { expansão }\end{array}$ & $\begin{array}{c}\text { pós- } \\
\text { expansão }\end{array}$ & $\begin{array}{c}\text { pós- } \\
\text { contenção }\end{array}$ \\
\hline 01-ACT & 3,1 & 3,2 & 0,8 & 67,5 & 66,6 & 67,2 \\
02-AB & $-0,1$ & $-0,7$ & $-1,6$ & 75,8 & 74,9 & 74,8 \\
03-BA & 2,4 & 8,4 & 3,9 & 72,3 & 76,8 & 73,0 \\
04-BN & 2,9 & 6,3 & 5,5 & 71,7 & 72,6 & 71,6 \\
05-BSM & 0,7 & 2,1 & 3,2 & 68,0 & 69,7 & 69,5 \\
06-DT & 7,2 & 7,5 & 7,0 & 76,3 & 76,7 & 78,0 \\
07-ECP & 1,3 & 5,3 & 2,0 & 70,1 & 72,8 & 70,9 \\
08-ESS & 5,3 & 5,2 & 8,8 & 67,7 & 67,9 & 70,8 \\
09-ES & 0,1 & 0,8 & $-1,0$ & 69,9 & 70,9 & 69,1 \\
10-FH & 4,9 & 4,5 & 6,2 & 72,7 & 72,1 & 73,4 \\
11-FR & 4,7 & 3,4 & 1,9 & 72,6 & 71,6 & 69,5 \\
12-GS & 0,9 & $-0,1$ & $-0,9$ & 69,0 & 68,8 & 67,9 \\
13-JG & 0,4 & 2,7 & 2,4 & 63,5 & 65,1 & 64,9 \\
14-JPP & 3,4 & 6,7 & 1,4 & 67,0 & 70,0 & 66,8 \\
15-MC & 12,2 & 13,8 & 8,7 & 85,1 & 85,8 & 81,9 \\
16-MR & 3,4 & 4,4 & 2,9 & 72,4 & 73,6 & 72,2 \\
17-ME & 2,0 & 3,5 & 1,8 & 72,4 & 74,0 & 72,8 \\
18-MM & 2,2 & $-0,7$ & 0,4 & 71,8 & 69,9 & 70,5 \\
19-NC & $-2,6$ & 1,8 & 2,6 & 69,0 & 72,9 & 73,7 \\
20-SA & 5,6 & 8,1 & 6,4 & 74,9 & 77,0 & 75,3 \\
21-VF & 2,0 & 1,6 & 2,9 & 74,1 & 74,4 & 74,9 \\
22-VH & $-4,4$ & $-3,6$ & $-5,9$ & 67,0 & 68,1 & 66,3 \\
23-WS & 5,1 & 4,9 & 1,7 & 69,3 & 71,0 & 68,4 \\
\hline
\end{tabular}


APÊNDICE 6 - Tabela com os valores cefalométricos das medidas analisadas (SNB e Nperp-Pog) nas 3 fases estudadas (pré-expansão, pós-expansão e pós-contenção), no grupo I (aparelhos dentossuportados - Colado).

\begin{tabular}{l|c|c|c|c|c|c}
\hline MEDIDA & \multicolumn{3}{|c|}{ SNB $\left(^{\circ}\right)$} & \multicolumn{3}{c}{ Nperp-Pog (mm) } \\
\hline \multicolumn{1}{c|}{ Fase } & $\begin{array}{c}\text { pré- } \\
\text { expansão }\end{array}$ & $\begin{array}{c}\text { pós- } \\
\text { expansão }\end{array}$ & $\begin{array}{c}\text { pós- } \\
\text { contenção }\end{array}$ & $\begin{array}{c}\text { pré- } \\
\text { expansão }\end{array}$ & $\begin{array}{c}\text { pós- } \\
\text { expansão }\end{array}$ & $\begin{array}{c}\text { pós- } \\
\text { contenção }\end{array}$ \\
\hline 01-ACT & 72,4 & 72,0 & 72,5 & 0,7 & $-2,1$ & $-6,4$ \\
02-AB & 80,5 & 80,4 & 80,3 & 1,3 & $-1,4$ & $-2,0$ \\
03-BA & 75,5 & 74,6 & 74,4 & $-5,7$ & 1,9 & $-4,7$ \\
04-BN & 78,6 & 73,4 & 76,5 & $-12,3$ & $-16,6$ & $-11,7$ \\
05-BSM & 78,1 & 75,4 & 77,0 & $-4,4$ & $-6,0$ & $-1,0$ \\
06-DT & 81,2 & 81,4 & 83,8 & 4,5 & 1,8 & 4,5 \\
07-ECP & 78,1 & 74,9 & 75,4 & $-9,1$ & $-7,8$ & $-10,5$ \\
08-ESS & 80,2 & 82,1 & 78,1 & 3,4 & 1,2 & 3,3 \\
09-ES & 75,4 & 76,1 & 76,9 & $-7,4$ & $-10,6$ & $-11,3$ \\
10-FH & 85,4 & 86,0 & 82,3 & $-2,2$ & $-5,7$ & $-0,6$ \\
11-FR & 82,6 & 83,7 & 82,6 & $-3,8$ & $-7,7$ & $-6,7$ \\
12-GS & 76,5 & 77,2 & 77,7 & $-0,8$ & $-5,1$ & $-3,7$ \\
13-JG & 79,5 & 77,3 & 79,1 & $-4,2$ & $-2,1$ & $-2,0$ \\
14-JPP & 75,3 & 75,3 & 75,1 & 4,4 & 8,7 & $-0,4$ \\
15-MC & 83,5 & 82,9 & 85,5 & 7,9 & 5,6 & 5,8 \\
16-MR & 74,4 & 73,4 & 74,8 & 1,6 & 0,1 & $-0,9$ \\
17-ME & 78,0 & 76,3 & 78,6 & 0,7 & $-4,6$ & $-1,2$ \\
18-MM & 79,5 & 77,0 & 78,4 & 4,5 & $-6,5$ & $-1,5$ \\
19-NC & 76,2 & 74,2 & 74,4 & $-1,6$ & 1,8 & 4,5 \\
20-SA & 79,4 & 79,0 & 78,4 & 0,5 & 0,8 & 0,1 \\
21-VF & 84,5 & 84,7 & 85,8 & 6,8 & 5,1 & 9,5 \\
22-VH & 76,2 & 76,5 & 76,9 & $-8,6$ & $-13,6$ & $-14,8$ \\
23-WS & 79,9 & 79,7 & 78,7 & 8,2 & $-0,1$ & $-1,4$ \\
\hline
\end{tabular}


APÊNDICE 7 - Tabela com os valores cefalométricos das medidas analisadas (ANB e NAP) nas 3 fases estudadas (préexpansão, pós-expansão e pós-contenção), no grupo I (aparelhos dentossuportados - Colado).

\begin{tabular}{l|c|c|c|c|c|c}
\hline MEDIDA & \multicolumn{3}{|c|}{ ANB $\left(^{\circ}\right)$} & \multicolumn{3}{c}{ NAP $\left(^{\circ}\right)$} \\
\hline \multicolumn{1}{c|}{ Fase } & $\begin{array}{c}\text { pré- } \\
\text { expansão }\end{array}$ & $\begin{array}{c}\text { pós- } \\
\text { expansão }\end{array}$ & $\begin{array}{c}\text { pós- } \\
\text { contenção }\end{array}$ & $\begin{array}{c}\text { pré- } \\
\text { expansão }\end{array}$ & $\begin{array}{c}\text { pós- } \\
\text { expansão }\end{array}$ & $\begin{array}{c}\text { pós- } \\
\text { contenção }\end{array}$ \\
\hline 01-ACT & 2,0 & 4,0 & 4,2 & 5,9 & 9,0 & 8,8 \\
02-AB & 1,8 & 2,1 & 1,8 & $-1,3$ & 0,0 & $-1,0$ \\
03-BA & 5,6 & 7,1 & 6,4 & 10,2 & 13,7 & 11,7 \\
04-BN & 8,2 & 13 & 10,2 & 16,6 & 25,4 & 20,9 \\
05-BSM & 2,5 & 4,3 & 3,7 & 6,1 & 10,1 & 7,6 \\
06-DT & 5,5 & 7,4 & 6,1 & 10,9 & 14,0 & 10,9 \\
07-ECP & 3,6 & 6,8 & 5,3 & 10,5 & 16,5 & 13,0 \\
08-ESS & 4,3 & 5,3 & 7,6 & 7,5 & 9,5 & 14,2 \\
09-ES & 3,7 & 5,7 & 4,3 & 8,2 & 12,0 & 9,1 \\
10-FH & 5,5 & 6,2 & 5,2 & 12,7 & 14,3 & 12,6 \\
11-FR & 8,2 & 8,3 & 6,2 & 14,1 & 14,9 & 11,3 \\
12-GS & 2,0 & 3,2 & 1,8 & 2,9 & 5,4 & 2,4 \\
13-JG & 2,9 & 4,7 & 4,5 & 5,8 & 8,6 & 7,9 \\
14-JPP & 2,7 & 3,4 & 2,7 & 2,8 & 5,4 & 3,3 \\
15-MC & 8,2 & 10,5 & 5,9 & 16,6 & 20,9 & 11,9 \\
16-MR & 3,4 & 4,7 & 4,2 & 5,8 & 9,3 & 7,4 \\
17-ME & 2,4 & 6,1 & 2,7 & 3,4 & 10,9 & 4,8 \\
18-MM & 0,9 & 3,5 & 2,3 & $-0,2$ & 5,4 & 2,6 \\
19-NC & $-0,8$ & 2,0 & 1,3 & $-3,9$ & 2,0 & 0,4 \\
20-SA & 5,5 & 6,2 & 6,3 & 11,2 & 15,2 & 12,9 \\
21-VF & $-0,1$ & 0,0 & $-0,8$ & $-3,4$ & $-2,4$ & $-4,6$ \\
22-VH & 0,4 & 3,1 & 1,6 & $-0,2$ & 5,6 & 2,3 \\
23-WS & 2,1 & 6,5 & 3,8 & 2,4 & 10,9 & 5,6 \\
\hline
\end{tabular}


APÊNDICE 8 - Tabela com os valores cefalométricos das medidas analisadas (N-ENA e ENA-PoOr) nas 3 fases estudadas (pré-expansão, pós-expansão e póscontenção), no grupo I (aparelhos dentossuportados Colado).

\begin{tabular}{l|c|c|c|c|c|c}
\hline MEDIDA & \multicolumn{3}{|c|}{ N-ENA (mm) } & \multicolumn{3}{c}{ ENA-PoOr (mm) } \\
\hline \multicolumn{1}{c|}{ Fase } & $\begin{array}{c}\text { pré- } \\
\text { expansão }\end{array}$ & $\begin{array}{c}\text { pós- } \\
\text { expansão }\end{array}$ & $\begin{array}{c}\text { pós- } \\
\text { contenção }\end{array}$ & $\begin{array}{c}\text { pré- } \\
\text { expansão }\end{array}$ & $\begin{array}{c}\text { pós- } \\
\text { expansão }\end{array}$ & $\begin{array}{c}\text { pós- } \\
\text { contenção }\end{array}$ \\
\hline 01-ACT & 53,8 & 53,4 & 52,8 & 20,6 & 21,2 & 23,9 \\
02-AB & 54,7 & 54,9 & 54,5 & 19,4 & 21,7 & 21,5 \\
03-BA & 56,8 & 58,6 & 58,4 & 26,5 & 26,5 & 28,9 \\
04-BN & 49,5 & 55,6 & 54,3 & 21,5 & 24,5 & 24,6 \\
05-BSM & 49,1 & 50,6 & 50,2 & 21,5 & 20,8 & 19,7 \\
06-DT & 46,1 & 45,3 & 43,6 & 15,4 & 16,3 & 17,3 \\
07-ECP & 52,5 & 55,2 & 55,3 & 22,8 & 23,0 & 22,2 \\
08-ESS & 52,5 & 49,3 & 55,6 & 20,5 & 20,6 & 20,7 \\
09-ES & 50,3 & 51,4 & 51,4 & 20,9 & 23,2 & 24,2 \\
10-FH & 51,0 & 50,8 & 54,7 & 19,9 & 20,3 & 19,6 \\
11-FR & 52,1 & 50,1 & 49,9 & 27,3 & 27,7 & 25,9 \\
12-GS & 49,4 & 48,0 & 49,4 & 19,1 & 21,5 & 23,2 \\
13-JG & 44,9 & 45,1 & 45,7 & 21,5 & 17,7 & 18,8 \\
14-JPP & 46,6 & 46,7 & 47,3 & 14,0 & 12,7 & 18,7 \\
15-MC & 54,6 & 55,1 & 51,3 & 19,1 & 21,2 & 21,1 \\
16-MR & 51,8 & 54,0 & 51,4 & 18,0 & 19,9 & 20,2 \\
17-ME & 52,1 & 53,4 & 53,3 & 20,3 & 21,6 & 21,5 \\
18-MM & 48,0 & 49,0 & 49,2 & 17,6 & 20,8 & 21,4 \\
19-NC & 51,3 & 51,1 & 52,8 & 18,9 & 19,9 & 19,5 \\
20-SA & 47,5 & 48,5 & 47,5 & 19,9 & 18,1 & 19,1 \\
21-VF & 54,8 & 55,1 & 55,5 & 25,4 & 28,3 & 25,3 \\
22-VH & 51,3 & 50,9 & 50,3 & 20,6 & 21,5 & 22,5 \\
23-WS & 47,0 & 44,5 & 48,1 & 15,9 & 18,9 & 19,6 \\
\hline
\end{tabular}


APÊNDICE 9 - Tabela com os valores cefalométricos das medidas analisadas (ENP-PoOr e PoOr.PP) nas 3 fases estudadas (pré-expansão, pós-expansão e póscontenção), no grupo I (aparelhos dentossuportados Colado).

\begin{tabular}{l|c|c|c|c|c|c}
\hline MEDIDA & \multicolumn{3}{|c|}{ ENP-PoOr (mm) } & \multicolumn{3}{c}{ PoOr.PP $\left({ }^{\circ}\right)$} \\
\hline \multicolumn{1}{c|}{ Fase } & $\begin{array}{c}\text { pré- } \\
\text { expansão }\end{array}$ & $\begin{array}{c}\text { pós- } \\
\text { expansão }\end{array}$ & $\begin{array}{c}\text { pós- } \\
\text { contenção }\end{array}$ & $\begin{array}{c}\text { pré- } \\
\text { expansão }\end{array}$ & $\begin{array}{c}\text { pós- } \\
\text { expansão }\end{array}$ & $\begin{array}{c}\text { pós- } \\
\text { contenção }\end{array}$ \\
\hline 01-ACT & 23,4 & 23,6 & 25,7 & $-3,7$ & $-3,3$ & $-2,2$ \\
02-AB & 26,1 & 27,3 & 27,3 & $-6,4$ & $-5,5$ & $-5,5$ \\
03-BA & 26,1 & 28,1 & 28,7 & 0,4 & $-1,6$ & 0,2 \\
04-BN & 21,6 & 23,0 & 22,4 & $-0,2$ & 1,5 & 2,3 \\
05-BSM & 26,3 & 25,3 & 26,0 & $-5,7$ & $-5,2$ & $-7,0$ \\
06-DT & 23,1 & 24,9 & 26,1 & $-8,2$ & $-9,0$ & $-9,6$ \\
07-ECP & 23,1 & 25,2 & 22,6 & $-0,3$ & $-2,3$ & $-0,4$ \\
08-ESS & 22,9 & 26,5 & 23,4 & $-3,0$ & $-7,8$ & $-3,1$ \\
09-ES & 19,5 & 21,5 & 20,6 & 1,5 & 1,8 & 3,9 \\
10-FH & 23,6 & 23,2 & 24,7 & $-0,3$ & $-3,1$ & $-5,4$ \\
11-FR & 25,7 & 25,4 & 25,9 & 1,6 & 2,3 & 0,0 \\
12-GS & 21,3 & 22,3 & 23,1 & $-2,6$ & $-0,9$ & 0,1 \\
13-JG & 20,4 & 18,8 & 17,6 & 1,5 & $-1,5$ & 1,6 \\
14-JPP & 22,1 & 23,6 & 24,5 & $-9,4$ & $-12,6$ & $-7,0$ \\
15-MC & 24,9 & 28,1 & 28,3 & $-5,7$ & $-6,2$ & $-7,5$ \\
16-MR & 25,2 & 25,0 & 27,2 & $-7,8$ & $-5,2$ & $-7,4$ \\
17-ME & 25,4 & 25,4 & 25,4 & $-6,2$ & $-4,1$ & $-4,2$ \\
18-MM & 19,7 & 19,3 & 20,3 & $-2,2$ & 1,5 & 1,2 \\
19-NC & 18,4 & 24,7 & 23,9 & 0,5 & $-5,3$ & $-4,9$ \\
20-SA & 25,8 & 25,9 & 26,5 & $-7,1$ & $-8,8$ & $-9,1$ \\
21-VF & 24,1 & 26,8 & 24,2 & 1,4 & 1,5 & 1,2 \\
22-VH & 22,5 & 21,1 & 22,1 & $-2,3$ & 0,6 & 0,5 \\
23-WS & 21,4 & 23,8 & 22,3 & $-6,3$ & $-5,5$ & $-2,2$ \\
\hline
\end{tabular}


APÊNDICE 10 - Tabela com os valores cefalométricos das medidas analisadas (SN.GoMe e FMA) nas 3 fases estudadas (pré-expansão, pós-expansão e pós-contenção), no grupo I (aparelhos dentossuportados - Colado).

\begin{tabular}{l|c|c|c|c|c|c}
\hline MEDIDA & \multicolumn{3}{|c|}{ SN.GoMe $\left(^{\circ}\right)$} & \multicolumn{3}{c}{ FMA $\left(^{\circ}\right)$} \\
\hline Fase & $\begin{array}{c}\text { pré- } \\
\text { expansão }\end{array}$ & $\begin{array}{c}\text { pós- } \\
\text { expansão }\end{array}$ & $\begin{array}{c}\text { pós- } \\
\text { contenção }\end{array}$ & $\begin{array}{c}\text { pré- } \\
\text { expansão }\end{array}$ & $\begin{array}{c}\text { pós- } \\
\text { expansão }\end{array}$ & $\begin{array}{c}\text { pós- } \\
\text { contenção }\end{array}$ \\
\hline 01-ACT & 47,0 & 48,6 & 47,7 & 28,4 & 31,4 & 33,7 \\
02-AB & 33,2 & 34,6 & 33,2 & 25,5 & 27,8 & 26,7 \\
03-BA & 43,7 & 44,8 & 44,5 & 32,5 & 28,9 & 31,6 \\
04-BN & 48,8 & 57,1 & 53,0 & 42,5 & 47,5 & 44,3 \\
05-BSM & 43,0 & 47,8 & 45,2 & 33,0 & 35,3 & 32,6 \\
06-DT & 34,1 & 35,1 & 31,6 & 23,1 & 25,7 & 23,4 \\
07-ECP & 44,4 & 48,6 & 47,9 & 35,0 & 35,4 & 36,8 \\
08-ESS & 41,8 & 42,0 & 44,7 & 30,9 & 33,8 & 31,9 \\
09-ES & 41,3 & 41,3 & 41,2 & 30,3 & 32,4 & 33,4 \\
10-FH & 33,9 & 35,5 & 35,9 & 30,0 & 33,3 & 27,6 \\
11-FR & 34,1 & 34,6 & 35,0 & 30,1 & 33,0 & 31,8 \\
12-GS & 38,4 & 39,0 & 36,1 & 26,0 & 29,6 & 26,5 \\
13-JG & 43,2 & 43,6 & 43,0 & 35,3 & 32,5 & 33,8 \\
14-JPP & 37,6 & 41,7 & 39,1 & 21,9 & 22,9 & 25,4 \\
15-MC & 35,9 & 42,3 & 36,4 & 25,7 & 32,3 & 28,8 \\
16-MR & 35,5 & 39,6 & 37,4 & 19,8 & 23,4 & 23,4 \\
17-ME & 36,3 & 41,0 & 38,6 & 24,7 & 30,0 & 28,2 \\
18-MM & 28,2 & 32,7 & 30,2 & 16,1 & 23,9 & 20,6 \\
19-NC & 34,3 & 36,6 & 33,0 & 22,4 & 20,8 & 16,1 \\
20-SA & 39,8 & 42,5 & 41,0 & 28,4 & 28,9 & 28,5 \\
21-VF & 26,8 & 27,6 & 25,6 & 19,3 & 20,7 & 17,8 \\
22-VH & 39,4 & 39,4 & 39,1 & 30,4 & 32,8 & 33,8 \\
23-WS & 36,8 & 38,5 & 39,8 & 23,1 & 28,9 & 30,0 \\
\hline
\end{tabular}


APÊNDICE 11 - Tabela com os valores cefalométricos das medidas analisadas (Sn.Gn e ÂBI) nas 3 fases estudadas (préexpansão, pós-expansão e pós-contenção), no grupo I (aparelhos dentossuportados - Colado).

\begin{tabular}{l|c|c|c|c|c|c}
\hline MEDIDA & \multicolumn{3}{|c|}{ SN.Gn $\left(^{\circ}\right)$} & \multicolumn{3}{c}{$\hat{\text { ABBI }\left({ }^{\circ}\right)}$} \\
\hline \multicolumn{1}{c|}{ Fase } & $\begin{array}{c}\text { pré- } \\
\text { expansão }\end{array}$ & $\begin{array}{c}\text { pós- } \\
\text { expansão }\end{array}$ & $\begin{array}{c}\text { pós- } \\
\text { contenção }\end{array}$ & $\begin{array}{c}\text { pré- } \\
\text { expansão }\end{array}$ & $\begin{array}{c}\text { pós- } \\
\text { expansão }\end{array}$ & $\begin{array}{c}\text { pós- } \\
\text { contenção }\end{array}$ \\
\hline 01-ACT & 74,3 & 76,0 & 74,1 & 32,1 & 34,7 & 35,9 \\
02-AB & 66,2 & 67,3 & 66,3 & 32,0 & 33,2 & 32,2 \\
03-BA & 72,0 & 74,2 & 73,8 & 32,1 & 30,5 & 31,4 \\
04-BN & 71,0 & 78,3 & 74,6 & 42,7 & 46,0 & 42,0 \\
05-BSM & 70,1 & 73,5 & 71,4 & 38,6 & 40,5 & 39,6 \\
06-DT & 64,4 & 65,0 & 60,8 & 31,3 & 34,7 & 33,0 \\
07-ECP & 73,7 & 77,2 & 76,2 & 35,3 & 37,7 & 37,2 \\
08-ESS & 70,3 & 68,9 & 72,7 & 33,9 & 41,5 & 35,0 \\
09-ES & 70,4 & 72,1 & 71,6 & 28,8 & 30,6 & 29,4 \\
10-FH & 65,0 & 66,7 & 69,2 & 33,5 & 36,3 & 32,9 \\
11-FR & 64,5 & 64,7 & 65,6 & 28,5 & 30,7 & 31,8 \\
12-GS & 67,6 & 67,9 & 66,3 & 28,6 & 30,5 & 26,4 \\
13-JG & 67,4 & 69,2 & 67,5 & 33,7 & 34,0 & 32,2 \\
14-JPP & 69,5 & 71,3 & 70,4 & 31,2 & 35,4 & 32,3 \\
15-MC & 64,6 & 68,3 & 63,6 & 31,3 & 38,5 & 36,4 \\
16-MR & 67,9 & 70,6 & 68,7 & 27,6 & 28,6 & 30,8 \\
17-ME & 68,2 & 71,3 & 69,4 & 30,9 & 34,1 & 32,4 \\
18-MM & 63,1 & 67,1 & 64,9 & 18,4 & 22,4 & 19,4 \\
19-NC & 67,2 & 68,7 & 67,6 & 21,9 & 26,1 & 21,0 \\
20-SA & 69,0 & 71,5 & 70,1 & 35,5 & 37,6 & 37,6 \\
21-VF & 61,2 & 61,7 & 60,5 & 17,9 & 19,2 & 16,6 \\
22-VH & 69,7 & 70,3 & 69,5 & 32,8 & 32,2 & 33,4 \\
23-WS & 66,0 & 66,6 & 67,4 & 29,4 & 34,5 & 32,6 \\
\hline
\end{tabular}


APÊNDICE 12 - Tabela com os valores cefalométricos das medidas analisadas (Ar-A e Ar-Gn) nas 3 fases estudadas (préexpansão, pós-expansão e pós-contenção), no grupo I (aparelhos dentossuportados - Colado).

\begin{tabular}{l|c|c|c|c|c|c}
\hline MEDIDA & \multicolumn{3}{|c|}{ Ar-A (mm) } & \multicolumn{3}{c}{ Ar-Gn (mm) } \\
\hline Fases & $\begin{array}{c}\text { pré- } \\
\text { expansão }\end{array}$ & $\begin{array}{c}\text { pós- } \\
\text { expansão }\end{array}$ & $\begin{array}{c}\text { pós- } \\
\text { contenção }\end{array}$ & $\begin{array}{c}\text { pré- } \\
\text { expansão }\end{array}$ & $\begin{array}{c}\text { pós- } \\
\text { expansão }\end{array}$ & $\begin{array}{c}\text { pós- } \\
\text { contenção }\end{array}$ \\
\hline 01-ACT & 76,1 & 76,9 & 78,6 & 97,7 & 97,8 & 97,0 \\
02-AB & 91,0 & 90,2 & 89,8 & 119,0 & 120,4 & 118,4 \\
03-BA & 91,5 & 90,9 & 91,5 & 113,6 & 113,6 & 112,9 \\
04-BN & 83,6 & 85,7 & 84,4 & 105,9 & 106,9 & 106,5 \\
05-BSM & 81,3 & 80,9 & 80,5 & 104,1 & 104,4 & 104,7 \\
06-DT & 83,9 & 86,2 & 85,8 & 103,6 & 105,4 & 105,1 \\
07-ECP & 89,7 & 89,4 & 88,6 & 114,3 & 112,0 & 113,2 \\
08-ESS & 77,0 & 75,8 & 80,0 & 102,3 & 103,3 & 102,7 \\
09-ES & 84,5 & 84,5 & 83,7 & 102,5 & 102,8 & 103,7 \\
10-FH & 85,3 & 84,9 & 83,7 & 106,4 & 110,7 & 107,7 \\
11-FR & 89,0 & 88,9 & 88,2 & 108,2 & 109,6 & 109,6 \\
12-GS & 82,4 & 83,2 & 82,6 & 102,5 & 104,2 & 102,7 \\
13-JG & 75,9 & 76,9 & 77,7 & 97,6 & 97,1 & 98,8 \\
14-JPP & 78,7 & 78,7 & 78,8 & 98,0 & 100,5 & 98,7 \\
15-MC & 99,0 & 94,3 & 96,4 & 116,8 & 107,4 & 119,6 \\
16-MR & 84,6 & 85,5 & 84,0 & 100,7 & 102,1 & 100,0 \\
17-ME & 86,3 & 89,2 & 88,3 & 110,3 & 112,3 & 116,6 \\
18-MM & 83,9 & 84,9 & 85,8 & 101,7 & 103,3 & 102,1 \\
19-NC & 84,0 & 85,8 & 87,1 & 105,5 & 104,4 & 103,8 \\
20-SA & 86,9 & 87,4 & 86,2 & 110,0 & 110,2 & 110,2 \\
21-VF & 88,9 & 87,7 & 88,4 & 115,8 & 115,6 & 117,6 \\
22-VH & 83,9 & 84,4 & 83,5 & 104,4 & 104,3 & 104,6 \\
23-WS & 79,5 & 81,2 & 80,3 & 101,8 & 103,3 & 101,0 \\
\hline & & & & & &
\end{tabular}


APÊNDICE 13 - Tabela com os valores cefalométricos das medidas analisadas (ENA-Me e Rㅡ-PP) nas 3 fases estudadas (pré-expansão, pós-expansão e pós-contenção), no grupo I (aparelhos dentossuportados - Colado).

\begin{tabular}{l|c|c|c|c|c|c}
\hline MEDIDA & \multicolumn{3}{|c|}{ ENA-Me (mm) } & \multicolumn{3}{c}{ R6-PP (mm) } \\
\hline Fase & $\begin{array}{c}\text { pré- } \\
\text { expansão }\end{array}$ & $\begin{array}{c}\text { pós- } \\
\text { expansão }\end{array}$ & $\begin{array}{c}\text { pós- } \\
\text { contenção }\end{array}$ & $\begin{array}{c}\text { pré- } \\
\text { expansão }\end{array}$ & $\begin{array}{c}\text { pós- } \\
\text { expansão }\end{array}$ & $\begin{array}{c}\text { pós- } \\
\text { contenção }\end{array}$ \\
\hline 01-ACT & 61,8 & 66,1 & 65,7 & 1,1 & 1,3 & 1,4 \\
02-AB & 78,6 & 81,9 & 79,7 & 5,7 & 4,7 & 7,6 \\
03-BA & 72,8 & 74,5 & 72,2 & 2,8 & 4,0 & 1,3 \\
04-BN & 76,8 & 83,3 & 78,4 & 0,7 & 1,4 & 1,6 \\
05-BSM & 69,6 & 74,5 & 71,5 & $-0,8$ & $-0,7$ & $-2,3$ \\
06-DT & 66,4 & 71,1 & 66,5 & 2,4 & 1,7 & 0,3 \\
07-ECP & 79,0 & 82,1 & 80,3 & 6,3 & 4,9 & 5,5 \\
08-ESS & 67,7 & 72,6 & 70,4 & 2,8 & 3,5 & 1,7 \\
09-ES & 73,1 & 75,5 & 74,3 & 1,3 & 1,2 & 1,4 \\
10-FH & 72,3 & 78,2 & 74,2 & 2,9 & 2,6 & 3,5 \\
11-FR & 65,8 & 69,8 & 68,4 & 0,6 & 0,4 & $-0,5$ \\
12-GS & 60,9 & 64,6 & 59,6 & $-2,3$ & $-1,2$ & $-2,0$ \\
13-JG & 60,8 & 63,8 & 62,2 & $-0,2$ & 1,0 & 0,8 \\
14-JPP & 63,4 & 69,0 & 66,0 & $-1,1$ & $-1,6$ & $-0,9$ \\
15-MC & 74,0 & 84,6 & 75,2 & 0,6 & $-0,1$ & $-1,4$ \\
16-MR & 59,4 & 64,0 & 62,2 & 0,7 & $-1,3$ & 1,6 \\
17-ME & 69,1 & 74,5 & 73,1 & 1,4 & 3,2 & 1,9 \\
18-MM & 59,2 & 65,6 & 60,7 & 2,1 & 1,8 & 2,8 \\
19-NC & 63,1 & 65,3 & 60,9 & 2,8 & $-0,4$ & $-0,3$ \\
20-SA & 75,1 & 79,5 & 76,9 & 5,1 & 4,0 & 3,0 \\
21-VF & 61,0 & 62,5 & 61,4 & 4,4 & 2,9 & 3,8 \\
22-VH & 67,6 & 71,3 & 71,0 & $-2,2$ & $-0,3$ & $-2,1$ \\
23-WS & 61,3 & 67,4 & 62,1 & 0,6 & 0,0 & $-1,4$ \\
\hline
\end{tabular}


APÊNDICE 14 - Tabela com os valores cefalométricos das medidas analisadas (Cㅁ-PP e Sperp-Rㅁ) nas 3 fases estudadas (pré-expansão, pós-expansão e pós-contenção), no grupo I (aparelhos dentossuportados - Colado).

\begin{tabular}{l|c|c|c|c|c|c}
\hline MEDIDA & \multicolumn{3}{|c|}{ C6-PP (mm) } & \multicolumn{3}{c}{ Sperp-R 6́ (mm) } \\
\hline Fase & $\begin{array}{c}\text { pré- } \\
\text { expansão }\end{array}$ & $\begin{array}{c}\text { pós- } \\
\text { expansão }\end{array}$ & $\begin{array}{c}\text { pós- } \\
\text { contenção }\end{array}$ & $\begin{array}{c}\text { pré- } \\
\text { expansão }\end{array}$ & $\begin{array}{c}\text { pós- } \\
\text { expansão }\end{array}$ & $\begin{array}{c}\text { pós- } \\
\text { contenção }\end{array}$ \\
\hline 01-ACT & 20,6 & 21,4 & 21,2 & 48,1 & 46,4 & 45,9 \\
02-AB & 27,0 & 26,6 & 26,9 & 47,9 & 47,0 & 47,8 \\
03-BA & 22,2 & 22,8 & 21,4 & 45,5 & 49,0 & 46,1 \\
04-BN & 25,3 & 25,0 & 23,9 & 51,7 & 49,5 & 49,5 \\
05-BSM & 19,9 & 20,8 & 20,0 & 43,5 & 44,4 & 45,0 \\
06-DT & 22,1 & 21,6 & 21,5 & 45,8 & 44,7 & 46,8 \\
07-ECP & 26,7 & 25,3 & 25,8 & 48,6 & 48,0 & 46,8 \\
08-ESS & 24,3 & 23,8 & 23,4 & 49,3 & 48,9 & 50,1 \\
09-ES & 24,9 & 24,9 & 25,4 & 44,2 & 44,9 & 44,7 \\
10-FH & 25,2 & 25,3 & 24,8 & 49,9 & 49,6 & 52,6 \\
11-FR & 20,3 & 21,3 & 21,8 & 45,9 & 45,4 & 46,0 \\
12-GS & 18,4 & 19,5 & 18,6 & 43,3 & 43,4 & 42,5 \\
13-JG & 20,2 & 21,3 & 19,6 & 42,0 & 44,1 & 42,7 \\
14-JPP & 19,0 & 20,5 & 19,9 & 42,8 & 46,4 & 43,0 \\
15-MC & 20,7 & 22,0 & 20,5 & 53,7 & 54,9 & 52,9 \\
16-MR & 18,7 & 19,9 & 19,9 & 46,4 & 48,1 & 45,8 \\
17-ME & 21,3 & 23,8 & 22,0 & 46,6 & 46,9 & 44,8 \\
18-MM & 21,5 & 23,4 & 21,4 & 46,6 & 45,0 & 46,1 \\
19-NC & 21,5 & 19,6 & 19,6 & 44,3 & 44,5 & 49,1 \\
20-SA & 25,2 & 26,1 & 24,4 & 49,6 & 51,3 & 50,7 \\
21-VF & 22,6 & 21,5 & 22,2 & 49,5 & 50,3 & 52,2 \\
22-VH & 20,4 & 21,8 & 20,7 & 41,7 & 41,0 & 34,5 \\
23-WS & 19,6 & 19,8 & 18,7 & 43,5 & 43,5 & 41,7 \\
\hline
\end{tabular}


APÊNDICE 15 - Tabela com os valores cefalométricos das medidas analisadas (Sperp-Cㅁ e ÂNL) nas 3 fases estudadas (pré-expansão, pós-expansão e pós-contenção), no grupo I (aparelhos dentossuportados - Colado).

\begin{tabular}{l|c|c|c|c|c|c}
\hline MEDIDA & \multicolumn{3}{|c|}{ Sperp-C $\underline{6}(\mathrm{~mm})$} & \multicolumn{3}{c}{$\hat{\text { ANL }\left({ }^{\circ}\right)}$} \\
\hline \multicolumn{1}{c|}{ Fase } & $\begin{array}{c}\text { pré- } \\
\text { expansão }\end{array}$ & $\begin{array}{c}\text { pós- } \\
\text { expansão }\end{array}$ & $\begin{array}{c}\text { pós- } \\
\text { contenção }\end{array}$ & $\begin{array}{c}\text { pré- } \\
\text { expansão }\end{array}$ & $\begin{array}{c}\text { pós- } \\
\text { expansão }\end{array}$ & $\begin{array}{c}\text { pós- } \\
\text { contenção }\end{array}$ \\
\hline 01-ACT & 48,0 & 44,8 & 43,9 & 121,6 & 120,0 & 131,2 \\
02-AB & 45,3 & 45,0 & 46,3 & 123,4 & 122,1 & 124,6 \\
03-BA & 41,4 & 45,1 & 40,4 & 128,8 & 118,8 & 126,2 \\
04-BN & 45,7 & 41,6 & 43,8 & 90,9 & 100,6 & 99,1 \\
05-BSM & 37,9 & 40,0 & 41,4 & 103,8 & 104,0 & 110,1 \\
06-DT & 44,7 & 44,2 & 47,9 & 114,9 & 112,4 & 105,3 \\
07-ECP & 44,1 & 43,4 & 43,5 & 119,4 & 119,7 & 117,7 \\
08-ESS & 46,2 & 45,5 & 48,4 & 119,1 & 119,8 & 114,8 \\
09-ES & 42,5 & 42,6 & 41,7 & 96,9 & 91,7 & 99,2 \\
10-FH & 49,5 & 46,8 & 50,3 & 94,3 & 97,0 & 93,1 \\
11-FR & 40,5 & 41,4 & 39,8 & 101,5 & 110,3 & 103,9 \\
12-GS & 43,1 & 41,4 & 41,2 & 106,0 & 104,1 & 104,3 \\
13-JG & 37,4 & 39,2 & 40,3 & 121,4 & 119,8 & 116,1 \\
14-JPP & 37,7 & 41,6 & 38,0 & 105,8 & 99,4 & 92,5 \\
15-MC & 51,6 & 50,6 & 49,9 & 96,4 & 98,4 & 97,1 \\
16-MR & 44,6 & 47,0 & 44,0 & 126,3 & 121,8 & 135,7 \\
17-ME & 45,9 & 43,8 & 44,9 & 118,5 & 113,2 & 114,4 \\
18-MM & 46,1 & 41,5 & 43,5 & 104,1 & 93,0 & 103,8 \\
19-NC & 43,3 & 46,8 & 49,3 & 113,6 & 115,7 & 115,4 \\
20-SA & 49,2 & 50,9 & 49,8 & 110,5 & 106,0 & 115,3 \\
21-VF & 49,1 & 49,5 & 50,4 & 107,3 & 96,6 & 100,1 \\
22-VH & 37,1 & 35,0 & 35,1 & 95,2 & 93,4 & 93,4 \\
23-WS & 39,6 & 38,9 & 37,7 & 87,4 & 92,9 & 90,7 \\
\hline
\end{tabular}


APÊNDICE 16 - Tabela com os valores cefalométricos das medidas analisadas (SNA e SN.ENA) nas 3 fases estudadas (pré-expansão, pós-expansão e pós-contenção), no grupo II (aparelhos dentomucossuportados - tipo Haas).

\begin{tabular}{l|c|c|c|c|c|c}
\hline MEDIDA & \multicolumn{3}{|c|}{ SNA $\left(^{\circ}\right)$} & \multicolumn{3}{c}{ SN.ENA $\left(^{\circ}\right)$} \\
\hline Fase & $\begin{array}{c}\text { pré- } \\
\text { expansão }\end{array}$ & $\begin{array}{c}\text { pós- } \\
\text { expansão }\end{array}$ & $\begin{array}{c}\text { pós- } \\
\text { contenção }\end{array}$ & $\begin{array}{c}\text { pré- } \\
\text { expansão }\end{array}$ & $\begin{array}{c}\text { pós- } \\
\text { expansão }\end{array}$ & $\begin{array}{c}\text { pós- } \\
\text { contenção }\end{array}$ \\
\hline 01-ACM & 82,7 & 84,5 & 83,8 & 86,8 & 88,9 & 89,1 \\
02-DCA & 74,5 & 72,9 & 74,3 & 78,5 & 77,7 & 77,6 \\
03-AFC & 77,4 & 79,5 & 75,3 & 80,4 & 83,9 & 78,1 \\
04-APD & 80,9 & 82,0 & 81,9 & 85,1 & 85,7 & 87,1 \\
05-IMM & 84,0 & 81,5 & 83,9 & 87,6 & 86,0 & 89,1 \\
06-MMR & 82,6 & 82,9 & 83,5 & 84,5 & 84,4 & 85,5 \\
07-KVF & 78,7 & 79,9 & 80,4 & 83,8 & 83,8 & 85,3 \\
08-JBN & 76,8 & 77,0 & 76,6 & 80,8 & 81,3 & 80,8 \\
09-PAB & 81,1 & 81,0 & 81,1 & 84,5 & 86,1 & 86,0 \\
10-VML & 81,8 & 81,7 & 82,7 & 87,5 & 86,3 & 87,1 \\
11-VAAO & 81,8 & 81,7 & 81,8 & 84,0 & 84,1 & 84,6 \\
12-RG & 81,7 & 82,0 & 81,7 & 86,2 & 87,2 & 84,8 \\
13-ASP & 84,6 & 85,6 & 84,6 & 91,5 & 91,5 & 91,5 \\
14-ALC & 80,6 & 81,8 & 82,3 & 85,8 & 86,7 & 86,2 \\
15-DO & 87,1 & 87,3 & 86,7 & 89,6 & 89,3 & 89,6 \\
16-DCJ & 84,2 & 84,4 & 82,1 & 90,1 & 89,3 & 87,7 \\
17-FBB & 75,3 & 75,0 & 74,5 & 78,5 & 77,3 & 78,3 \\
18-FMR & 84,3 & 83,0 & 83,3 & 89,1 & 87,2 & 87,4 \\
19-LFC & 79,8 & 82,8 & 80,2 & 84,5 & 86,4 & 86,0 \\
20-RBM & 76,7 & 78,3 & 75,4 & 77,8 & 79,0 & 77,5 \\
\hline
\end{tabular}


APÊNDICE 17 - Tabela com os valores cefalométricos das medidas analisadas (Nperp-A e Sperp-A) nas 3 fases estudadas (pré-expansão, pós-expansão e pós-contenção), no grupo II (aparelhos dentomucossuportados - tipo Haas).

\begin{tabular}{l|c|c|c|c|c|c}
\hline MEDIDA & \multicolumn{3}{|c|}{ Nperp-A (mm) } & \multicolumn{3}{c}{ Sperp-A (mm) } \\
\hline \multicolumn{1}{c|}{ Fase } & $\begin{array}{c}\text { pré- } \\
\text { expansão }\end{array}$ & $\begin{array}{c}\text { pós- } \\
\text { expansão }\end{array}$ & $\begin{array}{c}\text { pós- } \\
\text { contenção }\end{array}$ & $\begin{array}{c}\text { pré- } \\
\text { expansão }\end{array}$ & $\begin{array}{c}\text { pós- } \\
\text { expansão }\end{array}$ & $\begin{array}{c}\text { pós- } \\
\text { contenção }\end{array}$ \\
\hline 01-ACM & 2,8 & 4,3 & 4,6 & 68,9 & 70,4 & 70,0 \\
02-DCA & $-3,5$ & $-3,9$ & $-4,0$ & 64,6 & 66,0 & 65,6 \\
03-AFC & $-0,9$ & 0,5 & $-4,5$ & 69,9 & 70,3 & 66,5 \\
04-APD & 0,2 & 0,5 & $-1,0$ & 70,3 & 70,6 & 69,4 \\
05-IMM & 2,9 & 2,0 & 2,9 & 71,5 & 70,9 & 71,4 \\
06-MMR & 2,2 & 2,4 & 2,9 & 69,0 & 69,6 & 68,7 \\
07-KVF & $-4,5$ & $-3,6$ & $-4,0$ & 64,2 & 65,1 & 64,7 \\
08-JBN & $-4,9$ & $-2,9$ & $-2,4$ & 66,8 & 67,9 & 68,2 \\
09-PAB & $-0,7$ & $-3,1$ & $-1,9$ & 65,0 & 62,3 & 63,6 \\
10-VML & $-1,3$ & $-0,2$ & $-1,1$ & 68,6 & 69,4 & 69,6 \\
11-VAAO & $-3,2$ & $-2,7$ & $-3,3$ & 63,8 & 64,0 & 64,0 \\
12-RG & $-2,4$ & $-1,8$ & $-2,7$ & 63,2 & 63,4 & 63,9 \\
13-ASP & 4,5 & 4,1 & 3,1 & 76,7 & 76,4 & 76,1 \\
14-ALC & 3,5 & 4,1 & 5,2 & 71,4 & 72,4 & 72,9 \\
15-DO & $-0,6$ & $-2,0$ & $-2,2$ & 72,1 & 70,8 & 71,1 \\
16-DCJ & $-5,1$ & $-1,6$ & $-4,4$ & 69,5 & 72,8 & 71,0 \\
17-FBB & $-4,8$ & $-5,6$ & $-6,5$ & 63,1 & 62,6 & 63,1 \\
18-FMR & 1,6 & 2,3 & 0,0 & 71,2 & 72,5 & 71,2 \\
19-LFC & $-1,1$ & 2,3 & $-1,8$ & 70,6 & 73,6 & 70,4 \\
20-RBM & $-2,9$ & $-1,9$ & $-6,0$ & 70,8 & 71,7 & 68,3 \\
\hline
\end{tabular}


APÊNDICE 18 - Tabela com os valores cefalométricos das medidas analisadas (SNB e Nperp-Pog) nas 3 fases estudadas (pré-expansão, pós-expansão e pós-contenção), no grupo II (aparelhos dentomucossuportados - tipo Haas).

\begin{tabular}{l|c|c|c|c|c|c}
\hline MEDIDA & \multicolumn{3}{|c|}{ SNB $\left(^{\circ}\right)$} & \multicolumn{3}{c}{ Nperp-Pog $(\mathrm{mm})$} \\
\hline \multicolumn{1}{c|}{ Fase } & $\begin{array}{c}\text { pré- } \\
\text { expansão }\end{array}$ & $\begin{array}{c}\text { pós- } \\
\text { expansão }\end{array}$ & $\begin{array}{c}\text { pós- } \\
\text { contenção }\end{array}$ & $\begin{array}{c}\text { pré- } \\
\text { expansão }\end{array}$ & $\begin{array}{c}\text { pós- } \\
\text { expansão }\end{array}$ & $\begin{array}{c}\text { pós- } \\
\text { contenção }\end{array}$ \\
\hline 01-ACM & 80,4 & 81,3 & 80,0 & 1,0 & 2,7 & 1,7 \\
02-DCA & 78,6 & 75,7 & 78,4 & 3,1 & $-0,4$ & 1,8 \\
03-AFC & 72,6 & 72,9 & 71,5 & $-10,6$ & $-12,8$ & $-16,6$ \\
04-APD & 74,5 & 75,2 & 75,7 & $-10,4$ & $-10,7$ & $-12,3$ \\
05-IMM & 80,9 & 77,0 & 81,3 & 0,8 & $-4,4$ & 1,7 \\
06-MMR & 78,6 & 77,4 & 79,1 & $-3,0$ & $-5,5$ & $-2,3$ \\
07-KVF & 79,9 & 79,2 & 80,8 & $-4,3$ & $-6,4$ & $-5,2$ \\
08-JBN & 74,2 & 73,2 & 73,4 & $-14,0$ & $-12,4$ & $-9,6$ \\
09-PAB & 75,4 & 75,0 & 76,4 & $-9,4$ & $-16,5$ & $-10,8$ \\
10-VML & 79,6 & 78,1 & 79,4 & $-2,1$ & $-2,9$ & $-3,3$ \\
11-VAAO & 80,6 & 78,5 & 79,8 & $-9,4$ & $-11,7$ & $-10,6$ \\
12-RG & 79,9 & 79,5 & 80,1 & $-2,5$ & $-4,0$ & $-4,1$ \\
13-ASP & 80,2 & 78,8 & 79,4 & $-1,0$ & $-7,3$ & $-6,2$ \\
14-ALC & 76,1 & 76,7 & 77,8 & $-1,5$ & $-3,9$ & $-0,7$ \\
15-DO & 82,5 & 80,9 & 80,7 & $-8,6$ & $-15,1$ & $-14,6$ \\
16-DCJ & 78,3 & 77,6 & 76,3 & $-19,5$ & $-13,5$ & $-17,1$ \\
17-FBB & 72,6 & 71,5 & 72,0 & $-13,4$ & $-17,8$ & $-16,5$ \\
18-FMR & 81,7 & 79,1 & 80,6 & 0,1 & $-2,0$ & $-3,6$ \\
19-LFC & 76,6 & 75,6 & 75,6 & $-6,6$ & $-8,2$ & $-11,1$ \\
20-RBM & 73,1 & 72,7 & 72,5 & $-9,2$ & $-11,7$ & $-12,9$ \\
\hline
\end{tabular}


APÊNDICE 19 - Tabela com os valores cefalométricos das medidas analisadas (ANB e NAP) nas 3 fases estudadas (préexpansão, pós-expansão e pós-contenção), no grupo II (aparelhos dentomucossuportados - tipo Haas).

\begin{tabular}{l|c|c|c|c|c|c}
\hline MEDIDA & \multicolumn{3}{|c|}{ ANB $\left(^{\circ}\right)$} & \multicolumn{3}{c}{ NAP $\left(^{\circ}\right)$} \\
\hline \multicolumn{1}{c|}{ Fase } & $\begin{array}{c}\text { pré- } \\
\text { expansão }\end{array}$ & $\begin{array}{c}\text { pós- } \\
\text { expansão }\end{array}$ & $\begin{array}{c}\text { pós- } \\
\text { contenção }\end{array}$ & $\begin{array}{c}\text { pré- } \\
\text { expansão }\end{array}$ & $\begin{array}{c}\text { pós- } \\
\text { expansão }\end{array}$ & $\begin{array}{c}\text { pós- } \\
\text { contenção }\end{array}$ \\
\hline 01-ACM & 2,3 & 3,2 & 3,8 & 5,1 & 6,4 & 8,0 \\
02-DCA & $-4,1$ & $-2,8$ & $-4,1$ & $-11,2$ & $-7,8$ & $-10,8$ \\
03-AFC & 4,8 & 6,6 & 3,8 & 9,2 & 12,4 & 7,4 \\
04-APD & 6,4 & 6,8 & 6,3 & 12,7 & 13,0 & 12,3 \\
05-IMM & 3,1 & 4,6 & 2,7 & 5,2 & 8,5 & 4,3 \\
06-MMR & 3,9 & 5,5 & 4,4 & 7,8 & 10,6 & 8,5 \\
07-KVF & $-1,3$ & 0,7 & $-0,4$ & $-4,8$ & $-0,8$ & $-2,8$ \\
08-JBN & 2,6 & 3,9 & 3,1 & 5,0 & 7,2 & 5,6 \\
09-PAB & 5,7 & 6,0 & 4,8 & 8,6 & 10,9 & 7,7 \\
10-VML & 2,1 & 3,5 & 3,3 & $-0,4$ & 2,9 & 1,4 \\
11-VAAO & 1,2 & 3,2 & 2,0 & 3,3 & 6,8 & 4,6 \\
12-RG & 1,9 & 2,5 & 1,6 & $-2,6$ & 0,3 & $-1,4$ \\
13-ASP & 4,4 & 6,8 & 5,2 & 9,7 & 15,2 & 11,7 \\
14-ALC & 4,5 & 5,1 & 4,5 & 8,2 & 11,6 & 10,6 \\
15-DO & 4,6 & 6,4 & 6,0 & 7,6 & 11,1 & 10,6 \\
16-DCJ & 5,9 & 6,7 & 5,8 & 8,8 & 10,2 & 8,3 \\
17-FBB & 2,7 & 3,5 & 2,4 & 4,9 & 7,1 & 4,5 \\
18-FMR & 2,6 & 3,9 & 2,6 & 3,2 & 6,6 & 3,9 \\
19-LFC & 3,2 & 7,2 & 4,6 & 5,1 & 13,5 & 8,7 \\
20-RBM & 3,6 & 5,7 & 2,9 & 3,5 & 7,4 & 1,0 \\
\hline
\end{tabular}


APÊNDICE 20 - Tabela com os valores cefalométricos das medidas analisadas (N-ENA e ENA-PoOr) nas 3 fases estudadas (pré-expansão, pós-expansão e póscontenção), no grupo II (aparelhos dentomucossuportados - tipo Haas).

\begin{tabular}{l|c|c|c|c|c|c}
\hline MEDIDA & \multicolumn{3}{|c|}{ N-ENA (mm) } & \multicolumn{3}{c}{ ENA-PoOr (mm) } \\
\hline Fase & $\begin{array}{c}\text { pré- } \\
\text { expansão }\end{array}$ & $\begin{array}{c}\text { pós- } \\
\text { expansão }\end{array}$ & $\begin{array}{c}\text { pós- } \\
\text { contenção }\end{array}$ & $\begin{array}{c}\text { pré- } \\
\text { expansão }\end{array}$ & $\begin{array}{c}\text { pós- } \\
\text { expansão }\end{array}$ & $\begin{array}{c}\text { pós- } \\
\text { contenção }\end{array}$ \\
\hline 01-ACM & 49,8 & 49,8 & 49,7 & 22,8 & 22,5 & 23,3 \\
02-DCA & 45,4 & 47,8 & 47,6 & 18,1 & 18,1 & 19,6 \\
03-AFC & 54,8 & 54,4 & 56,1 & 21,0 & 21,7 & 24,1 \\
04-APD & 52,5 & 53,4 & 52,3 & 22,8 & 22,9 & 23,1 \\
05-IMM & 51,4 & 51,8 & 50,2 & 22,3 & 23,0 & 22,6 \\
06-MMR & 54,3 & 55,0 & 52,6 & 22,5 & 24,4 & 21,1 \\
07-KVF & 50,9 & 50,1 & 49,0 & 22,3 & 22,5 & 21,7 \\
08-JBN & 58,7 & 59,5 & 58,7 & 28,3 & 28,2 & 26,3 \\
09-PAB & 53,7 & 54,0 & 54,1 & 24,8 & 28,2 & 27,8 \\
10-VML & 45,8 & 45,8 & 45,9 & 19,1 & 18,4 & 20,1 \\
11-VAAO & 44,3 & 45,7 & 44,7 & 18,8 & 18,6 & 19,1 \\
12-RG & 46,0 & 45,8 & 46,7 & 21,2 & 20,7 & 21,0 \\
13-ASP & 56,5 & 58,1 & 58,7 & 24,1 & 27,5 & 28,2 \\
14-ALC & 54,1 & 53,5 & 54,5 & 24,6 & 25,6 & 25,9 \\
15-DO & 48,3 & 48,5 & 49,0 & 23,2 & 25,8 & 25,7 \\
16-DCJ & 48,9 & 50,0 & 50,6 & 21,2 & 20,6 & 21,1 \\
17-FBB & 53,8 & 53,5 & 54,1 & 22,4 & 21,6 & 22,6 \\
18-FMR & 51,5 & 53,3 & 52,6 & 20,8 & 19,1 & 21,6 \\
19-LFC & 50,2 & 51,0 & 51,5 & 21,1 & 20,7 & 23,4 \\
20-RBM & 53,5 & 55,7 & 54,3 & 19,3 & 22,0 & 22,9 \\
\hline
\end{tabular}


APÊNDICE 21 - Tabela com os valores cefalométricos das medidas analisadas (ENP-PoOr e PoOr.PP) nas 3 fases estudadas (pré-expansão, pós-expansão e póscontenção), no grupo II (aparelhos dentomucossuportados - tipo Haas).

\begin{tabular}{l|c|c|c|c|c|c}
\hline MEDIDA & \multicolumn{2}{|c|}{ ENP-PoOr (mm) } & \multicolumn{3}{c}{ PoOr.PP $\left(^{\circ}\right)$} \\
\hline Fase & $\begin{array}{c}\text { pré- } \\
\text { expansão }\end{array}$ & $\begin{array}{c}\text { pós- } \\
\text { expansão }\end{array}$ & $\begin{array}{c}\text { pós- } \\
\text { contenção }\end{array}$ & $\begin{array}{c}\text { pré- } \\
\text { expansão }\end{array}$ & $\begin{array}{c}\text { pós- } \\
\text { expansão }\end{array}$ & $\begin{array}{c}\text { pós- } \\
\text { contenção }\end{array}$ \\
\hline 01-ACM & 24,5 & 24,7 & 21,8 & $-2,0$ & $-2,5$ & 1,7 \\
02-DCA & 21,5 & 21,3 & 22,6 & $-3,9$ & $-3,7$ & $-3,7$ \\
03-AFC & 22,5 & 22,8 & 25,0 & $-1,8$ & $-1,2$ & $-1,1$ \\
04-APD & 19,3 & 17,7 & 19,0 & 3,6 & 5,4 & 4,2 \\
05-IMM & 20,9 & 21,0 & 21,3 & 1,5 & 2,1 & 1,3 \\
06-MMR & 23,2 & 24,4 & 22,5 & $-0,8$ & 0,0 & $-1,7$ \\
07-KVF & 19,7 & 19,6 & 19,6 & 2,9 & 3,3 & 2,4 \\
08-JBN & 22,2 & 23,6 & 23,9 & 6,6 & 5,0 & 2,6 \\
09-PAB & 21,3 & 23,3 & 23,8 & 4,1 & 5,7 & 4,6 \\
10-VML & 16,5 & 17,7 & 18,3 & 2,8 & 0,8 & 1,9 \\
11-VAAO & 19,8 & 20,5 & 20,5 & $-1,2$ & $-2,2$ & $-1,6$ \\
12-RG & 21,7 & 20,8 & 20,8 & $-0,6$ & $-0,1$ & 0,2 \\
13-ASP & 25,3 & 26,8 & 26,6 & $-1,2$ & 0,7 & 1,5 \\
14-ALC & 25,1 & 24,9 & 25,1 & $-0,5$ & 0,7 & 0,8 \\
15-DO & 22,6 & 23,6 & 23,9 & 0,7 & 2,4 & 1,9 \\
16-DCJ & 17,6 & 19,4 & 18,3 & 3,8 & 1,3 & 2,9 \\
17-FBB & 21,7 & 21,6 & 21,7 & 0,8 & 0,0 & 1,1 \\
18-FMR & 22,0 & 21,0 & 23,1 & $-1,3$ & $-2,0$ & $-1,6$ \\
19-LFC & 21,4 & 22,7 & 24,0 & $-0,3$ & $-2,1$ & $-0,6$ \\
20-RBM & 21,0 & 22,7 & 22,1 & $-2,0$ & $-0,8$ & 0,9 \\
\hline
\end{tabular}


APÊNDICE 22 - Tabela com os valores cefalométricos das medidas analisadas (SN.GoMe e FMA) nas 3 fases estudadas (pré-expansão, pós-expansão e pós-contenção), no grupo II (aparelhos dentomucossuportados - tipo Haas).

\begin{tabular}{l|c|c|c|c|c|c}
\hline MEDIDA & \multicolumn{3}{|c|}{ SN.GoMe $\left(^{\circ}\right)$} & \multicolumn{3}{c}{ FMA $\left(^{\circ}\right)$} \\
\hline Fase & $\begin{array}{c}\text { pré- } \\
\text { expansão }\end{array}$ & $\begin{array}{c}\text { pós- } \\
\text { expansão }\end{array}$ & $\begin{array}{c}\text { pós- } \\
\text { contenção }\end{array}$ & $\begin{array}{c}\text { pré- } \\
\text { expansão }\end{array}$ & $\begin{array}{c}\text { pós- } \\
\text { expansão }\end{array}$ & $\begin{array}{c}\text { pós- } \\
\text { contenção }\end{array}$ \\
\hline 01-ACM & 36,5 & 37,0 & 38,3 & 26,3 & 26,9 & 27,3 \\
02-DCA & 33,6 & 37,8 & 34,1 & 22,0 & 24,9 & 22,7 \\
03-AFC & 48,8 & 50,6 & 50,3 & 37,0 & 39,6 & 39,6 \\
04-APD & 36,6 & 37,6 & 36,0 & 27,3 & 29,1 & 28,9 \\
05-IMM & 38,8 & 41,7 & 36,9 & 29,7 & 31,2 & 27,8 \\
06-MMR & 36,3 & 37,9 & 35,2 & 26,7 & 28,5 & 25,8 \\
07-KVF & 37,2 & 37,7 & 36,7 & 30,5 & 31,3 & 31,2 \\
08-JBN & 44,6 & 44,5 & 45,3 & 35,7 & 34,1 & 34, \\
09-PAB & 40,9 & 43,5 & 41,3 & 32,7 & 37,4 & 34,2 \\
10-VML & 27,2 & 29,7 & 26,7 & 20,4 & 21,6 & 20,7 \\
11-VAAO & 41,6 & 43,2 & 41,6 & 36,9 & 37,7 & 37,0 \\
12-RG & 31,5 & 33,1 & 31,9 & 26,0 & 27,2 & 26,5 \\
13-ASP & 41,5 & 44,0 & 42,5 & 32,1 & 36,0 & 34,4 \\
14-ALC & 45,1 & 46,5 & 44,8 & 32,3 & 34,2 & 32,0 \\
15-DO & 34,1 & 37,0 & 36,3 & 31,8 & 36,5 & 35,3 \\
16-DCJ & 24,3 & 24,8 & 25,5 & 23,6 & 20,9 & 21,9 \\
17-FBB & 48,3 & 50,5 & 50,1 & 38,1 & 40,7 & 40,6 \\
18-FMR & 32,1 & 37,3 & 34,1 & 24,8 & 28,1 & 27,4 \\
19-LFC & 37,1 & 38,6 & 38,4 & 28,0 & 29,1 & 30,4 \\
20-RBM & 40,0 & 40,8 & 40,7 & 29,4 & 30,9 & 31,7 \\
\hline
\end{tabular}


APÊNDICE 23 - Tabela com os valores cefalométricos das medidas analisadas (SN.Gn e ÂBI) nas 3 fases estudadas (préexpansão, pós-expansão e pós-contenção), no grupo II (aparelhos dentomucossuportados - tipo Haas).

\begin{tabular}{l|c|c|c|c|c|c}
\hline MEDIDA & \multicolumn{3}{|c|}{ SN.Gn $\left(^{\circ}\right)$} & \multicolumn{3}{c}{$\hat{\text { ABBI }\left({ }^{\circ}\right)}$} \\
\hline Fase & $\begin{array}{c}\text { pré- } \\
\text { expansão }\end{array}$ & $\begin{array}{c}\text { pós- } \\
\text { expansão }\end{array}$ & $\begin{array}{c}\text { pós- } \\
\text { contenção }\end{array}$ & $\begin{array}{c}\text { pré- } \\
\text { expansão }\end{array}$ & $\begin{array}{c}\text { pós- } \\
\text { expansão }\end{array}$ & $\begin{array}{c}\text { pós- } \\
\text { contenção }\end{array}$ \\
\hline 01-ACM & 67,6 & 67,1 & 68,7 & 28,3 & 29,5 & 25,6 \\
02-DCA & 65,1 & 68,0 & 65,4 & 25,9 & 28,7 & 26,4 \\
03-AFC & 75,8 & 76,9 & 77,4 & 38,7 & 40,9 & 40,7 \\
04-APD & 69,5 & 70,0 & 68,6 & 23,7 & 23,7 & 24,7 \\
05-IMM & 67,1 & 70,9 & 66,3 & 28,2 & 29,0 & 26,5 \\
06-MMR & 70,7 & 72,0 & 70,3 & 27,6 & 28,5 & 27,5 \\
07-KVF & 67,9 & 68,2 & 67,1 & 27,6 & 28,1 & 28,8 \\
08-JBN & 74,2 & 75,5 & 75,3 & 29,1 & 29,2 & 31,4 \\
09-PAB & 72,9 & 74,6 & 72,8 & 28,6 & 31,7 & 29,6 \\
10-VML & 63,4 & 65,7 & 63,5 & 17,6 & 20,8 & 18,7 \\
11-VAAO & 68,4 & 70,6 & 69,0 & 38,0 & 39,8 & 38,6 \\
12-RG & 64,6 & 66,3 & 65,2 & 26,5 & 27,3 & 26,3 \\
13-ASP & 69,5 & 71,4 & 70,6 & 33,3 & 35,3 & 32,8 \\
14-ALC & 71,2 & 72,3 & 71,0 & 32,8 & 33,4 & 31,2 \\
15-DO & 64,0 & 65,9 & 65,8 & 31,2 & 34,0 & 33,3 \\
16-DCJ & 66,8 & 67,3 & 68,1 & 19,8 & 19,6 & 19,0 \\
17-FBB & 75,3 & 78,1 & 76,5 & 37,2 & 40,7 & 39,5 \\
18-FMR & 65,8 & 68,7 & 66,6 & 26,1 & 30,1 & 29,0 \\
19-LFC & 68,0 & 70,0 & 69,9 & 28,4 & 31,1 & 31,0 \\
20-RBM & 72,5 & 73,6 & 73,0 & 31,4 & 31,7 & 30,7 \\
\hline
\end{tabular}


APÊNDICE 24 - Tabela com os valores cefalométricos das medidas analisadas (Ar-A e Ar-Gn) nas 3 fases estudadas (préexpansão, pós-expansão e pós-contenção), no grupo II (aparelhos dentomucossuportados - tipo Haas).

\begin{tabular}{l|c|c|c|c|c|c}
\hline MEDIDA & \multicolumn{3}{|c|}{ Ar-A (mm) } & \multicolumn{3}{c}{ Ar-Gn (mm) } \\
\hline \multicolumn{1}{c|}{ Fase } & $\begin{array}{c}\text { pré- } \\
\text { expansão }\end{array}$ & $\begin{array}{c}\text { pós- } \\
\text { expansão }\end{array}$ & $\begin{array}{c}\text { pós- } \\
\text { contenção }\end{array}$ & $\begin{array}{c}\text { pré- } \\
\text { expansão }\end{array}$ & $\begin{array}{c}\text { pós- } \\
\text { expansão }\end{array}$ & $\begin{array}{c}\text { pós- } \\
\text { contenção }\end{array}$ \\
\hline 01-ACM & 83,1 & 82,8 & 83,3 & 107,1 & 108,3 & 108,0 \\
02-DCA & 82,6 & 83,6 & 84,5 & 109,8 & 110,8 & 111,1 \\
03-AFC & 87,0 & 87,7 & 87,1 & 109,6 & 113,3 & 112,1 \\
04-APD & 87,0 & 86,4 & 86,7 & 99,8 & 100,0 & 99,5 \\
05-IMM & 86,4 & 85,2 & 86,1 & 110,7 & 108,0 & 110,3 \\
06-MMR & 84,4 & 86,0 & 85,3 & 106,7 & 107,0 & 107,4 \\
07-KVF & 79,0 & 80,7 & 79,7 & 108,2 & 108,4 & 108,5 \\
08-JBN & 85,2 & 85,2 & 85,5 & 109,6 & 108,9 & 109,3 \\
09-PAB & 80,8 & 80,6 & 80,0 & 102,7 & 103,5 & 103,5 \\
10-VML & 83,0 & 84,2 & 84,1 & 102,7 & 103,6 & 102,5 \\
11-VAAO & 80,2 & 81,3 & 81,4 & 104,1 & 104,7 & 104,9 \\
12-RG & 79,9 & 80,3 & 80,7 & 104,0 & 104,2 & 105,0 \\
13-ASP & 93,7 & 94,2 & 92,2 & 118,4 & 118,5 & 118,1 \\
14-ALC & 87,2 & 87,1 & 88,2 & 11,3 & 110,4 & 112,2 \\
15-DO & 85,2 & 86,6 & 86,7 & 105,6 & 106,1 & 106,3 \\
16-DCJ & 91,0 & 92,6 & 90,9 & 108,8 & 107,3 & 107,2 \\
17-FBB & 78,6 & 79,0 & 79,4 & 102,6 & 103,2 & 105,2 \\
18-FMR & 87,3 & 88,8 & 89,3 & 109,7 & 111,0 & 112,2 \\
19-LFC & 85,7 & 88,7 & 87,2 & 104,1 & 103,5 & 105,1 \\
20-RBM & 86,8 & 89,5 & 87,1 & 109,6 & 110,7 & 111,1 \\
\hline
\end{tabular}


APÊNDICE 25 - Tabela com os valores cefalométricos das medidas analisadas (Ar-Gn e ENA-Me) nas 3 fases estudadas (pré-expansão, pós-expansão e pós-contenção), no grupo II (aparelhos dentomucossuportados - tipo Haas).

\begin{tabular}{l|c|c|c|c|c|c}
\hline MEDIDA & \multicolumn{3}{|c|}{ ENA-Me (mm) } & \multicolumn{3}{c}{ R6-PP (mm) } \\
\hline \multicolumn{1}{c|}{ Fase } & $\begin{array}{c}\text { pré- } \\
\text { expansão }\end{array}$ & $\begin{array}{c}\text { pós- } \\
\text { expansão }\end{array}$ & $\begin{array}{c}\text { pós- } \\
\text { contenção }\end{array}$ & $\begin{array}{c}\text { pré- } \\
\text { expansão }\end{array}$ & $\begin{array}{c}\text { pós- } \\
\text { expansão }\end{array}$ & $\begin{array}{c}\text { pós- } \\
\text { contenção }\end{array}$ \\
\hline 01-ACM & 64,3 & 65,7 & 66,6 & 4,2 & 3,8 & 4,8 \\
02-DCA & 62,1 & 66,6 & 62,3 & 3,6 & 2,4 & 1,1 \\
03-AFC & 75,6 & 80,4 & 77,3 & 6,2 & 4,8 & 6,6 \\
04-APD & 61,5 & 63,9 & 62,5 & $-0,3$ & 2,8 & 1,5 \\
05-IMM & 67,5 & 71,2 & 67,4 & 3,3 & 3,6 & 4,8 \\
06-MMR & 68,7 & 70,5 & 70,4 & 3,5 & 3,1 & 2,8 \\
07-KVF & 68,2 & 68,9 & 69,4 & 5,9 & 3,9 & 3,9 \\
08-JBN & 71,7 & 73,2 & 73,9 & 3,5 & 4,3 & 2,9 \\
09-PAB & 69,1 & 72,3 & 69,9 & 6,2 & 4,3 & 5,3 \\
10-VML & 62,5 & 66,2 & 63,4 & 6,3 & 6,5 & 7,0 \\
11-VAAO & 70,0 & 72,5 & 71,0 & 3,4 & 2,8 & 1,8 \\
12-RG & 63,6 & 65,7 & 64,2 & 3,8 & 5,4 & 5,4 \\
13-ASP & 75,2 & 78,4 & 77,0 & 2,8 & 3,7 & 5,9 \\
14-ALC & 66,3 & 70,3 & 66,3 & 1,4 & 0,7 & $-2,9$ \\
15-DO & 68,4 & 72,1 & 71,6 & 0,2 & 0,3 & 0,7 \\
16-DCJ & 76,0 & 74,5 & 74,5 & 9,7 & 8,4 & 10,4 \\
17-FBB & 70,0 & 73,2 & 73,1 & 1,8 & 2,7 & 1,8 \\
18-FMR & 66,6 & 70,6 & 68,8 & 5,0 & 3,7 & 4,2 \\
19-LFC & 66,6 & 70,9 & 70,2 & 4,3 & 2,6 & 4,5 \\
20-RBM & 76,4 & 77,2 & 76,7 & 6,2 & 4,3 & 4,9 \\
\hline
\end{tabular}


APÊNDICE 26 - Tabela com os valores cefalométricos das medidas analisadas (Cㅁ-PP e Sperp-Rㅁ) nas 3 fases estudadas (pré-expansão, pós-expansão e pós-contenção), no grupo II (aparelhos dentomucossuportados - tipo Haas).

\begin{tabular}{l|c|c|c|c|c|c}
\hline MEDIDA & \multicolumn{3}{|c|}{ C6-PP (mm) } & \multicolumn{3}{c}{ Sperp-R 6 (mm) } \\
\hline \multicolumn{1}{c|}{ Fase } & $\begin{array}{c}\text { pré- } \\
\text { expansão }\end{array}$ & $\begin{array}{c}\text { pós- } \\
\text { expansão }\end{array}$ & $\begin{array}{c}\text { pós- } \\
\text { contenção }\end{array}$ & $\begin{array}{c}\text { pré- } \\
\text { expansão }\end{array}$ & $\begin{array}{c}\text { pós- } \\
\text { expansão }\end{array}$ & $\begin{array}{c}\text { pós- } \\
\text { contenção }\end{array}$ \\
\hline 01-ACM & 21,4 & 21,8 & 23,8 & 47,4 & 47,6 & 47,8 \\
02-DCA & 22,5 & 21,7 & 19,9 & 43,0 & 44,4 & 43,3 \\
03-AFC & 24,7 & 25,8 & 25,0 & 46,4 & 44,9 & 43,8 \\
04-APD & 20,4 & 21,8 & 20,3 & 44,6 & 46,0 & 44,4 \\
05-IMM & 23,6 & 24,0 & 24,4 & 48,8 & 48,6 & 48,8 \\
06-MMR & 23,5 & 25,0 & 23,8 & 45,9 & 45,8 & 44,8 \\
07-KVF & 24,2 & 24,9 & 25,1 & 43,9 & 44,7 & 44,6 \\
08-JBN & 25,0 & 24,5 & 24,1 & 40,7 & 42,5 & 43,4 \\
09-PAB & 24,1 & 24,3 & 23,8 & 40,2 & 38,7 & 39,6 \\
10-VML & 25,7 & 24,9 & 24,6 & 43,7 & 44,5 & 45,6 \\
11-VAAO & 25,2 & 23,9 & 23,9 & 36,2 & 36,1 & 36,7 \\
12-RG & 23,1 & 25,3 & 24,2 & 40,1 & 38,9 & 39,0 \\
13-ASP & 24,9 & 25,4 & 25,6 & 49,5 & 49,2 & 50,5 \\
14-ALC & 17,1 & 19,9 & 18,9 & 47,5 & 48,5 & 46,7 \\
15-DO & 21,2 & 21,1 & 21,1 & 47,8 & 47,0 & 45,6 \\
16-DCJ & 29,8 & 27,8 & 27,1 & 41,7 & 43,4 & 43,5 \\
17-FBB & 21,7 & 21,4 & 21,6 & 39,2 & 39,4 & 40,4 \\
18-FMR & 23,2 & 23,1 & 22,4 & 42,8 & 46,8 & 44,0 \\
19-LFC & 22,8 & 23,4 & 22,8 & 43,7 & 44,1 & 43,5 \\
20-RBM & 26,2 & 25,0 & 25,0 & 47,6 & 46,5 & 45,6 \\
\hline
\end{tabular}


APÊNDICE 27 - Tabela com os valores cefalométricos das medidas analisadas (Sperp-Cㅁ e ÂNL) nas 3 fases estudadas (pré-expansão, pós-expansão e pós-contenção), no grupo II (aparelhos dentomucossuportados - tipo Haas).

\begin{tabular}{l|c|c|c|c|c|c}
\hline MEDIDA & \multicolumn{3}{|c|}{ Sperp-C $\underline{6}(\mathrm{~mm})$} & \multicolumn{3}{c}{$\hat{\text { ANL }\left(^{\circ}\right)}$} \\
\hline \multicolumn{1}{c|}{ Fase } & $\begin{array}{c}\text { pré- } \\
\text { expansão }\end{array}$ & $\begin{array}{c}\text { pós- } \\
\text { expansão }\end{array}$ & $\begin{array}{c}\text { pós- } \\
\text { contenção }\end{array}$ & $\begin{array}{c}\text { pré- } \\
\text { expansão }\end{array}$ & $\begin{array}{c}\text { pós- } \\
\text { expansão }\end{array}$ & $\begin{array}{c}\text { pós- } \\
\text { contenção }\end{array}$ \\
\hline 01-ACM & 44,8 & 46,4 & 47,0 & 91,8 & 84,7 & 99,8 \\
02-DCA & 42,4 & 44,5 & 43,0 & 79,4 & 87,1 & 77,3 \\
03-AFC & 41,8 & 42,2 & 40,1 & 99,3 & 94,2 & 97,2 \\
04-APD & 40,3 & 40,8 & 40,4 & 96,5 & 96,7 & 106,8 \\
05-IMM & 45,8 & 46,1 & 45,7 & 106,4 & 101,1 & 100,2 \\
06-MMR & 43,4 & 43,9 & 41,7 & 109,2 & 103,4 & 101,9 \\
07-KVF & 42,3 & 43,4 & 42,8 & 85,7 & 96,9 & 99,7 \\
08-JBN & 38,2 & 38,2 & 38,6 & 112,5 & 105,6 & 111,5 \\
09-PAB & 36,1 & 34,4 & 35,3 & 113,3 & 103,4 & 107,7 \\
10-VML & 41,5 & 40,9 & 42,3 & 107,1 & 95,6 & 99,8 \\
11-VAAO & 34,3 & 34,2 & 35,0 & 68,9 & 76,2 & 71,7 \\
12-RG & 37,6 & 39,1 & 37,9 & 83,0 & 85,8 & 90,2 \\
13-ASP & 49,9 & 46,9 & 48,4 & 102,1 & 107,3 & 109,5 \\
14-ALC & 49,0 & 48,5 & 48,9 & 80,4 & 84,1 & 77,5 \\
15-DO & 44,5 & 43,1 & 42,0 & 88,7 & 95,2 & 99,7 \\
16-DCJ & 41,3 & 44,8 & 42,7 & 111,4 & 97,9 & 107,4 \\
17-FBB & 34,0 & 34,4 & 34,5 & 93,6 & 91,4 & 97,4 \\
18-FMR & 42,6 & 43,9 & 43,2 & 78,9 & 81,7 & 85,6 \\
19-LFC & 40,4 & 43,0 & 39,8 & 93,6 & 96,0 & 98,1 \\
20-RBM & 45,5 & 43,9 & 41,4 & 93,0 & 94,4 & 98,8 \\
\hline
\end{tabular}


APÊNDICE 28 - Tabela com os valores cefalométricos das medidas analisadas (SNA e SN.ENA) nas 3 fases estudadas (pré-expansão, pós-expansão e pós-contenção), no grupo III (aparelhos dentossuportados - Hyrax).

\begin{tabular}{|c|c|c|c|c|c|c|}
\hline MEDIDA & \multicolumn{3}{|c|}{$\operatorname{SNA}\left({ }^{\circ}\right)$} & \multicolumn{3}{|c|}{ SN.ENA $\left({ }^{\circ}\right)$} \\
\hline Fase & $\begin{array}{c}\text { pré- } \\
\text { expansão }\end{array}$ & $\begin{array}{c}\text { pós- } \\
\text { expansão }\end{array}$ & $\begin{array}{c}\text { pós- } \\
\text { contenção }\end{array}$ & $\begin{array}{c}\text { pré- } \\
\text { expansão }\end{array}$ & $\begin{array}{l}\text { pós- } \\
\text { expansão }\end{array}$ & $\begin{array}{c}\text { pós- } \\
\text { contenção }\end{array}$ \\
\hline 01-ACPS & 82,3 & 82,9 & 83,5 & 85,7 & 85,7 & 86,6 \\
\hline 02-JLU & 78,5 & 82,7 & 78,5 & 83,1 & 88,6 & 83,5 \\
\hline 03-CAD & 79,6 & 82,4 & 82,5 & 85,8 & 89,2 & 85,9 \\
\hline 04-ACS & 82,7 & 85,2 & 82,3 & 88,1 & 89,5 & 86,4 \\
\hline 05-MSCB & 79,0 & 79,5 & 79,3 & 82,0 & 82,7 & 82,8 \\
\hline 06-FMFM & 77,7 & 75,0 & 75,1 & 78,2 & 76,6 & 78,7 \\
\hline 07-AFC & 83,6 & 82,4 & 82,7 & 87,6 & 86,5 & 87,2 \\
\hline 08-NCM & 81,2 & 79,7 & 81,0 & 83,4 & 82,7 & 85,6 \\
\hline 09-GMM & 77,4 & 76,8 & 77,2 & 86,9 & 83,9 & 83,7 \\
\hline 10-CLCS & 82,6 & 83,1 & 81,2 & 88,5 & 88,9 & 88,5 \\
\hline 11-PRDB & 81,2 & 82,6 & 82,6 & 87,8 & 89,6 & 88,9 \\
\hline 12-ТCM & 81,2 & 81,1 & 82,0 & 85,5 & 84,3 & 85,7 \\
\hline 13-VGS & 80,4 & 80,8 & 80,0 & 83,0 & 83,9 & 82,8 \\
\hline 14-ROTP & 80,5 & 80,4 & 81,9 & 87,7 & 87,3 & 87,6 \\
\hline $15-A G$ & 85,7 & 87,3 & 85,5 & 92,1 & 93,7 & 91,4 \\
\hline 16-DRS & 77,5 & 78,4 & 78,0 & 78,3 & 80,5 & 78,9 \\
\hline 17-MVS & 78,1 & 79,8 & 77,4 & 81,3 & 82,0 & 81,8 \\
\hline 18-BMAN & 78,8 & 79,0 & 79,8 & 83,8 & 83,5 & 83,8 \\
\hline 19-FRP & 85,8 & 88,0 & 87,1 & 91,0 & 90,8 & 90,6 \\
\hline 20-RCD & 86,8 & 87,7 & 90,2 & 91,0 & 91,8 & 95,8 \\
\hline 21-SAOJ & 85,8 & 85,5 & 85,6 & 91,0 & 89,2 & 88,7 \\
\hline
\end{tabular}


APÊNDICE 29 - Tabela com os valores cefalométricos das medidas analisadas (Nperp-A e Sperp-A) nas 3 fases estudadas (pré-expansão, pós-expansão e pós-contenção), no grupo III (aparelhos dentossuportados - Hyrax).

\begin{tabular}{l|c|c|c|c|c|c}
\hline MEDIDA & \multicolumn{3}{|c|}{ Nperp-A (mm) } & \multicolumn{3}{c}{ Sperp-A (mm) } \\
\hline \multicolumn{1}{c|}{ Fase } & $\begin{array}{c}\text { pré- } \\
\text { expansão }\end{array}$ & $\begin{array}{c}\text { pós- } \\
\text { expansão }\end{array}$ & $\begin{array}{c}\text { pós- } \\
\text { contenção }\end{array}$ & $\begin{array}{c}\text { pré- } \\
\text { expansão }\end{array}$ & $\begin{array}{c}\text { pós- } \\
\text { expansão }\end{array}$ & $\begin{array}{c}\text { pós- } \\
\text { contenção }\end{array}$ \\
\hline 01-ACPS & 1,2 & 0,6 & 2,6 & 73,1 & 72,7 & 75,0 \\
02-JLU & 0,0 & $-0,7$ & 0,7 & 65,5 & 65,4 & 67,4 \\
03-CAD & 0,9 & 0,6 & 3,3 & 73,5 & 72,7 & 75,6 \\
04-ACS & 0,7 & 1,9 & $-1,1$ & 64,2 & 65,0 & 63,5 \\
05-MSCB & $-0,4$ & $-0,4$ & 0,1 & 66,8 & 66,6 & 67,0 \\
06-FMFM & $-2,5$ & $-2,3$ & $-3,8$ & 61,8 & 62,2 & 61,2 \\
07-AFC & 1,1 & 1,2 & $-0,2$ & 71,1 & 71,4 & 71,2 \\
08-NCM & 0,1 & 0,4 & 1,9 & 66,2 & 66,5 & 67,4 \\
09-GMM & $-1,0$ & $-1,2$ & $-0,2$ & 70,3 & 70,3 & 71,1 \\
10-CLCS & 1,5 & $-0,1$ & 0,0 & 66,7 & 65,9 & 65,9 \\
11-PRDB & $-0,5$ & 0,5 & $-0,6$ & 62,6 & 63,1 & 62,4 \\
12-TCM & 0,0 & 1,0 & 0,3 & 69,0 & 71,1 & 70,6 \\
13-VGS & $-1,6$ & $-1,7$ & $-1,2$ & 67,1 & 67,9 & 67,6 \\
14-ROTP & 1,7 & 0,9 & 1,4 & 70,5 & 70,4 & 71,7 \\
15-AG & 2,3 & 2,2 & 2,1 & 73,2 & 73,0 & 73,6 \\
16-DRS & $-5,4$ & $-4,9$ & $-4,6$ & 66,8 & 66,1 & 66,8 \\
17-MVS & $-1,1$ & 1,7 & $-0,2$ & 64,8 & 68,0 & 67,8 \\
18-BMAN & $-3,5$ & $-7,6$ & $-7,4$ & 60,6 & 57,1 & 56,9 \\
19-FRP & 5,4 & 7,3 & 5,0 & 73,6 & 76,1 & 74,4 \\
20-RCD & 2,8 & 4,7 & 4,0 & 75,0 & 74,2 & 73,7 \\
21-SAOJ & 3,2 & 1,5 & 2,5 & 67,8 & 66,6 & 68,0 \\
\hline
\end{tabular}


APÊNDICE 30 - Tabela com os valores cefalométricos das medidas analisadas (SNB e Nperp-Pog) nas 3 fases estudadas (pré-expansão, pós-expansão e pós-contenção), no grupo III (aparelhos dentossuportados - Hyrax).

\begin{tabular}{|c|c|c|c|c|c|c|}
\hline MEDIDA & \multicolumn{3}{|c|}{$\mathrm{SNB}\left(^{\circ}\right)$} & \multicolumn{3}{|c|}{ Nperp-Pog (mm) } \\
\hline Fase & $\begin{array}{c}\text { pré- } \\
\text { expansão }\end{array}$ & $\begin{array}{c}\text { pós- } \\
\text { expansão }\end{array}$ & $\begin{array}{c}\text { pós- } \\
\text { contenção }\end{array}$ & $\begin{array}{c}\text { pré- } \\
\text { expansão }\end{array}$ & $\begin{array}{c}\text { pós- } \\
\text { expansão }\end{array}$ & $\begin{array}{c}\text { pós- } \\
\text { contenção }\end{array}$ \\
\hline 01-ACPS & 78,2 & 78,0 & 78,6 & $-4,2$ & $-7,3$ & $-3,9$ \\
\hline 02-JLU & 80,4 & 82,2 & 77,9 & 5,1 & $-0,9$ & 1,8 \\
\hline 03-CAD & 75,2 & 76,4 & 75,9 & $-4,9$ & $-8,4$ & $-5,7$ \\
\hline 04-ACS & 85,8 & 85,0 & 85,0 & 9,7 & 6,9 & 5,2 \\
\hline 05-MSCB & 75,8 & 73,9 & 74,1 & $-5,1$ & $-9,6$ & $-6,9$ \\
\hline 06-FMFM & 74,8 & 72,5 & 73,2 & $-8,8$ & $-8,8$ & $-9,9$ \\
\hline 07-AFC & 75,5 & 74,8 & 76,1 & $-10,8$ & $-10,2$ & $-11,6$ \\
\hline 08-NCM & 78,7 & 77,4 & 78,0 & $-2,7$ & $-2,1$ & $-0,7$ \\
\hline 09-GMM & 74,2 & 73,7 & 73,5 & $-6,3$ & $-6,6$ & $-6,2$ \\
\hline 10-CLCS & 76,4 & 76,0 & 75,6 & $-7,8$ & $-13,3$ & $-10,6$ \\
\hline 11-PRDB & 77,3 & 76,5 & 77,5 & $-6,7$ & $-9,9$ & $-9,8$ \\
\hline 12-TCM & 78,1 & 76,6 & 78,3 & $-3,0$ & $-4,5$ & $-4,6$ \\
\hline 13-VGS & 76,9 & 78,6 & 76,5 & $-7,0$ & $-5,8$ & $-6,9$ \\
\hline 14-ROTP & 72,2 & 73,2 & 74,7 & $-10,4$ & $-8,9$ & $-9,2$ \\
\hline $15-A G$ & 85,7 & 85,9 & 85,6 & 6,5 & 3,7 & 6,6 \\
\hline 16-DRS & 76,9 & 74,6 & 75,5 & $-11,1$ & $-15,9$ & $-12,5$ \\
\hline 17-MVS & 74,7 & 72,9 & 73,2 & $-6,9$ & $-8,4$ & $-6,0$ \\
\hline 18-BMAN & 79,8 & 80,2 & 81,6 & $-3,5$ & $-11,8$ & $-11,2$ \\
\hline 19-FRP & 86,7 & 86,7 & 87,1 & 13,3 & 12,6 & 11,3 \\
\hline 20-RCD & 82,8 & 82,7 & 85,0 & $-0,3$ & 2,0 & 1,6 \\
\hline 21-SAOJ & 80,1 & 78,1 & 78,3 & $-5,2$ & $-11,8$ & $-9,6$ \\
\hline
\end{tabular}


APÊNDICE 31 - Tabela com os valores cefalométricos das medidas analisadas (ANB e NAP) nas 3 fases estudadas (préexpansão, pós-expansão e pós-contenção), no grupo III (aparelhos dentossuportados - Hyrax).

\begin{tabular}{l|c|c|c|c|c|c}
\hline MEDIDA & \multicolumn{3}{|c|}{ ANB $\left(^{\circ}\right)$} & \multicolumn{3}{c}{ NAP $\left(^{\circ}\right)$} \\
\hline Fase & $\begin{array}{c}\text { pré- } \\
\text { expansão }\end{array}$ & $\begin{array}{c}\text { pós- } \\
\text { expansão }\end{array}$ & $\begin{array}{c}\text { pós- } \\
\text { contenção }\end{array}$ & $\begin{array}{c}\text { pré- } \\
\text { expansão }\end{array}$ & $\begin{array}{c}\text { pós- } \\
\text { expansão }\end{array}$ & $\begin{array}{c}\text { pós- } \\
\text { contenção }\end{array}$ \\
\hline 01-ACPS & 4,1 & 4,9 & 4,9 & 7,8 & 10,1 & 10,7 \\
02-JLU & $-1,9$ & 0,6 & 0,7 & $-5,8$ & $-0,6$ & $-0,5$ \\
03-CAD & 4,4 & 6,0 & 6,6 & 6,9 & 9,7 & 12,4 \\
04-ACS & $-3,1$ & 0,1 & $-2,7$ & $-10,9$ & $-3,8$ & $-8,8$ \\
05-MSCB & 3,2 & 5,6 & 5,3 & 4,7 & 8,8 & 7,5 \\
06-FMFM & 2,9 & 2,6 & 2,0 & 4,5 & 4,5 & 2,9 \\
07-AFC & 8,1 & 7,6 & 6,6 & 13,5 & 13,0 & 12,0 \\
08-NCM & 2,5 & 2,3 & 3,1 & 3,2 & 3,1 & 4,8 \\
09-GMM & 3,2 & 3,1 & 3,7 & 3,9 & 3,8 & 5,5 \\
10-CLCS & 6,2 & 7,0 & 5,6 & 11,7 & 13,5 & 11,1 \\
11-PRDB & 3,9 & 6,2 & 5,1 & 6,5 & 11,2 & 9,1 \\
12-TCM & 3,1 & 4,5 & 3,7 & 3,1 & 6,5 & 5,4 \\
13-VGS & 3,5 & 2,2 & 3,5 & 3,8 & 2,3 & 4,5 \\
14-ROTP & 8,3 & 7,2 & 7,3 & 14,1 & 11,7 & 12,9 \\
15-AG & 0,0 & 1,4 & $-0,1$ & $-2,0$ & 0,8 & $-2,5$ \\
16-DRS & 0,7 & 3,8 & 2,5 & 1,1 & 7,0 & 3,9 \\
17-MVS & 3,3 & 6,9 & 4,2 & 4,7 & 11,6 & 5,6 \\
18-BMAN & $-1,1$ & $-1,1$ & $-1,7$ & $-3,4$ & $-3,1$ & $-3,7$ \\
19-FRP & $-0,9$ & 1,3 & 0,0 & $-3,6$ & 1,3 & $-2,2$ \\
20-RCD & 4,0 & 4,9 & 5,2 & 5,6 & 7,0 & 6,2 \\
21-SAOJ & 5,7 & 7,4 & 7,3 & 13,1 & 16,9 & 15,9 \\
\hline
\end{tabular}


APÊNDICE 32 - Tabela com os valores cefalométricos das medidas analisadas (N-ENA e ENA-PoOr) nas 3 fases estudadas (pré-expansão, pós-expansão e póscontenção), no grupo III (aparelhos dentossuportados Hyrax).

\begin{tabular}{l|c|c|c|c|c|c}
\hline MEDIDA & \multicolumn{3}{|c|}{ N-ENA (mm) } & \multicolumn{3}{c}{ ENA-PoOr (mm) } \\
\hline \multicolumn{1}{c|}{ Fase } & $\begin{array}{c}\text { pré- } \\
\text { expansão }\end{array}$ & $\begin{array}{c}\text { pós- } \\
\text { expansão }\end{array}$ & $\begin{array}{c}\text { pós- } \\
\text { contenção }\end{array}$ & $\begin{array}{c}\text { pré- } \\
\text { expansão }\end{array}$ & $\begin{array}{c}\text { pós- } \\
\text { expansão }\end{array}$ & $\begin{array}{c}\text { pós- } \\
\text { contenção }\end{array}$ \\
\hline 01-ACPS & 56,4 & 55,1 & 54,8 & 30,4 & 30,6 & 27,1 \\
02-JLU & 49,2 & 47,0 & 50,9 & 18,3 & 22,7 & 20,8 \\
03-CAD & 48,3 & 49,5 & 50,1 & 19,2 & 19,9 & 19,4 \\
04-ACS & 50,5 & 50,8 & 50,8 & 24,1 & 23,4 & 23,6 \\
05-MSCB & 51,0 & 51,8 & 52,2 & 22,6 & 23,7 & 24,1 \\
06-FMFM & 46,0 & 46,3 & 45,2 & 19,0 & 16,7 & 17,4 \\
07-AFC & 44,9 & 45,4 & 46,9 & 17,1 & 16,7 & 19,1 \\
08-NCM & 47,5 & 48,6 & 49,1 & 21,7 & 21,1 & 21,6 \\
09-GMM & 51,0 & 52,9 & 52,4 & 18,0 & 19,6 & 19,9 \\
10-CLCS & 45,2 & 45,7 & 45,8 & 16,1 & 18,1 & 16,3 \\
11-PRDB & 47,9 & 47,7 & 48,3 & 21,0 & 21,2 & 23,2 \\
12-TCM & 55,5 & 55,7 & 55,2 & 22,5 & 22,4 & 22,9 \\
13-VGS & 50,3 & 49,2 & 51,7 & 21,8 & 21,6 & 21,9 \\
14-ROTP & 51,1 & 51,6 & 51,3 & 23,1 & 23,8 & 23,5 \\
15-AG & 49,9 & 49,0 & 51,9 & 20,4 & 20,6 & 22,5 \\
16-DRS & 51,5 & 51,3 & 52,1 & 22,5 & 22,4 & 22,5 \\
17-MVS & 45,8 & 46,9 & 46,4 & 14,9 & 15,7 & 14,6 \\
18-BMAN & 50,8 & 51,1 & 50,0 & 22,0 & 28,2 & 28,0 \\
19-FRP & 53,1 & 54,2 & 54,3 & 20,0 & 21,7 & 23,8 \\
20-RCD & 54,0 & 55,0 & 52,9 & 26,9 & 26,7 & 26,8 \\
21-SAOJ & 49,7 & 50,8 & 51,5 & 21,6 & 24,3 & 23,7 \\
\hline
\end{tabular}


APÊNDICE 33 - Tabela com os valores cefalométricos das medidas analisadas (ENP-PoOr e PoOr.PP) nas 3 fases estudadas (pré-expansão, pós-expansão e póscontenção), no grupo III (aparelhos dentossuportados Hyrax).

\begin{tabular}{l|c|c|c|c|c|c}
\hline MEDIDA & \multicolumn{3}{|c|}{ ENP-PoOr (mm) } & \multicolumn{3}{c}{ PoOr.PP $\left(^{\circ}\right)$} \\
\hline \multicolumn{1}{c|}{ Fase } & $\begin{array}{c}\text { pré- } \\
\text { expansão }\end{array}$ & $\begin{array}{c}\text { pós- } \\
\text { expansão }\end{array}$ & $\begin{array}{c}\text { pós- } \\
\text { contenção }\end{array}$ & $\begin{array}{c}\text { pré- } \\
\text { expansão }\end{array}$ & $\begin{array}{c}\text { pós- } \\
\text { expansão }\end{array}$ & $\begin{array}{c}\text { pós- } \\
\text { contenção }\end{array}$ \\
\hline 01-ACPS & 26,8 & 27,1 & 24,6 & 3,9 & 3,8 & 2,7 \\
02-JLU & 20,5 & 23,6 & 23,3 & $-2,6$ & $-1,0$ & $-2,8$ \\
03-CAD & 22,9 & 22,2 & 23,3 & $-3,9$ & $-2,4$ & $-4,1$ \\
04-ACS & 25,4 & 24,9 & 25,0 & $-1,6$ & $-1,8$ & $-1,8$ \\
05-MSCB & 25,4 & 26,3 & 27,0 & $-3,4$ & $-3,0$ & $-3,5$ \\
06-FMFM & 21,4 & 21,6 & 21,8 & $-3,2$ & $-6,3$ & $-5,6$ \\
07-AFC & 22,3 & 21,8 & 23,1 & $-5,5$ & $-5,3$ & $-4,1$ \\
08-NCM & 21,0 & 22,1 & 22,0 & 0,8 & $-1,2$ & $-0,5$ \\
09-GMM & 19,8 & 21,9 & 22,5 & $-1,8$ & $-2,4$ & $-2,7$ \\
10-CLCS & 19,2 & 19,1 & 16,6 & $-2,4$ & $-1,1$ & $-0,3$ \\
11-PRDB & 20,4 & 22,0 & 22,0 & 0,7 & $-0,9$ & 1,4 \\
12-TCM & 24,4 & 25,5 & 25,2 & $-2,1$ & $-3,5$ & $-2,5$ \\
13-VGS & 23,2 & 24,1 & 23,3 & $-1,7$ & $-2,9$ & $-1,6$ \\
14-ROTP & 21,3 & 22,5 & 23,1 & 1,8 & 1,3 & 0,4 \\
15-AG & 21,7 & 21,7 & 22,4 & $-1,4$ & $-1,1$ & 0,1 \\
16-DRS & 24,5 & 23,8 & 24,3 & $-2,5$ & $-1,8$ & $-2,3$ \\
17-MVS & 21,6 & 22,0 & 23,2 & $-7,6$ & $-7,1$ & $-9,5$ \\
18-BMAN & 21,4 & 23,5 & 23,1 & 0,7 & 5,9 & 6,0 \\
19-FRP & 22,1 & 22,7 & 24,9 & $-2,2$ & $-1,0$ & $-1,1$ \\
20-RCD & 23,5 & 24,9 & 24,7 & 3,7 & 1,9 & 2,2 \\
21-SAOJ & 18,6 & 18,9 & 20,0 & 3,3 & 6,0 & 4,1 \\
\hline
\end{tabular}


APÊNDICE 34 - Tabela com os valores cefalométricos das medidas analisadas (SN.GoMe e FMA) nas 3 fases estudadas (pré-expansão, pós-expansão e pós-contenção), no grupo III (aparelhos dentossuportados - Hyrax).

\begin{tabular}{l|c|c|c|c|c|c}
\hline MEDIDA & \multicolumn{3}{|c|}{ SN.GoMe $\left(^{\circ}\right)$} & \multicolumn{3}{c}{ FMA $\left(^{\circ}\right)$} \\
\hline Fase & $\begin{array}{c}\text { pré- } \\
\text { expansão }\end{array}$ & $\begin{array}{c}\text { pós- } \\
\text { expansão }\end{array}$ & $\begin{array}{c}\text { pós- } \\
\text { contenção }\end{array}$ & $\begin{array}{c}\text { pré- } \\
\text { expansão }\end{array}$ & $\begin{array}{c}\text { pós- } \\
\text { expansão }\end{array}$ & $\begin{array}{c}\text { pós- } \\
\text { contenção }\end{array}$ \\
\hline 01-ACPS & 32,1 & 34,8 & 31,6 & 23,2 & 27,1 & 22,6 \\
02-JLU & 33,5 & 32,3 & 37,4 & 22,0 & 25,8 & 25,2 \\
03-CAD & 40,9 & 40,0 & 40,7 & 29,6 & 31,7 & 30,0 \\
04-ACS & 33,9 & 35,4 & 33,0 & 25,8 & 28,5 & 26,5 \\
05-MSCB & 42,8 & 45,3 & 43,5 & 32,2 & 35,3 & 32,8 \\
06-FMFM & 37,7 & 42,0 & 39,4 & 28,2 & 29,5 & 28,7 \\
07-AFC & 34,1 & 36,3 & 34,8 & 26,5 & 27,4 & 27,7 \\
08-NCM & 40,2 & 42,4 & 42,0 & 31,3 & 31,7 & 31,0 \\
09-GMM & 39,8 & 42,5 & 42,0 & 28,3 & 30,4 & 29,4 \\
10-CLCS & 46,4 & 46,4 & 45,0 & 37,4 & 39,6 & 36,2 \\
11-PRDB & 46,7 & 48,5 & 46,9 & 38,4 & 40,5 & 40,2 \\
12-TCM & 41,1 & 42,8 & 41,6 & 32,3 & 33,1 & 33,3 \\
13-VGS & 40,1 & 40,4 & 42,7 & 32,1 & 32,9 & 33,8 \\
14-ROTP & 39,6 & 35,3 & 34,6 & 28,4 & 24,9 & 25,2 \\
15-AG & 32,2 & 32,8 & 32,8 & 25,5 & 27,8 & 26,2 \\
16-DRS & 41,3 & 44,6 & 42,3 & 34,1 & 37,8 & 34,8 \\
17-MVS & 37,5 & 40,2 & 39,0 & 26,8 & 28,1 & 26,6 \\
18-BMAN & 40,9 & 39,2 & 38,4 & 33,1 & 36,1 & 36,1 \\
19-FRP & 30,6 & 30,1 & 31,3 & 21,1 & 21,1 & 23,6 \\
20-RCD & 35,1 & 36,4 & 32,4 & 29,2 & 29,7 & 28,7 \\
21-SAOJ & 40,4 & 41,2 & 41,2 & 32,9 & 35,2 & 34,3 \\
\hline
\end{tabular}


APÊNDICE 35 - Tabela com os valores cefalométricos das medidas analisadas (SN.Gn e ÂBI) nas 3 fases estudadas (préexpansão, pós-expansão e pós-contenção), no grupo III (aparelhos dentossuportados - Hyrax).

\begin{tabular}{l|c|c|c|c|c|c}
\hline MEDIDA & \multicolumn{3}{|c|}{ SN.Gn $\left(^{\circ}\right)$} & \multicolumn{3}{c}{$\hat{\text { ÂBI }\left(^{\circ}\right)}$} \\
\hline Fase & $\begin{array}{c}\text { pré- } \\
\text { expansão }\end{array}$ & $\begin{array}{c}\text { pós- } \\
\text { expansão }\end{array}$ & $\begin{array}{c}\text { pós- } \\
\text { contenção }\end{array}$ & $\begin{array}{c}\text { pré- } \\
\text { expansão }\end{array}$ & $\begin{array}{c}\text { pós- } \\
\text { expansão }\end{array}$ & $\begin{array}{c}\text { pós- } \\
\text { contenção }\end{array}$ \\
\hline 01-ACPS & 66,0 & 67,6 & 66,3 & 19,3 & 23,3 & 19,9 \\
02-JLU & 66,0 & 65,4 & 68,6 & 24,7 & 26,9 & 28,0 \\
03-CAD & 69,2 & 69,3 & 69,7 & 33,5 & 34,1 & 34,1 \\
04-ACS & 62,2 & 63,8 & 63,5 & 27,4 & 30,4 & 28,3 \\
05-MSCB & 70,6 & 73,0 & 72,1 & 35,6 & 38,3 & 36,3 \\
06-FMFM & 70,4 & 73,2 & 71,8 & 31,4 & 35,7 & 34,3 \\
07-AFC & 68,6 & 69,9 & 68,5 & 32,0 & 32,7 & 31,8 \\
08-NCM & 68,3 & 70,0 & 70,3 & 30,5 & 32,9 & 31,5 \\
09-GMM & 72,1 & 73,5 & 73,2 & 30,0 & 32,8 & 32,1 \\
10-CLCS & 72,1 & 73,0 & 72,8 & 39,8 & 40,7 & 36,5 \\
11-PRDB & 71,2 & 73,8 & 71,7 & 37,7 & 41,5 & 38,8 \\
12-TCM & 69,9 & 71,2 & 69,6 & 34,4 & 36,6 & 35,9 \\
13-VGS & 70,5 & 69,3 & 71,7 & 33,8 & 35,9 & 35,5 \\
14-ROTP & 74,3 & 72,2 & 71,1 & 26,7 & 23,6 & 24,8 \\
15-AG & 62,7 & 62,9 & 63,1 & 26,8 & 28,9 & 26,1 \\
16-DRS & 68,6 & 71,6 & 70,4 & 36,6 & 39,5 & 37,1 \\
17-MVS & 71,6 & 73,2 & 71,9 & 34,4 & 35,2 & 36,1 \\
18-BMAN & 70,7 & 70,2 & 68,6 & 32,3 & 30,1 & 30,0 \\
19-FRP & 63,0 & 63,2 & 63,0 & 23,3 & 22,2 & 24,8 \\
20-RCD & 66,1 & 67,3 & 64,7 & 25,5 & 27,8 & 26,5 \\
21-SAOJ & 70,4 & 72,0 & 71,9 & 29,6 & 29,2 & 30,2 \\
\hline
\end{tabular}


APÊNDICE 36 - Tabela com os valores cefalométricos das medidas analisadas (Ar-A e Ar-Gn) nas 3 fases estudadas (préexpansão, pós-expansão e pós-contenção), no grupo III (aparelhos dentossuportados - Hyrax).

\begin{tabular}{l|c|c|c|c|c|c}
\hline MEDIDA & \multicolumn{3}{|c|}{ Ar-A (mm) } & \multicolumn{3}{c}{ Ar-Gn (mm) } \\
\hline \multicolumn{1}{c|}{ Fase } & $\begin{array}{c}\text { pré- } \\
\text { expansão }\end{array}$ & $\begin{array}{c}\text { pós- } \\
\text { expansão }\end{array}$ & $\begin{array}{c}\text { pós- } \\
\text { contenção }\end{array}$ & $\begin{array}{c}\text { pré- } \\
\text { expansão }\end{array}$ & $\begin{array}{c}\text { pós- } \\
\text { expansão }\end{array}$ & $\begin{array}{c}\text { pós- } \\
\text { contenção }\end{array}$ \\
\hline 01-ACPS & 88,8 & 90,2 & 90,4 & 107,3 & 107,6 & 107,5 \\
02-JLU & 74,9 & 77,2 & 76,5 & 105,4 & 105,3 & 105,1 \\
03-CAD & 82,1 & 82,2 & 85,3 & 104,7 & 105,1 & 105,7 \\
04-ACS & 77,3 & 80,2 & 77,9 & 107,4 & 108,0 & 109,3 \\
05-MSCB & 77,1 & 79,6 & 79,7 & 99,8 & 101,0 & 100,4 \\
06-FMFM & 75,1 & 75,0 & 75,0 & 96,5 & 97,2 & 97,4 \\
07-AFC & 84,7 & 84,8 & 87,3 & 100,1 & 101,8 & 104,1 \\
08-NCM & 80,1 & 80,7 & 80,0 & 130,6 & 105,0 & 103,8 \\
09-GMM & 87,0 & 87,8 & 87,8 & 113,0 & 114,4 & 112,6 \\
10-CLCS & 84,0 & 84,1 & 83,1 & 103,1 & 103,6 & 103,6 \\
11-PRDB & 79,7 & 79,9 & 80,5 & 100,4 & 100,3 & 100,5 \\
12-TCM & 84,9 & 87,9 & 85,5 & 110,1 & 109,0 & 108,5 \\
13-VGS & 82,0 & 81,2 & 81,4 & 107,4 & 109,5 & 107,6 \\
14-ROTP & 88,1 & 88,5 & 90,1 & 103,7 & 105,9 & 105,0 \\
15-AG & 89,7 & 88,2 & 89,9 & 117,0 & 118,0 & 120,0 \\
16-DRS & 78,7 & 80,0 & 79,7 & 100,3 & 99,3 & 101,9 \\
17-MVS & 79,3 & 80,7 & 80,2 & 99,9 & 100,5 & 100,8 \\
18-BMAN & 78,2 & 77,5 & 77,6 & 104,8 & 106,4 & 106,4 \\
19-FRP & 91,0 & 93,9 & 93,5 & 122,3 & 123,5 & 125,3 \\
20-RCD & 88,9 & 89,5 & 87,7 & 118,8 & 117,0 & 118,0 \\
21-SAOJ & 82,4 & 84,8 & 84,9 & 101,9 & 102,1 & 104,8 \\
\hline
\end{tabular}


APÊNDICE 37 - Tabela com os valores cefalométricos das medidas analisadas (ENA-Me e Rㅡ-PP) nas 3 fases estudadas (pré-expansão, pós-expansão e pós-contenção), no grupo III (aparelhos dentossuportados - Hyrax).

\begin{tabular}{l|c|c|c|c|c|c}
\hline MEDIDA & \multicolumn{3}{|c|}{ ENA-Me (mm) } & \multicolumn{3}{c}{ R6-PP (mm) } \\
\hline \multicolumn{1}{c|}{ Fase } & $\begin{array}{c}\text { pré- } \\
\text { expansão }\end{array}$ & $\begin{array}{c}\text { pós- } \\
\text { expansão }\end{array}$ & $\begin{array}{c}\text { pós- } \\
\text { contenção }\end{array}$ & $\begin{array}{c}\text { pré- } \\
\text { expansão }\end{array}$ & $\begin{array}{c}\text { pós- } \\
\text { expansão }\end{array}$ & $\begin{array}{c}\text { pós- } \\
\text { contenção }\end{array}$ \\
\hline 01-ACPS & 58,5 & 64,0 & 61,8 & $-0,4$ & 1,9 & 1,8 \\
02-JLU & 61,6 & 64,9 & 64,5 & 4,1 & 3,5 & 2,6 \\
03-CAD & 71,3 & 74,4 & 72,3 & 6,6 & 6,5 & 5,9 \\
04-ACS & 56,9 & 59,5 & 60,6 & 0,1 & 0,4 & $-0,9$ \\
05-MSCB & 65,4 & 68,8 & 66,6 & 3,6 & 3,7 & 3,2 \\
06-FMFM & 61,7 & 65,2 & 64,2 & $-0,2$ & 1,3 & 0,7 \\
07-AFC & 69,4 & 71,4 & 70,0 & 2,2 & 3,1 & 1,8 \\
08-NCM & 66,8 & 68,4 & 68,6 & 3,6 & 3,4 & 4,4 \\
09-GMM & 76,9 & 78,5 & 77,2 & 9,7 & 8,0 & 7,8 \\
10-CLCS & 73,3 & 75,7 & 74,7 & 4,7 & 4,1 & 4,5 \\
11-PRDB & 67,4 & 71,9 & 68,9 & 3,2 & 4,8 & 1,8 \\
12-TCM & 70,1 & 70,5 & 69,4 & $-1,4$ & $-0,5$ & $-0,8$ \\
13-VGS & 73,2 & 75,6 & 74,9 & 4,0 & 5,2 & 5,3 \\
14-ROTP & 75,2 & 71,9 & 71,3 & 5,4 & 3,9 & 3,3 \\
15-AG & 70,0 & 73,5 & 70,5 & 2,0 & 2,8 & 1,1 \\
16-DRS & 64,6 & 69,4 & 68,3 & 0,5 & 2,9 & 1,6 \\
17-MVS & 69,1 & 71,1 & 70,9 & 6,0 & 4,9 & 3,7 \\
18-BMAN & 69,0 & 68,4 & 65,8 & 4,3 & 2,4 & 1,3 \\
19-FRP & 65,7 & 67,2 & 68,8 & 4,9 & 4,5 & 7,0 \\
20-RCD & 76,0 & 76,7 & 76,3 & 3,9 & 4,7 & 4,8 \\
21-SAOJ & 70,3 & 71,7 & 72,9 & 1,8 & 3,7 & 1,8 \\
\hline
\end{tabular}


APÊNDICE 38 - Tabela com os valores cefalométricos das medidas analisadas (Cㅁ-PP e Sperp-Rㅁ) nas 3 fases estudadas (pré-expansão, pós-expansão e pós-contenção), no grupo III (aparelhos dentossuportados - Hyrax).

\begin{tabular}{l|c|c|c|c|c|c}
\hline MEDIDA & \multicolumn{3}{|c|}{ C6-PP (mm) } & \multicolumn{3}{c}{ Sperp-R6́6 (mm) } \\
\hline \multicolumn{1}{c|}{ Fase } & $\begin{array}{c}\text { pré- } \\
\text { expansão }\end{array}$ & $\begin{array}{c}\text { pós- } \\
\text { expansão }\end{array}$ & $\begin{array}{c}\text { pós- } \\
\text { contenção }\end{array}$ & $\begin{array}{c}\text { pré- } \\
\text { expansão }\end{array}$ & $\begin{array}{c}\text { pós- } \\
\text { expansão }\end{array}$ & $\begin{array}{c}\text { pós- } \\
\text { contenção }\end{array}$ \\
\hline 01-ACPS & 20,2 & 22,1 & 21,9 & 46,4 & 48,0 & 48,2 \\
02-JLU & 20,8 & 22,6 & 22,7 & 44,6 & 42,6 & 45,3 \\
03-CAD & 26,2 & 26,3 & 25,9 & 49,9 & 48,5 & 50,2 \\
04-ACS & 17,2 & 18,0 & 17,3 & 42,5 & 41,6 & 41,5 \\
05-MSCB & 20,5 & 22,6 & 20,5 & 43,2 & 43,7 & 44,5 \\
06-FMFM & 17,4 & 17,7 & 18,3 & 39,2 & 41,4 & 37,1 \\
07-AFC & 21,2 & 22,8 & 21,8 & 43,7 & 43,4 & 45,6 \\
08-NCM & 24,8 & 22,9 & 22,6 & 42,0 & 42,9 & 45,3 \\
09-GMM & 28,5 & 28,1 & 26,4 & 43,0 & 41,4 & 42,8 \\
10-CLCS & 22,7 & 24,1 & 24,1 & 41,9 & 40,6 & 42,4 \\
11-PRDB & 22,1 & 22,9 & 22,4 & 37,1 & 37,3 & 37,3 \\
12-TCM & 21,6 & 21,9 & 21,7 & 42,1 & 43,2 & 43,1 \\
13-VGS & 24,6 & 25,3 & 24,9 & 44,1 & 43,0 & 43,1 \\
14-ROTP & 25,4 & 25,0 & 22,8 & 46,0 & 45,1 & 45,4 \\
15-AG & 24,4 & 25,4 & 24,2 & 41,4 & 43,1 & 43,0 \\
16-DRS & 19,4 & 22,0 & 20,7 & 45,4 & 45,1 & 45,6 \\
17-MVS & 21,4 & 23,0 & 22,4 & 41,8 & 43,5 & 45,6 \\
18-BMAN & 23,0 & 21,9 & 21,7 & 42,1 & 38,1 & 38,0 \\
19-FRP & 24,7 & 24,6 & 24,7 & 51,5 & 49,4 & 52,3 \\
20-RCD & 24,7 & 26,4 & 26,7 & 49,1 & 47,3 & 46,2 \\
21-SAOJ & 22,4 & 22,6 & 22,3 & 40,0 & 38,7 & 40,0 \\
\hline
\end{tabular}


APÊNDICE 39 - Tabela com os valores cefalométricos das medidas analisadas (Sperp-C $\underline{6}$ e ÂNL) nas 3 fases estudadas (pré-expansão, pós-expansão e pós-contenção), no grupo III (aparelhos dentossuportados - Hyrax).

\begin{tabular}{l|c|c|c|c|c|c}
\hline MEDIDA & \multicolumn{3}{|c|}{ Sperp-C $\underline{6}(\mathrm{~mm})$} & \multicolumn{3}{c}{$\hat{\text { ANL }\left(^{\circ}\right)}$} \\
\hline Fase & $\begin{array}{c}\text { pré- } \\
\text { expansão }\end{array}$ & $\begin{array}{c}\text { pós- } \\
\text { expansão }\end{array}$ & $\begin{array}{c}\text { pós- } \\
\text { contenção }\end{array}$ & $\begin{array}{c}\text { pré- } \\
\text { expansão }\end{array}$ & $\begin{array}{c}\text { pós- } \\
\text { expansão }\end{array}$ & $\begin{array}{c}\text { pós- } \\
\text { contenção }\end{array}$ \\
\hline 01-ACPS & 44,8 & 43,5 & 46,0 & 109,5 & 97,3 & 108,3 \\
02-JLU & 45,4 & 45,2 & 45,7 & 87,0 & 86,1 & 86,2 \\
03-CAD & 49,1 & 47,5 & 48,9 & 101,5 & 91,3 & 98,9 \\
04-ACS & 40,8 & 39,5 & 39,5 & 98,6 & 100,5 & 98,0 \\
05-MSCB & 39,9 & 39,0 & 39,6 & 118,6 & 107,1 & 117,7 \\
06-FMFM & 39,2 & 40,8 & 36,3 & 102,9 & 104,9 & 102,2 \\
07-AFC & 39,7 & 40,9 & 44,5 & 90,4 & 90,3 & 94,7 \\
08-NCM & 41,2 & 41,6 & 43,2 & 98,2 & 104,1 & 107,7 \\
09-GMM & 39,3 & 39,5 & 40,1 & 103,7 & 105,9 & 102,1 \\
10-CLCS & 39,6 & 36,1 & 39,5 & 90,2 & 90,7 & 90,9 \\
11-PRDB & 34,8 & 33,2 & 31,1 & 99,6 & 104,8 & 98,6 \\
12-TCM & 40,6 & 41,7 & 40,5 & 113,3 & 111,3 & 113,3 \\
13-VGS & 41,3 & 41,2 & 40,9 & 111,3 & 114,2 & 114,5 \\
14-ROTP & 45,8 & 44,7 & 45,2 & 131,1 & 130,0 & 116,0 \\
15-AG & 42,7 & 42,4 & 41,8 & 92,7 & 99,0 & 100,6 \\
16-DRS & 40,4 & 39,6 & 41,1 & 72,8 & 73,8 & 72,5 \\
17-MVS & 38,3 & 40,0 & 42,7 & 108,7 & 100,2 & 101,5 \\
18-BMAN & 36,4 & 31,6 & 31,9 & 89,6 & 95,6 & 90,5 \\
19-FRP & 52,5 & 48,4 & 50,3 & 107,8 & 106,9 & 104,8 \\
20-RCD & 46,5 & 44,5 & 43,3 & 120,9 & 115,3 & 126,3 \\
21-SAOJ & 38,5 & 37,3 & 37,7 & 106,4 & 107,0 & 104,5 \\
\hline
\end{tabular}

